\title{
Proposed Adaptation of the Standard Review Plan NUREG-0800, Chapter 4 (Reactor) for Sodium-Cooled Fast Reactors and Modular High-Temperature Gas-Cooled Reactors
}

Approved for public release. Distribution is unlimited.
Randy Belles Willis Poore Nicholas Brown George Flanagan Mark Holbrook, INL Wayne Moe, INL Tanju Sofu, ANL

March 2017 


\title{
DOCUMENT AVAILABILITY
}

Reports produced after January 1, 1996, are generally available free via US Department of Energy (DOE) SciTech Connect.

Website http://www.osti.gov/scitech/

Reports produced before January 1, 1996, may be purchased by members of the public from the following source:

\author{
National Technical Information Service \\ 5285 Port Royal Road \\ Springfield, VA 22161 \\ Telephone 703-605-6000 (1-800-553-6847) \\ TDD 703-487-4639 \\ Fax 703-605-6900 \\ E-mail info@ntis.gov \\ Website http://www.ntis.gov/help/ordermethods.aspx
}

Reports are available to DOE employees, DOE contractors, Energy Technology Data Exchange representatives, and International Nuclear Information System representatives from the following source:

Office of Scientific and Technical Information

PO Box 62

Oak Ridge, TN 37831

Telephone 865-576-8401

Fax 865-576-5728

E-mail reports@osti.gov

Website http://www.osti.gov/contact.html

\begin{abstract}
This report was prepared as an account of work sponsored by an agency of the United States Government. Neither the United States Government nor any agency thereof, nor any of their employees, makes any warranty, express or implied, or assumes any legal liability or responsibility for the accuracy, completeness, or usefulness of any information, apparatus, product, or process disclosed, or represents that its use would not infringe privately owned rights. Reference herein to any specific commercial product, process, or service by trade name, trademark, manufacturer, or otherwise, does not necessarily constitute or imply its endorsement, recommendation, or favoring by the United States Government or any agency thereof. The views and opinions of authors expressed herein do not necessarily state or reflect those of the United States Government or any agency thereof.
\end{abstract}


Reactor and Nuclear Systems Division

\title{
PROPOSED ADAPTATION OF THE STANDARD REVIEW PLAN NUREG-0800, CHAPTER 4 (REACTOR) FOR SODIUM-COOLED FAST REACTORS AND MODULAR HIGH-TEMPERATURE GAS-COOLED REACTORS
}

\author{
Randy Belles \\ Willis Poore \\ Nicholas R. Brown \\ George Flanagan \\ Mark Holbrook, INL \\ Wayne Moe, INL \\ Tanju Sofu, ANL
}

Date Published: March 2017

Prepared by

OAK RIDGE NATIONAL LABORATORY

Oak Ridge, TN 37831-6283

managed by

UT-BATTELLE, LLC

for the

US DEPARTMENT OF ENERGY

under contract DE-AC05-00OR22725 



\section{CONTENTS}

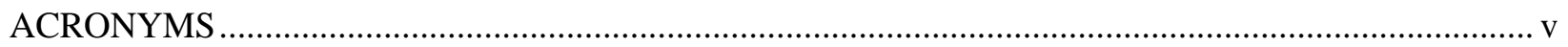

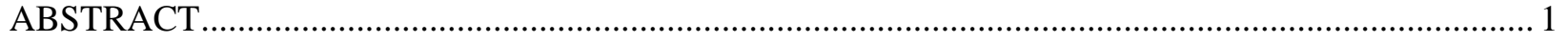

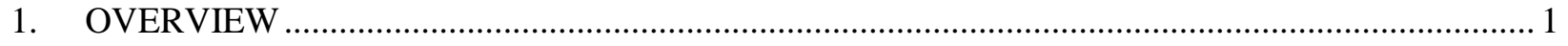

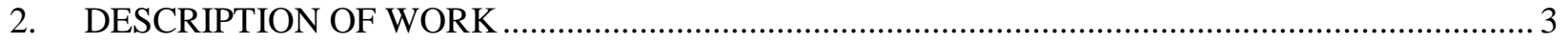

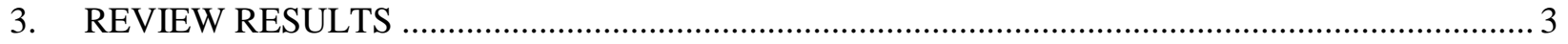

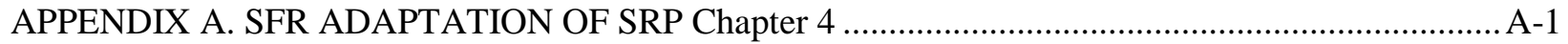

APPENDIX B. mHTGR ADAPTATION OF SRP Chapter 4 ........................................................... B-1 



\section{ACRONYMS}

$\begin{array}{ll}\text { ANL } & \text { Argonne National Laboratory } \\ \text { AOO } & \text { anticipated operational occurrence } \\ \text { ARDC } & \text { advanced reactor design criteria } \\ \text { ATWS } & \text { anticipated transient without scram } \\ \text { BDBE } & \text { beyond design basis event } \\ \text { CDF } & \text { cumulative damage fraction } \\ \text { CFR } & \text { Code of Federal Regulations } \\ \text { CHF } & \text { critical heat flux } \\ \text { COL } & \text { combined operating license } \\ \text { CP } & \text { construction permit } \\ \text { DBA } & \text { design basis accident } \\ \text { DBE } & \text { design basis event } \\ \text { DC } & \text { design certification } \\ \text { DNB } & \text { departure from nucleate boiling } \\ \text { DOE } & \text { US Department of Energy } \\ \text { DOE-NE } & \text { DOE Office of Nuclear Energy } \\ \text { GDC } & \text { general design criteria } \\ \text { INL } & \text { Idaho National Laboratory } \\ \text { LBE } & \text { licensing basis event } \\ \text { LWR } & \text { light water reactor } \\ \text { mHTGR } & \text { modular high temperature gas-cooled reactor } \\ \text { mHTGR-RP } & \text { modular high temperature gas-cooled reactor review plan } \\ \text { MHTGR } & \text { (General Atomics) Modular High Temperature Gas Reactor } \\ \text { NGNP } & \text { Next Generation Nuclear Plant } \\ \text { NRC } & \text { US Nuclear Regulatory Commission } \\ \text { ORNL } & \text { Oak Ridge National Laboratory } \\ \text { PRISM } & \text { Power Reactor Innovative Small Module } \\ \text { PSAR } & \text { preliminary safety analysis report } \\ \text { SAFDL } & \text { specified acceptable fuel design limit } \\ \text { SAR } & \text { safety analysis report } \\ \text { SARRDL } & \text { specified acceptable core radionuclide release limit } \\ \text { SFR } & \text { sodium-cooled fast reactor } \\ \text { SFR-RP } & \text { sodium-cooled fast reactor review plan } \\ \text { SRP } & \text { standard review plan } \\ \text { TRISO } & \text { tristructural isotropic } \\ & \\ \text { DHE } & \end{array}$





\begin{abstract}
This report proposes adaptation of the previous regulatory gap analysis ${ }^{1}$ in Chapter 4 (Reactor) of NUREG-0800, "Standard Review Plan (SRP) for the Review of Safety Analysis Reports for Nuclear Power Plants: LWR [Light Water Reactor] Edition.” The proposed adaptation would result in a Chapter 4 review plan applicable to certain advanced reactors. This report addresses two technologies: the sodiumcooled fast reactor (SFR) and the modular high temperature gas-cooled reactor (mHTGR). SRP Chapter 4, which addresses reactor components, was selected for adaptation because of the possible significant differences in advanced non-light water reactor (non-LWR) technologies compared with the current LWR-based description in Chapter 4. SFR and mHTGR technologies were chosen for this gap analysis because of their diverse designs and the availability of significant historical design detail. This report satisfies milestone M3AT-17OR2001041, "Complete ORNL Report on Advanced Reactor Adaptation of the SRP Chapter 4 for SFR and mHTGR," in support of the US Department of Energy (DOE) Office of Nuclear Energy (NE) Advanced Reactor Technology program. A draft version of this report was made available to industry stakeholders for comment (milestone M3AT-16OR2001042, "Complete Development of an Advanced Reactor Adaptation of Chapter 4 NUREG-0800"), and those inputs have been incorporated.
\end{abstract}

\title{
1. OVERVIEW
}

In July 2013, DOE-NE and the US Nuclear Regulatory Commission (NRC) established a joint initiative to address a key portion of the licensing framework essential to advanced (non-light water) reactor technologies. The initiative addressed the "General Design Criteria for Nuclear Power Plants," which is Appendix A to Title 10 of the Code of Federal Regulations (CFR) Part 50. These criteria were developed primarily for LWRs and are specific to the needs of LWR design and licensing. The need for general design criteria (GDC) clarifications in non-LWR applications has been consistently identified as a concern by the industry and various stakeholders. This concern is identified as an area for enhancement in the NRC 2012 Report to Congress. ${ }^{3}$ Personnel from Argonne National Laboratory (ANL), Idaho National Laboratory (INL), and Oak Ridge National Laboratory (ORNL) led a DOE evaluation of the LWR-based GDC and recommended advanced reactor design criteria (ARDC) appropriate for non-LWR applications to the NRC.

The ARDC effort ${ }^{4}$ is documented in an INL report to DOE currently under NRC review. ${ }^{5}$ DOE also began developing recommendations to address and adapt or modify other key aspects of the NRC licensing framework as needed for advanced non-LWR technologies. This effort was initiated by identifying the areas in SRP Chapter 4 that lack the review guidance needed to develop an application for an SFR or an mHTGR plant: a gap analysis. Chapter 4 addresses reactor components and was selected for review and adaptation due to the possible significant differences in advanced non-LWR technologies compared with those presented in the current LWR-based Chapter 4. SFR and mHTGR technologies were chosen for this gap analysis because of their diverse designs and the availability of their significant

\footnotetext{
${ }^{1}$ Poore, Willis, et al., Regulatory Gap Analysis of the Standard Review Plan NUREG-0800, Chapter 4 (Reactor) for Applicability to Advanced Reactors, ORNL/SR-2016/325, July 2016.

${ }^{2}$ NUREG-0800, Standard Review Plan for the Review of Safety Analysis Reports for Nuclear Power Plants: LWR Edition, June 1987, ML052340534.

${ }^{3}$ NRC Report to Congress: Advanced Reactor Licensing, August 2012, ML12153A014.

${ }^{4}$ Guidance for Developing Principal Design Criteria for Advanced (Non-Light Water) Reactors, INL/EXT-31179, Revision 1, December 2014.

5 The NRC issued DG-1330, “Guidance for Developing Principle Design Criteria for Non-Light Water Reactors,” for public comment in February 2017.
} 
historical design detail. The gap analysis began in October 2015 and was completed in July 2016. The gap analysis focused on:

- the content of SRP Chapter 4 (body),

- technical reports referenced in Chapter 4,

- regulatory guides referenced in Chapter 4,

- consensus standards referenced in Chapter 4, and

- $\quad$ appendices of 10 CFR 50 referenced in Chapter 4.

This report proposes adaptation of SRP Chapter 4 based on the regulatory gap analysis for SFR and mHTGR designs. It is the next logical step in DOE's ongoing initiative to provide recommendations to DOE and NRC that address and adapt or modify key aspects of the NRC licensing framework for advanced non-LWR technologies. The goals of this effort are to elicit feedback from non-LWR stakeholders, provide a pilot for other SRP chapters, and continue interactive discussion with the NRC regarding the licensing framework for advanced non-LWRs. This report reflects the industry comments provided on the initial draft version of this report.

The proposed adaptation of SRP Chapter 4 was conducted by staff members from ORNL, INL, and ANL. The ARDC documented in the INL report to DOE as adapted for the SFR and mHTGR were initially used in place of the GDC referenced in SRP Chapter 4 in the draft version of this report for stakeholder comment. However, the NRC released a draft Regulatory Guide, "Guidance for Developing Principal Design Criteria for Non-Light Water Reactors” (DG-1330) while this report was being updated to reflect stakeholder input. Therefore, this report now reflects the non-LWR design criteria proposed in DG-1330. The LWR-specific criteria in Chapter 4 were replaced with advanced non-LWR design-specific criteria, technology-neutral criteria, or performance-based criteria.

No extensive effort was made to review standards, ASME codes, or code cases to verify their applicability to the SFR or mHTGR designs. Furthermore, no effort was made to recommend the correct references for review of the SFR or mHTGR designs. References to materials such as regulatory guides produced by the NRC that have since been withdrawn are proposed for deletion. In addition, NRC letters and industry letters on very specific LWR topics are proposed for deletion from the reference list. Otherwise, reference materials are left as listed in NUREG-0800, Chapter 4, to provide appropriate topical information even though the actual references listed may not apply.

It is understood that most of the detailed technical requirements are found in the references. For example, SRP Section 4.2, which addresses fuel design, contains 59 references, 46 of which are regulatory guides, technical reports, or NUREG documents. These documents form the technical basis for the NRC reviewers to evaluate an application. However, based on a cursory review of titles or abstracts, nearly all reference documents appear to be LWR-specific based on over 40 years of commercial licensing experience. Significant effort is required by the NRC staff and non-LWR vendors to either enhance the information in the existing references to be relevant to advanced non-LWR designs or replace existing references with equivalent documentation.

Available industry technical materials and NRC review materials for each of the two reactor technologies were used as guidance in revising the body of each section for design-specific applications. In addition, the non-power reactor SRP, NUREG-1537, ${ }^{6}$ provided guidance for performance-based language to be included in sections where the prescriptive nature of the SRP was not viable. NUREG-1537 addresses

\footnotetext{
${ }^{6}$ NUREG-1537, Guidelines for Preparing and Reviewing Applications for the Licensing of Non-Power Reactors, Part 2, February
} 1996. 
non-power reactors with smaller source terms and lower power levels as a performance-based equivalent to NUREG-0800.

Proposed adaptations to SRP Chapter 4 are presented in Appendix A for the SFR and Appendix B for the mHTGR advanced non-LWRs. For brevity, clarity, and readability, the adaptations are presented in clean text with comment bubbles noting significant changes from the original SRP. Redline/strikeout versions of each section are available.

\section{DESCRIPTION OF WORK}

A structured review process was developed to guide adaptation of SRP Chapter 4 for SFR and mHTGR design perspectives. ORNL and ANL staff members conducted the SRP Chapter 4 adaptation for the SFR perspective, and INL staff members conducted the SRP Chapter 4 adaptation for the mHTGR perspective. Reviewers proposed adaptations for each technology in each section of SRP Chapter 4. Design-specific design criteria based on the ARDC proposed by NRC replaced the GDC in each section. Chapter 4 of the SRP includes the following sections:

- $\quad 4.2 \quad$ Fuel System Design

- $4.3 \quad$ Nuclear Design

- $4.4 \quad$ Thermal and Hydraulic Design

- 4.5.1 Control Rod Drive Structural Materials

- 4.5.2 Reactor Internal and Core Support Structure Materials

- 4.6 Functional Design of Control Rod Drive System

The SRP is very prescriptive, specifying detailed requirements based on over 40 years of experience with LWR fuels and other reactor components covered by Chapter 4. In most cases, the SFR team could use the SRP structure and propose adaptations, modifications, or alternatives to LWR-based criteria when preparing the SFR Review Plan (SFR-RP). For the SFR design, some adaptations propose more performance-based criteria, such as alternatives for critical heat flux (CHF) and departure from nucleate boiling (DNB). The SRP calls for an evaluation of two-phase flow, CHF, and the DNB ratio calculations. These specific evaluations do not apply to an SFR design, so they were replaced in the SFR-RP with a performance-based consideration that the SFR design have sufficient margin to coolant boiling in any fuel channel.

Some additional criteria were proposed to address the unique aspects of an SFR design. These additional criteria were determined based on a review of preliminary safety analysis reports for the Clinch River Breeder Reactor and the Power Reactor Innovative Small Module (PRISM) reactor. In addition, the preapplication safety evaluation report for $\operatorname{PRISM}^{7}$ provided insight on commitments made by the PRISM design team to meet certain SRP criteria.

Some of the mHTGR's unique design aspects are not easily adapted to the SRP's historical LWR-based review framework, including the CHF and DNB issues noted above for SFR designs. However, a more specific example is that the fuel system design (Section 4.2) is fundamentally different for the mHTGR. Major advances have recently been made in mHTGR design and tristructural-isotropic (TRISO)-coated particle fuel safety. However, mHTGR designs have not undergone an independent regulatory safety review for almost three decades. Consequently, developers preparing Section 4.2, "Fuel System Design," for the mHTGR Review Plan (mHTGR-RP) must exercise caution when relying on historic precedents as

\footnotetext{
${ }^{7}$ NUREG-1368, Preapplication Safety Evaluation Report for the Power Reactor Innovative Small Module (PRISM) Liquid-Metal
} Reactor, January 1994, ML063410561. 
a guide to evaluate the more evolved coated particle fuel system designs of today. System configurations can vary greatly within the coated particle fuel technology design category (e.g., a prismatic block graphite core vs. a graphite pebble-bed core), and overly prescriptive acceptance criteria based on one fuel system configuration increases risk that review acceptance criteria may be cited that are incompatible with alternate configurations.

Section 4.2 of the proposed mHTGR-RP could not be revised to follow the SRP review structure closely by applying modest adaptations, modifications, or alternatives to its prescriptive LWR-based criteria. The existing SRP Section 4.2 is specific to LWR technology, and it deals with fuel performance phenomena that do not apply to mHTGR fuel performance. The mHTGR design criteria for fuel design limits must be appropriately adapted to reflect the underlying intent in preserving TRISO-coated fuel performance and integrity. The team developed Section 4.2 for the mHTGR-RP largely from fuel system design work performed in association with the Next Generation Nuclear Plant (NGNP) and the older General Atomics Modular High Temperature Gas Reactor (MHTGR). Guidance was also drawn from NUREG-1537 for performance-based review language to make key review parameters of the coated particle fuel system design more generic. Key resources used to adapt SRP Section 4.2 for the mHTGR design are listed in lieu of the typical reference list found in other SRP sections.

A review based on mHTGR-RP Chapter 4.2 for coated particle fuel requires consideration of statistically significant measurements that reliably indicate overall fuel system performance. Hundreds of thousands of TRISO-coated fuel particles (each independently functioning as a separate radionuclide containment vessel) are in an mHTGR core. These coated fuel particles are embedded in a solid graphite matrix nominally shaped as either a spherical pebble or a compact block. This type of fuel design makes it infeasible for direct damage assessment of individual coated particles after manufacture while loaded in the core. Therefore, mHTGR fuel system design review must encompass the coated particle fuel manufacturing process and rely on appropriate indirect methods of measurement (such as a specified acceptable core radionuclide release design limit [SARRDL]) that communicate coated particle fuel failure rates and enable predictions of overall radionuclide barrier performance. Section 4.2 reviews for the mHTGR are proposed with this in mind. They focus on (1) evaluating the quality of TRISO-coated particle fuel during manufacture; (2) understanding fuel system performance impacts that result from normal operation and anticipated operational occurrences (AOOs); (3) characterizing fuel system performance as it relates to reactivity control; (4) establishing in-service performance requirements and fission product release requirements for postulated accidents; and (5) enabling fuel performance and fission product release prediction/modeling under normal operations and postulated accidents with statistical certainty.

In other sections, the mHTGR team used the SRP structure and proposed adaptations, modifications, or alternatives to LWR-based criteria. For example, modifications to mHTGR-RP Section 4.6 primarily involved deleting irrelevant LWR-specific acceptance criteria, adding system descriptors applicable to the mHTGR control rod drive system, and substituting cited GDCs with equivalent mHTGR-DCs now undergoing review by the NRC.

The SFR technology team met frequently to discuss preliminary observations and the initial Chapter 4 adaptation process to help ensure consistency across the individual sections. The mHTGR team also held internal discussions to ensure a consistent adaptation process. The teams for the two technologies also jointly discussed progress, consistency, and significant differences in the adaptation of various sections as necessary. 


\section{REVIEW RESULTS}

This DOE-sponsored effort represents an initial (iterative) attempt to define the scope of changes necessary to adapt NUREG-0800 to allow for NRC staff review of advanced non-LWR SFR or mHTGR designs. Additional effort will be required to develop design-specific review standards for individual applicants in the future. The goals of the adapted SRP versions under development are (1) to improve efficiency, effectiveness, and timeliness of the NRC safety analysis report review process, (2) to highlight the need for references to validate technology safety and performance, and (3) to inform applicants of the NRC's expectation of how their applications will be reviewed. The applicant must put forth significant effort to provide sufficient information to ensure that the performance-based review requirements are met. Similarly, NRC reviewers must also expend significant effort to review inputs supporting a performancebased application since detailed guidance information will not likely be available.

An initial draft of this report for SRP Chapter 4 was shared with industry stakeholders to obtain their feedback. Proposed changes to the initial draft are included in Appendices A and B. Some specific stakeholder concerns are outlined in the following paragraphs.

General stakeholder concern was expressed over hot and cold terminology relative to advanced nonLWRs. Terms include:

- hot standby

- hot shutdown

- hot zero power

- cold shutdown

- cold condition

The temperature aspect of these terms is the most obvious application. However, the traditional use of the terminology also implies the reactivity condition of the reactor. Adequate shutdown margin for each reactor state is generally defined as having at least $1 \% \Delta \mathrm{k} / \mathrm{k}$ ( or $\mathrm{k}_{\text {eff }}<0.99$ ) with any single control device not fully inserted. In a thermal reactor, cold, xenon-free conditions are the conditions of the most reactive core. Furthermore, cold conditions also imply a readiness to perform certain maintenance operations. Therefore, advanced non-LWR designs should at least discuss possible reactor states with regard to the traditional use of hot and cold terminology even though the temperature ranges associated with the terminology may be small. Furthermore, this is consistent with terminology used in the draft Regulatory Guide, “Guidance for Developing Principal Design Criteria for Non-Light Water Reactors,” DG-1330. For some advanced non-LWRs, the distinction between hot and cold conditions can be further complicated by using a coolant that solidifies at "room” temperatures.

The term safe shutdown also appears in the merged version of ARDC 26 and ARDC 27 in DG-1330. This is closely related to the term cold shutdown. The Generation IV International Forum defines safe shutdown as the state in which the reactivity of the reactor is kept to a margin below criticality under a prescribed coolant temperature condition so that interventions such as fuel reloading, periodic inspection, and repair can be accomplished.

\section{Sample SFR Adaptation Challenges}

In SFR Section 4.2, terminology was clarified with regard to fuel pins. In an SFR, the general use of the term fuel pin means the same as fuel rod. Pins and rods both refer to the entire fuel element, including the cladding, fuel pellets (or slugs), end fittings, etc. Therefore, in SFR-RP Section 4.2, and throughout SFRRP Chapter 4, the LWR-based term fuel pin is replaced with fuel slug for clarity. 
In SFR-RP Section 4.2, fuel cumulative damage fraction (CDF) is noted as a parameter that is provided as an interface to organizations that review Chapter 15. CDF is one approach for ensuring damage and failure criteria are conservative. CDF is not a specific failure mechanism; it is a bookkeeping method of assessing multiple damage mechanisms with a single parameter. Stakeholders recommended that CDF not be a regulatory compliance requirement. Other approaches can be used to demonstrate that damage/failure criteria are met (cladding strain limits, temperature limits, etc.). Therefore, references to CDF in SFR Chapter 4 are replaced with "limits for fuel temperature” and "time-at-temperature.”

In SFR Section 4.3, references to "temperature and power coefficients" were replaced by "the Doppler coefficient," "the coolant density and void coefficients," "the fuel axial expansion coefficient," "the core radial expansion and other geometry deformation coefficients," and "the control rod driveline expansion coefficient” to add clarity. Instead of stating “....all reactivity coefficients must be negative to maintain inherent safety and stability," the text is modified to reflect “...the net of all the reactivity feedback effects must be negative at temperatures above the normal operating range to maintain inherent safety and stability."

For SFR designs, it was noted that the thermal-hydraulic limits discussed in SFR-RP Section 4.4 tend to be bounded by the specified acceptable fuel design limit (SAFDL) criteria established in Section 4.2. LWR thermal-hydraulic correlations include critical heat flux and critical power ratio resulting in technical specification limits and protection actions based on the departure from nucleate boiling ratio and linear power density. SFR vendors must demonstrate a more generic correlation that evaluates the margin to boiling. However, SFR SAFDLs would likely be violated before the SFR margin to boiling would become a concern. In an SFR, material thermal stresses and vessel integrity are key concerns that force the designer to consider conservative fuel design criteria that ultimately provide a very large margin to boiling. Thus, for SFR designs, thermal-hydraulic limits are not anticipated to be dominant design criteria.

In SFR-RP Section 4.6, references to 10 CFR 50.62, "Requirements for reduction of risk from anticipated transient without scram (ATWS) events for light-water cooled nuclear power plants,” are eliminated in the text because the requirement only addresses LWRs. Stakeholder comments recommend addressing ATWS events for non-LWRs in this section and others. However, this will require a separate regulatory effort beyond the scope of the effort documented herein. The stakeholder comment is valid, and the point is noted as a comment in the proposed SFR-RP Section 4.6 text.

\section{Sample mHTGR Adaptation Challenges}

With respect to the mHTGR concept, stakeholder feedback focused heavily on the text associated with mHTGR-RP Section 4.2, "Fuel Design.” Relatively little feedback was received on mHTGR-RP Sections 4.3 and 4.4, and very few comments were provided concerning mHTGR-RP Sections 4.5 and 4.6.

As stated earlier, to recognize and incorporate the unique fuel performance attributes and radionuclide retention capabilities of TRISO-coated particle fuel into a fuel design review outlined in SRP Section 4.2, the proposed mHTGR-RP text underwent a complete rewrite. This was necessary to more fully address the importance of particle fuel manufacturing processes in overall fuel design and performance and to accommodate the unique attributes of incremental reduction in coated particle fuel performance. Industry reviewer comments targeted details of the proposed text, but generally they did not challenge the overall approach as suggested in the coated particle fuel design review.

One commenter noted that mHTGR-RP Section 4.2 should be made more technology inclusive by expanding discussions to better address spherical fuel elements and the unique core design associated with pebble bed HTGRs. In response, text discussions were adjusted where necessary to clarify 
application to pebble fuels as well as the fuel compacts and elements characteristic of prismatic block fuel designs.

Many comments were provided concerning the use of terminology dealing with postulated accidents and licensing basis events (LBEs) in mHTGR-RP Section 4. In general, stakeholders sought greater refinement in nomenclature rather than relying on the latter interpretation of the generic LBE discussions suggested in the initial draft. Although LBE terminology has yet to be codified or formally adopted by NRC through regulatory guidance, the framework of the LBE selection process and the language nominally associated with the approach was established during the NGNP project. ${ }^{8}$ During NGNP prelicensing interactions, NRC staff members stated that the safety basis of the next mHTGR is expected to be established using a risk-informed and performance-based LBE selection approach.

LBEs are defined as the events derived from the mHTGR plant design that are considered by the licensing process and used in development of a license application. Defining LBEs creates a comprehensive set of event sequences that form the basis for plant analysis and represent the plant's characteristic performance in all analyzed frequency and consequence ranges. LBEs include conditions of normal operation, including AOOs, infrequent design basis events (DBEs), and beyond design basis events (BDBEs) that inform the deterministically selected design basis accidents (DBAs). The LBE structure (and associated individual event terminology) proposed under NGNP and discussed above was used in the updated mHTGR-RP.

Regarding Section 4.2 of the mHTGR-RP, one reviewer noted that given the amount and depth of information needed for a design certification (DC) or combined operating license (COL), it is difficult to imagine that such information would be completely available for the first commercial scale mHTGR (and likely the same for SFR) module. It is therefore likely that a Part 50 licensing path would be defined to license the first mHTGR reactor. Data collected from that initial module would then be used to update the DC and to license subsequent modules using Part 52. The reviewer further noted that NUREG-0800 was written to support a safety analysis report (SAR). However, the initial deployment of a new reactor technology module first needs the review standard for a preliminary SAR (PSAR) followed by a SAR. The commenter stated that no first-of-a-kind advanced reactor can be licensed under Part 52 and noted that the first mHTGR reactor module will be licensed under Part 50. Thus, a PSAR review standard is needed first, and a SAR review standard would be used thereafter. The reviewer also stated that it would be highly beneficial to initial reactor module vendors to establish a standard review plan for a modern era PSAR to obtain a construction permit (CP) under Part 50.

While the call for a PSAR standard review plan is considered valid, the SAR adaptation effort discussed in this report was scoped to begin the iterative process of revising existing NUREG-0800 contents to address the overall needs of mHTGRs without expressly tailoring the NUREG to meet the unique needs of a single module, first-of-a-kind plant. Furthermore, because no template exists for a preliminary SRP, considerable uncertainty would be introduced regarding the focus and approach to be used in generating such a document. The SRP adaptation was initiated to aid safety evaluation reviewers and license applicants for mHTGR in general, and compliance with the adapted SRP per se is not required. Departures from the adapted SRP descriptions and discussions are allowed for technological deviations that might be present in the first-of-a-kind module deployment. In such an instance, the mHTGR-RP can still be used as a tool for applicants and reviewers to use according to that particular design and should offer a sound foundation upon which a Part 50-oriented review plan can be developed later.

Regarding mHTGR-RP Section 4.3, comments were typically related to the unique characteristics of the mHTGR design. For example, consideration of LWR-based density coefficients was removed, and some

\footnotetext{
${ }^{8}$ INL, Next Generation Nuclear Plant Licensing Basis Event Selection White Paper, INL/EXT-10-19521, September 2010.
} 
technical questions related to mHTGR thermal neutron spectrum were resolved. Similar comments on mHTGR-RP Section 4.4 were resolved, including word changes that address helium bypass flows in core, confirmation of potential sources of excessive power oscillations for mHTGRs, added wording to address current graphite research results, and deletion of unneeded LWR-specific references. As noted above, few comments were received concerning mHTGR-RP Section 4.5; changes in this section were limited to deleting LWR-specific references. 
APPENDIX A. SFR ADAPTATION OF SRP CHAPTER 4 



\title{
SODIUM FAST REACTOR REVIEW PLAN
}

\author{
4.2 FUEL SYSTEM DESIGN
}

REVIEW RESPONSIBILITIES

Primary - The organization responsible for the review of advanced non-light water reactor transient and accident analyses

\author{
Secondary - None
}

\section{AREAS OF REVIEW}

The organization responsible for the review of Sodium Fast Reactor (SFR) transient and accident analyses evaluates the thermal, mechanical, and materials design of the fuel system and other core components. The fuel system consists of arrays (assemblies or bundles) of fuel rods (including fuel slugs or pellets, tubular cladding, axial blankets, reflectors, shielding, fission gas plenum and fill gas, liners, and end closures), wire wraps or spacer grids with springs, end plates, inlet nozzles, and fuel assembly ducts (hexcans). Other core components include the radial blanket assemblies with parts similar to those in the fuel assemblies, and reactivity control elements/rods that extend from the coupling interface of the drive mechanism into the core.

The fuel system safety review provides assurance that (1) the fuel system is not damaged as a result of normal operation and anticipated operational occurrences (AOOs), (2) fuel system damage during postulated accidents is never so severe as to prevent control element/rod insertion when required, (3) the number of fuel rod failures is not underestimated for postulated accidents (such as loss of flow, loss of heat sink, or reactivity initiated accidents), and (4) coolability is maintained.

Sodium Fast Reactor Design Criterion (SFR-DC) 10, which is reflected in Draft Regulatory Guide DG-1330 (Proposed New Regulatory Guide 1.232) as guidance for complying with the requirements of Appendix A to 10 CFR Part 50, also addresses item 1 above. Specifically, SFR-DC 10 establishes specified acceptable fuel design limits (SAFDLs) that should not be exceeded during any condition of normal operation, including the effects of AOOs. Therefore, the SAFDLs are established to ensure that the fuel is not damaged. Within this context, "not damaged" means that the tubular cladding does not fail, fuel system dimensions remain within operational tolerances, and functional capabilities are not reduced below those assumed in the safety analysis. The design limits of SFR-DC 10 (i.e., the SAFDLs) accomplish these objectives. In a "fuel rod failure," the fuel cladding leaks, partially releasing some fission products. The dose analysis required by 10 CFR Part 100 for postulated accidents must account for fuel rod failures. "Coolability," in general, means that the fuel assembly retains its rod-bundle geometry with adequate coolant channels (flow area) to permit removal of residual heat even after fuel failures. The general requirements to maintain control element/rod insertability and core coolability appear in the SFR-DC found in DG-1330 and are the focus of SFR-DC 26, 34, and 35.

Comment [A1]: Fuel pins generally refers to the entire fuel rod. The intended meaning here is fuel slugs or pellets. This is a global change.

Comment [A2]: Other SFR core components are included for complete discussion. However, Section 4.2 focus is on the fuel.

Comment [A3]: This text anticipates the NRC RG for advanced reactor design criteria and subsequent SFR-DC (proposed RG 1.232). The current markup reflects the proposed language in Draft RG-1330.

Comment [A4]: Fuel failure is a better term than severe accident in this sentence. If a whole core melt accident is considered in the safety analysis, the rod bundle geometry would no longer be maintained, and core melt coolability would be ensured differently.

Comment [A5]: This text anticipates the NRC RG for advanced reactor design criteria and subsequent SFR-DC (proposed RG 1.232). The current markup reflects the proposed language in Draft RG-1330. 
Sodium Fast Reactor Review Plan (SFR-RP) Section 4.2 describes fuel damage criteria. SFR-RP Section 4.4 provides specific thermal-hydraulic criteria for instances when the coolant temperature approaches the boiling point or the thermal-creep limit for the primary coolant boundary (reactor vessel, and primary coolant pipes in a loop type SFR). The available radioactive fission product inventory in fuel rods is provided to the U.S. Nuclear Regulatory Commission's (NRC) organization that is responsible for the review of design basis accident radiological consequence analyses for use in estimating the radiological consequences of plant releases. When part of the core design, the radial blanket rods/assemblies are subject to the same review as the fuel system. Therefore, additional criteria for radial blanket rods/assemblies are not required.

The specific areas of review are as follows:

1. Design Bases. Design bases for the safety analysis address fuel system damage mechanisms and provide limiting values for important parameters to prevent damage from exceeding acceptable levels. The design bases should reflect the safety review objectives as described above. When available, the reviewer should evaluate established (past) design-basis limits and associated SAFDLs to determine whether they remain applicable to the new fuel design (including the introduction of new materials) given the operating conditions (temperature, burnup, and power). If they do not apply, new limits must be established based on appropriate data.

2. Description and Design Drawings. The reviewer examines the fuel system description and fuel rod and fuel assembly design drawings. In general, the description will emphasize product specifications rather than process specifications.

3. Design Evaluation. The reviewer evaluates the performance of the fuel system during normal operation, AOOs, and postulated accidents to determine whether all design bases are met. The fuel system components, as listed above, are reviewed not only as separate components but also as integral units such as fuel rods and fuel assemblies. New fuel designs, new operating limits (e.g., rod burnup and power), and the introduction of new materials to the fuel system require a review to verify that existing design-basis limits, analytical models, and evaluation methods remain applicable for the specific design for normal operation, AOOs, and postulated accidents. When available, the review also evaluates operating experience, direct experimental comparisons, detailed mathematical analyses (including fuel performance codes), and other information.

4. Testing, Inspection, and Surveillance Plans. The licensee performs testing and inspection of new fuel to ensure that the fuel is fabricated in accordance with the design and that it reaches the plant site and is loaded in the core without damage. Fuel rod failure monitoring and postirradiation surveillance should be performed to detect anomalies or confirm that the fuel system is performing as expected; surveillance of control elements/rods containing neutron absorbers should be performed to preclude loss of shutdown capabilities. The organization responsible for reactor systems reviews the testing, inspection, and surveillance plans, along with their reporting provisions, to ensure that the important fuel design considerations have been addressed.

5. Inspections, Tests, Analyses, and Acceptance Criteria (ITAAC). For design certification (DC) and combined license (COL) reviews, the staff reviews the applicant's proposed 
ITAAC associated with the structures, systems, and components (SSCs) related to this SFR-RP section in accordance with SFR-RP Section 14.3, "Inspections, Tests, Analyses, and Acceptance Criteria." The staff recognizes that the review of ITAAC cannot be completed until after the rest of this portion of the application has been reviewed against acceptance criteria contained in this SFR-RP section. Furthermore, the staff reviews the ITAAC to ensure that all SSCs in this area of review are identified and addressed as appropriate in accordance with SFR-RP Section 14.3.

6. COL Action Items and Certification Requirements and Restrictions. For a DC application, the review will also address COL action items and requirements and restrictions (e.g., interface requirements and site parameters). For a COL application referencing a DC, a COL applicant must address COL action items (referred to as COL license information in certain DCs) included in the referenced DC. Additionally, a COL applicant must address requirements and restrictions (e.g., interface requirements and site parameters) included in the referenced DC.

\section{$\underline{\text { Review Interfaces }}$}

SFR-RP Section 4.2 describes fuel damage criteria. SFR-RP Section 4.4 provides specific thermal-hydraulic criteria. The available radioactive fission product inventory in fuel rods is provided to those organizations that estimate the radiological consequences of plant releases in accordance with SFR-RP Chapter 15. Fuel stored energy, flow blockage, peak cladding temperature and strain limits, limits for fuel temperature and time-at-temperature are provided to those organizations that review Chapter 15.

Other SFR-RP sections interface with this section as follows:

1. Review of the nuclear design of the fuel assemblies, control systems, and reactor core under SFR-RP Section 4.3 .

2. Review of the thermal margins and the acceptability of hydraulic loads under SFR-RP Section 4.4 .

3. Review of the design bases for the residual heat removal system (RHRS), including SFR-DC 34 and 35, and performance analysis of the RHRS using an acceptable evaluation model under SFR-RP Chapter 6.

4. Review of the postulated fuel failures resulting from overheating of cladding, overheating of fuel slugs or pellets, excessive fuel enthalpy, fuel-cladding mechanical and chemical interactions, and bursting under Chapter 15.

5. Review of the control element/rod drive mechanism design in SFR-RP Section 3.9.4 and the reactor internals design under SFR-RP Section 3.9.5.

6. Review of the estimates of radiological dose consequences under Chapter 15.

The specific acceptance criteria and review procedures are contained in the referenced SFR-RP sections. 


\section{II. $\quad$ ACCEPTANCE CRITERIA}

\section{Requirements}

Acceptance criteria are based on meeting the relevant requirements of the following Commission regulations:

1. The cooling performance analysis of the RHRS using an acceptable evaluation model in compliance with SFR-DC 34 and 35.

2. 10 CFR Part 100 and 10 CFR 50.67 , as they relate to determining the acceptability of a reactor site based on calculating the exposure to an individual as a result of fission product releases to the environment following a major accident scenario. These references do not need major revisions for SFRs. However, the mechanistic SFR source term evaluations might require a different approach depending on consequences of specific SFR postulated accidents, fuel forms, and coolant's radionuclide retention characteristics.

3. SFR-DC 10, as it relates to assuring that specified acceptable fuel design limits are not exceeded during any condition of normal operation, including the effects of AOOs.

4. SFR-DC 26 as it relates to a means of shutting down the reactor and maintaining a safe shutdown under design-basis event conditions, with appropriate margin for malfunctions, and a second means of reactivity control that is independent, diverse, and capable of achieving and maintaining safe shutdown under design-basis event conditions.

5. SFR-DC 35, as it relates to providing a RHRS to transfer heat from the reactor core following a postulated accident at a rate such that (1) fuel and clad damage that could interfere with continued effective core cooling is prevented and (2) the design conditions of the reactor primary coolant boundary are not exceeded.

6. 10 CFR 52.47(b)(1), which requires that a DC application contain the proposed inspections, tests, analyses, and acceptance criteria (ITAAC) that are necessary and sufficient to provide reasonable assurance that, if the inspections, tests, and analyses are performed and the acceptance criteria met, a plant that incorporates the design certification is built and will operate in accordance with the design certification, the provisions of the Atomic Energy Act, and the NRC's regulations.

7. 10 CFR 52.80(a), which requires that a COL application contain the proposed inspections, tests, and analyses, including those applicable to emergency planning, that the licensee shall perform, and the acceptance criteria that are necessary and sufficient to provide reasonable assurance that, if the inspections, tests, and analyses are performed and the acceptance criteria met, the facility has been constructed and will operate in conformity with the combined license, the provisions of the Atomic Energy Act, and the NRC's regulations.

Comment [A6]: Revised per DG-1330 as SFRDC 26 relates to DBEs. SFR-DC 27 combined with SFR-DC 26 in DG-1330. 


\section{SFR-RP Acceptance Criteria}

Specific SFR-RP acceptance criteria to meet the relevant requirements of the NRC's regulations identified above are as follows for the review described in this SFR-RP section. The SFR-RP is not a substitute for the NRC's regulations, and compliance with it is not required. However, an applicant is required to identify differences between the design features, analytical techniques, and procedural measures proposed for its facility and the SFR-RP acceptance criteria and evaluate how the proposed alternatives to the SFR-RP acceptance criteria provide acceptable methods of compliance with the NRC regulations.

Specific criteria necessary to meet the relevant requirements of SFR-DC 10, 26, 34 and 35, and 10 CFR Part 100 are as follows:

\section{Design Bases}

The fuel system design bases must reflect the four objectives described in Subsection I, Areas of Review. To satisfy these objectives, acceptance criteria are needed for fuel system damage, fuel rod failure, and fuel coolability. These criteria are discussed in the following paragraphs:

\section{A. $\quad$ Fuel System Damage}

This subsection applies to normal operation, and Section 4.2 of the safety analysis report should contain the information to be reviewed.

To meet the requirements of SFR-DC 10, as it relates to SAFDLs for normal operation, including AOOs, fuel system damage criteria should be included for known damage mechanisms. During the operation, the fuel assembly may be subject to mechanical stresses due to processes such as fuel handling and loading, power and thermal gradients, burnup shifts, movements of control assemblies, irradiation, flow-induced vibration and fretting, and creep deformation. The fuel system design should account for the impact of these factors on the integrity of the fuel assemblies and rods. Fuel damage criteria should assure that fuel system dimensions remain within operational tolerances and that functional capabilities are not reduced below those assumed in the safety analysis. When applicable, the fuel damage criteria should consider high burnup effects based on irradiated material properties data. The effects of fast neutrons on the metallurgical properties and structural stability of the fuel, blanket, and control assemblies should also be considered.

\section{Damage criteria address the following:}

i. Stress, strain, or loading limits for wire wraps or spacer grids, guide tubes, thimbles, fuel and blanket rods, control elements/rods, fuel assembly ducts, and other fuel system structural members should be provided. Stress limits that are obtained by methods similar to those given in Section III of the Boiler and Pressure Vessel Code of the American Society of Mechanical Engineers (ASME) are acceptable. Other proposed limits must be justified. 
ii. The cumulative number of strain fatigue cycles on the structural members mentioned in item (i) above should be significantly less than the design fatigue lifetime, which is based on appropriate data and includes a safety factors on stress amplitude and the number of cycles.

iii. Thermal-hydraulic and flow-induced vibration effects that depend on the fuel element spacing, the fuel element power, coolant flow rate, and the wire-wrap or grid spacers should be considered to limit fretting wear at contact points on the structural members mentioned in item (i) above. Fretting wear tests and analyses that demonstrate compliance with this design basis should account for grid spacer spring relaxation, if applicable. The allowable fretting wear should be stated in the safety analysis report, and the stress and fatigue limits in items (i) and (ii) above should presume the existence of this wear.

iv. Corrosion and the buildup of corrosion products should be limited, with a limit specified for each fuel system component. These limits should be established based on mechanical testing to demonstrate that each component maintains acceptable strength and ductility. The safety analysis report should discuss allowable corrosion levels and demonstrate their acceptability. These levels should be presumed to exist in items (i) and (ii) above. The effect of corrosion products on thermal-hydraulic considerations is reviewed as described in SFR-RP Sections 4.3 and 4.4 .

v. Dimensional changes, such as rod or fuel assembly duct bowing or irradiation and thermal creep/swelling of fuel rods, fuel assemblies, control elements/rods, and guide tubes, should be limited to prevent fuel failures or a situation in which the thermal-hydraulic limits established in Section 4.4 are exceeded. The gap between the fuel assemblies should be sufficient to allow for irradiation swelling so that a clearance remains to permit fuel assembly removal. Strain fatigue should not be able to cause the failure of a fuel assembly.

Control element/rod may bow as a result of (1) differential irradiation swelling (from fluence gradients), (2) thermal expansion, and (3) stress relaxation, and this can impact its insertability. A bulge of the channel into which a control element/rod is inserted should also be considered for interference problems. Any deformation of the fuel element or the fuel assembly should not affect the capability for the insertion of control and/or safety elements/rods for the safe shutdown of the reactor. Design changes can alter the insertability of a control rod/element, thus necessitating an evaluation of such changes. Material changes can also impact the differential swelling, stress relaxation, and the amount of bulge and therefore must be evaluated. If interference is determined to be possible, tests are needed to demonstrate control element/rod insertability consistent with assumptions in safety analyses. Additional inreactor surveillance (e.g., insertion times) may also be necessary for new designs, dimensions, and materials to demonstrate satisfactory performance.

Comment [A7]: Noted that in an SFR application, channel refers to the space into which control rods/assemblies are inserted. 
vi. Fuel and blanket rod internal gas pressures remains within limits based on, but not limited to, the following criteria.

(1) No unacceptable cladding liftoff for oxide fuel form during normal operation (when the cladding outward creep rate due to internal gas pressure exceeds the fuel swelling rate, resulting in an increase in pellet-cladding gap, thus, the pellet temperature). No significant cladding thinning due to fuel-cladding chemical interaction $(\mathrm{FCCl})$ for metallic fuel form during normal operation (although pressure does not affect $\mathrm{FCCl}$, a reduction in cladding thickness due to $\mathrm{FCCl}$ can affect cladding dependability against the burnup-induced increase in internal gas pressure).

Rod internal pressure should also be considered in assessing margin to failure and coolability criteria during AOOs and DBAs (in items $B$ and $C$ below).

vii. Because unseating of a fuel assembly is a coolability and reactivity concern, an evaluation of worst-case hydraulic loads should be performed for normal operation, AOOs, and accidents. These worst-case hydraulic loads for normal operation should not exceed the holddown capability of the fuel assembly (either gravity or other holddown devices). Hydraulic loads for this evaluation are reviewed as described in SFR-RP Section 4.4

viii. Control element/rod reactivity and insertability must be maintained. This requires that, at a minimum, the following may need to be reviewed:

(1) Changes in control element/rod configuration.

(2) Introduction of new materials.

(3) Changes in neutronics and mechanical lifetime.

(4) Changes in mechanical design.

Changes in mechanical and neutronics lifetimes need to be calculated using acceptable methods. Safety analyses must specifically account for the reduction in neutron-absorbing capabilities with time in-reactor.

\section{B. Fuel Rod Failure}

This subsection applies to normal operation, AOOs, and postulated accidents. To meet the requirements of (1) SFR-DC 10 as it relates to SAFDLs for normal operation, including AOOs and (2) 10 CFR Part 100 as it relates to fission product releases for postulated accidents, fuel rod failure criteria should be provided for known fuel rod failure mechanisms. Fuel rod failure is defined as the loss of fuel rod integrity. Although the staff recognizes that it is impossible to avoid all fuel rod failures and that cleanup systems are installed to handle a small number of leaking rods, the review must ensure that fuel does not fail as a result of specific causes during normal operation and AOOs. Fuel rod failures are permitted during postulated accidents, but they must be accounted for in the dose analysis. 
Fuel rod failures can be caused by overheating, fuel-cladding mechanical interactions (FCMI), fuel-cladding chemical interactions (FCCI), creep rupture, bursting, mechanical fracturing, and fretting. When applicable, the fuel rod failure criteria should consider high burnup effects based on irradiated material properties data.

Fuel failure criteria should address the following:

i. Overheating of Cladding. SFR fuel acceptance criteria is expected to be more conservative than the thermal margin criteria covered in SFR-RP Section 4.4. Exceeding the fuel acceptance or thermal margin criteria is not permitted for normal operation and AOOs. For postulated accidents, the total number of fuel rods that exceed the criteria has been assumed to fail for radiological dose calculation purposes. The fuel acceptance criteria are sufficient to demonstrate that overheating from a deficient cooling mechanism can be avoided and it must be considered together with the internal rod pressure, $\mathrm{FCCl}, \mathrm{FCMI}$, and duration of the exposure to temperatures above the normal range.

ii. Overheating of Fuel Slugs or Pellets. The analysis should be performed for the maximum linear heat generation rate anywhere in the core, including all hot spots and hot channel factors, and should account for the effects of burnup and changes in composition (due to constituent redistribution, swelling, accumulation of fission products, and other microstructural changes) on the melting point. For normal operation and AOOs, fuel melting is not permitted; therefore, the peak fuel temperature should be maintained lower than the fuel melting temperature by a sufficient margin, with allowance for uncertainties. For postulated accidents, the fuel melting should not induce cladding failure (typically achieved by avoiding the contact of molten fuel with the cladding). If the cladding failure is considered, it should be checked that core coolability is not impaired. The total number of rods that experience fuel melting should be estimated to account for radiological dose implications.

iii. Excessive Fuel Enthalpy. The sudden increase in fuel enthalpy from a reactivity initiated accident (RIA) below fuel melting can result in fuel failure due to FCMI, especially for oxide fuel. This potential should be evaluated.

iv. Fuel/Cladding Interactions. The margin-to-failure assessments for the cladding should account for major effects that may occur during irradiation, including any fuel-cladding mechanical and chemical interactions, increases in the internal pressure, and changes in cladding mechanical properties (strength, creep and stress relaxation).

Fast reactor fuels are typically designed to reach higher burnup than LWR fuels to take advantage of higher initial fissile loading and the "breed and burn" characteristics unique to fast neutron spectrum. Furthermore, the fuel swelling is expected to be greater in fast spectrum. However, for 
both the oxide and metallic fuel forms, gaseous swelling is not an issue at high burnup since the rate of fission gas release is high after the initial few percent burnup. Solid fission product swelling is the main cause of the clad straining at high burnup.

FCMI analyses of cladding strain for AOOs and postulated accidents should apply the approved fuel thermal expansion, solid fission product induced fuel swelling, and fuel creep models. The criterion for FCMI should address the stress-driven failure of the cladding, and limit the uniform cladding strain to a specified value. In this context, uniform strain (elastic and inelastic) is defined as the steady-state (creep/swelling) and transient-induced deformation with gauge lengths corresponding to cladding dimensions. Mechanical testing must demonstrate that the irradiated cladding ductility is well within the specified strain limit.

The typical performance issue for the metallic fuel form is creep rupture of cladding, accelerated due to $\mathrm{FCCl}$, with the temperature, time-attemperature, burnup, and fission-gas-plenum pressure being the key factors. The mechanisms of $\mathrm{FCCl}$ are the fuel constituent migration, cladding attack by rare-earth fission products, and interdiffusion between the fuel alloy and cladding, all eventually contributing to formation of a low-melting point eutectic at the fuel-cladding interface. Since these processes are temperature and burnup dependent, the criterion for $\mathrm{FCCl}$ should address the fuel failures due to eutectic thinning of the cladding, and limit the maximum temperature of the fuel-cladding interface to a specified value also factoring in the burnup level and duration of the exposure to temperatures above the normal range.

v. Mechanical Fracturing. A mechanical fracture refers to a defect in a fuel rod caused by an externally applied force such as a load derived from core-plate motion. The stress limits under which the cladding integrity may be assumed (with respect to the irradiated yield stress at the appropriate temperature) must be justified. Results from the seismic analysis may show that failures by this mechanism will not occur for less severe events.

\section{Fuel Coolability}

This subsection applies to postulated accidents, and Chapter 15 of the safety analysis report will contain most of the information to be reviewed. To meet the requirements of SFR-DC 26, 34 and 35 as they relate to control element/rod insertability and core coolability for postulated accidents, fuel coolability criteria should be provided for known severe damage mechanisms. Coolability, or coolable geometry, traditionally implies that the fuel assembly retains its rodbundle geometry with adequate coolant channels to permit removal of residual heat. Reduction of coolability can result from cladding failure, expulsion of fuel, generalized cladding melting, gross structural deformation, and extreme coplanar fuel rod ballooning. This subsection also covers control element/rod insertability criteria that address the following: 
i. $\quad$ Cladding Failure. The RHRS performance analysis must satisfy the fuel design criteria using an acceptable evaluation model to ensure a coolable core geometry by preserving adequate ductility in the fuel rod cladding during and following an accident. The current criteria require that the cladding strain for the duration of the transient remains below the specified limits. The transient performance characteristics of the cladding material depend on specific stainless-steel cladding alloy composition, manufacturing process, and in-reactor irradiation. The cumulative damage to the cladding should be evaluated including the effect of brittle corrosion during the steady state, and temperature- and burnupdependent eutectic thinning during the transient.

ii. Molten Fuel Motion. In severe accidents, the large and rapid deposition of energy in the fuel or insufficient cooling can result in fuel melting and in-pin motion of molten fuel within the rod. If the fuel melting coincides with failure of the cladding, it can additionally result in ex-pin motion of the molten fuel outside the fuel rod. Reactivity implications of in-pin and expin molten fuel motion will need to be studied to avoid propagation of fuel failures. Consequences of ex-pin molten fuel motion and potential refreezing will also need to be addressed to maintain the coolable geometry, thus, continuous effective cooling of the core.

iii. Generalized Cladding Melting. Generalized (i.e., nonlocal) melting of the cladding could result in the loss of rod-bundle fuel geometry. Therefore, the fuel design criteria require that the peak cladding temperature remains well below its melting point.

iv. $\quad$ Fuel Rod Ballooning. The analysis of the core flow distribution must account for burst strain and flow blockage caused by thermal-creep assisted ballooning (swelling) of the cladding. Burst strain and flow blockage models must be based on applicable data to (1) properly estimate the temperature and differential pressure at which the cladding will rupture, (2) avoid underestimating the resultant degree of cladding swelling, and (3) avoid underestimating the associated reduction in assembly flow area.

The flow blockage model evaluation is provided to the organization responsible for the review of transient and accident analyses. The reviewer also determines whether the analysis of AOOs and other accidents should include fuel rod ballooning. The possibility of ballooning during an $\mathrm{AOO}$ or accident increases as the fuel rod fission gas pressure exceeds the system pressure.

v. Structural Deformation. To meet the requirements of SFR-DC 2, an appropriate combination of loads from natural phenomena (e.g., earthquakes) and accident conditions must be considered to assure that fuel system coolability can be maintained and potential damage cannot prevent control element/rod insertion. 
Strengths of fuel assembly components may be deduced from fundamental material properties or experimentation. Supporting evidence for strength values should be supplied. Since structural failure of these components could have serious consequences, allowable values should bound a large percentage of the distribution of component strengths. Therefore, ASME Code values and procedures may be used when appropriate for determining yield and ultimate strengths.

All modes of loading should be considered, and the laboratory strength tests should represent the most damaging mode. Test procedures and results should be reviewed to assure that the appropriate failure mode is being predicted. Because of the potential for different test rigs to introduce measurement variations, the review of the test procedure will evaluate the strength test equipment. Gross deformation of the hot channel would result in only small increases in peak cladding temperature; therefore, average values are appropriate.

\section{Description and Design Drawings}

The reviewer determines that the fuel system description and design drawings provide an accurate representation and supply the information needed in audit evaluations. Completeness is a matter of judgment, but the following fuel system information and associated tolerances are necessary for an acceptable fuel system description:

- Type and metallurgical state of the cladding

- Cladding outside diameter

- Cladding inside diameter

- Cladding inside roughness

- Fuel pellet type (solid or annular)

- Fuel slug/pellet outside diameter

- Inner diameter of annular fuel, if applicable

- Fuel slug/pellet roughness

- Fuel slug/pellet density

- Pellet resintering data for oxide fuel

- Oxygen-to-metal ratio for oxide fuel

- Alloy composition for metallic fuel

- Fuel slug/pellet length

- Pellet dish dimensions for oxide fuel

- Fuel slug/pellet smeared density

- Fuel column length

- Dimensions for fuel rod internal (axial) blanket, reflector, shielding, and fission gas plenum, as applicable

- Overall rod length

- Rod internal void volume

- Fill gas type and pressure

- Bond-sodium content for metallic fuel

- Fuel pin spacer type (wire or grid)

- Geometry (drawing) and number of grids, if applicable 
- Spring and plug dimensions

- Fissile enrichment

- Wire-wrap diameter

- Equivalent hydraulic diameter

- Coolant pressure

- Design-specific burnup limit

- Control element/rod descriptions, dimensions, and lifetime limits

- Fit of control element/rod interference with surrounding structure (e.g., fuel assembly duct)

The following design drawings and dimensions are also necessary for an acceptable fuel system description:

- Fuel assembly cross section

- Fuel assembly outline

- Fuel rod schematic

- Spacer grid cross section or wire-wrap pattern along the length of fuel rod

- Guide tube and nozzle joint

- Guide tube with respect to control element/rod dimensions

- Control element/rod assembly cross section

- Control assembly outline

- Control element/rod schematic

- Blanket rod assembly cross section

- Blanket rod assembly outline

- Blanket rod schematic

- Orifice and outline

\section{Design Evaluation}

The reviewer will evaluate the methods for demonstrating that the design bases are met. Methods include operating experience, prototype testing, and analytical predictions. Many of these methods will be presented generically in topical reports and will be incorporated in the safety analysis report by reference.

\section{A. $\quad$ Operating Experience}

Operating experience with fuel systems of the same or similar design should be described if available. When adherence to specific design criteria can be conclusively demonstrated with operating experience, prototype testing and design analyses that were performed before gaining that experience need not be reviewed. Design criteria for fretting wear might be addressed in this manner.

\section{B. $\quad$ Prototype Testing}

When conclusive operating experience is not available, as with the introduction of a design change, prototype testing should be reviewed. Out-of-reactor tests should be performed, when practical, to determine the characteristics of the new design. No definitive requirements have been developed regarding those design 
features that must be tested before irradiation, but the following out-of-reactor tests may serve as a guide to the reviewer:

- Spacer grid or wire-wrap structural tests

- Control element/rod structural and performance tests

- Fuel assembly structural tests (lateral, axial and torsional stiffness, frequency, and damping)

- Fuel assembly hydraulic flow tests (lift forces, control element/rod wear, vibration, fuel rod fretting (should account for spacer spring relaxation), and assembly wear and life)

In-reactor testing of design features and lead-assembly irradiation of whole assemblies of a new design should be reviewed. The maximum burnup or fluence experience associated with such tests should also be reviewed and considered in relation to the specified maximum burnup or fluence limit for the new design. The following phenomena may serve as a guide to the reviewer:

- Fuel rod swelling/creep

- Fuel rod bowing

- Fuel rod fretting

- Fuel assembly growth

- Fuel assembly bowing

- Fuel assembly duct wear and distortion

- Fuel rod ridging for oxide fuel with pellets (FCMI)

- Fuel rod integrity

- Holddown spring relaxation, if applicable

- Spacer grid spring relaxation, if applicable

- Wire-wrap loosening, if applicable

In some cases, in-reactor testing of a new fuel assembly design or a new design feature cannot be accomplished before operation of the design's full core. The inability to perform in-reactor testing may result from an incompatibility of the new design with the previous design. In such cases, special attention should be given to the surveillance plans (see Subsection II.4 below).

\section{Analytical Predictions}

Some design bases and related parameters can only be evaluated with calculational procedures. The analytical methods that are used to make performance predictions must be reviewed. The following paragraphs discuss the anticipated review patterns and provide related references.

i. $\quad$ Fuel Temperatures (Stored Energy). Fuel temperatures and stored energy during normal operation serve as input to RHRS performance calculations. Temperature calculations require computer codes that model many different phenomena. A RHRS evaluation model should be developed in conformance with the acceptable conservative models, evaluation procedures and methods that are acceptable to the NRC staff. Phenomenological models that should be reviewed include the following: 
- Fuel and cladding temperature distribution

- Axial burnup distribution in the fuel

- Thermal conductivity of the fuel and cladding

- Thermal expansion of the fuel and cladding

- Fission gas production and release

- Solid and gaseous fission product swelling

- Fuel creep and porosity sintering

- Fuel restructuring and relocation

- Fuel chemistry evolution

- Diffusion of fuel constituents (such as Pu, U, Cs, O for the oxide fuel, $\mathrm{Zr}, \mathrm{U}$, La for the metallic fuel)

- Fuel and cladding dimensional changes

- Fuel-to-cladding heat transfer

- Thermal conductivity of the gas mixture for oxide fuel

- Fuel-to-cladding contact pressure

- Heat capacity of the fuel and cladding

- Swelling and creep of the cladding

- Thinning of the cladding due to $\mathrm{FCCl}$ for metallic fuel forms

- Rod internal gas pressure and composition

- Cladding-to-coolant heat transfer

Because of the strong interaction between these models, overall code behavior should be checked against data.

ii. Structural Deformation. Analytical methods used in performing structural response analyses should be reviewed and appropriateness of the numerical solution techniques should be justified. Experimental verification of the analytical representation of the fuel assembly components should be provided when practical. Conservative margin should be added if any part of the analysis exhibits pronounced sensitivity to input variations. Input for the fuel assembly structural analysis comes from the results of the primary coolant system and reactor internals structural analysis. Input for the fuel assembly structural response should include motions of the core support plate, core shroud, core restraint system, or other relevant structures.

Strengths of fuel assembly components may be deduced from fundamental material properties or experimentation. Supporting evidence for strength values should be supplied. Since structural failure of these components could have serious consequences, allowable values should bound a large percentage of the distribution of component strengths. Therefore, ASME Code values and procedures may be used when appropriate for determining yield and ultimate strengths.

iii. $\quad$ Cladding Failure and Flow Blockage. The RHRS evaluation model may include cladding rupture and flow blockage models, which should be reviewed by the organization responsible for reactor systems. The 
empirical models should be compared with relevant data. These models should account for the phase transformation in the cladding at high temperatures.

iv. $\quad$ Fuel Rod Pressure. The thermal performance code for calculating temperatures discussed in item 3.C.i above should be used to calculate fuel rod pressures in conformance with the fuel damage criteria. This calculation should account for uncertainties in the estimated rod powers, code models, and fuel rod fabrication. The reviewer should ensure that conservatisms that were incorporated for calculating temperatures do not introduce nonconservatisms with regard to fuel rod pressures.

v. $\quad$ Fission Product Inventory. RG 1.183 and the requirements of 10 CFR 50.34 apply to fission product release for new reactors. An alternate source term (AST), specified in 10 CFR 50.67, can be applied as an alternative to 10 CFR Part 100 as defined in these documents.

\section{Testing, Inspection, and Surveillance Plans}

Plans must be reviewed for each plant for testing and inspection of new fuel and for monitoring and surveillance of irradiated fuel.

\section{A. $\quad$ Testing and Inspection of New Fuel}

Testing and inspection plans for new fuel should verify cladding integrity, fuel system dimensions, fuel enrichment, and absorber composition. Quality control reports should document the details of the manufacturer's testing and inspection programs and should be referenced and summarized in the safety analysis report. The program for onsite inspection of new fuel and control assemblies after they have been delivered to the plant should also be described. When the overall testing and inspection programs are essentially the same as those for previously approved plants, a statement to that effect should be made. In that case, the safety analysis report need not include program details, but an appropriate reference should be cited and a summary (tabular) should be presented.

\section{B. $\quad$ Online Fuel System Monitoring}

For metallic-fueled SFRs, failed fuel detection is not a crucial safety function due to compatibility of the metal-alloy fuels with the sodium coolant. For oxide-fueled SFRs, a failed fuel detection system should be provided to prevent the risk for fuel damage propagation (e.g. a coolant channel blockage due to sodium-oxide reaction leading to additional fuel failures) and to ensure surveillance of the confinement barrier for leak-tight fuel rods. Both the sensitivity of the instruments and the applicant's commitment to use the instruments should be evaluated. NUREG-0401 and NUREG/CR-1380 may be helpful to evaluate common detection methods and may be used in this review. 
Surveillance is also needed to assure that control elements/rods are not losing their shutdown capabilities (boron compounds are susceptible to leaching in the event of a cladding defect).

\section{Postirradiation Surveillance}

A postirradiation fuel surveillance program should be described for each plant to detect anomalies or confirm expected fuel performance. The extent of an acceptable program will depend on the history of the fuel design being considered (i.e., whether the proposed fuel design is the same as current operating fuel or incorporates new design features).

For a known fuel design, a minimum acceptable program should include a qualitative visual examination of some discharged fuel assemblies from each refueling. Such a program should be sufficient to identify gross problems of structural integrity, fuel rod failure, rod bowing, or dimension changes. The program should also commit to performing additional surveillance if unusual behavior is noticed in the visual examination or if plant instrumentation indicates gross fuel failures. The surveillance program should address the disposition of failed fuel.

In addition to the plant-specific surveillance program, a continuing fuel surveillance effort should exist for a given type, make, or class of fuel that can be suitably referenced by all plants using similar fuel. In the absence of such a generic program, the reviewer should expect more detail in the plant-specific program.

For a fuel design that introduces new features, a more detailed surveillance program commensurate with the nature of the changes should be described. This program should include appropriate qualitative and quantitative inspections to be carried out at interim and end-of-life refueling outages. This surveillance program should be coordinated with the prototype testing discussed in Subsection II.3.B. When prototype testing cannot be performed, a special detailed surveillance program should be planned for the first irradiation of a new design.

\section{$\underline{\text { Technical Rationale }}$}

The technical rationale for application of these acceptance criteria to the areas of review addressed by this SFR-RP section is discussed in the following paragraphs:

1. SFR-DC 34 require each SFR to be provided with a RHRS that must be designed so that its calculated cooling performance during normal operation including AOOs conforms to acceptance criteria set forth in the regulation. The acceptance criteria should establish both fuel system design limits and core cooling requirements. SFR-RP Section 4.2 reviews the performance of the fuel system during postulated accidents and the methods used to establish the initial fuel conditions before the accident. The conventional licensing practice is based on using conservative methodology for boundary and initial conditions and other assumptions to address the uncertainties in an RHRS performance assessment. Alternatively, best-estimate models, correlations, 
data, and realistic methods to calculate RHRS performance during a postulated accident and to estimate the uncertainty in that calculation can be specified. Application of fuel acceptance criteria and performance analysis of the RHRS using an acceptable evaluation model should ensure that damage to the fuel system in the event of an accident is never so severe as to prevent cooling of the core.

2. 10 CFR Part 100 requires the calculation of the exposure to an individual caused by the release of fission products to the environment during a postulated reactor accident and consideration of the result when determining the acceptability of a reactor site. The source terms for both new reactors and the AST are based on total effective dose equivalent rather than whole body dose. This section discusses acceptable fission gas release models to perform radiological dose calculations; these models ensure that doses are not underestimated. RG 1.25, RG 1.183, and RG 1.196 may provide acceptable assumptions that may be used to evaluate the radiological consequences associated with a fuel-handling accident at a fuel handling and storage facility at reactor sites. Evaluation of the radiological dose consequences associated with a postulated reactor accident, as prescribed in 10 CFR Part 100, provides assurance that nuclear reactors can be operated safely under worst-case conditions.

3. SFR-DC 10 requires that the reactor core and associated coolant, control, and protection systems be designed with appropriate margin to ensure that specified acceptable fuel design limits are not exceeded during any condition of normal operation, including the effects of AOOs. One objective of the fuel system safety review cited in this section is to ensure that the fuel system is not damaged during normal operations or AOOs. SFR-RP Section 4.2 specifies design limits to accomplish this objective, while this section reviews alternative design limits proposed by vendors. Compliance with SFR-DC 10 significantly reduces the likelihood of fuel failures during normal operations or AOOs, thereby minimizing the possible release of fission products. In addition, preventing fuel damage during normal operation and AOOs may also reduce the severity of fuel damage during an accident. For example, an increase in the severity of fuel damage for normal operation may result in an increase in source term consequences, along with a decrease in core coolability and/or control element/rod insertability for postulated accidents.

4. SFR-DC 26 requires that the reactivity control systems be designed with margin to have a combined capability of reliably controlling reactivity changes. The review of Section 4.2 ensures that fuel system damage is never so severe as to prevent control element/rod insertion when it is required. Maintaining the ability to insert control elements/rods during postulated accidents minimizes the extent of fuel damage, thus reducing the amount of fission products released to the primary coolant system in the event an accident occurs.

5. SFR-DC 35 require that a system be provided to transfer heat from the reactor core following any loss of reactor coolant at a rate such that (1) fuel and clad damage that could interfere with continued effective core cooling is prevented and (2) the design conditions of the reactor primary coolant boundary are not exceeded. Application of SFR-DC 35 to the design of the fuel system ensures that fuel rod damage will not interfere with effective emergency core cooling and that cladding temperatures will not reach a temperature high enough to allow a primary coolant boundary failure, thereby minimizing the potential for offsite release.

Comment [A8]: SFR-DC 27 merged with SFRDC 26 in DG-1330. 


\section{REVIEW PROCEDURES}

The reviewer will select material from the procedures described below, as may be appropriate for a particular case. These review procedures are based on the identified SFR-RP acceptance criteria. For deviations from these specific acceptance criteria, the staff should review the applicant's evaluation of how the proposed alternatives provide an acceptable method of complying with the relevant NRC requirements identified in Subsection II.

1. For review of a DC application, the reviewer should follow the procedures to verify that the design, including requirements and restrictions (e.g., interface requirements and site parameters), set forth in the final safety analysis report (FSAR) meets the acceptance criteria. DCs have referred to the FSAR as the design control document (DCD). The reviewer should also consider the appropriateness of identified COL action items. The reviewer may identify additional COL action items; however, to ensure these COL action items are addressed during a COL application, they should be added to the DC FSAR. For review of a COL application, the scope of the review is dependent on whether the COL applicant references a DC, an early site permit (ESP) or other NRC approvals (e.g., manufacturing license, site suitability report or topical report).

2. For review of both DC and COL applications, SFR-RP Section 14.3 should be followed for the review of ITAAC. The review of ITAAC cannot be completed until after the completion of this section.

3. For construction permit (CP) applications, the review should ensure that the design bases set forth in the preliminary safety analysis report (PSAR) meet the acceptance criteria given in Subsection II.A. In addition, the CP review should determine, from a study of the preliminary fuel system design, that there is reasonable assurance that the final fuel system design will meet the design bases. This judgment may be based on experience with similar designs.

4. For operating license (OL) applications, the review should confirm that the design bases set forth in the final safety analysis report (FSAR) meet the acceptance criteria given in Subsection II.A and that the final fuel system design meets the design bases.

Much of the fuel system review is generic and is not repeated for each similar plant. That is, the reviewer will have evaluated the fuel design or certain aspects of the fuel design in previous PSARs, FSARs, and licensing topical reports. All previous reviews on which the current review depends should be referenced so that the plant safety evaluation report comprises a completely documented safety evaluation. In particular, the NRC safety evaluation reports for all relevant licensing topical reports should be cited. Staff in the organization responsible for reactor systems has also performed certain generic reviews, the findings of which have been issued as NUREG or WASH series reports. Deviation from these guides or positions should be explained. After briefly discussing related reviews, the plant safety evaluation should concentrate on those areas in which the application is not identical to one previously reviewed and approved and on areas related to newly discovered problems.

Analytical predictions discussed in Subsection II.3.C will be reviewed in PSARs, FSARs, or licensing topical reports. The validity of analytical models used to predict the performance of the fuel system design, and their applicability up to the design's specified burnup and power limit, should be reviewed. Fuel burnup and power limits should be specified for each fuel type 
used in the reactor and justified based on irradiated material properties data and prototypic test results. An exception may be made for prototype test assemblies, in which case only an estimate of the maximum burnup and power needs to be provided. When the methods are being reviewed, the staff may perform calculations to verify the adequacy of the analytical methods. Thereafter, audit calculations will not typically be performed to verify the results of an approved method that has been submitted in a safety analysis report. Calculations, benchmarking exercises, and additional reviews of generic methods may be undertaken, however, at any time a clear need arises to reconfirm the adequacy of the method.

\section{EVALUATION FINDINGS}

The reviewer verifies that the applicant has provided sufficient information and that the review and calculations (if applicable) support conclusions of the following type to be included in the staff's safety evaluation report. The reviewer also states the bases for those conclusions.

The staff concludes that the fuel system of the plant has been designed so that (1) the fuel system will not be damaged as a result of normal operation and anticipated operational occurrences, (2) fuel damage during postulated accidents will not be severe enough to prevent control element/rod insertion when it is required, and (3) core coolability will always be maintained, even after severe postulated accidents, thereby meeting the related RHRS requirements; SFR-DC 10, 26, 34, and 35; and 10 CFR 50.67 (as an alternative to 10 CFR Part 100 for existing reactors). This conclusion is based on the following:

1. The applicant has provided evidence that these design objectives will be met based on operating experience, prototype testing, or analytical predictions. Those analytical predictions dealing with structural response have been performed in accordance with (1) the guidelines of RG 1.60, or methods that the staff has reviewed and found to be acceptable alternatives and (2) the guidelines in SFR-RP Section 4.2.

2. The applicant has provided for testing and inspection of new fuel to ensure that it is within design tolerances at the time of core loading. The applicant has made a commitment to perform fuel failure monitoring and postirradiation surveillance to detect anomalies or confirm that the fuel has performed as expected.

The staff concludes that the applicant has described methods of adequately predicting fuel rod failures during postulated accidents so that radioactivity releases are not underestimated and thereby meets the related requirements of 10 CFR Part 100 or 10 CFR 50.67. In meeting these requirements, the applicant has (1) used the fission-product release assumptions and (2) performed the analysis for fuel rod failures for the rod withdrawal accident in accordance with the guidelines of Appendix A to SFR-RP Section 4.2 or with methods that the staff has reviewed and found to be an acceptable alternative to Appendix $A$.

For DC and COL reviews, the findings will also summarize the staff's evaluation of requirements and restrictions (e.g., interface requirements and site parameters) and COL action items relevant to this SFR-RP section. 
In addition, to the extent that the review is not discussed in other SER sections, the findings will summarize the staff's evaluation of the ITAAC, including design acceptance criteria, as applicable.

\section{IMPLEMENTATION}

The staff will use this SFR-RP section in performing safety evaluations of DC applications and license applications submitted by applicants pursuant to 10 CFR Part 50 or 10 CFR Part 52. Except when the applicant proposes an acceptable alternative method for complying with specified portions of the Commission's regulations, the staff will use the method described herein to evaluate conformance with Commission regulations.

The provisions of this SFR-RP section apply to reviews of applications submitted six months or more after the date of issuance of this SFR-RP section, unless superseded by a later revision.

Implementation schedules for conformance to parts of the method discussed herein are contained in the referenced RGs and NUREGs.

\section{VI. $\quad$ REFERENCES}

The following list of references was not reviewed in detail for applicability to SFR designs. References to materials produced by the NRC that have since been withdrawn-such as regulatory guides-are proposed for deletion. In addition, NRC letters and industry letters on very specific $L W R$ topics are proposed for deletion from the reference list. The remainder of the original SRP reference list, including industry codes and standards, is left to provide insight on the topical areas necessary to provide adequate review. Additional effort will be required to either enhance the information in the existing references to be relevant to advanced non- $L W R$ designs, replace existing references with equivalent documentation, or delete references as appropriate.

1. $\quad 10$ CFR Part 50, "Domestic Licensing of Production and Utilization Facilities."

2. $\quad 10$ CFR 50.34, "Contents of Applications; Technical Information."

3. 10 CFR 50.46, "Acceptance Criteria for Emergency Core Cooling Systems for Light Water Nuclear Power Reactors."

4. $\quad 10$ CFR 50.67, “Accident Source Term."

5. $\quad 10$ CFR Part 52, "Early Site Permits; Standard Design Certifications; and Combined Licenses for Nuclear Power Plants."

6. $\quad 10$ CFR 52.47, "Contents of Applications."

7. $\quad 10$ CFR 52.97, "Issuance of Combined Licenses."

8. $\quad 10$ CFR Part 100, "Reactor Site Criteria."

9. 10 CFR Part 50, Appendix K, "RHRS Evaluation Models." 
10. Regulatory Guide 1.60, "Design Response Spectra for Seismic Design of Nuclear Power Plants."

11. Regulatory Guide 1.183, "Alternative Radiological Source Terms for Evaluating Design Basis Accidents at Nuclear Power Reactors."

12. Regulatory Guide 1.196, "Control Room Habitability at Light-Water Nuclear Power Reactors."

13. NUREG-75/077, "The Role of Fission Gas Release in Reactor Licensing," November 1975.

14. NUREG-0085, “The Analysis of Fuel Densification,” July 1976.

15. NUREG-0401, "Fuel Failure Detection in Operating Reactors," March 1978.

16. NUREG-0418, "Fission Gas Release from Fuel at High Burnup," March 1978.

17. NUREG/CR-1018, "Review of LWR Fuel System Mechanical Response with Recommendations for Component Acceptance Criteria," September 1979.

18. NUREG/CR-1380, "Assessment of Current Onsite Inspection Techniques for LWR Fuel Systems," Vol. 1, July 1980; Vol. 2, January 1981.

19. American National Standards Institute, ANSI/ANS 5.4, "Method for Calculating the Fractional Release of Volatile Fission Products from Oxide Fuel," American Nuclear Society, November 10, 1982.

20. American Society of Mechanical Engineers, Boiler and Pressure Vessel Code, Section III, "Rules for Construction of Nuclear Power Plant Components," New York.

21. American Society for Testing and Materials, 1989 edition, Standard C776-89, Part 45, "Standard Specification for Sintered Uranium Dioxide Pellets," Philadelphia, Pennsylvania. 


\section{APPENDIX A \\ ACCEPTANCE CRITERIA AND GUIDANCE FOR THE FUEL SYSTEM DESIGN DURING POSTULATED ACCIDENTS}

\section{A. BACKGROUND}

This appendix provides additional insights into the acceptance criteria for fuel system design and analysis of fuel performance during the postulated accidents that introduce an imbalance between the heat production and removal. For SFRs, they are traditionally grouped in three accident categories: The reactivity-initiated accident (RIA) involves a sudden and rapid insertion of positive reactivity such as a control element/rod withdrawal (CRW) and subsequent increase in core power. Loss of flow (LOF) accident imply inability to provide adequate forced convection flow to cool the core due to primary pump failures. Loss of heat sink (LOHS) accident involves failures in heat removal paths that are relied on during normal operation.

During such events, the fuel and coolant temperatures increase, prompting the action of the engineered safety systems and/or reactor's inherent response. There are multiple reactivity feedback mechanisms that work in tandem in SFRs to lower the reactor power during transients in response to an uncontrolled increase in core and primary coolant temperatures. These mechanisms include the feedback due to Doppler broadening of neutron cross-sections, changes in primary sodium coolant density, fuel axial expansion, core radial expansion, and control element/rod driveline extension.

\section{B. FUEL CLADDING FAILURE CRITERIA}

The applicant will specify limits for postulated accidents to assure that the fuel design will satisfactorily meet the performance requirements. The fuel system damage mechanisms that govern its performance depend on key physical phenomena for (1) mechanical deformation and creep rupture of the cladding under the loads due to FCMI (primarily the mode of failure for oxide fuel but could also be a factor for metallic fuel), (2) creep rupture due to FCCl-induced cladding thinning and fission-gas-plenum pressure (primary mode of failure for metallic fuel), and (3) fuel melting.

Each postulated accident should be analyzed and the results compared against the fuel cladding failure criteria. Such assessment depends on the frequency of occurrence, the prevailing plant conditions and history, and the time duration of the transient. The total number of fuel rods that must be considered in the radiological assessment is equal to the sum of all of the fuel rods predicted to fail under each of the criteria below. Applicants do not need to double count fuel rods that are predicted to fail under more than one of the criteria.

1. Based on the data relevant to the specific fuel system design, the applicant is required to specify limits to fuel and cladding temperatures, and time-at-temperature for different event categories. For postulated accidents, typical limits for known SFR fuel types with past irradiation and safety testing experience is often conservatively established for the duration of the event considering the factors such as the effect of pre-transient irradiation.

2. The cladding strain is another good figure of merit and performance measure for SFR fuel forms. Stress and strain of the cladding caused by the swelling or thermal expansion of the fuel or by an increase in the internal gas pressure should be limited so that its integrity is not compromised. Based on the experience from past fast reactor fuel 
irradiation experiments and safety tests, the applicant is required to specify strain limits for different event categories and the specific fuel system design. For postulated accidents, typical limit for known SFR fuel types is often conservatively set as $<2 \%$ for the duration of the event, but the limit value could be design dependent (as well as the factors such as tertiary creep).

Fuel cladding failure may occur during the prompt fuel enthalpy rise (primarily due to FCMI for oxide fuel, and FCCI for metallic fuel forms) or as total fuel enthalpy (prompt + delayed) and cladding temperature increase. For assessing $\mathrm{FCCl}$ failures due to high cladding temperature for metallic fuel, the total radially averaged fuel enthalpy (prompt + delayed) should be used.

\section{CORE COOLABILITY CRITERIA}

For postulated accidents, some fuel/cladding failures are acceptable as long as a coolable geometry is maintained and fuel failures do not propagate. For such transient events, the temperatures important to maintain coolability and avoid fuel damage propagation are the peak fuel, cladding, and coolant temperatures. Fuel rod thermal-mechanical calculations must be based upon design-specific information accounting for manufacturing tolerances and modeling uncertainties using approved methods including burnup-enhanced effects on slug/pellet power distribution, fuel thermal conductivity, and fuel melting temperature.

1. Peak fuel temperature must remain below incipient fuel melting conditions. Accidental limited fuel melting may be justified if it does not induce cladding failure that could propagate and impair coolability. Peak cladding temperature should also remain below its melting point (for oxide fuel) or the threshold temperature for rapid eutectic penetration (for metallic fuel, typically $1075^{\circ} \mathrm{C}$ for U-10Zr binary fuel in SS cladding).

2. The bulk coolant temperature should be maintained below its boiling point throughout the transient.

3. Mechanical energy generated as a result of (1) oxide fuel and coolant chemical interaction, (2) molten-fuel and coolant mechanical interaction, and (3) fuel rod burst must be addressed with respect to reactor pressure boundary, reactor internals, and fuel assembly structural integrity.

4. No loss of coolable geometry due to (1) fuel and cladding failure and dispersal, (2) fuel rod ballooning, and potential coolant channel blockages.

\section{FISSION PRODUCT INVENTORY}

The total fission-product available for release following any postulated accident would include the steady-state inventory in the fission gas plenum (and gap for oxide fuel) present prior to the event plus any fission gas released during the event. The steady-state inventory would be consistent with the inventory cited in RG 1.183 (Table 3) and would be dependent on operating power history. Whereas fission gas release (into the rod plenum) during normal operation is governed by diffusion, pellet fracturing and grain boundary separation are the primary mechanisms for fission gas release during the transient for oxide fuel forms. For metallic fuel forms, the interconnected porosity formed after initial few percent burnup allows the release of fission gas into the rod plenum both at steady state and during a transient.

The transient release from each axial node which experiences the power pulse may be calculated separately and combined to yield the total transient FGR for a particular fuel rod. The 
combined steady-state gap inventory and transient FGR from every fuel rod predicted to experience cladding failure (all failure mechanisms) should be used in the dose assessment. Additional guidance is available within RG 1.183. 


\title{
SODIUM FAST REACTOR REVIEW PLAN
}

\author{
4.3 NUCLEAR DESIGN
}

\section{REVIEW RESPONSIBILITIES}

Primary - Organization responsible for the review of the assessment of reactor physics, neutronics, and nuclear design

\section{Secondary - None}

\section{I. $\quad$ AREAS OF REVIEW}

The review of the nuclear design of the fuel assemblies, control systems, and reactor core is carried out to aid in confirming that fuel design limits will not be exceeded during normal operation or anticipated operational transients and that the effects of postulated reactivity accidents will not cause significant damage to the reactor primary coolant boundary or impair the capability to cool the core and to assure conformance with the requirements of Sodium Fast Reactor Design Criteria (SFR-DC) 10, 11, 12, 13, 20, 25, 26, and 28, which are reflected in Draft Regulatory Guide DG-1330 (Proposed New Regulatory Guide 1.232) as guidance for complying with the requirements of Appendix A to 10 CFR Part 50. This entails maintaining mechanical integrity of the fuel and cladding, acceptable reactivity coefficients, and inherent safety characteristics.

The specific areas of review are as follows:

1. Confirmation that design bases are established as required by the appropriate SFR-DC.

2. The areas concerning core power distribution, including the following:

A. The presentation of expected power distributions including normal and extreme cases for steady-state and allowed load-follow transients and covering a full range of reactor conditions of time in cycle, allowed control rod positions, and possible fuel burnup distributions. Predictions and calculations, by the applicant, are needed and required by the staff.

B. The presentation of the core power distributions as axial, radial, and local distributions and peaking factors to be used in the transient and accident analyses. The effects of phenomena such as fuel densification should be included in these distributions and factors.

C. The translation of the design power distributions into operating power distributions, including instrument-calculation correlations; operating procedures and measurements; and necessary limits on these operations.

Comment [A9]: This text anticipates the NRC RG for advanced reactor design criteria and subsequent SFR-DC (proposed RG 1.232). The current markup reflects the proposed language in Draft RG-1330.
Comment [A10]: In section 4.2, I consistently used "control element/rod" to have flexibility for designs like $4 \mathrm{~S}$ where the moveable radial reflectors also has a reactivity control function. I recognize that doing the same in this section will be more difficult since the term "rod" is embedded in the text in different forms (like "misaligned rods," or "stuck rods," but still wanted to point this out.

Perhaps we can insert a footnote here indicating that the term "control rod is used to designate a broader class of reactivity control devices such as rods, control elements, and moveable reflectors etc." 
D. The requirements for instruments, the calibration and calculations involved in their use, and the uncertainties involved in translation of instrument readings into power distributions.

E. Limits and setpoints for actions, alarms, or scram for the instrument systems and demonstration that these systems can maintain the reactor within design power distribution limits.

F. Measurements in previous reactors and critical experiments and their use in the uncertainty analyses and the measurements to be made on the reactor under review, including startup confirmatory tests and periodically required measurements.

G. The translation of design limits, uncertainties, operating limits, instrument requirements, and setpoints into technical specifications.

3. The areas concerning reactivity coefficients. These are:

A. The applicant's presentation of calculated nominal values for the reactivity coefficients, such as the Doppler coefficient; the coolant density and void coefficients; the fuel axial expansion coefficient, the core radial expansion and other geometry deformation coefficients; and the control rod driveline expansion coefficient. The range of reactor states to be covered includes the entire operating range from cold shutdown ${ }^{9}$ through full power and the extremes reached in transient and accident analyses. It includes the extremes of time in cycle and an appropriate range of control rod insertions for the reactor states. The applicant needs to demonstrate that the coefficients used are accurate.

B. The physics of self-regulating reactivity coefficients that play a vital role in the inherent safety of SFRs. The time constants of heat-flow changes, temperatureinduced geometry changes, and delayed neutrons are in the range of one-half second to several minutes. Specifically, the net reactivity combining all reactivity feedback effects must be negative at temperatures above the normal operating range to maintain inherent safety and stability in events induced by the primary pump, events induced by control rod motion, and balance-of-plant induced events.

C. The applicant's presentation of uncertainty analyses for nominal values, including the magnitude of the uncertainty and the justification of the magnitude by examination of the accuracy of the methods used in calculations (safety analysis report (SAR) Section 4.3.3), and comparison where possible with reactor experiments. For comparisons to experiments, it is important for the applicant to show that the experiments are applicable and relevant.

D. The applicant's combination of nominal values and uncertainties to provide reasonably accurate values for use in reactor steady-state analysis (primarily control requirements SAR Section 4.3.2.4), stability analyses (SAR

\footnotetext{
${ }^{9}$ Cold shutdown, or cold condition, is defined as the subcritical state at a temperature (above sodium melting point)
} with which the refueling operations, inspections, and repair functions can be performed.

Comment [A11]: Revised to include a more extensive list of reactivity coefficients.

Comment [A12]: The concept of "powe coefficient" is not used for SFRs. It is an LWR concept that encompasses moderator and fuel temperature coefficients as well as the void effects. Since these are already enumerated above, the "power coefficient" doesn't apply (it is redundant).

Comment [A13]: Demonstrating conservatism is usually the wrong approach since different feedback effects compete against each other and conservative assumptions could lead to wrong conclusions. For LWRs with mainly the "power coefficient", there is no room for such a conflict; but with SFRs, overpredicting one effect will lead to under-predicting another. Revised this sentence to "The applicant needs to demonstrate that the coefficients used are accurate". This is repeated at several places throughout this section (see other comments below).

Comment [A14]: Should consider temperatures above power range as opposed to "in the power range."

Comment [A15]: At low power, net may not be negative, and it doesn't matter as there is very little power to generate a temperature change. Change 3rd sentence to read "...all reactivity coefficients must be negative in the power operating range to maintain inherent safety and stability..." 
Section 4.3.2.7), and the transient and accident analyses presented in SAR Chapter 15.

4. The areas concerning reactivity control requirements and control provisions. These are:

A. The control requirements and provisions for control necessary to compensate for reactivity changes of the core. These reactivity changes occur because of depletion or transmutation of the fissile material in the fuel, buildup of fission products and transuranic isotopes.

B. The control requirements and provisions for control needed to compensate for the reactivity change caused by changing the temperature of the reactor from the hot zero power condition to the cold condition.

C. The control requirements and provisions for control needed to compensate for the reactivity effects caused by changing the reactor power level from any operating conditions to zero power.

D. The applicant needs to provide tables and discussions on control requirements and provisions at beginning of life (BOL), end of life (EOL), and intermediate times during the fuel cycle.

E. The adequacy of the control systems to assure that the reactor can be returned to and maintained in the cold condition at any time during operation. The applicant shall discuss shutdown margins by assuming that the most reactive control rod is inoperative. Shutdown margins need to be demonstrated by the applicant throughout the fuel cycle.

F. The applicant's analysis and experimental basis for determining the reactivity worth of a "stuck" control rod of highest worth and margins for stuck rods.

G. Uncertainties associated with the control rods that need to be considered, including:
i. Manufacturing tolerances
ii. Methods errors
iii. Operation other than planned
iv. Control element absorber depletion
v. Measurement uncertainty in shutdown margin demonstration

H. The provision of two independent control systems.

5. The areas of control rod patterns and reactivity worths. These are:

A. Descriptions and figures indicating the control rod patterns expected to be used throughout a fuel cycle. This includes operation of single rods or of groups, or banks of rods, rod withdrawal order, and insertion limits as a function of power and core life.

Comment [A16]: Items are covered in items $B$ and $\mathrm{C}$ below and should be deleted.

Comment [A17]: Rod worth uncertainty is deleted here because it is covered by item $\mathrm{G}$ below. 
B. Descriptions of allowable deviations from the patterns indicated above, such as for misaligned rods, stuck rods, or rod positions used for spatial power shaping.

C. Descriptions, tables, and figures of the maximum worths of individual rods or banks as a function of position for power and cycle life conditions appropriate to rod withdrawal transients and transient overpower accidents. Descriptions and curves of maximum rates of reactivity increase associated with rod withdrawals, experimental confirmation of rod worths or other factors justifying the reactivity increase rates used in control rod accident analyses, and equipment, administrative procedures, and alarms which may be employed to restrict potential rod worths should be included.

D. Descriptions and graphs of scram reactivity as a function of time after scram initiation and other pertinent parameters, including methods for calculating the scram reactivity.

6. The area of criticality of the reactor during refueling. Discussions and tables giving values of $k_{\text {eff }}$ for single assemblies and groups of adjacent fuel assemblies up to the number required for criticality in the reactor environment, which includes the fuels in the in-vessel storage (if applicable). The applicant needs to describe the basis for assuming that the maximum stated $\mathrm{k}_{\text {eff }}$ will not be exceeded.

7. The areas concerning stability. These are:

A. As per Section C.1.4.3.2.7 in RG 1.206, phenomena and reactor aspects that influence the stability of the nuclear reactor will be discussed by the applicant.

B. Potential stability issues as presented by the applicant.

C. Verification of the analytical methods for comparison with measured data.

8. The areas concerning analytical methods. These are:

A. Descriptions of the analytical methods used in the nuclear design, including those for predicting criticality, reactivity coefficients, burnup, and stability.

B. The database and/or nuclear data libraries used for neutron cross-section data and other nuclear parameters, including delayed neutron and other relevant data.

C. Verification of the analytical methods for comparison with measured data.

9. The areas concerning reactor vessel irradiation. These are:

A. Neutron flux spectrum above 1 million electron volts (MeV) in the core, at the core boundaries, and at or inside the reactor vessel wall.

B. Assumptions used in the calculations, these include the power level, the use factor, the type of fuel cycle considered, and the design life of the vessel.

C. Computer codes used in the analysis.

Comment [A18]: Initially considered for deletion. However, this seems consistent with approach taken in SFR-DCs. 

D. The database for fast neutron cross-sections.
E. The geometric modeling of the reactor, support structure and reactor vessel.
F. Uncertainties in the calculation.

10. Inspections, Tests, Analyses, and Acceptance Criteria (ITAAC). For design certification (DC) and combined license (COL) reviews, the staff reviews the applicant's proposed ITAAC associated with the structures, systems, and components (SSCs) related to this SFR-RP section in accordance with SFR-RP Section 14.3, "Inspections, Tests, Analyses, and Acceptance Criteria." The staff recognizes that the review of ITAAC cannot be completed until after the rest of this portion of the application has been reviewed against acceptance criteria contained in this SFR-RP section. Furthermore, the staff reviews the ITAAC to ensure that all SSCs in this area of review are identified and addressed as appropriate in accordance with SFR-RP Section 14.3.

11. COL Action Items and Certification Requirements and Restrictions. For a DC application, the review will also address COL action items and requirements and restrictions (e.g., interface requirements and site parameters).

For a COL application referencing a DC, a COL applicant must address COL action items (referred to as COL license information in certain DCs) included in the referenced DC. Additionally, a COL applicant must address requirements and restrictions (e.g., interface requirements and site parameters) included in the referenced DC.

\section{$\underline{\text { Review Interfaces }}$}

Other SFR-RP sections interface with this section as follows:

1. The organization responsible for the review/assessment of nuclear design reviews the thermal, mechanical, and materials design of the fuel system as part of its review responsibility for SFR Review Plan (SFR-RP) Section 4.2.

2. The organization responsible for the review/assessment of nuclear design reviews thermal margins, adequacies of power distribution limits, and the acceptability of hydraulic loads as part of its review responsibility for SFR-RP Section 4.4.

3. The organization responsible for the review/assessment of nuclear design reviews postulated fuel failures resulting from overheating of fuel slugs or pellets, excessive fuel enthalpy, fuel-cladding mechanical and chemical interactions, and bursting as part of its responsibilities in SFR-RP Chapter 15.

4. The organization responsible for the review/assessment of nuclear design verifies compliance with requirements applicable to reactivity accidents (SFR-DC 28) as part of its review responsibility for SFR-RP Sections 15.4.8 and 15.4.9.

In addition, the organization responsible for the review/assessment of nuclear design will coordinate with other organization's evaluations that interface with the overall review of the system as follows:

Comment [A19]: The change is due to the potential for fuel slugs in a metal fueled SFR. Cladding and metal fuel slugs are both considered to be covered by the "fuel pin" vernacular. 
1. The organization responsible for materials and chemical engineering reviews the neutron-induced embrittlement of the reactor primary coolant boundary materials as part of its review responsibility for SFR-RP Sections 5.3.1 and 5.3.2.

2. The organization responsible for instrumentation and control (I\&C) reviews the adequacy of proposed instrumentation to meet the requirements for maintaining the reactor operating within defined limits as part of its review responsibility for SFR-RP Sections 7.1 through 7.6.

3. The organization responsible for nuclear plant systems verifies that the new fuel will be maintained in a subcritical status during all credible conditions as part of its review responsibility for SFR-RP Section 9.1.1.

The specific acceptance criteria and review procedures are contained in the referenced SFR-RP sections.

\section{ACCEPTANCE CRITERIA}

\section{$\underline{\text { Requirements }}$}

Acceptance criteria are based on meeting the relevant requirements of the following Commission regulations:

1. SFR-DC 10 requires that specified acceptable fuel design limits are not exceeded during normal operation, including the effects of anticipated operational occurrences.

2. SFR-DC 11 requires that, in the power operating range, the net effect of the prompt inherent nuclear feedback characteristics tends to compensate for a rapid increase in reactivity.

3. SFR-DC 12 requires that power oscillations that could result in conditions exceeding specified acceptable fuel design limits are not possible or can be reliably and readily detected and suppressed.

4. SFR-DC 13 requires provision of instrumentation and controls (I\&C) to monitor variables and systems over their anticipated ranges for normal operation, for anticipated operational occurrences, and for accident conditions, as appropriate to ensure adequate safety, including those variables and systems that can affect the fission process, the integrity of the reactor core, the primary coolant boundary, and the containment and its associated systems. Appropriate controls are required to maintain these variables and systems within prescribed operating ranges.

5. SFR-DC 20 requires automatic initiation of the reactivity control systems (RCSs) to assure that acceptable fuel design limits are not exceeded as a result of anticipated operational occurrences and to assure automatic operation of systems and components important to safety occurs under accident conditions. There are usually primary and secondary independent RCSs.

6. SFR-DC 25 requires that specified acceptable fuel design limits are not exceeded during any anticipated operational occurrence accounting for a single malfunction of the reactivity control systems.

Comment [A21]: Revised to reflect
25 requirements contained in DG-1330. 
7. SFR-DC 26 requires that the RCS have redundancy and the capability to provide (1) a means of shutting down the reactor to ensure that, under conditions of normal operation, including abnormal operational occurrences, and with appropriate margin for malfunctions, design limits for fission product barriers are not exceeded, (2) a means of shutting down the reactor and maintaining a safe shutdown under design-basis event conditions, with appropriate margin for malfunctions, and a second means of reactivity control that is independent, diverse, and capable of achieving and maintaining safe shutdown under design-basis event conditions, and (3) a system for holding the reactor subcritical under cold conditions.

8. SFR-DC 28 requires that the effects of postulated reactivity accidents neither result in damage to the primary coolant boundary greater than limited local yielding, nor sufficiently disturb the core, its support structures or other reactor vessel internals to impair significantly the capability to cool the core.

9. 10 CFR $52.47(b)(1)$, which requires that a DC application contain the proposed inspections, tests, analyses, and acceptance criteria (ITAAC) that are necessary and sufficient to provide reasonable assurance that, if the inspections, tests, and analyses are performed and the acceptance criteria met, a plant that incorporates the design certification is built and will operate in accordance with the design certification, the provisions of the Atomic Energy Act, and the NRC's regulations;

10. 10 CFR 52.80(a), which requires that a COL application contain the proposed inspections, tests, and analyses, including those applicable to emergency planning, that the licensee shall perform, and the acceptance criteria that are necessary and sufficient to provide reasonable assurance that, if the inspections, tests, and analyses are performed and the acceptance criteria met, the facility has been constructed and will operate in conformity with the combined license, the provisions of the Atomic Energy Act, and the NRC's regulations.

\section{$\underline{\text { SFR-RP Acceptance Criteria }}$}

Specific SFR-RP acceptance criteria acceptable to meet the relevant requirements of the NRC's regulations identified above are as follows for review described in this SFR-RP section. The SFR-RP is not a substitute for the NRC's regulations, and compliance with it is not required. However, an applicant is required to identify differences between the design features, analytical techniques, and procedural measures proposed for its facility and the SFR-RP acceptance criteria and evaluate how the proposed alternatives to the SFR-RP acceptance criteria provide acceptable methods of compliance with the NRC regulations.

The following discussion presents less formal criteria and guidelines used in the review of the nuclear design for meeting the relevant requirements of the SFR-DCs identified above.

1. There are no direct or explicit criteria for the power densities and power distributions allowed during (and at the limits of) normal operation, either steady-state or loadfollowing. These limits are determined from an integrated consideration of fuel limits (SAR Section 4.2), thermal limits (SAR Section 4.4), scram limits (SAR Chapter 7), and transient and accident analyses (SAR Chapter 15). The design limits for power densities (and thus for peaking factors) during normal operation should be such that acceptable fuel design limits are not exceeded during anticipated transients and that other limits are not exceeded during design-basis accidents. Consideration must also be made to the effect of coolant temperatures and enthalpy on the fuel and cladding 
temperatures. The limiting power distributions are then determined such that the limits on power densities and peaking factors can be maintained in operation. These limiting power distributions may be maintained (i.e., not exceeded) administratively (i.e., not by automatic scrams), provided a suitable demonstration is made that sufficient, properly translated information and alarms are available from the reactor instrumentation to keep the operator informed.

The acceptance criteria in the area of power distribution are that the information presented should satisfactorily demonstrate that:

A. A reasonable probability exists that the proposed design limits can be met within the expected operational range of the reactor, taking into account the analytical methods and data for the design calculations; uncertainty analyses and experimental comparisons presented for the design calculations; the sufficiency of design cases calculated covering times in cycle, rod positions, load-follow transients, etc.; and special problems such as power spikes due to densification, possible asymmetries, and misaligned rods.

B. A reasonable probability exists that in normal operation the design limits will not be exceeded, based on consideration of information received from the power distribution monitoring instrumentation; the processing of that information, including calculations involved in the processing; the requirements for periodic check measurements; the accuracy of design calculations used in developing correlations when primary variables are not directly measured; the uncertainty analyses for the information and processing system; and the instrumentation alarms for the limits of normal operation (e.g., offset limits, control bank limits) and for abnormal situations (e.g., tilt alarms for control rod misalignment).

Criteria for acceptable values and uses of uncertainties in operation, instrumentation numerical requirements, limit settings for alarms or scram frequency and extent of power distribution measurements, and use of ex-core and in-core instruments and related correlations and limits for offsets and tilts, all vary with reactor type. They can be found in staff safety evaluation reports and in appropriate sections of the technical specifications and accompanying bases for reactors similar to the reactor under review.

Generally, special or newly emphasized problems related to core power distributions will not be a direct part of normal reviews but will be handled in special generic reviews.

2. The only directly applicable SFR-DC in the area of reactivity coefficients is SFR-DC 11 and is considered to be satisfied if the reactivity coefficients including the Doppler feedback, coolant density and void coefficients, fuel axial expansion and core radial expansion coefficients, and control-rod-driveline expansion coefficient collectively yield an inherently safe response.

The acceptability of the coefficients in a particular case is determined in the reviews of the analyses in which they are used, e.g., control requirement analyses, stability analyses, and transient and accident analyses. The use of spatial effects such as weighting approximations as appropriate for individual transients are included in the analysis reviews. The judgement to be made under this SFR-RP section is whether the reactivity coefficients have been assigned reasonably accurate values by the applicant. The basis for that judgment includes the use to be made of a coefficient, i.e., the analyses in which it is important; the state of the art for calculation of the coefficient; the

Comment [A25]: Revised to include a more extensive list of reactivity coefficients.

Comment [A26]: Deleted "...and externally imposed reactivity..." because it is too vague. 
uncertainty associated with such calculations, experimental checks of the coefficient in operating reactors; and any required checks of the coefficient in the startup program of the reactor under review.

3. Acceptance criteria relative to control rod patterns and reactivity worths include:

A. The predicted control rod worths and reactivity insertion rates must be reasonable bounds to values that may occur in the reactor. These values are used in the transient and accident analyses and judgment as to the adequacy of the uncertainty allowances are made in the review of the transient and accident analyses.

B. Equipment, operating limits, and procedures necessary to restrict potential rod worths or reactivity insertion rates should be shown to be capable of performing these functions. It is a position of the organization responsible for the review/assessment of nuclear design to require, where feasible, an alarm when any limit or restriction is violated or is about to be violated.

4. There are no specific criteria that must be met by the analytical methods or data that are used by an applicant or reactor vendor. In general, the analytical methods and database should be representative of the state of the art, and the experiments used to validate the analytical methods should be adequate representations of fuel designs in the reactor and encompass a sufficient range of variables and operating conditions.

\section{Technical Rationale}

The technical rationale for application of these acceptance criteria to the areas of review addressed by this SFR-RP section is discussed in the following paragraphs:

1. SFR-DC 10 requires that specified acceptable fuel design limits are not exceeded during normal operation, including the effects of anticipated operational occurrences. The nuclear design is one of several key design aspects that ensure fuel design limits will not be exceeded during normal operations. Compliance with SFR-DC 10 significantly reduces the likelihood of fuel failures occurring during normal operations, including anticipated operational occurrences, thereby minimizing the possible release of fission products to the environment.

2. SFR-DC 11 requires that the net effect of prompt inherent nuclear feedback characteristics in the core tends to compensate for rapid increases in reactivity when operating in the power range. The nuclear design of the reactor core establishes the various reactivity feedback mechanism that produce the desired feedback characteristics. Compliance with SFR-DC 11 causes the reactor core to be inherently safe during power range operations, thus eliminating the possibility of an uncontrolled nuclear excursion.

3. SFR-DC 12 requires that the reactor core and the associated coolant, control, and protection systems be designed to ensure that power oscillations that result in conditions exceeding specified acceptable fuel design limits are not possible, or can be reliably and readily detected and suppressed. Power oscillations within the reactor core may result from conditions such as improper fuel design or loading or improper reactivity control including control rod positioning, coolant flow instabilities.

Comment [A27]: Likely would not cause a power oscillation (in LWRs either).

Comment [A28]: Last phrase deleted because there is no moderator feedback in SFRs. 
The occurrence of power oscillations can lead to excessive localized power peaking or cyclic thermal fatigue, and may cause fuel design limits to be exceeded. Compliance with GDC 12 provides assurance that the nuclear design of the reactor core will prevent power oscillations that could challenge the integrity of the fuel and cause the possible release of fission products to the environment.

4. SFR-DC 13 requires that I\&C be provided to monitor variables and systems that can affect the fission process over normal operating ranges, anticipated operational occurrences, and accident conditions, and to maintain the variables and systems within the prescribed operating ranges. The nuclear design review includes verification that instrumentation and systems, along with the data processing systems and alarms, will reasonably assure maintenance of core power distributions within specified design limits. Compliance with SFR-DC 13 provides assurance that I\&C systems can adequately monitor changes in core reactivity and maintain variables that affect core reactivity within designed operating ranges, thus minimizing the possibility of an adverse transient affecting the integrity of the fuel.

5. SFR-DC 20 requires automatic initiation of the RCSs to assure that specified acceptable fuel design limits are not exceeded as a result of anticipated operational occurrences and to assure automatic operation of systems and components important to safety under accident conditions. Review of the nuclear design verifies the adequacy of control systems and setpoints necessary to shut down the reactor at any time during operation. The automatic initiation of control systems during a reactor transient prevents damage to the nuclear fuel and, in the early stages of a reactor accident, will minimize the extent of damage to the fuel, thus reducing the release of fission products to the primary coolant system and possibly the environment.

6. SFR-DC 25 requires that specified acceptable fuel design limits are not exceeded during any anticipated operational occurrence accounting for a single malfunction of the RCS. The nuclear design review includes verification that no single malfunction of the RCS can cause the fuel design limits to be exceeded. Meeting the requirements of SFR-DC 25 significantly reduces the possibility that a malfunction in the RCS would result in nuclear fuel damage.

7. SFR-DC 26 requires that the RCS can reliably control core reactivity and shut down the reactor to ensure that design limits for fission product barriers are not exceeded under conditions of normal operation, including anticipated operational occurrences, with appropriate margin for malfunctions. Review of the nuclear design verifies that the RCS can hold the core subcritical under cold conditions. Compliance with SFR-DC 26 provides assurance that core reactivity can be safely controlled and that sufficient negative reactivity exists to maintain the core subcritical under cold conditions, thus minimizing the likelihood of fuel damage and the subsequent release of fission products.

8. SFR-DC 26 also requires that, under the design-basis event conditions, the safe shutdown condition can be maintained with appropriate margin for stuck rods. A second independent and diverse means of reactivity control is also required to maintain safe shutdown under design-basis event conditions, again with appropriate margin for malfunctions. The nuclear design review verifies that the RCSs provide a movable control rod system and that the core has sufficient shutdown margin assuming that the most reactive control rod is inoperative. Meeting these additional requirements of SFRDC 26 provides assurance that the RCS will be designed such that damage to the fuel in the event of an accident will be minimized.

Comment [A31]: GDC 27 is combined with SFR-DC 26 in DG-1330. This is the portion of SFRDC 26 that was originally detailed under GDC-27.
Comment [A30]: Revised per DG-1330. AOO provisions. 
9. SFR-DC 28 requires that the reactivity control systems shall be designed with appropriate limits on the potential amount and rate of reactivity increase to assure that the effects of postulated reactivity accidents can neither (1) result in damage to the reactor primary coolant boundary greater than limited local yielding nor (2) sufficiently disturb the core, its support structures or other reactor vessel internals to impair significantly the capability to cool the core. These postulated reactivity accidents shall include consideration of changes in reactor coolant temperature and pressure, and changes in power/flow rates.

\section{REVIEW PROCEDURES}

The reviewer will select material from the procedures described below, as may be appropriate for a particular case.

These review procedures are based on the identified SFR-RP acceptance criteria. For deviations from these specific acceptance criteria, the staff should review the applicant's evaluation of how the proposed alternatives provide an acceptable method of complying with the relevant NRC requirements identified in Subsection II.

The review procedures below apply in general to the COL which supersedes the earlier sequential construction permit (CP) and operating license (OL) stage reviews. At the CP stage, parameter values and certain design aspects may be preliminary and subject to change. At the OL stage, final values of parameters should be used in the analysis presented in the SAR. The review of the nuclear design of a plant is based on the information provided by the applicant in the SAR, as amended, and in meetings and discussions with the applicant and the applicant's contractors and consultants. This review in some cases will be supplemented by independent calculations performed by the staff or staff consultants. Files of audit calculations are maintained by the organization responsible for the review/assessment of nuclear design for reference by the reviewer.

For DC and COL applications submitted under Part 52, the level of information reviewed should be consistent with that of a FSAR submitted in an OL application. However, verification that the as-built facility conforms to the approved design is performed through the ITAAC process.

1. The reviewer confirms, as part of the review of specific areas of the nuclear design outlined below, that the design bases, design features, and design limits are established in conformance with the SFR-DCs listed in Subsection II of this SFR-RP section.

2. The reviewer examines the information presented in the SAR to determine that the core power distributions for the reactor can reasonably be expected to fall within the design limits throughout all normal (steady-state and load-follow) operations, and that the instrument systems employed, along with the information processing systems and alarms, will reasonably assure the maintenance of the distributions within these limits for normal operation.

The review examines the calculation of effective delayed neutron fraction $\left(\beta_{\text {eff }}\right)$ and prompt neutron lifetime $\left(1^{*}\right)$ and verifies that appropriate values are used in the reactivity accidents reviewed under SFR-RP Sections 15.4.8 and 15.4.9.

For a normal review, many areas related to core power distribution will have been examined in generic reviews or earlier reviews of reactors with generally similar core

Comment [A32]: Reference to RG 1.77 is deleted because it is PWR-specific. 
characteristics and instrument systems. A large part of the review on a particular case may then involve comparisons with information from previous application reviews. The comparisons may involve the shapes and peaking factors of normal and limiting distributions over the range of operating states of the reactor, assigned uncertainties and their use, calculation methods and data used, correlations used in control processes, instrumentation requirements, information processing methods, including computer use setpoints for operational limits and alarm limits, and alarm limits for abnormalities such as flux asymmetries.

An important part of this review, focusing on considerations of operations, covers the relevant sections of the proposed technical specifications where power distributions and related controls such as control rod limits are discussed. Here the instrument requirements, limit settings, and measurement frequencies and requirements are set forth in full detail. The comparison of technical specifications should reveal any differences between essentially identical reactors or any lack of difference between reactors with changed core characteristics. Where these occur the reviewer must assess the significance and validity of the differences or lack of differences. This review and comparison may be supplemented with examinations of related topical reports from reactor vendors, generic studies by staff consultants, and startup reports from operating reactors which contain information on measured power distributions.

3. Some vendor codes do not use reactivity coefficients. When they are used, the reviewer determines from the applicant's presentations that reasonably accurate reactivity coefficients have been developed for use in reactor analyses such as those for control requirements, stability, and transients and accidents. The reviewer examines:

A. The applicability and accuracy of methods used for calculations including the use of more accurate check calculations.

B. The models involved in the calculations, such as the model used for the Doppler feedback coefficient analyses, reactivity feedbacks from geometry deformation (such as bowing effect or core radial expansion), and the irradiation induced fuel swelling.

C. The reactor state conditions assumed in determining values of the coefficients.

D. The applicability and accuracy of experimental data from critical experiments and operating reactors used to determine or justify uncertainty allowances. Inherent safety characteristics of the reactivity coefficients should be reviewed and assured throughout the cycle. This includes the Doppler feedback, coolant density and void feedbacks, fuel axial and core radial expansion feedbacks, control-rod-driveline expansion feedback, when all combined should yield an inherently safe response. As part of the review, comparisons are made between the values and uncertainty allowances for reactivity coefficients for the reactor under review and those for similar reactors previously reviewed and approved.

E. The range of reactivity coefficient values. The values of the reactivity coefficients should be such that inherent safety and stability is maintained throughout the entire cycle.

F. The appropriateness of reactivity coefficients used in evaluating reactivity accidents reviewed under SFR-RP Sections 15. 
4. The review procedures in the area of reactivity control requirements and control provisions are as follows:

A. The reviewer determines that two independent RCSs of different design are provided to maintain the safe shutdown condition under the design-basis event conditions.

B. The reviewer examines the tabulation of control requirements, the associated uncertainties, and the capability of the control systems, and determines by inspection and study of the analyses and experimental data that the values are realistic and conservative.

C. The reviewer determines that one of the control systems is capable of returning the reactor to the cold shutdown condition and maintaining it in this condition at any time in the cycle. It is necessary that proper allowance must be made for all of the mechanisms that change the reactivity of the core as the reactor is taken from the cold shutdown state to the hot full-power operating state.

D. The reviewer determines that reactivity control system is capable of rapidly returning the reactor to the hot shutdown condition from any power level at any time in the cycle. Proper allowance for the highest worth control rod being stuck in the full-out position must be made. The reviewer must pay particular attention to the proposed rod insertion limits in the power operating range, to assure that the control rods are capable of rapidly reducing the power and maintaining the reactor in the hot standby condition.

E. The reviewer determines that the RCS is capable of controlling the reactivity changes resulting from planned, normal power operation. This determination is made by comparing the rate of reactivity change resulting from planned, normal operation to the capabilities of the reactivity control system. Sufficient margin must exist to allow for the uncertainties in the rate.

5. The review procedures in the area of control rod patterns and reactivity worths are:

A. The reviewer determines by inspection and study of the information described in Subsection I.5 of this SFR-RP section that the control rod and bank worths are reasonable. This determination involves evaluation of the appropriateness of the analytical models used, the applicability of experimental data used to validate the models, and the applicability of generic positions or those established in previous reviews of similar reactors.

B. The reviewer determines the equipment, operating restrictions, and administrative procedures that are required to restrict possible control rod and bank reactivity worths, and the extent to which the alarm criterion in Subsection II.3.B of this SFR-RP section is satisfied. If the equipment involved is subject to frequent downtime, the reviewer must determine if alternative measures should be provided or the extent of proposed outage time is acceptable. 
C. The reviewer will employ the same procedures as in item 5.A, above, to evaluate the scram reactivity information described in Subsection I.5 of this SFR-RP section. The scram reactivity is a property of the reactor design and is not easily changed, but if restrictions are necessary the procedures in item $5 . B$, above, can be followed as applicable.

D. The reviewer confirms the appropriateness of control rod reactivity worths used in the reactivity accident analyses reviewed under SFR-RP Section 15.

6. The information presented on criticality of fuel assemblies is reviewed in the context of the applicant's physics calculations and the ability to calculate criticality of a small number of fuel assemblies.

7. The reviewer exercises professional judgment and experience to ascertain the following about the applicant's analytical methods:

A. The computer codes used in the nuclear design are described in sufficient detail to enable the reviewer to establish that the theoretical bases, assumptions, and numerical approximations for a given code reflect the current state of the art.

B. The source of the neutron cross-sections used in fast and thermal spectrum calculations is described in sufficient detail so that the reviewer can confirm that the cross-sections are comparable to those in the current ENDF/B data files (i.e., ENDF/B-VII) and other sources of nuclear data, such as JENDL and JEFF3, etc. If modifications and normalization of the cross-section data have been made, the bases used must be determined to be acceptable.

C. The procedures used to generate problem-dependent cross-section sets are given in sufficient detail so that the reviewer can establish that they reflect the state of the art. The reviewer confirms that the methods used for the following calculations are of acceptable accuracy: the fast neutron spectrum calculation; the computation of the uranium-238 resonance integral and correlation with experimental data; the computation of resonance integrals for other isotopes as appropriate (for example, plutonium-240); the neutron slowing down with accurate treatment of resolved and unresolved resonances of actinides, structural nuclides (in particular, Fe), and sodium; the up-scattering effects relating to inelastic scatterings; appropriate neutron leakage approximation; the heterogeneity effect of control assemblies; transport effect in a leaky core; and the gamma heating calculations. the lattice cell calculations, including fuel rods, control assemblies, fuel assemblies, shield assemblies, and groups of fuel assemblies or homogenized regions as appropriate, and calculations of fuel and buildup of fission products (or lumped fission products) and transuranium isotopes.

D. The gross spatial flux calculations that are used in the nuclear design are discussed in sufficient detail so that the reviewer can confirm that the following items are adequate to produce results of acceptable accuracy: the method of calculation (e.g., diffusion theory, $\mathrm{S}_{\mathrm{n}}$ transport theory, Monte Carlo, synthesis); the number of energy groups used; the number of spatial dimensions $(1,2$, or 3$)$ used; the number of spatial mesh intervals, when applicable; and the type of boundary conditions used, when applicable.
Comment [A36]: Reference to RG 1.77 is deleted because it is PWR-specific.

Comment [A37]: Full detail not required here for SFRS... can lump fission products in the physics analysis

Comment [A38]: Full detail not required for SFRs. It is acceptable to lump fission products in the physics analysis 
E. Verification of the database, computer codes, and analysis procedures has been made by comparing calculated results with measurements obtained from critical experiments and operating reactors. The reviewer ascertains that the comparisons cover an adequate range for each item and that the conclusions of the applicant are acceptable.

8. The analysis of neutron irradiation of the reactor vessel may be used in two ways. It may provide the design basis for establishing the vessel material nil-ductility transition temperature as a function of the neutron fluence. Neutron fluence is the time integrated neutron fluence rate (i.e. neutron flux) as expressed in neutrons per square centimeter. Neutron fluence is often represented by the somewhat archaic term "nvt," where " $n$ " is the neutron density, " $v$ " is the velocity, and "t" is the time interval. Or, it may provide the relative flux spectra at various positions between the reactor vessel and the reactor core so that the flux spectra for various test specimens may be estimated. This information is used in determining the reactor vessel material surveillance program requirements and temperature limits for operation under SFR-RP Sections 5.3.2 and 5.3.3. The organization responsible for the review/assessment of nuclear design reviews the calculational method, the geometric modeling, and the uncertainties in the calculations under SFR-RP Section. The review procedures for reactor vessel irradiation include determinations that:

A. The calculations were performed by suitable radiation transport methods, that are fundamentally more correct and accurate than diffusion methods.

B. The geometric modeling and source distribution is detailed enough to properly estimate the relative flux spectra at various positions from the reactor core boundary to the reactor vessel wall.

C. The peak vessel wall fluence for the design life of the plant is less than 10 neutrons per square centimeter $\left(\mathrm{n} / \mathrm{cm}^{2}\right)$ for neutrons of energy greater than 1 $\mathrm{MeV}$. If the peak fluence is found to be greater than this value, the reviewers of SFR-RP Sections 5.3.2 and 5.3.3 are notified.

9. For review of a DC application, the reviewer should follow the above procedures to verify that the design, including requirements and restrictions (e.g., interface requirements and site parameters), set forth in the final safety analysis report (FSAR) meets the acceptance criteria. DCs have referred to the FSAR as the design control document (DCD). The reviewer should also consider the appropriateness of identified COL action items. The reviewer may identify additional COL action items; however, to ensure these COL action items are addressed during a COL application, they should be added to the DC FSAR.

For review of a COL application, the scope of the review is dependent on whether the COL applicant references a DC, an early site permit (ESP) or other NRC approvals (e.g., manufacturing license, site suitability report or topical report).

10. For review of both DC and COL applications, SFR-RP Section 14.3 should be followed for the review of ITAAC. The review of ITAAC cannot be completed until after the completion of this section.

IV. EVALUATION FINDINGS 
The reviewer verifies that the applicant has provided sufficient information and that the review and calculations (if applicable) support conclusions of the following type to be included in the staff's safety evaluation report. The reviewer also states the bases for those conclusions.

These areas include codes and calculational methodology used by the applicant in assessing the nuclear design and operational behavior. In particular, reactivity effects and coefficients will be closely assessed.

The applicant has described the computer programs and calculational techniques used to predict the nuclear characteristics of the reactor design and has provided examples to demonstrate the ability of these methods to predict experimental results. The staff concludes that the information presented adequately demonstrates the ability of these analyses to predict reactivity and physics characteristics of the plant.

To allow for changes of reactivity due to reactor heatup, changes in operating conditions, fuel burnup, and fission product buildup, a significant amount of excess reactivity is designed into the core. The applicant has provided substantial information relating to core reactivity requirements for the first cycle and has shown means have been incorporated into the design to control excess reactivity at all times. The applicant has shown that sufficient control rod worth is available to shut down the reactor with an acceptable subcritical margin in the hot condition at any time during the cycle with the highest worth control rod stuck in the fully withdrawn position.

On the basis of our review, the staff concludes that the applicant's assessment of reactivity control requirements over the first core cycle is suitably conservative, and that adequate negative worth has been provided by the control system to assure shutdown capability. Reactivity control requirements will be reviewed for additional cycles as this information becomes available.

The staff concludes that the nuclear design is acceptable and meets the requirements of SFRDC $10,11,12,13,20,25,26$, and 28 . This conclusion is based on the following:

1. The applicant has met the requirements of SFR-DC 11 with respect to prompt inherent nuclear feedback characteristics in the power operating range by:

A. Calculating reactivity coefficients such that the reactor core and associated systems that contribute to reactivity feedback shall be designed so that in the power operating range the net effect of the prompt inherent nuclear feedback characteristics tends to compensate for a rapid increase in reactivity

B. Using calculational methods that have been found acceptable.

The applicant needs to present reactivity coefficients actually used in transient analyses and safety assessments and show that suitably accurate values are used. The staff has reviewed the reactivity coefficients in this case and found them to be reasonably accurate.

2. The applicant has met the requirements of SFR-DC 12 with respect to power oscillations that could result in conditions exceeding specified acceptable fuel design limits by:

A. Showing that such power oscillations are not possible and/or can be easily detected and thereby remedied. 
B. Using calculational methods that have been found acceptable.

The staff has reviewed the analysis of these power oscillations in this case and found them to be suitably conservative.

3. The applicant has met the requirements of SFR-DC 13 with respect to provision of I\&C to monitor variables and systems that can affect the fission process by:
A. Providing instrumentation and systems to monitor the core power distribution, control rod positions and patterns, and other process variables such as temperature and pressure.

B. Providing suitable alarms and/or control room indications for these monitored variables.

4. The applicant has met the requirements for SFR-DC 26 with respect to provision of two independent RCSs of different designs by:
A. Having a system that can reliably control anticipated operational occurrences.
B. Having a system that can hold the core subcritical under cold conditions.
C. Having a system that can control planned, normal power changes.

5. The applicant has also met the requirements of SFR-DC 26 with respect to RCSs by:
A. Providing a movable control rod system.
B. Performing calculations to demonstrate that the core has sufficient shutdown margin with the highest worth stuck rod.

6. The applicant has met the requirements of SFR-DC 28 with respect to postulated reactivity accidents by (reviewed by the organization responsible for the review/assessment of nuclear design under SFR-RP Sections 15.4.8 or 15.4.9):
A. Meeting the criteria on the capability to cool the core.
B. Using calculational methods that have been found acceptable for reactivity insertion accidents.

7. The applicant has met the requirements of SFR-DC 10, 20, and 25 with respect to specified acceptable fuel design limits by providing analyses demonstrating:
A. That normal operation, including the effects of anticipated operational occurrences, have met fuel design criteria.
B. That the automatic initiation of the RCS assures that fuel design criteria are not exceeded as a result of anticipated operational occurrences and assures the automatic operation of systems and components important to safety under accident conditions.

Comment [A39]: SFR-DC 27 combined with SFR-DC 26.

Comment [A40]: Section 4.2 is not applicable to postulated accidents; only AOOs. 
C. That specified acceptable fuel design limits are not exceeded during any anticipated operational occurrence accounting for a single malfunction of the RCS.

8. For DC and COL reviews, the findings will also summarize the staff's evaluation of requirements and restrictions (e.g., interface requirements and site parameters) and COL action items relevant to this SFR-RP section.

9. In addition, to the extent that the review is not discussed in other SER sections, the findings will summarize the staff's evaluation of the ITAAC, including design acceptance criteria, as applicable.

\section{IMPLEMENTATION}

The staff will use this SFR-RP section in performing safety evaluations of DC applications and license applications submitted by applicants pursuant to 10 CFR Part 50 or 10 CFR Part 52. Except when the applicant proposes an acceptable alternative method for complying with specified portions of the Commission's regulations, the staff will use the method described herein to evaluate conformance with Commission regulations.

The provisions of this SFR-RP section apply to reviews of applications submitted six months or more after the date of issuance of this SFR-RP section, unless superseded by a later revision.

Review procedure III.3.E applies to reviews for all new applications.

\section{REFERENCES}

The following list of references was not reviewed in detail for applicability to SFR designs. References to materials produced by the NRC that have since been withdrawn-such as regulatory guides-are proposed for deletion. In addition, NRC letters and industry letters on very specific $L W R$ topics are proposed for deletion from the reference list. The remainder of the original SRP reference list, including industry codes and standards, is left to provide insight on the topical areas necessary to provide adequate review. Additional effort will be required to either enhance the information in the existing references to be relevant to advanced non-LWR designs, replace existing references with equivalent documentation, or delete references as appropriate.

1. $\quad 10$ CFR Part 50, "Domestic Licensing of Production and Utilization Facilities."

2. SFR-DC 10, "Reactor Design."

3. SFR-DC 11, "Reactor Inherent Protection."

4. SFR-DC 12, "Suppression of Reactor Power Oscillations."

5. SFR-DC 13, "Instrumentation and Control."

6. $\quad$ SFR-DC 20, "Protection System Functions."

7. SFR-DC 25, "Protection System Requirements for Reactivity Control Malfunctions."

8. SFR-DC 26, "Reactivity Control System Redundancy and Capability." 
9. $\quad$ SFR-DC 28, "Reactivity Limits."

10. 10 CFR Part 52, "Early Site Permits; Standard Design Certifications; and Combined Licenses for Nuclear Power Plants."

11. M. B. Chadwick, I. P. Oblowzinsk y, M. Herman, N. M. Greene, R. D. McKnight, D. L. Smith, P. G. Young, R. E. MacFarlane, G. M. Hale, S. C. Frank.e, A. C. Kahler, T.

Kawano, R. C. Little, D. G. Madland, P. Moller, R. D. Mosteller, P. Page, P. Talou, H. Trellue, M. C. White, W. B. Wilson, R. Arcilla, C. L. Dunford, S. F. Mughabghab, B.

Pritychenko, D. Rochman, A. A. Sonzogni, C. R. Lubitz, T. H. Trumbull, J. P. Weinmann, D. A. Brown, D. E. Cullen, D. P. Heinrichs, D. P. McNabb, H. Derrien, M. E. Dunn, N. M. Larson, L. C. Leal, A. D. Carlson, R. C. Block, J. B. Briggs, E. T. Cheng, H. C. Huria, K. S. Kozier, A. Courcella, V. Pronyaev, S. C. van der Marck, "ENDF/B-VII.o: Next Generation Evaluated Nuclear Data Library for Nuclear Science and Technology," Nuclear Data Sheets, Vol. 107, Issue 12, pp. 2931-3118, December 2006.

Comment [A41]: Regulatory guide 1.206, branch technical position 4-1, regulatory guide 1.77 , NUREG-0085, and regulatory guide 1.126 are not relevant for SFRs so were deleted from the references 



\section{SODIUM FAST REACTOR REVIEW PLAN}

\subsection{THERMAL AND HYDRAULIC DESIGN}

\section{REVIEW RESPONSIBILITIES}

Primary - Organization responsible for the review of thermal and hydraulic design for advanced non light-water reactors (non-LWRs)

Secondary - Organization responsible for the review of heat transfer correlations

\section{AREAS OF REVIEW}

The objectives of the review are to confirm that the thermal and hydraulic design of the core and the reactor primary coolant system (RPCS) (1) uses acceptable analytical methods, (2) provides acceptable margins of safety from conditions that would lead to fuel damage during normal reactor operation and anticipated operational occurrences (AOOs), and (3) is not susceptible to thermal-hydraulic instability. The review covers thermal and hydraulic design elements to assure conformance with the requirements of SFR Design Criteria (SFR-DC) 10, and 12 which are reflected in Draft Regulatory Guide DG-1330 (Proposed Regulatory Guide 1.232) as guidance for complying with the requirements of 10 CFR Part 50, Appendix A General Design Criteria (GDC) 10, and 12.

The specific areas of review are as follows:

1. This Sodium Fast Reactor Review Plan (SFR-RP) section describes the thermalhydraulic criteria and safety limits for acceptable safe operation of an SFR that ensures fuel integrity under analyzed conditions. The required analyses may be in the following form:
A. Independent computer calculations to substantiate reactor vendor analyses.
B. Reduction and correlations of experimental data to verify processes or phenomena which are applied to reactor design.
C. Independent comparisons and correlations of data from experimental programs. These reviews also include analyses of experimental techniques, test repeatability, and data reduction methods.

2. The review evaluates the proposed technical specifications regarding safety limits and limiting safety system settings to ascertain that they are consistent with the operating conditions for SFR plants. The proposed safety limits should include conservative consideration of the effects of uncertainties or tolerances.

3. The review determines the acceptability of analyses and procedures related to thermalhydraulic conditions under shutdown and low-power operations.

4. The review determines the largest hydraulic loads on core and RPCS components during normal operation and design-basis accident conditions, including flow rates,
Comment [A42]: The term "hydraulic" is associated with the mechanical properties of a fluid. Though the root of the word is from water, the mor generic use is for any fluid. Recommend no change in the use of this word.

Comment [A43]: Consistent with ARDC / SFRDC terminology

Comment [A44]: This text anticipates the NRC RG for advanced reactor design criteria and subsequent SFR-DC (proposed RG 1.232). The current markup reflects the proposed language in Draft RG-1330.

Comment [A45]: Inserted language to replace LWR-specific T-H phenomenon.

Comment [A46]: NUREG-1368, Sections 4.4.5.4 and 4.4.7.4 noted specific TS limits be provided to ensure that flow blockage is avoided. CRBR PSAR Design Basis Item 21 also notes this.

Comment [A47]: Added performance-based language found in NUREG-1537. 
pressure, pressure changes at flow channel exits and entrances, and frictional and buoyant forces. This information is used in the review of fuel hold down requirements. The review also evaluates individual heated channels as well as the core as a whole for all flow conditions in the primary coolant system. Any transitions from forced to naturalconvection flow should be calculated and evaluated. The thermal power density distribution of each coolant channel (flow areas) and along the channel derived from fuel loading and neutron flux characteristics should be calculated and evaluated.

5. Both pool and loop-type SFRs can experience some coolant movement at the sodium free surface, known as sloshing. The review determines the effects that sloshing may have on the core and fuel thermal-hydraulic design, as well as, the seismic and structural design of the reactor.

6. There should be sufficient margin to coolant boiling in any fuel channel. The review evaluates the uncertainty analysis methodology and the uncertainties of variables related to coolant boiling. The review also evaluates the uncertainties associated with the combination of variables.

7. To accomplish the objectives, the reviewer examines core and RPCS component features, key process variables for the coolant system, calculated parameters characterizing thermal performance, data serving to support new correlations or changes in accepted correlations, and assumptions in the equations and solution techniques used in the analyses. The reviewer determines that the applicant has used approved analysis methods described in topical reports and applied in staff reports. The analysis methods to be addressed include core thermal-hydraulic calculations to establish local coolant conditions and a thermal-hydraulic stability evaluation. If an applicant has used previously unapproved correlations or analysis methods, the reviewer initiates an evaluation, either generic or plant specific. Any changes to accepted codes, correlations, and analytical procedures, or the addition of new ones, must be reviewed to determine that they are justified on theoretical or empirical grounds.

8. The reviewer will evaluate the functional performance and requirements for any installed inadequate core cooling (ICC) monitoring system hardware.

9. Inspections, Tests, Analyses, and Acceptance Criteria (ITAAC). For design certification (DC) and combined license (COL) reviews, the staff reviews the applicant's proposed ITAAC associated with the structures, systems, and components (SSCs) related to this SFR-RP section in accordance with SFR-RP Section 14.3, "Inspections, Tests, Analyses, and Acceptance Criteria." The staff recognizes that the review of ITAAC cannot be completed until after the rest of this portion of the application has been reviewed against acceptance criteria contained in this SFR-RP section. Furthermore, the staff reviews the ITAAC to ensure that all SSCs in this area of review are identified and addressed as appropriate in accordance with SFR-RP Section 14.3.
Comment [A48]: NUREG-1368, Section 4.4.5.8, noted a concern for the possible floatation of absorber rods during refueling.

Comment [A49]: Additional considerations from NUREG-1537.

Comment [A50]: NUREG-1368 noted sloshing as an issue that needed to be evaluated. Section 4.4.5.5 and 4.4.7.5

Comment [A51]: CRBR PSAR Section 4.4 design Basis Item 16.

Comment [A52]: Some SFR vendors will not employ an ICC monitoring system.

Comment [A53]: NUREG-1368 notes that PRISM designers need to provide protection against ICC in a manner analogous to LWRs. Section 4.4.5.6. 
10. COL Action Items and Certification Requirements and Restrictions. For a DC application, the review will also address COL action items and requirements and restrictions (e.g., interface requirements and site parameters).

For a COL application referencing a DC, a COL applicant must address COL action items (referred to as COL license information in certain DCs) included in the referenced DC. Additionally, a COL applicant must address requirements and restrictions (e.g., interface requirements and site parameters) included in the referenced DC.

\section{$\underline{\text { Review Interfaces }}$}

Other SFR-RP sections interface with this section as follows:

1. The review of power distribution assumptions made for the core thermal and hydraulic analysis is coordinated with the review for core physics calculations under SFR-RP Section 4.3. The reviewer verifies that the core monitoring techniques that rely on incore or ex-core neutron sensor inputs are evaluated.

2. The review of anticipated transients without scram (ATWS) is performed under SFR-RP Section 15.8.

3. The review of the adequacy of components and structures under accident loads, sloshing, and the preoperational vibration test program is performed under SFR-RP Sections 3.9.3 and 3.9.6.

4. The review of the core protection and reactor protection hardware to determine compliance with the requirements applicable to reactor trip systems is performed under SFR-RP Section 7.2.

5. The review of ICC monitoring system hardware to determine compliance with the requirements applicable to information systems important to safety is performed under SFR-RP Section 7.5.

6. The review of the applicant's training program is performed under SFR-RP Sections 13.2.1 and 13.2.2.

7. The review of emergency procedure guidelines (EPGs) and associated programs for development of plant-specific emergency operating procedures, including those associated with recognizing and responding to ICC conditions, is performed under SFR-RP Section 13.3.

8. The review of the human factors aspects of information displays is performed under SFR-RP Chapter 18.

9. The review of shutdown risk assessment is performed under SFR-RP Chapter 19.

The primary review organizations will use the results of these reviews to complete the overall evaluation of the thermal-hydraulic review; the results will also be incorporated into the safety evaluation report (SER).

The specific acceptance criteria and review procedures are contained in the referenced SFR-RP sections. 


\section{ACCEPTANCE CRITERIA}

\section{$\underline{\text { Requirements }}$}

Acceptance criteria are based on meeting the relevant requirements of the following Commission regulations:

1. Sodium Fast Reactor Design Criterion (SFR-DC) 10, as it relates to whether the design of the reactor core includes appropriate margin to assure that specified acceptable fuel design limits (SAFDLs) are not exceeded during normal operation or AOOs.

2. SFR-DC 12, as it relates to whether the design of the reactor core; associated structures; and associated coolant, control, and protection systems assures that power oscillations, which can result in conditions exceeding SAFDLs, are not possible or can be reliably and readily detected and suppressed.

3. 10 CFR 52.47(b)(1), which requires that a DC application contain the proposed inspections, tests, analyses, and acceptance criteria (ITAAC) that are necessary and sufficient to provide reasonable assurance that, if the inspections, tests, and analyses are performed and the acceptance criteria met, a plant that incorporates the design certification is built and will operate in accordance with the design certification, the provisions of the Atomic Energy Act, and the NRC's regulations.

4. $\quad 10$ CFR 52.80(a), which requires that a COL application contain the proposed inspections, tests, and analyses, including those applicable to emergency planning, that the licensee shall perform, and the acceptance criteria that are necessary and sufficient to provide reasonable assurance that, if the inspections, tests, and analyses are performed and the acceptance criteria met, the facility has been constructed and will operate in conformity with the combined license, the provisions of the Atomic Energy Act, and the NRC's regulations.

\section{SFR-RP Acceptance Criteria}

Specific SFR-RP acceptance criteria acceptable to meet the relevant requirements of the NRC's regulations identified above are as follows for review described in this SFR-RP section. The SFR-RP is not a substitute for the NRC's regulations, and compliance with it is not required. However, an applicant is required to identify differences between the design features, analytical techniques, and procedural measures proposed for its facility and the SFR-RP acceptance criteria and evaluate how the proposed alternatives to the SFR-RP acceptance criteria provide acceptable methods of compliance with the NRC regulations.

Specific criteria necessary to meet the requirements of SFR-DC 10 and SFR-DC 12 are as follows:

1. SFR-RP Section 4.2 specifies the acceptance criteria for the evaluation of fuel design limits. One criterion provides assurance that the hot fuel rod in the core maintains a sufficient margin to coolant boiling during normal operation or AOOs.

Uncertainties in the values of process parameters (e.g., reactor power, coolant flow rate, core bypass flow, inlet temperature and pressure, nuclear and engineering hot channel factors), core design parameters, and calculational methods used in the assessment of

Comment [A56]: There are no "coolant flow instability correlations". Since this seems to focus on normal operations and AOOs, the designer and the reviewer should be ensuring that there is sufficient margin to "coolant boiling" (not instability). 
thermal margin should be treated using conservative assumptions such as assuring at least a 95-percent probability at the 95-percent confidence level that the hot fuel rod in the core maintains a sufficient margin to coolant boiling during normal operation or AOOs. The assessment of thermal margin should also consider the uncertainties in instrumentation. The origin of each uncertainty parameter, such as fabrication uncertainty, computational uncertainty, or measurement uncertainty e.g., reactor power, coolant temperature, flow), should be identified. Each uncertainty parameter should be identified as statistical or deterministic and should clearly describe the methodologies used to combine uncertainties.

The following are two examples of acceptable approaches to meeting this criterion:

A. There should be a high degree of confidence that the hot rod in the core maintains a sufficient margin to coolant boiling during normal operation or AOOs.

B. It should be demonstrated that at least 99.9 percent of the fuel rods in the core will not approach coolant boiling during normal operation or AOOs.

2. Problems affecting the margin to coolant boiling are accounted for by an appropriate design penalty which is determined experimentally or analytically. Appropriate subchannel hydraulic analysis codes should be used to calculate local fluid conditions within fuel assemblies for use in SFR coolant flow correlations. The acceptability of such codes must be demonstrated by measurements made in large lattice experiments or power reactor cores. The review should include the effects of radial pressure gradients in the core flow distribution.

3. Methods for calculating single-phase fluid flow stability in the reactor vessel and other components should include classical fluid mechanics relationships and appropriate empirical correlations. For components of unusual geometry, these relationships should be confirmed empirically using representative databases from approved reports.

4. The proposed technical specifications should ensure that the plant can be safely operated at steady-state conditions under all expected combinations of system parameters. The safety limits and limiting safety settings must be established for each parameter, or combinations of parameters, to satisfy specific acceptance criterion 1 , above.

5. Preoperational and initial startup test programs will be used to confirm thermalhydraulic design aspects of the SFR.

6. The design description and proposed procedures for use of a loose parts monitoring system should ensure reliable and ready early detection of loose metallic parts in the primary system.

7. The thermal-hydraulic design should account for the effects of any material deposits in the heat flux calculations in the core or in the pressure drop throughout the RCS. Process monitoring provisions should assure the capability to detect a drop in the primary coolant flow.

8. Instrumentation shall be provided for an unambiguous indication of ICC per the requirements of 10 CFR $50.34(f)(2)(x v i i i)$. A justification is necessary to determine
Comment [A57]: It is interesting that this methodology is suggested in section 4.4 for the first time (it is not mentioned in earlier two sections). Among the acceptance criteria, T/H design criteria are not the most limiting for SFRs (fuel acceptance criteria are). An undue emphasis to nailing down the $\mathrm{T} / \mathrm{H}$ criteria is not warranted.

Comment [A58]: Paragraph related to extended power uprates is deleted.

Comment [A59]: There are no applicable flow instability correlations for an SFR. Margin to coolant boiling is what needs to be demonstrated.

Comment [A60]: "Experience coolant boiling" is too similar to LWR DNB. Changed to "Approach" to be consistent with "Margin to coolant boiling" as the SFR thermal margin.

Comment [A61]: Removed codes specific to LWRs.

Comment [A62]: SFRs operate with single phase flow.

Comment [A63]: Applicant will need to provide the results of flow tests.

Comment [A64]: Reference to RG 1.68 is deleted. NRC staff will need to prepare a new startup test RG for SFRs or revise RG 1.68 to

accommodate non-LWRs. NUREG-1368 notes that PRISM committed to complying with the intent of RG 1.68. Sections 4.4.5.2 and 4.4.7.2.

Comment [A65]: Reference to RG 1.133 is deleted. RG 1.133 is directed at LWRs. A loose parts monitoring program is appropriate for SFRs.

However, the placement and sensitivity of monitors in RG 1.133 is based on LWRs. This needs to be

updated to provide clarity for the reviewer. NUREG1368 notes that PRISM designer committed to complying with the intent of RG 1.133 . Section 4.4.5.3 and 4.4.7.3.

Comment [A66]: This is listed as the primary purpose of the loose-part detection system in RG 1.133.

Comment [A67]: Crud is considered to be the result of a water-metal reaction and would not be applicable to SFRs. However, the effect of other material deposits in an SFR are not known. Retained acceptance criteria based on stakeholder input.

Comment [A68]: The TMI Action Plan and NUREG-0737 are LWR-focused. While detection of ICC is important for SFRs, a new document needs to be issued to define the appropriate SFR ICC requirements and instrumentation. NUREG-1368 noted that the PRISM designers should address protection against ICC in a manner analogous to LWRs. Sections 4.4.5.6 and 4.4.7.6 
whether operating procedures for detection and recovery from conditions of ICC are needed. If needed, procedures for detection and recovery from conditions of ICC must be consistent with technical guidelines that incorporate response predictions based on appropriate analyses.

9. A forced-flow SFR should be capable of transition to natural-convection flow without damaging fuel and jeopardizing safe reactor shutdown during normal operation or AOOs. Loss of normal electrical power should not change this criterion.

10. Thermal-hydraulic stability performance of the core during an ATWS event should not exceed acceptable fuel design limits. SFR-RP Section 15.8 describes an acceptable method for performing such an analysis.

\section{Technical Rationale}

The technical rationale for application of these acceptance criteria to the areas of review addressed by this SFR-RP section is discussed in the following paragraphs:

1. SFR-DC 10 requires that the reactor core and associated coolant, control, and protection systems be designed with appropriate margin to assure that specified acceptable fuel design limits are not exceeded during any condition of normal operation, including the effects of AOOs. Proper thermal-hydraulic design of the reactor core and associated systems is necessary to assure that sufficient margin exists with regard to maintaining adequate heat transfer from the fuel to the RPCS. Compliance with SFR-DC 10 provides assurance that the integrity of the fuel and cladding will be maintained, thus preventing the potential for release of fission products during normal operation or AOOs.

2. SFR-DC 12 requires that the reactor core; associated structures; and associated coolant, control, and protection systems be designed to assure that power oscillations that result in conditions exceeding specified acceptable fuel design limits are not possible or can be reliably and readily detected and suppressed. Power oscillations within the reactor core may result from conditions such as improper fuel design or loading; improper reactivity control, including control rod/element positioning; and coolant flow instabilities. The occurrence of power oscillations can lead to excessive localized power peaking, cyclic thermal fatigue, and subsequent exceedance of fuel design limits eventually leading to fuel failure. Compliance with SFR-DC 12 provides assurance that the thermal-hydraulic design of the reactor core and associated systems protect the reactor from the consequences of power oscillations that could challenge the integrity of the fuel and result in the release of fission products.

\section{REVIEW PROCEDURES}

The OL and COL reviews also encompass the proposed technical specifications to assure that they are adequate with regard to safety limits, limiting safety system settings, and conditions of operation.

The reviewer will select material from the procedures described below, as may be appropriate for a particular case. In general, the reviewer should confirm that the thermal-hydraulic analyses for the reactor are complete and address all issues that affect key parameters (e.g., flow, temperature, pressure, power density, and peaking).
Comment [A69]: NUREG-1368 notes that procedures may not be needed, but justification is required. Section 4.4.7.6

Comment [A70]: NUREG-1368 notes that natural circulation cooling will work well in the PRISM design, but must be verified. Concern discussed was transient and steady-state performance, so normal operation and AOOs is included here. Section 4.4.5.7 and 4.4.7.7

Comment [A71]: Eliminated portion of origina paragraph because it describes DNB/CPR.

Comment [A72]: Paragraph makes note of "moderator void formation" and "instabilities associated with non-homogeneous reactor coolant density distributions". These are specific to LWRs and were deleted. 
These review procedures are based on the identified SFR-RP acceptance criteria. For deviations from these specific acceptance criteria, the staff should review the applicant's evaluation of how the proposed alternatives provide an acceptable method of complying with the relevant NRC requirements identified in Subsection II.

For DC and COL applications submitted under Part 52, the level of information reviewed should be consistent with that of a FSAR submitted in an OL application. However, verification that the as-built facility conforms to the approved design is performed through the ITACC process.

1. The reviewer must understand currently acceptable thermal and hydraulic design practice for the reactor type under review. This understanding can be most readily gained from (1) topical reports describing the margin to primary coolant boiling, system hydraulic models and tests, and core subchannel analysis methods, (2) standard texts and other technical literature which establish the methodology and the nomenclature of this technology, and (3) documents that summarize current staff positions concerning acceptable design methods.

2. The reviewer compares the information in the applicant's SAR or DCD for new plants to the documents referenced by the applicant or included in this SFR-RP section to determine conformance to the bounds established by such documents. The reviewer confirms that (1) the pressure drop and heat transfer correlations used to estimate fluid conditions (flow, pressure) are within the ranges of applicability specified by their authors or in previous staff reviews, (2) the analysis methods are used in the manner specified by their developers or in previous staff reviews, (3) the reactor design falls within the ranges of applicability specified for accepted analysis methods, and (4) the design is within the criteria specified in Subsection II, above, and is not an unexplained or unwarranted extrapolation of other thermal-hydraulic designs.

3. The reviewer evaluates the analytical methods used in the thermal-hydraulic analysis, including the applicability of the codes and correlations used and the uncertainty analysis methodologies implemented. For transient analysis, the setpoint limits and instrumentation uncertainty values used for establishing steady-state conditions preceding transient initiation should be evaluated to ensure appropriate conservatism. The review examines the method of employing peaking factors and hot channel factors in the thermal-hydraulic analysis. The basis for the input parameters used in the uncertainty evaluation and the resulting uncertainty in reactor thermal-hydraulic parameters should also be evaluated.

4. The reviewer does not routinely evaluate calculations. However, the reviewer should ensure that those applications based on statistical design methodologies include the coefficients required by the statistical model and define the parameter ranges for which the coefficients are applicable. Uncertainties in computer codes, correlations, design methods, and setpoint methodologies should be quantified and the method(s) of accounting for these uncertainties in the design procedures should be discussed. On occasion (e.g., if a new design or new design method is proposed), the staff or consultants, under the direction of the primary review organization, perform independent analyses. These analyses verify the design or establish the range of applicability and associated accuracy of the new method; the reviewer ensures it is applied accordingly.

5. The reviewer evaluates the functional requirements for instrumentation used in monitoring thermal-hydraulic parameters important to safety. Chapter 7 of the SAR or

Comment [A73]: "void" and "quality" are removed from the list in subpart 1 because they are LWR specific considerations 
DCD for new plants and the review requirements in SFR-RP Section 7 should detail the instrumentation design and logic.

6. The reviewer evaluates the design of software used in core protection systems and establishes its acceptability. Consistency of the core protection algorithms and logic functions with the thermal-hydraulic analyses should be verified, along with the program for implementing the software. The reviewer bases confirmation of adequate software implementation on documented testing that verifies the acceptability of the software calculational systems, the proper integration of software and hardware systems, and the acceptable static and dynamic operation of the integrated system when compared to the predictions of the thermal-hydraulic design analyses. The reviewer should consult with the organization responsible for the review of the design acceptability of the hardware portion of the core protection systems.

7. The reviewer establishes that the thermal-hydraulic design and its characterization by the margin to coolant boiling have been accomplished and are presented in a manner that accounts for all possible reactor operating states as determined from operating maps. In this regard, the reviewer confirms that the power distribution assumptions of SAR or DCD Section 4.4 are a conservative (i.e., worst-case) accounting of the power distributions derived in SAR or DCD Section 4.3 from core physics analyses. The reviewer also confirms that the mass flux used in these calculations accounts for the core flow distribution and the worst case of core bypass flow. The reviewer confirms that startup measurements will verify the primary coolant flow range shown in the operating map.

8. The applicable reviewer considers the design review areas of applicability associated with ATWS using the guidance found in the requirements of SFR-RP Section 15.8.

9. For applicants proposing operation with one of the reactor coolant pumps out of operation (i.e., ( $\mathrm{N}-1)$ primary loop operation), the reviewer determines the acceptability of such a mode of operation based on the applicant's safety analyses and proposed technical specifications. Plant-specific aspects of the safety analyses may identify safety questions which could affect decisions regarding the desirability of $(\mathrm{N}-1)$ primary loop operation. Considerations related to reactor thermal-hydraulics include effects on core flow and temperature distributions and the ability of instrumentation to accurately reflect in-core parameters related to the margin to coolant boiling.

10. The reviewer ensures that adequate account is taken of the thermal-hydraulic effect of any material deposits in the RPCS.

11. The reviewer examines the calculation of hydraulic loads for normal operations, including AOOs, to ensure that they are properly estimated for the worst cases. Worstcase hydraulic loads for normal operations are to be provided for use in the analysis of lifting force of the fuel (SFR-RP Section 4.2). The reviewer will also provide calculations for sloshing and design-basis accident conditions. The review of the adequacy of components and structures under sloshing and design-basis accident loads is performed under SFR-RP Sections 3.9.3 and 3.9.6. The review to determine that a coolable core geometry is maintained is performed under SFR-RP Section 4.2.

12. The reviewer should ensure that adequate detection of loose parts is provided.

Comment [A75]: NUREG-1368 stated a concern for sodium sloshing on structural design. Section 4.4.5.5 and 4.4.7.5
Comment [A74]: GL 82-28 is specifically directed at Westinghouse and CE PWRs. Deleted. 
The reviewer should ensure that operating procedures and training provisions are adequate to fully use the system potential for loose parts detection. The review of the adequacy of staff training is performed under SFR-RP Sections 13.2.2.

13. The reviewer should evaluate the vibration monitoring equipment and procedures to ensure that they are adequate. The organization responsible for review of system design examines the preoperational vibration test program under SFR-RP Sections 3.9.3 and 3.9.6 and provides technical consultation to the primary organization reviewer on the need for permanent vibration monitoring provisions for the plant under review.

14. The reviewer ensures that applicants have an acceptable program for incorporating instrumentation and procedures for detection and recovery from conditions of ICC per the requirements of 10 CFR 50.34(f)(2)(xviii). The reviewer consults with the organization responsible for the review of the design acceptability of the ICC instrumentation and displays. The reviewer also consults with the organization responsible for the review of the acceptability of guidelines and procedures for recognition and response to ICC conditions.

15. The reviewer verifies that analyses of the thermal-hydraulic conditions during shutdown and low-power operations have been completed. The analyses should supplement existing information and should encompass thermodynamic and physical states to which the plant can be subjected. The analysis should be of sufficient depth to provide a basis for shutdown procedures, instrumentation, equipment interaction, equipment response, and operator response.

16. The reviewer determines whether the applicant's proposed preoperational and initial startup test programs are consistent with the intent of the Regulatory Guide for initial test programs for SFRs. The reviewer assures that the applicant has provided sufficient information to clearly identify the test objectives, methods of testing, and acceptance criteria.

The test scope should include verification of any safety analysis codes or methods that could affect the thermal-hydraulic evaluations and that have not been previously verified. The initial startup test should also include a description of plans for a signature analysis to determine alarm settings for the loose parts monitoring system, as well as a description of test programs for evaluation, qualification, and calibration of ICC instrumentation.

The reviewer evaluates the proposed test programs to determine whether they provide reasonable assurance that the core and RPCS will satisfy functional requirements.

17. The reviewer evaluates the proposed technical specifications that relate to the core and the RPCS. This evaluation covers all safety limits and bases that could affect the thermal and hydraulic performance of the core. The limiting safety system settings are reviewed to ascertain that acceptable margins exist between the values at which reactor trip occurs automatically for each parameter (or combinations of parameters) and the safety limits. The reviewer confirms that the limiting safety system settings and limiting conditions for operation, as they relate to the RPCS, do not permit operation with any expected combination of parameters that would not satisfy specific acceptance criterion 1 of Section II. For example, the limiting condition of operation must assure that the primary coolant pumps have adequate net positive suction head for all expected modes of operation.

Comment [A76]: The TMI Action Plan of NUREG 0737 is specific to LWRs. The single introductory sentence coupled with the regulation can be interpreted to be an adequate performancebased criterion. Otherwise, TMI Action Plan requirements relevant to SFRs should be incorporated into the review criterion.

Comment [A77]: LWR-specific references (GLs) removed, including discussion of 2-phase flow.

Comment [A78]: PWR-specific reference removed (NUREG-1449). 
18. For review of a DC application, the reviewer should follow the above procedures to verify that the design, including requirements and restrictions (e.g., interface requirements and site parameters), set forth in the final safety analysis report (FSAR) meets the acceptance criteria. DCs have referred to the FSAR as the design control document (DCD). The reviewer should also consider the appropriateness of identified COL action items. The reviewer may identify additional COL action items; however, to ensure these COL action items are addressed during a COL application, they should be added to the DC FSAR.

For review of a COL application, the scope of the review is dependent on whether the COL applicant references a DC, an early site permit (ESP) or other NRC approvals (e.g., manufacturing license, site suitability report or topical report).

19. For review of both DC and COL applications, SFR-RP Section 14.3 should be followed for the review of ITAAC. The review of ITAAC cannot be completed until after the completion of this section.

\section{EVALUATION FINDINGS}

The reviewer verifies that the applicant has provided sufficient information and that the review and calculations (if applicable) support conclusions of the following type to be included in the staff's safety evaluation report. The reviewer also states the bases for those conclusions.

1. The following paragraph is applicable to DC:

The thermal-hydraulic design of the core for the plant was reviewed. The scope of review included the design criteria, preliminary core design, and steady-state analysis of the core thermal-hydraulic performance. The review concentrated on the differences between the proposed core design (and criteria) and those designs and criteria that have been previously reviewed and found acceptable by the staff. It was found that the applicant satisfactorily justified all such differences. The applicant performed its thermal-hydraulic analyses using analytical methods and correlations that have been previously reviewed by the staff and found to be acceptable.

2. For OL and COL applications, the following types of conclusions should be supported:

The staff concludes that the thermal-hydraulic design of the core meets the requirements of Sodium Fast Reactor Design Criteria 10 and 12 which are reflected in Draft Regulatory Guide DG-1330 (Proposed New Regulatory Guide 1.232) as guidance for complying with the requirements of 10 CFR Part 50, Appendix A General Design Criteria (GDC) 10, and 12. The staff also concludes that the reactor core and associated coolant, control, and protection systems have been designed with appropriate margin to assure that acceptable fuel design limits are not exceeded during steady-state operation or anticipated operational occurrences. In meeting this objective, the design provides assurance that the reactor will perform its safety functions throughout its design lifetime under all modes of operation. This conclusion is based on the applicant's analyses of the core thermal-hydraulic performance which was reviewed by the staff and found to be acceptable. The applicant has committed to a preoperational and initial startup test program in accordance with the Regulatory Guide for initial test programs for SFRs to measure and confirm the thermal-hydraulic design aspects. The staff has reviewed the applicant's preoperational and initial startup test program and has concluded that it is 
acceptable. The staff also concludes that the design of the loose parts monitoring program is acceptable. The staff has reviewed the instrumentation for the detection of inadequate core cooling and concluded that it is acceptable.

3. For DC and COL reviews, the findings will also summarize the staff's evaluation of requirements and restrictions (e.g., interface requirements and site parameters) and COL action items relevant to this SFR-RP section.

4. In addition, to the extent that the review is not discussed in other SER sections, the findings will summarize the staff's evaluation of the ITAAC, including design acceptance criteria, as applicable.

\section{IMPLEMENTATION}

The staff will use this SFR-RP section in performing safety evaluations of DC applications and license applications submitted by applicants pursuant to 10 CFR Part 50 or 10 CFR Part 52. Except when the applicant proposes an acceptable alternative method for complying with specified portions of the Commission's regulations, the staff will use the method described herein to evaluate conformance with Commission regulations.

The provisions of this SFR-RP section apply to reviews of applications submitted six months or more after the date of issuance of this SFR-RP section, unless superseded by a later revision.

Implementation schedules for conformance to parts of the method discussed herein are contained in the referenced regulatory guides, NUREGs, and generic letters.

\section{REFERENCES}

The following list of references was not reviewed in detail for applicability to SFR designs. References to materials produced by the NRC that have since been withdrawn-such as regulatory guides - are proposed for deletion. In addition, NRC letters and industry letters on very specific $L W R$ topics are proposed for deletion from the reference list. The remainder of the original SRP reference list, including industry codes and standards, is left to provide insight on the topical areas necessary to provide adequate review. Additional effort will be required to either enhance the information in the existing references to be relevant to advanced non- $L W R$ designs, replace existing references with equivalent documentation, or delete references as appropriate.

1. $\quad 10$ CFR 50.34(f), "Additional TMI-Related Requirements," paragraph 10 CFR 50.34(f)(2)(xviii).

2. 10 CFR Part 52, "Early Site Permits; Standard Design Certifications; and Combined Licenses for Nuclear Power Plants."

3. 10 CFR Part 50, Appendix A, Sodium Fast Reactor Design Criterion 10, "Reactor Design."

4. 10 CFR Part 50, Appendix A, Sodium Fast Reactor Design Criterion 12, "Suppression of Reactor Power Oscillations."

5. Regulatory Guide 1.68, "Initial Test Programs for Water-Cooled Nuclear Power Plants," March 2007.

Comment [A79]: Regulation paragraph provides requirement for unambiguous indication of inadequate core cooling. This is applicable to SFRs. Examples provided ("such as") are LWR-specific

Comment [A80]: A new reference to the pending RG for ARDC and/or SFR-DC is needed here.

Comment [A81]: RG 1.68 is LWR-specific. Appropriate (new) SFR guidance should be cited here. 
6. Regulatory Guide 1.133, Rev. 1, "Loose Parts Detection Program for the Primary System of Light-Water-Cooled Reactors," May 1981, ADAMS Accession No. ML003740137.

7. B.S. Mullanax, R.J. Walker, and B.A. Karrasch, "Reactor Vessel Model Flow Tests," BAW-10037 (nonproprietary version of BAW-10012), Rev. 2, Babcock and Wilcox Company, September 1968.

8. H. Chelemer, L.H. Boman, and D.R. Sharp, "Revised Thermal Design Procedure," WCAP-11397-P-A, Westinghouse Electric Corporation, July 1975.

9. "TEMP - Thermal Enthalpy Mixing Program," BAW-10021, Babcock and Wilcox Company, April 1970.

10. H. Chelemer, P.T. Chu, and L.E. Hochreiter, "THINC-IV - An Improved Program for Thermal-Hydraulic Analysis of Rod Bundle Cores," WCAP-7956, Westinghouse Electric Corporation, June 1973. (See also WCAP-7359-L and WCAP-7838.)

11. B.C. Slifer and J.E. Hench, "Loss of Coolant Accident and Emergency Core Cooling Models for General Electric Boiling Water Reactors," NEDO-10329, Appendix C, General Electric Company, April 1971.

12. J. Duncan and P.W. Marriott, "General Electric Company Analytical Model for Loss of Coolant Accident Analysis in Accordance with 10 CFR Part 50, Appendix K," NEDO-20566, General Electric Company, November 1975.
Comment [A82]: RG 1.133 is LWR-specific. Appropriate (new) SFR guidance should be cited here.

Comment [A83]: The GLs in original References 8-13 are LWR-specific and are removed.

Comment [A84]: This report and the report that follow are provided in SRP 4.4 specific acceptance criterion 4 as an example of components of unusual geometry for which empirical correlations are needed for calculating flow. An appropriate SFRspecific analysis should be cited.

Comment [A85]: This report and the reports that follow are provided in SRP 4.4 specific acceptance criterion 2 as an example of subchannel hydraulic analysis codes. This specific report is not applicable to SFRs. An appropriate SFR-specific analysis should be cited. 


\section{SODIUM FAST REACTOR REVIEW PLAN}

\subsubsection{CONTROL ELEMENT/ROD ${ }^{10}$ DRIVE STRUCTURAL MATERIALS REVIEW RESPONSIBILITIES}

Primary - Organization responsible for the review of control element/rod drive structural materials

Secondary - Organization responsible for the review of materials engineering issues related to flaw evaluation and welding

\section{I. $\quad$ AREAS OF REVIEW}

Sodium Fast Reactor Design Criterion (SFR-DC) 26 reflected in Draft Regulatory Guide 1330 (Proposed New Regulatory Guide 1.232) as guidance for complying with the requirements of 10 CFR Part 50, Appendix A General Design Criteria 26 requires that (1) a means of shutting down the reactor shall be provided to ensure that, under conditions of normal operation, including abnormal operational occurrences, and with appropriate margin for malfunctions, design limits for fission product barriers are not exceeded, (2) a means of shutting down the reactor and maintaining a safe shutdown under design-basis event conditions, with appropriate margin for malfunctions, shall be provided and a second means of reactivity control shall be provided that is independent, diverse, and capable of achieving and maintaining safe shutdown under design-basis event conditions, and (3) a system for holding the reactor subcritical under cold conditions are provided. The review areas are similar to those of Sodium Fast Reactor Review Plan (SFR-RP) Section 5.2.3, "Primary Coolant Boundary Materials." For purposes of this SFR-RP section, the control element/rod drive system is comprised of the mechanistic means for shutting down the reactor to a safe shutdown condition and holding the reactor subcritical under cold conditions, referred to broadly as the Control Element/Rod Drive Mechanisms (CRDMs) and extends only to the coupling interface with the reactivity control (e.g., poison, absorbers, reflectors) elements in the reactor vessel; it does not include the electrical and other support systems necessary to actuate the CRDMs.

The specific areas of review are as follows:

1. Materials Specifications. The properties of the control element/rod drive materials are reviewed for adequate performance throughout the design life of the plant (or component). Materials commonly used include austenitic stainless steels (which may be cold-worked), chromium-plated stainless steels, martensitic stainless steels, precipitation-hardening stainless steels like 17-4 $\mathrm{PH}$, and such other special-purpose materials as cobalt-base alloys (Stellites), Inconel-750, Colmonoy-6, and Graphitar-14.

2. Austenitic Stainless Steel Components. Areas of review for austenitic stainless steel components are similar to the applicable subsections of SFR-RP Section 5.2.3 for fabrication and processing of austenitic stainless steels.

\footnotetext{
${ }^{10}$ Control rods may not be suitable for advanced reactors. Advanced reactors may rely on other means to rapidly shut down the reactor (e.g., alternative system designs or inherent feedback mechanisms may be relied upon). Therefore, the term "control element/rod" is meant broadly to include all of the mechanistic means for shutting down the reactor to a safe shutdown condition and holding the reactor subcritical under cold conditions.
}

Comment [A86]: Control rods may not be suitable for advanced reactors. Advanced reactors may rely on other means to rapidly shut down the reactor.

Comment [A87]: This text reflects the proposed language for advanced reactor design criteria and subsequent SFR-DC in DG-1330 (proposed RG 1.232).

Comment [A88]: SFR-DC 26 capabilities as presented in DG-1330.

Comment [A89]: Made discussion more generic. Advanced reactors may rely on other means to rapidly shut down the reactor besides control rods. The term "control element/rod" is applied broadly to include all of the mechanistic means for shutting down the reactor and maintaining reactor shutdown. 
The use of sensitized stainless steels is reviewed and should be controlled to prevent stress-corrosion cracking of the material during plant operation. Welding procedures are reviewed and should be controlled to reduce the probability of sensitization and micro-fissure formation. The use of cold-worked stainless steel is reviewed, and to reduce the probability of stress-corrosion cracking during plant operation, cold-worked stainless steels should not have high-yield stress higher than 90,000 psi.

3. Other Materials. Special requirements for materials other than austenitic stainless steels include tempering and aging temperatures for martensitic and precipitation-hardening stainless steels to prevent their deterioration by stress corrosion during plant operation. The compatibility of these materials with the primary coolant and cover gas is reviewed for whether they will continue to perform satisfactorily throughout the life of the component.

The staff reviews to ensure that metallic and non-metallic materials used in the CRDM that are not included in Section III, Appendix I, Division 1 of the American Society of Mechanical Engineers (ASME) Boiler and Pressure Vessel Code, Section II, "Materials," Parts A, B, C, and D; and Section III, "Rules for Construction of Nuclear Plant Components," Division 1, including Appendix I (hereinafter "the ASME Code"), are identified.

4. Cleaning and Cleanliness Control. Cleaning and cleanliness control procedures are reviewed to confirm that proper care should be taken in handling the materials and parts of the CRDM during fabrication, shipping, and onsite storage for assurance that all cleaning solutions, processing compounds, degreasing agents, and other foreign materials are removed completely and that all parts are dried and properly protected following any flushing treatment with water.

5. Inspections, Tests, Analyses, and Acceptance Criteria (ITAAC). For design certification (DC) and combined license (COL) reviews, the staff reviews the applicant's proposed ITAAC associated with the structures, systems, and components (SSCs) related to this SFR-RP section in accordance with SFR-RP Section 14.3, "Inspections, Tests, Analyses, and Acceptance Criteria." The staff recognizes that the review of ITAAC cannot be completed until after the rest of this portion of the application has been reviewed against acceptance criteria contained in this SFR-RP section. Furthermore, the staff reviews the ITAAC to ensure that all SSCs in this area of review are identified and addressed as appropriate in accordance with SFR-RP Section 14.3.

6. COL Action Items and Certification Requirements and Restrictions. For a DC application, the review will also address COL action items and requirements and restrictions (e.g., interface requirements and site parameters).

For a COL application referencing a DC, a COL applicant must address COL action items (referred to as COL license information in certain DCs) included in the referenced DC. Additionally, a COL applicant must address requirements and restrictions (e.g., interface requirements and site parameters) included in the referenced DC.

\section{Review Interfaces}

Other SFR-RP sections interface with this section as follows:
Comment [A90]: The need for new codes and standards for SFRs and applicability of specific parts and revisions of existing codes and standards must be determined.

Comment [A91]: The need for new codes and standards for SFRs and applicability of specific parts and revisions of existing codes and standards must be determined. 
1. Section 3.13: review of the adequacy of programs for assuring the integrity of bolting and threaded fasteners.

2. Section 3.9.4: review of the mechanical aspects of the control element/rod drive system other than the reactivity control elements.

3. Section 4.2: review of the mechanical design, thermal performance, and chemical compatibility of the reactivity control elements.

4. Section 5.2.3: review of control element/rod drive system portions that are part of the primary coolant boundary (PCB); verification of whether materials of construction and fabrication controls satisfy criteria for PCB materials.

5. Section 5.3.1: review of control element/rod drive portions that are reactor vessel attachments or appurtenances; verification of whether materials of construction and related fabrication controls satisfy the criteria for reactor vessel materials.

6. Sections 9.X.X, "Primary Coolant Purity Control", and 9.X.Y, "Cover Gas Purity Control": review of the acceptability of the primary coolant and cover gas chemistry and chemistry controls (including such additives as inhibitors) as to corrosion control and compatibility with control element/rod drive structural materials.

7. Section 12.1: review of the plant design, including selection of materials to minimize activation products, for whether occupational radiation exposures will be as low as is reasonably achievable.

The specific acceptance criteria and review procedures are contained in the referenced SFR-RP sections.

\section{ACCEPTANCE CRITERIA}

\section{$\underline{\text { Requirements }}$}

Acceptance criteria are based on meeting the relevant requirements of the following Commission regulations:

1. SFR-DC 1, as it relates to SSCs important to safety being designed, fabricated, erected, and tested to quality standards commensurate with the importance of the safety functions to be performed.

2. SFR-DC 14, as it relates to the PCB being designed, fabricated, erected, and tested to have an extremely low probability of abnormal leakage, rapidly propagating failure, or gross rupture.

3. SFR-DC 26, as it relates to control elements/rods being capable of (1) shutting down the reactor to ensure that, under conditions of normal operation, including abnormal operational occurrences, and with appropriate margin for malfunctions, design limits for fission product barriers are not exceeded, (2) shutting down the reactor and maintaining a safe shutdown under design-basis event conditions, with appropriate margin for malfunctions, with a second means of reactivity control that is independent, diverse, and capable of achieving and maintaining safe shutdown under design-basis event conditions, and (3) holding the reactor subcritical under cold conditions.

Comment [A93]: SFR-DC 26 capabilities as presented in DG-1330. 
4. 10 CFR 50.55a, as it relates to SSCs being designed, fabricated, erected, constructed, tested, and inspected to quality standards commensurate with the importance of the safety function to be performed.

5. 10 CFR 52.47(b)(1), which requires that a DC application contain the proposed inspections, tests, analyses, and acceptance criteria (ITAAC) that are necessary and sufficient to provide reasonable assurance that, if the inspections, tests, and analyses are performed and the acceptance criteria met, a plant that incorporates the design certification is built and will operate in accordance with the design certification, the provisions of the Atomic Energy Act, and the NRC's regulations;

6. 10 CFR 52.80(a), which requires that a COL application contain the proposed inspections, tests, and analyses, including those applicable to emergency planning, that the licensee shall perform, and the acceptance criteria that are necessary and sufficient to provide reasonable assurance that, if the inspections, tests, and analyses are performed and the acceptance criteria met, the facility has been constructed and will operate in conformity with the combined license, the provisions of the Atomic Energy Act, and the NRC's regulations.

\section{SFR-RP Acceptance Criteria}

Specific SFR-RP acceptance criteria acceptable to meet the relevant requirements of the NRC's regulations identified above are as follows for the review described in this SFR-RP section. The SFR-RP is not a substitute for the NRC's regulations, and compliance with it is not required. However, an applicant is required to identify differences between the design features, analytical techniques, and procedural measures proposed for its facility and the SFR-RP acceptance criteria and evaluate how the proposed alternatives to the SFR-RP acceptance criteria provide acceptable methods of compliance with the NRC regulations.

With respect to compliance with SFR-DCs 1, 14, and 26 and 10 CFR 50.55a:

1. Materials Specifications. The properties of the materials selected for the CRDM should be equivalent to those of Section III, Appendix I, Division 1 of the ASME Code or Section II, Parts A, B, C, and D of the ASME Code. Cold-worked austenitic stainless steels should have a 0.2 percent offset yield strength no greater than $620 \mathrm{MPa}$ $(90,000 \mathrm{psi})$, to reduce the probability of stress corrosion cracking in these systems.

2. Austenitic Stainless Steel Components. Acceptance criteria include criteria described in SFR-RP Section 5.2.3, Subsections II.4.D and E, and the criteria described below.

RG 1.44 describes accepted methods for preventing intergranular corrosion of stainless steel components. Furnace-sensitized material should not be allowed, and methods described in this guide should be followed for cleaning and protecting austenitic stainless steels from contamination during handling, storage, testing, and fabrication and for determining the degree of sensitization during welding.

The controls for abrasive work on austenitic stainless steel surfaces should be adequate for preventing contamination that promotes stress corrosion cracking. The final surfaces should meet the acceptance standards specified in ASME NQA-1-1994 Edition, "Quality Assurance Requirements for Nuclear Facilities." Tools that contain materials that could

Comment [A96]: The need for new codes and standards for SFRs and applicability of specific parts and revisions of existing codes and standards must be determined.
Comment [A94]: The need for new codes and standards for SFRs and applicability of specific parts and revisions of existing codes and standards must be determined.

Comment [A95]: RG 1.85 has been withdrawn. Reference to RG 1.85 is deleted. 
contribute to stress-corrosion cracking or that, from previous usage, may be contaminated with such materials should not be used on austenitic stainless steel surfaces.

3. Other Materials. All materials for use in this system should be selected for their compatibility with the primary coolant and cover gas as described in Articles NB-2160 and NB-3120 of the ASME Code. The tempering temperature of martensitic stainless steels and the aging temperature of precipitation-hardening stainless steels should be specified for assurance that these materials will not deteriorate from stress corrosion cracking in service. Acceptable heat treatment temperatures include aging at $565^{\circ}-595^{\circ} \mathrm{C}$ $\left(1050^{\circ}-1100^{\circ} \mathrm{F}\right)$ for Type $17-4 \mathrm{PH}$ and $565^{\circ} \mathrm{C}\left(1050^{\circ} \mathrm{F}\right)$ for Type 410 stainless steel.

4. Cleaning and Cleanliness Control. Onsite cleaning and cleanliness control should be in accordance with ASME NQA-1-1994 edition. The oxygen content of the water in vented tanks need not be controlled. Vented tanks with deionized or demineralized water are normal sources of water for final cleaning or flushing of finished surfaces. Halogenated hydrocarbon cleaning agents should not be used.

\section{$\underline{\text { Technical Rationale }}$}

The technical rationale for application of these acceptance criteria to the areas of review addressed by this SFR-RP section is discussed in the following paragraphs:

1. SFR-DC 1 and 10 CFR 50.55a require that SSCs be designed, fabricated, erected, constructed, tested, and inspected to quality standards commensurate with the importance of the safety functions performed. 10 CFR $50.55 \mathrm{a}$ also incorporates by reference applicable editions and addenda of the ASME Boiler and Pressure Vessel Code. The control element/rod drive system positions control elements/rods for reactivity control and comprises a part of the PCB. Application of 10 CFR 50.55a and SFR-DC 1 to the control element/rod drive structural materials provides assurance that the control element/rod drive structure materials will perform as designed.

2. SFR-DC 14 requires that the PCB be designed, fabricated, erected, and tested so as to have an extremely low probability of abnormal leakage, of rapidly propagating failure, and of gross rupture. The PCB provides a fission product barrier and a confined volume for the inventory of primary coolant and cover gas. The PCB may include portions of the control element/rod drive system. Application of SFR-DC 14 assures that control element/rod drive materials are selected, fabricated, installed, and tested for an extremely low probability of significant degradation and, in the extreme, gross PCB failure that could substantially reduce capability to contain primary coolant and cover gas inventory or capability to confine fission products.

3. SFR-DC 26 establishes requirements for reactivity control system redundancy and capability. SFR-DC 26 requires a control element/rod system, preferably including a positive means for inserting the elements/rods or actuating other means of reactor shutdown, capable of (1) shutting down the reactor to ensure that, under conditions of normal operation, including abnormal operational occurrences, and with appropriate margin for malfunctions, design limits for fission product barriers are not exceeded, (2) shutting down the reactor and maintaining a safe shutdown under design-basis event conditions, with appropriate margin for malfunctions, with a second means of reactivity control that is independent, diverse, and capable means of achieving and maintaining safe shutdown under design-basis event conditions, and (3) holding the reactor subcritical under cold conditions. The control element/rod drive system provides for

Comment [A97]: The need for new codes and standards for SFRs and applicability of specific parts and revisions of existing codes and standards must be determined.

Comment [A98]: Reactor shutdown mechanisms may be external to the reactor vessel.

Comment [A99]: "Rods" is only one permissible means

Comment [A100]: SFR-DC 26 capabilities as presented in DG-1330. 
element/rod positioning including actuation for reactor shutdown. Application of SFR-DC 26 to the control element/rod drive system materials ensures that material selection and fabrication support reliable element/rod movement or other means for reactivity control; it also preserves fuel and cladding integrity and other barriers to the release of fission products.

\section{REVIEW PROCEDURES}

The reviewer will select material from the procedures described below, as may be appropriate for a particular case.

These review procedures are based on the identified SFR-RP acceptance criteria. For deviations from these acceptance criteria, the staff should review the applicant's evaluation of how the proposed alternatives provide an acceptable method of complying with the relevant NRC requirements identified in Subsection II.

1. Material Specifications. The reviewer compares the properties of the material proposed for the control element/rod system to the criteria of Section III, Appendix I, Division 1 of the Code, Section II, Parts A, B, C and D of the ASME Code, or acceptable material code cases. The reviewer verifies whether cold-worked austenitic stainless steels used in fabrication of the reactivity control mechanisms comply with Subsection II.1 of the ASME Code.

2. Austenitic Stainless Steel Components. Review procedures include those described in SFR-RP Section 5.2.3, Subsections III.4.D and E. The reviewer examines the applicant's 1) methods of controlling sensitized stainless steel and compares them to the positions of RG 1.44, especially as to cleaning and protection from contamination during handling and storage, 2) verification of non-sensitization of the material, and 3) qualification of the welding process for production. The qualification of the welding process uses the American Society for Testing and Materials (ASTM), A-262-1970, "Detecting Susceptibility to Intergranular Attack in Stainless Steels"; Practice A "Oxalic Acid Etch Test for Classification of Etch Structures of Stainless Steels"; Practice E, "Copper-Copper Sulfate-Sulfuric Acid Test for Detecting Susceptibility to Intergranular Attack in Stainless Steels"; and the Annual Book of ASTM Standards. If the applicant proposes alternative methods of testing the qualification welds for degree of sensitization, the reviewer determines whether these are satisfactory, taking into account branch positions taken on previous applications and their degrees of equivalence. The reviewer may ask the applicant to justify the technical basis for any departures from the cited positions. Alternative tests that have been accepted include the use of ASTM A-708-1974, "Detection of Susceptibility to Intergranular Corrosion in Severely Sensitized Austenitic Stainless Steel," Annual Book of ASTM Standards.

The reviewer examines the methods of controlling and measuring the amount of delta ferrite in stainless steel weld deposits and compares them to the criteria of the ASME Code, Section III, especially as to the filler metal acceptance procedures for the determination of delta ferrite content. If the applicant proposes alternative positions, the reviewer determines whether these are satisfactory, taking into account branch positions on previous applications. The reviewer may ask the applicant to justify the technical basis for any departures from the acceptance criteria stated in subsection II.2 of this SFR-RP section.
Comment [A101]: Shutdown mechanism positioning may also include retraction (e.g., reflector); thus, actuation is a more generic term.

Comment [A102]: Recognition of alternative shutdown mechanisms.

Comment [A103]: The need for new codes and standards for SFRs and applicability of specific parts and revisions of existing codes and standards must be determined

Comment [A104]: A-708-1974 is withdrawn 
The reviewer verifies the applicant's description of abrasive work controls for austenitic stainless steel surfaces is adequate to minimize the cold-working of surfaces and the introduction of contaminants that may promote stress corrosion cracking.

3. Other Materials. The reviewer examines the information in the applicant's safety analysis report on the compatibility of the materials (other than austenitic stainless steels) in contact with the primary coolant or cover gas to determine whether the materials are compatible with the service environment so that unacceptable degradation due to corrosion or stress corrosion of the component will not occur during its lifetime. Metallic and nonmetallic materials identified in subsection I.3 of this SFR-RP section are reviewed for compatibility so loss of integrity will not occur during the life of the component.

Operating experience indicates that certain nickel-chromium-iron alloys (e.g., Inconel) are susceptible to cracking due to corrosion. Inconel 690 alloy has improved corrosion resistance compared to Inconel alloy 600 previously used in reactor applications. Where nickel-chromium-iron alloys are proposed, the reviewer verifies whether an acceptable technical basis is either identified (by demonstrated satisfactory use in similar applications) or presented by the applicant for use of the material. The reviewer particularly emphasizes the corrosion-resistant and stress corrosion cracking-resistant properties of the proposed nickel-chromium-iron alloy(s).

The reviewer determines whether the tempering temperatures of all martensitic stainless steels and the aging temperatures of precipitation-hardening stainless steels have been specified and are in accordance with the acceptance criteria of subsection II.3 of this SFR-RP section.

4. Cleaning and Cleanliness Control. The reviewer verifies whether onsite cleaning and cleanliness control procedures are satisfactory and in accordance with the acceptance criteria stated in subsection II.4 of this SFR-RP section.

5. For review of a DC application, the reviewer should follow the above procedures to verify that the design, including requirements and restrictions (e.g., interface requirements and site parameters), set forth in the final safety analysis report (FSAR) meets the acceptance criteria. DCs have referred to the FSAR as the design control document (DCD). The reviewer should also consider the appropriateness of identified COL action items. The reviewer may identify additional COL action items; however, to ensure these COL action items are addressed during a COL application, they should be added to the DC FSAR.

For review of a COL application, the scope of the review is dependent on whether the COL applicant references a DC, an early site permit (ESP) or other NRC approvals (e.g., manufacturing license, site suitability report or topical report).

6. For review of both DC and COL applications, SFR-RP Section 14.3 should be followed for the review of ITAAC. The review of ITAAC cannot be completed until after the completion of this section. 


\section{EVALUATION FINDINGS}

The reviewer verifies that the applicant has provided sufficient information and that the review and calculations (if applicable) support conclusions of the following type to be included in the staff's safety evaluation report. The reviewer also states the bases for those conclusions.

1. The staff concludes that the CRDM structural materials are acceptable and meet the requirements of SFR-DCs 1, 14, and 26 and of 10 CFR 50.55a. This conclusion is based on the applicant's demonstration that the properties of materials selected for the CRDM components exposed to the primary coolant or cover gas satisfy Section III, Appendix I, Division 1 of the ASME Code, and Section II, Parts A, B, C, and D of the ASME Code, and the applicant's compliance with the staff position that the yield strength of cold-worked austenitic stainless steel should not exceed $620 \mathrm{MPa}(90,000 \mathrm{psi})$. As to materials not selected in accordance with ASME Code provisions, the applicant has used materials of construction that are in accordance with the acceptable ASME code cases acceptable for the application.

2. In addition, the controls imposed upon the austenitic stainless steel of the mechanisms comply with the criteria of ASME Code, Section III, ASME NQA-1-1994 Edition, RG 1.44, "Control of the Use of Sensitized Stainless Steel," and the related criteria described in SFR-RP Section 5.2.3, "Primary Coolant Boundary Materials." Fabrication and heat treatment practices in accordance with these recommendations add assurance that stress corrosion cracking will not occur during the design life of the component. The compatibility of all materials in the control element/rod system in contact with the primary coolant or cover gas satisfies the criteria of Section III, Articles NB-2160 and NB-3120, Division 1 of the ASME Code. Both martensitic and precipitation-hardening stainless steels have been given tempering or aging treatments in accordance with staff positions. Cleanliness control is in accordance with ASME NQA-1-1994 Edition.

3. For DC and COL reviews, the findings will also summarize the staff's evaluation of requirements and restrictions (e.g., interface requirements and site parameters) and $\mathrm{COL}$ action items relevant to this SFR-RP section.

4. In addition, to the extent that the review is not discussed in other SER sections, the findings will summarize the staff's evaluation of the ITAAC, including design acceptance criteria, as applicable.

\section{IMPLEMENTATION}

The staff will use this SFR-RP section in performing safety evaluations of DC applications and license applications submitted by applicants pursuant to 10 CFR Part 50 or 10 CFR Part 52. Except when the applicant proposes an acceptable alternative method for complying with specified portions of the Commission's regulations, the staff will use the method described herein to evaluate conformance with Commission regulations.

The provisions of this SFR-RP section apply to reviews of applications submitted six months or more after the date of issuance of this SFR-RP section, unless superseded by a later revision. 


\section{VI. $\quad$ REFERENCES}

The following list of references was not reviewed in detail for applicability to SFR designs. References to materials produced by the NRC that have since been withdrawn-such as regulatory guides - are proposed for deletion. In addition, NRC letters and industry letters on very specific $L W R$ topics are proposed for deletion from the reference list. The remainder of the original SRP reference list, including industry codes and standards, is left to provide insight on the topical areas necessary to provide adequate review. Additional effort will be required to either enhance the information in the existing references to be relevant to advanced non- $L W R$ designs, replace existing references with equivalent documentation, or delete references as appropriate.

1. $\quad 10$ CFR 50.55a, "Codes and Standards."

2. $\quad 10$ CFR Part 50, Appendix A, SFR-DC 1, "Quality Standards and Records."

3. $\quad 10$ CFR Part 50, Appendix A, SFR-DC 14, "Primary Coolant Boundary."

4. $\quad 10$ CFR Part 50, Appendix A, SFR-DC 26, "Reactivity Control Systems."

5. Regulatory Guide 1.44, "Control of the Use of Sensitized Stainless Steel."

6. ASME Boiler and Pressure Vessel Code, Section II, "Materials," Parts A, B, C, and D; and Section III, "Rules for Construction of Nuclear Plant Components," Division 1, including Appendix I; American Society of Mechanical Engineers.

7. ASTM, A-262-1970, "Detecting Susceptibility to Intergranular Attack in Stainless Steels"; Practice A "Oxalic Acid Etch Test for Classification of Etch Structures of Stainless Steels"; Practice E, "Copper-Copper Sulfate-Sulfuric Acid Test for Detecting Susceptibility to Intergranular Attack in Stainless Steels"; Annual Book of ASTM Standards, American Society for Testing and Materials.

8. ASTM A-708-1974, "Detection of Susceptibility to Intergranular Corrosion in Severely Sensitized Austenitic Stainless Steel," Annual Book of ASTM Standards, American Society for Testing and Materials.

9. ASME NQA-1-1994 Edition, "Quality Assurance Requirements for Nuclear Facility Applications," Revision and Consolidation of ASME NQA-1-1989 and ASME NQA-2-1989 Editions, American Society of Mechanical Engineers.

Comment [A105]: The need for new codes and standards for SFRs and applicability of specific parts and revisions of existing codes and standards must be determined

Comment [A106]: Revised

Comment [A107]: Withdrawn

Comment [A108]: The need for new codes and standards for SFRs and applicability of specific parts and revisions of existing codes and standards must be determined 



\title{
SODIUM FAST REACTOR REVIEW PLAN
}

\author{
4.5.2 REACTOR INTERNAL AND CORE SUPPORT STRUCTURE MATERIALS \\ REVIEW RESPONSIBILITIES
}

Primary - Organization responsible for review of component integrity issues related to reactor vessel internals

Secondary - Organization responsible for the review of materials engineering issues related to flaw evaluation and welding

\section{AREAS OF REVIEW}

Section 50.55a, "Codes and Standards," of 10 CFR Part 50, and Sodium Fast Reactor Design Criterion (SFR-DC) 1 are reflected in Draft Regulatory Guide DG-1330 (Proposed New Regulatory Guide 1.232) as guidance for complying with the requirements of 10 CFR Part 50, Appendix A General Design Criteria 1 require that structures, systems, and components (SSCs) important to safety be designed, fabricated, and tested to quality standards commensurate with the importance of the safety function to be performed. The purpose of this sodium fast reactor review plan (SFR-RP) section is to review and evaluate the adequacy of the materials selected for the construction of the reactor internal and core support structures, as defined in NG-1120 of Section III of the ASME Boiler and Pressure Vessel Code (hereafter "the Code"), and to assure that the reactor internal and core support structures meet these regulations. The reactor internal and core support structures reviewed under this SFR-RP section include all structures and components within the reactor vessel other than the fuel and control assemblies and instrumentation.

This SFR-RP section covers the material, component design, fabrication and inspection to assure structural integrity in compliance with Section 50.55a and SFR-DC 1.

The following areas in the applicant's safety analysis report (SAR) relating to reactor internal and core support structure materials are reviewed; specific areas of review are as follows:

1. Materials. The review includes the acceptability of the materials, including weld materials, to be used for the reactor internals and core support structures.

The adequacy and suitability of the materials specified for the reactor internals and core support structures are reviewed in terms of their fracture toughness, stress corrosion resistance, fabricability, use in high temperature and high radiation environments, and other mechanical and physical properties.

2. Controls on Welding. The review includes the controls on welding for reactor internals and core support structures.

3. Nondestructive Examination. The review includes information submitted by the applicant on the nondestructive examination procedures used for inspection of each product form.

4. Austenitic Stainless Steel. Austenitic stainless steels may be used for the construction of the reactor internals and core support structures. These steels may be used in a

Comment [A109]: This text anticipates the NRC RG for advanced reactor design criteria and subsequent SFR-DC (proposed RG 1.232). The current markup reflects the proposed language in Draft RG-1330.

Comment [A110]: The need for new codes and standards for SFRs and applicability of specific parts and revisions of existing codes and standards must be determined 
variety of product forms, including several stabilized product forms. Unstabilized austenitic stainless steels, such as Types 304 and 316, may be specified.

Since unstabilized compositions are susceptible to stress corrosion cracking when exposed to certain environmental conditions, process controls must be exercised during all stages of component manufacturing and reactor construction to avoid sensitization of the material, and to minimize exposure of the stainless steel to contaminants that lead to stress corrosion cracking. The review includes information submitted by the applicant in these areas, as described in SFR-RP Section 5.2.3, "Primary Coolant Boundary Materials."

5. Other Materials. Materials other than austenitic stainless steels are reviewed and evaluated in terms of their fracture toughness, corrosion and erosion resistance, fabricability, suitability for high temperature and high radiation conditions, and other mechanical and physical properties.

6. Inspections, Tests, Analyses, and Acceptance Criteria (ITAAC). For design certification (DC) and combined license (COL) reviews, the staff reviews the applicant's proposed ITAAC associated with the structures, systems, and components (SSCs) related to this SFR-RP section in accordance with SFR-RP Section 14.3, "Inspections, Tests, Analyses, and Acceptance Criteria." The staff recognizes that the review of ITAAC cannot be completed until after the rest of this portion of the application has been reviewed against acceptance criteria contained in this SFR-RP section. Furthermore, the staff reviews the ITAAC to ensure that all SSCs in this area of review are identified and addressed as appropriate in accordance with SFR-RP Section 14.3.

7. COL Action Items and Certification Requirements and Restrictions. For a DC application, the review will also address COL action items and requirements and restrictions (e.g., interface requirements and site parameters).

For a COL application referencing a DC, a COL applicant must address COL action items (referred to as COL license information in certain DCs) included in the referenced DC. Additionally, a COL applicant must address requirements and restrictions (e.g., interface requirements and site parameters) included in the referenced DC.

\section{$\underline{\text { Review Interfaces }}$}

Other SFR-RP sections interface with this section as follows:

1. The review of the adequacy of programs for assuring the integrity of bolting and threaded fasteners is performed under SFR-RP Section 3.13, "Threaded Fasteners ASME Code 1, 2, and 3."

2. The evaluation of corrosion and compatibility of reactor internals and core support structures materials with the expected environment during service is performed using procedures under SFR-RP Section 5.2.3, "Primary Coolant Boundary Materials."

3. The review of acceptability of the primary coolant and cover gas chemistry and associated chemistry controls (including additives such as inhibitors) as it relates to corrosion control and compatibility with materials to be exposed to primary coolant is performed under SFR-RP Sections 9.X.X, Primary Coolant Purity Control, and 9.X.Y, Cover Gas Purity Control."

Comment [A111]: The need for new codes and standards for SFRs and applicability of specific parts and revisions of existing codes and standards must be determined

Comment [A112]: Clarified the relationship between 4.5.2 and 5.2.3. Section 5.2.3 does not specifically address reactor internals or core support structures but it provides procedures that could be used for internals and core support materials.

Comment [A113]: Replace LWR purification systems with SFR coolant and cover gas purification systems. 
4. The review of the adequacy of design fatigue curves for reactor internals and core support structures materials with respect to cumulative reactor service-related environmental and usage factor effects and consideration of each combination of loadings is performed under SFR-RP Sections 3.9.1, "Special Topics for Mechanical Components," and 3.9.3, "ASME Code Class 1, 2, and 3 Components, Component Supports, and Core Support Structures."

5. The review of the reactor internals and core support structures with respect to their mechanical design adequacy to withstand design and service loading combinations is performed under SFR-RP Section 3.9.5, "Reactor Vessel Internals."

6. The review of the plant design, including the selection of materials to minimize activation products, to verify that occupational radiation exposures will be as low as is reasonably achievable (ALARA) is performed under SFR-RP Section 12.1, "Assuring That Occupational Radiation Exposures Are As Low As Is Reasonably Achievable."

The specific acceptance criteria and review procedures are contained in the reference SFR-RP sections.

\section{ACCEPTANCE CRITERIA}

\section{$\underline{\text { Requirements }}$}

Acceptance criteria are based on meeting the relevant requirements of the following Commission regulations:

The design, fabrication, and testing of the materials used in the reactor internals and core support structures are reviewed and evaluated to meet codes and standards commensurate with the safety functions to be performed such that the relevant requirements of $10 \mathrm{CFR} 50.55 \mathrm{a}$ and SFR-DC 1 are met.

1. 10 CFR 50.55a, "Codes and Standards," which requires that SSCs shall be designed, fabricated, erected, constructed, tested, and inspected to quality standards commensurate with the importance of the safety function to be performed.

2. SFR-DC 1, "Quality Standards and Records," which requires that SSCs important to safety shall be designed, fabricated, erected, and tested to quality standards commensurate with the importance of the safety functions to be performed. Where generally recognized codes and standards are used, they shall be identified and evaluated to determine their applicability, adequacy, and sufficiency and shall be supplemented or modified as necessary to assure a quality product in keeping with the required safety function. SFR-DC 1 also requires that appropriate records of the design, fabrication, erection, and testing of SSCs important to safety shall be maintained by or under the control of the nuclear power unit licensee throughout the life of the unit.

3. 10 CFR 52.47(b)(1), which requires that a DC application contain the proposed inspections, tests, analyses, and acceptance criteria (ITAAC) that are necessary and sufficient to provide reasonable assurance that, if the inspections, tests, and analyses are performed and the acceptance criteria met, a plant that incorporates the design certification is built and will operate in accordance with the design certification, the provisions of the Atomic Energy Act, and the NRC's regulations; 
4. $\quad 10$ CFR 52.80(a), which requires that a COL application contain the proposed inspections, tests, and analyses, including those applicable to emergency planning, that the licensee shall perform, and the acceptance criteria that are necessary and sufficient to provide reasonable assurance that, if the inspections, tests, and analyses are performed and the acceptance criteria met, the facility has been constructed and will operate in conformity with the combined license, the provisions of the Atomic Energy Act, and the NRC's regulations.

\section{SFR-RP Acceptance Criteria}

Specific SFR-RP acceptance criteria acceptable to meet the relevant requirements of the NRC's regulations identified above are as follows for the review described in this SFR-RP section. The SFR-RP is not a substitute for the NRC's regulations, and compliance with it is not required. However, an applicant is required to identify differences between the design features, analytical techniques, and procedural measures proposed for its facility and the SFR-RP acceptance criteria and evaluate how the proposed alternatives to the SFR-RP acceptance criteria provide acceptable methods of compliance with the NRC regulations.

1. Materials. For core support structures and reactor internals, the permitted material specifications are those given in the ASME Code, Section III, Division 1,

Subarticle NG-2120. The properties of these materials are specified in Tables 2A, $2 B$ and 4 of Section II of the Code.

Additional permitted materials and their applications are identified in ASME Code Cases approved for use as described in Regulatory Guide 1.84, "Design, Fabrication, and Material Code Case Acceptability, ASME, Section III."

2. Controls on Welding. Methods and controls for core support structures and reactor internals welds shall be in accordance with ASME Code, Section III, Division 1, Article NG-4000. The examination requirements and acceptance criteria for these welds are specified in Article NG-5000.

3. Nondestructive Examination. Nondestructive examinations shall be in accordance with the requirements of ASME Code, Section III, Division 1, Subarticle NG-2500. The nondestructive examination acceptance criteria shall be in accordance with the requirements of ASME Code, Section III, Division 1, Subarticle NG-5300.

4. Austenitic Stainless Steels. The acceptance criteria for this area of review are given in SFR-RP Section 5.2.3, subsections II.2 and II.4.a, b, d, and e.

Regulatory Guide 1.44 provides acceptance criteria for preventing intergranular corrosion of stainless steel components. In conformance with this guide, furnace sensitized material should not be allowed. Methods described in this guide should be followed for cleaning and protecting austenitic stainless steel from contamination during handling, storage, testing, and fabrication, and for determining the degree of sensitization that occurs during welding.

5. Other Materials. All materials used for reactor internals and core support structures must be selected for compatibility with the primary coolant, as specified in Subarticles NG-2160 and NG-3120 of Section III, Division 1 of the ASME Code. The tempering 
temperature and the aging temperature of materials should be specified to provide assurance that these materials will not deteriorate in service.

Other materials shall have similar appropriate heat treat and fabrication controls in accordance with strength and compatibility requirements.

\section{$\underline{\text { Technical Rationale }}$}

The technical rationale for application of these acceptance criteria to the areas of review addressed by this SFR-RP section is discussed in the following paragraphs:

SFR-DC 1 and 10 CFR 50.55a require that SSCs be designed, fabricated, erected, constructed, tested, and inspected to quality standards commensurate with the importance of the safety function to be performed. 10 CFR $50.55 \mathrm{a}$ also incorporates by reference the applicable editions and addenda of the ASME Boiler and Pressure Vessel Code. The reactor internals and core support structures include SSCs that perform safety functions and/or whose failure could affect the performance of safety functions by other SSCs. These safety functions include reactivity monitoring and control, core cooling, and fission product confinement (within both the fuel cladding and the primary coolant system). Application of 10 CFR 50.55a and SFR-DC 1 to the materials of construction provides assurance that established standard practices of proven or demonstrated effectiveness for selecting materials, fabrication, and testing/ inspection of SSCs are used to achieve a high likelihood that these safety functions will be performed.

\section{REVIEW PROCEDURES}

The reviewer will select material from the procedures described below, as may be appropriate for a particular case.

These review procedures are based on the identified SFR-RP acceptance criteria. For deviations from these acceptance criteria, the staff should review the applicant's evaluation of how the proposed alternatives provide an acceptable method of complying with the relevant NRC requirements identified in Subsection II.

1. Materials. The list of the materials for reactor internals and core support structures that are exposed to the primary coolant or cover gas is reviewed.

The materials identified for each component or part used in the reactor internals and core support structures are compared with the materials identified as being acceptable in Sections II and III of the ASME Code and/or acceptable ASME Code Cases identified in Regulatory Guide 1.84, as described in the acceptance criteria. The reviewer verifies that any exceptions to the ASME Code-specified materials are clearly identified. The reviewer evaluates the basis for the exceptions, taking into account precedents set in earlier cases, and determines the acceptability of such materials. 
2. Controls on Welding. The reviewer verifies that welding methods and controls for the reactor internals and core support structures are in accordance with the procedures of ASME Code, Section III, Division 1, Article NG-4000. The reviewer verifies that welding controls submitted by the applicant are in conformance with the welding controls in SFR-RP Section 5.2.3, which are also considered applicable to welding of reactor internals. The reviewer assures that any special welding processes or welding controls conform to the qualification requirements of ASME Code, Section IX, or that justification is made for any deviation.

3. Nondestructive Examination. The information submitted by the applicant is reviewed to determine methods used for nondestructive examination. The reviewer verifies that the nondestructive examination methods proposed by the applicant are in conformance with the examination methods specified by the ASME Code. Section III, Division 1 , Subarticle NG-2500 of the ASME Code specifies that examination by either radiographic or ultrasonic examination plus surface examinations as required is acceptable.

4. Austenitic Stainless Steel. The materials and fabrication procedures used for reactor internals are reviewed. The areas of review and review procedures include those described in SFR-RP Section 5.2.3. The reviewer verifies that environmental conditions are controlled and welding procedures are developed such that the probabilities of sensitization and microfissuring are minimized. SFR-RP Section 4.5.1, Subsection III.2, identifies an acceptable alternate to the methods described in Regulatory Guide 1.44 for verifying the degree of sensitization that occurs during welding. In addition, the reviewer verifies that materials are selected to assure compatibility with the compositions of the primary coolant and cover gas, and that the fabrication and cleaning controls imposed on stainless steel components are adequate to prevent contamination with chloride and fluoride ions.

Where cast austenitic stainless steels are proposed for use, the reviewer verifies that under the expected environmental conditions, the selected material will provide adequate fracture toughness over its design life (e.g., considering thermal aging due to exposure to primary coolant operating temperatures).

5. Other Materials. The reviewer verifies that the heat treatment and welding controls provided in the material specifications and fabrication procedures are appropriate for the material. The reviewer verifies that the fabrication and cleaning controls will preclude contamination of materials, e.g., by chloride ions, fluoride ions, or lead.

The reviewer verifies that acceptable inspection requirements have been proposed based on operating experience and service conditions. For all PCB environments, particular review emphasis is placed upon the corrosion resistance and stress corrosion cracking resistance properties of the proposed materials and other degradation mechanisms, such as sodium transfer of carbon and nitrogen from hotter to cooler regions, erosion, radiation-induced swelling, and thermal striping

6. For review of a DC application, the reviewer should follow the above procedures to verify that the design, including requirements and restrictions (e.g., interface requirements and site parameters), set forth in the final safety analysis report (FSAR) meets the acceptance criteria. DCs have referred to the FSAR as the design control document (DCD). The reviewer should also consider the appropriateness of identified COL action items. The reviewer may identify additional COL action items; however, to ensure these 
COL action items are addressed during a COL application, they should be added to the DC FSAR.

For review of a COL application, the scope of the review is dependent on whether the COL applicant references a DC, an early site permit (ESP) or other NRC approvals (e.g., manufacturing license, site suitability report or topical report).

7. For review of both DC and COL applications, SFR-RP Section 14.3 should be followed for the review of ITAAC. The review of ITAAC cannot be completed until after the completion of this section.

\section{EVALUATION FINDINGS}

The reviewer verifies that the applicant has provided sufficient information and that the review and calculations (if applicable) support conclusions of the following type to be included in the staff's safety evaluation report. The reviewer also states the bases for those conclusions.

1. The staff concludes that the materials used for the reactor internals and core support structures are acceptable and meet the requirements of 10 CFR 50.55a and SFR-DC 1. This conclusion is based upon the following considerations:

The applicant has selected, and identified by specification, materials for the reactor internals and core support structures that satisfy the requirements of Subarticle NG-2120 of Section III, Division 1 and Tables 2A, 2B and 4 of Section II of the ASME Code. For materials not in accordance with ASME Code provisions, the applicant has selected materials of construction that are approved for use by NRC-accepted ASME Code Cases, as identified in Regulatory Guide 1.84, or that have otherwise been demonstrated acceptable for the application. As proven by extensive tests and satisfactory performance, the specified materials are compatible with the expected environment and corrosion is expected to be negligible.

The applicant has demonstrated that the design, fabrication, and testing of the materials used in the reactor internals and core support structures are of high quality standards and are adequate to assure structural integrity. The controls imposed upon austenitic stainless steel components satisfy the positions of Regulatory Guide 1.44, "Control of the Use of Sensitized Stainless Steel," and the related criteria provided in SFR-RP Section 5.2.3, "Reactor Coolant Boundary Materials."

The controls imposed on the primary coolant and cover gas chemistry provide reasonable assurance that the reactor internals and core support structures will be adequately protected during operation from conditions that could lead to stress corrosion of the materials and loss of component structural integrity.

The material selection, fabrication practices, examination and testing procedures, and control practices provide reasonable assurance that the materials used for the reactor internals and core support structures will be in a metallurgical condition that will preclude inservice deterioration.

Conformance with relevant requirements of the ASME Code, or accepted Code Cases, and the recommendations of Regulatory Guides 1.31 and 1.44 and the related criteria in SFR-RP Section 5.2.3, constitutes an acceptable basis for meeting the relevant requirements of 10 CFR $50.55 a$ and SFR-DC 1. 
2. For DC and COL reviews, the findings will also summarize the staff's evaluation of requirements and restrictions (e.g., interface requirements and site parameters) and COL action items relevant to this SFR-RP section.

3. In addition, to the extent that the review is not discussed in other SER sections, the findings will summarize the staff's evaluation of the ITAAC, including design acceptance criteria, as applicable.

\section{IMPLEMENTATION}

The following is intended to provide guidance to applicants and licensees regarding the staff's plan for implementing this section of the Standard Review Plan.

The staff will use this SFR-RP section in performing safety evaluations of DC applications and license applications submitted by applicants pursuant to 10 CFR Part 50 or 10 CFR Part 52. Except when the applicant proposes an acceptable alternative method for complying with specified portions of the Commission's regulations, the staff will use the method described herein to evaluate conformance with Commission regulations.

The provisions of this SFR-RP section apply to reviews of applications submitted six months or more after the date of issuance of this SFR-RP section, unless superseded by a later revision. Implementation schedules for conformance to parts of the method discussed herein are contained in the referenced regulatory guides.

\section{VI. $\quad$ REFERENCES}

The following list of references was not reviewed in detail for applicability to SFR designs. References to materials produced by the NRC that have since been withdrawn-such as regulatory guides-are proposed for deletion. In addition, NRC letters and industry letters on very specific $L W R$ topics are proposed for deletion from the reference list. The remainder of the original SRP reference list, including industry codes and standards, is left to provide insight on the topical areas necessary to provide adequate review. Additional effort will be required to either enhance the information in the existing references to be relevant to advanced non-LWR designs, replace existing references with equivalent documentation, or delete references as appropriate.

1. $\quad 10$ CFR 50.55a, "Codes and Standards."

2. $\quad$ SFR-DC 1, "Quality Standards and Records."

3. Regulatory Guide 1.31, "Control of Ferrite Content in Stainless Steel Weld Metal."

4. Regulatory Guide 1.44, "Control of the Use of Sensitized Stainless Steel."

5. Regulatory Guide 1.84, "Design, Fabrication, and Material Code Case Acceptability, ASME Section III."

6. ASME Boiler and Pressure Vessel Code, Section II, "Materials," Tables 2A, 2B and 4; Section III, "Rules for Construction of Nuclear Facility Components," Division 1; and

Comment [A121]: The need for new codes and standards for SFRs and applicability of specific parts and revisions of existing codes and standards must be determined 
Section IX, "Welding and Brazing Qualifications." American Society of Mechanical Engineers.

7. NUREG-1823, "U.S. Plant Experience with Alloy 600 Cracking and Boric Acid Corrosion of Light-Water Reactor Pressure Vessel Materials." U.S. Nuclear Regulatory Commission. Washington, DC. April 2005.

8. NRC Letter to All Licensees of Pressurized Water Reactors (PWRs), "Degradation of Control Rod Drive Mechanism Nozzle and Other Vessel Closure Head Penetrations" (Generic Letter 97-01). April 1, 1997.
Comment [A122]: The need for new codes and standards for SFRs and applicability of specific parts and revisions of existing codes and standards must be determined

Comment [A123]: The need for new codes and standards for SFRs and applicability of specific parts and revisions of existing codes and standards must be determined 



\section{SODIUM FAST REACTOR REVIEW PLAN}

\subsection{FUNCTIONAL DESIGN OF CONTROL ELEMENT/ROD ${ }^{11}$ DRIVE SYSTEM REVIEW RESPONSIBILITIES}

Primary - Organization responsible for the review of transient and accident analyses

Secondary - Organization responsible for the review of plant design for protection of structures, systems, and components from internal and external hazards

\section{I. $\quad$ AREAS OF REVIEW}

The organization responsible for reactor systems reviews the functional performance of the control element/rod drive system (CRDS) to confirm that the system can effect a safe shutdown, respond within acceptable limits during anticipated operational occurrences (AOOs), and prevent or mitigate the consequences of postulated accidents. The review covers the CRDS to ensure conformance with Sodium Fast Reactor Design Criteria (SFR-DC) 4, 23, 25, 26, 28 , and 29 which are reflected in Draft Regulatory Guide DG-1330 (Proposed New Regulatory Guide 1.232) as guidance for complying with the requirements of 10 CFR Part 50, Appendix A General Design Criteria (GDC) 4, 23, 25, 26, 28, and 29.

The specific areas of review are as follows:

1. Examination of the CRDS design to identify possible single failures.

2. Evaluation of the CRDS to verify the following:
A. Essential portions can be isolated from nonessential portions.
B. The CRDS cooling system meets the design requirements.
C. The functional tests verify the proper element/rod insertion, withdrawal, and scram operation times, or that the inspections, tests, analyses, and acceptance criteria (ITAAC) are sufficient to ensure that element/rod insertion, withdrawal, and scram operation times will operate in accordance with the certification.

D. Redundant reactivity control systems are not vulnerable to common mode failures.

3. Inspections, Tests, Analyses, and Acceptance Criteria (ITAAC). For design certification (DC) and combined license (COL) reviews, the staff reviews the applicant's proposed ITAAC associated with the structures, systems, and components (SSCs) related to this

\footnotetext{
${ }^{11}$ Control rods may not be suitable for advanced reactors. Advanced reactors may rely on other means to rapidly shut down the reactor (e.g., alternative system designs or inherent feedback mechanisms may be relied upon). Therefore, the term "control element/rod” is meant broadly to include all of the mechanistic means for shutting down the reactor to a safe shutdown condition and holding the reactor subcritical under cold conditions.
}

Comment [A124]: Control rods may not be suitable for advanced reactors. Advanced reactors may rely on other means to rapidly shut down the reactor.
Comment [A125]: This text anticipates the NRC RG for advanced reactor design criteria and subsequent SFR-DC (proposed RG 1.232). The current markup reflects the proposed language in Draft RG-1330. 
Sodium Fast Reactor Review Plan (SFR-RP) section in accordance with SFR-DC Section 14.3, "Inspections, Tests, Analyses, and Acceptance Criteria." The staff recognizes that the review of ITAAC cannot be completed until after the rest of this portion of the application has been reviewed against acceptance criteria contained in this SFR-DC section. Furthermore, the staff reviews the ITAAC to ensure that all SSCs in this area of review are identified and addressed as appropriate in accordance with SFR-DC Section 14.3.

4. COL Action Items and Certification Requirements and Restrictions. For a DC application, the review will also address COL action items and requirements and restrictions (e.g., interface requirements and site parameters).

For a COL application referencing a DC, a COL applicant must address COL action items (referred to as COL license information in certain DCs) included in the referenced DC. Additionally, a COL applicant must address requirements and restrictions (e.g., interface requirements and site parameters) included in the referenced DC.

\section{Review Interfaces}

Other SFR-DC sections interface with this section as follows:

1. The review encompasses all transients and accidents in Chapter 15 of the safety analysis report (SAR) that require reactivity control systems to function. The reviewer ascertains that the reactivity and response characteristics of the reactivity control system are conservative with respect to the parameters assumed in the Chapter 15 analyses.

2. Verification of the reactivity control requirements is performed under SFR-DC Section 4.3.

3. Verification of the results of failure modes and effects analyses to ensure that a single failure occurring in the control element/rod system, or an operator error, will not result in the loss of capability for safe shutdown is performed under SFR-DC Section 7.2.

4. Verification of the adequacy of the control element/rod drive mechanisms to perform their mechanical functions (e.g., rod insertion and withdrawal, scram operation and time) and to maintain the primary coolant boundary is performed under SFR-DC Section 3.9.4. Verification that the design and requirements, as applicable to the assigned safety class and seismic category, are met is performed under SFR-DC Sections 3.2.1 and 3.2.2. Under SFR-DC Section 3.6.2, postulated piping failures inside the containment, including their associated locations and dynamic effects, are evaluated, as they relate to the protection of SSCs against such effects.

5. Determination of the acceptability of the design and analyses, procedures, and criteria used to establish the ability of seismic Category I structures housing the system and supporting systems to withstand the effects of natural phenomena such as the safeshutdown earthquake, the probable maximum flood, and the tornado missiles, is performed under SFR-DC Sections 3.3.1, 3.3.2, 3.5.3, 3.7.1 through 3.7.4, 3.8.4, and 3.8.5. 
6. Verification of the adequacy of the design, installation, inspection, and testing of all electrical systems (sensing, control, and power) required for proper operation is performed under SFR-DC Section 7.1 and Appendix 7-A and SFR-DC Section 8.3.1.

7. The evaluation of potential sources of internally generated missiles and, where applicable, determination that SSCs are adequately protected against the effects of such missiles are performed under SFR-DC Sections 3.5.1.1 and 3.5.1.2. The verification of the adequacy of specified environments and service conditions for equipment qualification as they relate to the locations of affected equipment and the overall demonstration that systems and components are qualified to perform their function are performed under SFR-DC Section 3.11.

8. Reviews of fire protection, technical specifications, and quality assurance and maintenance are performed under SFR-DC Sections 9.5.1 and Chapters 16 and 17, respectively.

9. Review of the seismic qualification of Category I instrumentation and electrical equipment and the environmental qualification of electrical and mechanical equipment is performed under SFR-DC Sections 3.10 and 3.11, respectively.

The specific acceptance criteria and review procedures are contained in the referenced SFRDC sections.

\section{ACCEPTANCE CRITERIA}

\section{$\underline{\text { Requirements }}$}

Acceptance criteria are based on meeting the relevant requirements of the following Commission regulations:

1. SFR-DC 4 as it relates to the structures, systems, and components important to safety that shall be designed to accommodate the effects of and to be compatible with the environmental conditions during normal plant operation, AOOs, as well as during postulated accidents, including the effects of liquid sodium and its aerosols and oxidations products.

2. SFR-DC 23, as it relates to the protection system failure modes such that the system shall fail into a safe state or into a state demonstrated to be acceptable on some other defined basis if conditions such as disconnection of system, loss of energy, or postulated adverse environment are experienced.

3. SFR-DC 25, as it relates to the fuel design such that the specified limits are not exceeded during AOOs resulting from a single malfunction of the reactivity control system.

4. SFR-DC 26, as it relates to the reactivity control system redundancy and capability of providing (1) a means of shutting down the reactor to ensure that, under conditions of normal operation, including abnormal operational occurrences, and with appropriate margin for malfunctions, design limits for fission product barriers are not exceeded, (2) a means of shutting down the reactor and maintaining a safe shutdown under design-basis event conditions, with appropriate margin for malfunctions, and a second means of 
reactivity control that is independent, diverse, and capable of achieving and maintaining safe shutdown under design-basis event conditions, and (3) a system for holding the reactor subcritical under cold conditions

5. SFR-DC 28, as it relates to reactivity limits such that reactivity control systems shall be designed with appropriate limits on the potential amount and rate of reactivity increase to assure that the effects of postulated reactivity accidents can neither result in damage to the primary coolant boundary nor disturb the core and its supports structures to impair significant capability to cool the core.

6. SFR-DC 29, as it relates to protecting system against AOOs such that the design of the protection and reactor control systems should assure an extremely high probability of accomplishing their safety functions in the event of AOOs.

7. 10 CFR 52.47(b)(1), which requires that a DC application contain the proposed inspections, tests, analyses, and acceptance criteria (ITAAC) that are necessary and sufficient to provide reasonable assurance that, if the inspections, tests, and analyses are performed and the acceptance criteria met, a plant that incorporates the design certification is built and will operate in accordance with the design certification, the provisions of the Atomic Energy Act, and the NRC's regulations;

8. 10 CFR 52.80(a), which requires that a COL application contain the proposed inspections, tests, and analyses, including those applicable to emergency planning, that the licensee shall perform, and the acceptance criteria that are necessary and sufficient to provide reasonable assurance that, if the inspections, tests, and analyses are performed and the acceptance criteria met, the facility has been constructed and will operate in conformity with the combined license, the provisions of the Atomic Energy Act, and the NRC's regulations.

\section{$\underline{\text { SFR-DC Acceptance Criteria }}$}

Specific SFR-DC acceptance criteria acceptable to meet the relevant requirements of the NRC's regulations identified above are as follows for the review described in this SFR-DC section. The SFR-DC is not a substitute for the NRC's regulations, and compliance with it is not required. However, an applicant is required to identify differences between the design features, analytical techniques, and procedural measures proposed for its facility and the SFR-DC acceptance criteria and evaluate how the proposed alternatives to the SFR-DC acceptance criteria provide acceptable methods of compliance with the NRC regulations.

1. To meet the requirements of SFR-DC 4, the CRDS should remain functional and provide reactor shutdown capabilities under adverse environmental conditions and after postulated accidents.

2. To meet the requirements of SFR-DC 23, the CRDS should fail in an acceptable condition, even under adverse conditions, that prevents damage to the fuel cladding and excessive reactivity changes during failure.

3. To meet the requirements of SFR-DC 25, the design of the reactivity control systems should assure that a single malfunction of the CRDS will not result in exceeding specified acceptable fuel design limits. 
4. To meet the requirements of SFR-DC 26, the CRDS should be capable of (1) shutting down the reactor to ensure that, under conditions of normal operation, including abnormal operational occurrences, and with appropriate margin for malfunctions, design limits for fission product barriers are not exceeded, (2) shutting down the reactor and maintaining a safe shutdown under design-basis event conditions, with appropriate margin for malfunctions, with a second means of reactivity control that is independent, diverse, and capable of achieving and maintaining safe shutdown under design-basis event conditions, and (3) holding the reactor subcritical under cold conditions.

5. To meet the requirements of SFR-DC 28, the CRDS should be designed to assure that reactivity accidents do not result in damage to the primary coolant boundary, or result in sufficient damage to the core or support structures so as to significantly impair coolability.

6. The CRDS should be designed to ensure an extremely high probability of functioning during AOOs to in conformance is SFR-DC, 29.

\section{Technical Rationale}

The technical rationale for application of these acceptance criteria to the areas of review addressed by this SFR-DC section is discussed in the following paragraphs:

1. SFR-DC 4 requires that SSCs be designed to accommodate the effects of, and to be compatible with, the environmental conditions associated with normal operation, maintenance, testing, and postulated accidents, including the effects of liquid sodium and its aerosols and oxidation products, and be appropriately protected against dynamic effects, including the effects of missiles, pipe whipping, and discharging fluids, that may result from equipment failures and from external events. The CRDS provides the capability to safely shut down the reactor during normal operations and AOOs and either prevents or mitigates the consequences associated with postulated accident scenarios. The design of the CRDS must ensure that the ability to perform these safety-related functions is not compromised by adverse environmental conditions. Compliance with SFR-DC 4 ensures that the CRDS will remain functional under adverse postulated environmental conditions and provide essential reactor shutdown capabilities.

2. SFR-DC 23 requires that the protection system be designed to fail into a safe state in the event of adverse conditions or environments. The CRDS provides positive core reactivity control through the use of movable control elements/rods. The movable control elements/rods provide reactivity control for all modes of operation, including all plant conditions from the cold shutdown condition to the full-load condition. The CRDS, in conjunction with the protection system, must actuate the control elements/rods to effect safety-related functions when necessary to provide core protection during normal operation, AOOs, and accidents. Meeting the requirements of SFR-DC 23 provides assurance that the protection system in conjunction with the CRDS will fail in a manner that prevents damage to the fuel cladding by providing positive control and preventing excessive reactivity changes during a failure.

3. SFR-DC 25 requires that the protection system be designed to ensure that specified acceptable fuel design limits are not exceeded for any single malfunction of the reactivity control systems. The CRDS provides the motive force for the moveable control elements/rods providing one functional method for reactivity control. Meeting the
Comment [A130]: Revised to reflect the SFRDC 26 requirements contained in DG-1330.

Comment [A131]: Conditions added in DG1330. 
requirements of SFR-DC 25 by designing these systems to withstand single failures ensures that a single malfunction of the control element/rod drive system, such as accidental withdrawal, will not prevent proper control of core reactivity and therefore will not result in exceeding acceptable fuel design limits. Maintaining acceptable fuel design limits enhances plant safety by preventing the occurrence of mechanisms that could result in fuel cladding damage such as severe overheating, excessive cladding strain, or exceeding the thermal margin limits. Preventing excessive cladding damage ensures maintenance of the integrity of the cladding as a fission product barrier.

4. SFR-DC 26 requires reactivity control system redundancy and capability. SFR-DC 26 requires a control element/rod system, preferably including a positive means for inserting the elements/rods or actuating other means of reactor shutdown, capable of (1) shutting down the reactor to ensure that, under conditions of normal operation, including abnormal operational occurrences, and with appropriate margin for malfunctions, design limits for fission product barriers are not exceeded, (2) shutting down the reactor and maintaining a safe shutdown under design-basis event conditions, with appropriate margin for malfunctions, with a second means of reactivity control that is independent, diverse, and capable means of achieving and maintaining safe shutdown under designbasis event conditions, and (3) holding the reactor subcritical under cold conditions. The CRDS should be capable of rendering a reactor subcritical under conservative conditions with the control element/rod with the highest worth fully withdrawn from the core. The conservative conditions include the highest positive reactivity contributions resulting from effects such as temperature and power and the lowest negative reactivity contributions. Meeting the requirements of SFR-DC 26 ensures that the CRDS will be capable of providing sufficient operational control, reliability, and safety during reactivity changes, including those during normal operation, AOOs, and design-basis event conditions.

5. SFR-DC 28 requires that the reactivity control systems be designed with appropriate limits on the potential amount and rate of reactivity increase to prevent the adverse effects of postulated reactivity accidents. A postulated failure of the control element/rod system which, if large enough, could cause a prompt power excursion. Such a prompt power excursion could cause a fuel element rupture, rapid fragmentation of the fuel cladding, and dispersal of fuel and cladding into the coolant. This type of event is accompanied by the conversion of nuclear energy to mechanical energy, which if sufficient, could breach the primary coolant boundary or impair the coolability of the core. Meeting the requirements of SFR-DC 28 for the CRDS enhances plant safety by limiting the effects of postulated reactivity accidents, thereby mitigating the adverse effects which could result in damage to the primary coolant boundary or impair the capability to cool the core.

6. SFR-DC 29 requires that the protection and reactivity control systems be designed to ensure an extremely high probability of accomplishing their safety functions in the event of AOOs. The design relies on the CRDS to function in conjunction with the protection systems under AOOs, including loss of power to all recirculation pumps, tripping of the turbine generator, isolation of the main condenser, and loss of all offsite power. The CRDS provides an adequate means of inserting sufficient negative reactivity to shut down the reactor and prevent exceeding acceptable fuel design limits during AOOs. Meeting the requirements of SFR-DC 29 for the CRDS prevents occurrence of mechanisms that could result in fuel cladding damage such as severe overheating, excessive cladding strain, or exceeding the thermal margin limits during AOOs. 
Preventing excessive cladding damage in the event of anticipated transients ensures maintenance of the integrity of the cladding as a fission product barrier.

7. 10 CFR 52.47(b)(1) and 10 CFR 52.80(a) require that ITAAC be identified for DCs and COLs. Because the DC or license approval is being granted before facility construction, there is a potential that the as-built configuration of a facility may not meet the requirements of the DC or COL as granted. The purpose of the ITAAC is to ensure that the as-built facility meets the requirements set forth in the DC or COL.

\section{III. $\quad$ REVIEW PROCEDURES}

The reviewer will select material from the procedures described below, as may be appropriate for a particular case.

These review procedures are based on the identified SFR-DC acceptance criteria. For deviations from these acceptance criteria, the staff should review the applicant's evaluation of how the proposed alternatives provide an acceptable method of complying with the relevant NRC requirements identified in Subsection II.

1. The reviewer evaluates the CRDS design with respect to associated fluid systems and possible single failures. The review of the system description includes piping and instrumentation diagrams (P\&IDs), layout drawings, process flow diagrams, and descriptive information on essential supporting systems. The review evaluates the SAR to ascertain that failure modes and effects analyses have been completed to determine that the CRDS (not the individual drives) is capable of performing its safety-related function following the loss of any active component.

2. The reviewer evaluates the CRDS, P\&IDs, layout drawings, and component descriptions and characteristics to verify that essential portions of the system are correctly identified and are isolable from nonessential portions. The essential portions should be protected from the effects of dynamic conditions (such as high- or moderate-energy line breaks). The reviewer examines layout drawings of the system to ensure that no high- or moderate-energy piping systems are close to the CRDS, or that protection is provided from the effects of high- or moderate-energy pipe breaks. If the dynamic effects of pipe ruptures are proposed to be excluded from the design basis, then the review includes analyses justifying the exclusion. When an essential system or component is designed to perform multiple functions, the review encompasses the additional operating modes to ensure that there can be no adverse impacts on the essential system function. The reviewer should ensure that systems not relied on for safe shutdown cannot impair essential or passive component functions. Where two or more reactivity systems are used, the reviewer evaluates the combined functional performance under postulated accident conditions.

3. For plants containing control element/rod drive cooling systems (e.g., using air as coolant), the reviewer examines descriptions and drawings to determine that the systems meet the design requirements. The SAR should delineate essential equipment. The reviewer of transient and accident analyses confirms by failure modes and effects analysis that the cooling system is capable of maintaining the CRDS temperature below the applicant's maximum temperature criterion. The review performed under SFR-DC Section 7.2 confirms that there are sufficient instrumentation and controls available so that the reactor operator in the control room can monitor the CRDS conditions, including
Comment [A134]: 10 CFR 50.62(c)(3) pertains only to BWRs.

Comment [A135]: Water removed from example list because it is not likely for an SFR. 
the more significant parameters such as coolant flow, temperature, pressure, and stator temperature.

4. Reviewers examine the functional tests of the CRDS related to element/rod insertion and withdrawal and scram operation and time. The reviewers check the elements of the test program to ensure that all required thermal-hydraulic conditions have been included for all postulated operating conditions. The test program should include experimental verification of system operation where a single failure has been assumed (e.g., stuck element/rod operation). The reviewers ensure that the system requirements (such as required scram times) are clearly identified and are consistent with the system requirements in the technical specifications and SFR-DC Sections 14 and 15.

5. The reactivity control systems are evaluated to verify that redundant reactivity control systems are not vulnerable to common mode failures. The review identifies the common mode failures and evaluates transient and accident analyses under SFR-DC Sections 7.4, and 3.9.4.

6. For review of a DC application, the reviewer should follow the above procedures to verify that the design, including requirements and restrictions (e.g., interface requirements and site parameters), set forth in the final safety analysis report (FSAR) meets the acceptance criteria. DCs have referred to the FSAR as the design control document (DCD). The reviewer should also consider the appropriateness of identified COL action items. The reviewer may identify additional COL action items; however, to ensure these COL action items are addressed during a COL application, they should be added to the DC FSAR.

For review of a COL application, the scope of the review is dependent on whether the COL applicant references a DC, an early site permit (ESP) or other NRC approvals (e.g., manufacturing license, site suitability report or topical report).

7. For review of both DC and COL applications, SFR-DC Section 14.3 should be followed for the review of ITAAC. The review of ITAAC cannot be completed until after the completion of this section.

Upon request from the primary reviewer, the organization with secondary responsibilities will provide input for the areas of review stated in Subsection I. The primary reviewer obtains and uses such input as required to ensure that this review procedure is complete.

\section{EVALUATION FINDINGS}

The reviewer verifies that the applicant has provided sufficient information and that the review and calculations (if applicable) support conclusions of the following type to be included in the staff's safety evaluation report. The reviewer also states the bases for those conclusions.

The staff has reviewed the functional design of the control element/rod drive system (CRDS) to confirm that the system has the capability to shut down the reactor with appropriate margin during normal operation, AOOs, and accident conditions, including single failures. The scope of review included process flow diagrams, layout drawings, piping and instrumentation diagrams, and descriptive information for the systems and for the supporting systems essential for operation of the system. 
The review has determined the adequacy of the applicant's proposed design criteria, design basis, and safety classification of the CRDS and the requirements for providing a safe shutdown during normal operation, AOOs, and accident conditions, including single failures. The staff concludes that the design of the CRDS is acceptable and meets the requirements of SFR-DC 4, 23, 25, 26, 28, and 29 in Regulatory Guide X.XXX[TBD]. This conclusion is based on the following:

1. The applicant has met the requirements of SFR-DC 4 with respect to the design of the system against the adverse effects of missile hazards inside the containment, pipe whipping and jets caused by broken pipes, and adverse environmental conditions resulting from high- and moderate-energy pipe breaks during normal plant operations, AOOs, and postulated accident conditions.

2. The applicant has met the requirements of SFR-DC 23 by demonstrating the ability to insert the control elements/rods upon any failure of the drive mechanism or any induced failure by an outside force (e.g., loss of electric power, instrumentation air, fire, radiation, extreme heat, sodium and sodium reaction products, pressure).

3. The applicant has met the requirements of SFR-DC 25 by ensuring that no fuel design limits are exceeded for any single malfunction or element/rod withdrawal accident.

4. The applicant has met the requirement of SFR-DC 26 by demonstrating that the control element/rod system is capable of (1) shutting down the reactor to ensure that, under conditions of normal operation, including abnormal operational occurrences, and with appropriate margin for malfunctions, design limits for fission product barriers are not exceeded, (2) shutting down the reactor and maintaining a safe shutdown under design-basis event conditions, with appropriate margin for malfunctions, with a second means of reactivity control that is independent, diverse, and capable means of achieving and maintaining safe shutdown under design-basis event conditions, and (3) holding the reactor subcritical under cold conditions.

5. The applicant has met the requirements of SFR-DC 28 by demonstrating the ability to reliably control the amount and rate of reactivity change to ensure that no reactivity accident will damage the primary coolant boundary or disturb the core or the core's appurtenances such as to impair coolant flow.

6. The applicant has met the requirements of SFR-DC 29 by demonstrating a high probability of control element/rod insertion under AOOs.

For DC and COL reviews, the findings will also summarize the staff's evaluation of requirements and restrictions (e.g., interface requirements and site parameters) and COL action items relevant to this SFR-DC section.

In addition, to the extent that the review is not discussed in other SER sections, the findings will summarize the staff's evaluation of the ITAAC, including design acceptance criteria, as applicable. 


\section{IMPLEMENTATION}

The staff will use this SFR-DC section in performing safety evaluations of DC applications and license applications submitted by applicants pursuant to 10 CFR Part 50 or 10 CFR Part 52. Except when the applicant proposes an acceptable alternative method for complying with specified portions of the Commission's regulations, the staff will use the method described herein to evaluate conformance with Commission regulations.

The provisions of this SFR-DC section apply to reviews of applications submitted six months or more after the date of issuance of this SFR-DC section, unless superseded by a later revision.

\section{REFERENCES}

The following list of references was not reviewed in detail for applicability to SFR designs. References to materials produced by the NRC that have since been withdrawn-such as regulatory guides-are proposed for deletion. In addition, NRC letters and industry letters on very specific $L W R$ topics are proposed for deletion from the reference list. The remainder of the original SRP reference list, including industry codes and standards, is left to provide insight on the topical areas necessary to provide adequate review. Additional effort will be required to either enhance the information in the existing references to be relevant to advanced non- $L W R$ designs, replace existing references with equivalent documentation, or delete references as appropriate.

1. Sodium Fast Reactor Design Criterion 4, "Environmental and Dynamic Effects Design Bases."

2. Sodium Fast Reactor Design Criterion 23, "Protection System Failure Modes."

3. Sodium Fast Reactor Design Criterion 25, "Protection System Requirements for Reactivity Control Malfunctions."

4. Sodium Fast Reactor Design Criterion 26, "Reactivity Control Systems."

5. Sodium Fast Reactor Design Criterion 28, "Reactivity Limits."

6. Sodium Fast Reactor Design Criterion 29, "Protection Against Anticipated Operational Occurrences." 
APPENDIX B. MHTGR ADAPTATION OF SRP CHAPTER 4 



\title{
MODULAR HIGH TEMPERATURE GAS- COOLED REACTOR REVIEW PLAN
}

\author{
4.2 FUEL SYSTEM DESIGN

\section{REVIEW RESPONSIBILITIES}

Primary - The organization responsible for the review of transient and accident analyses

Secondary - None

\section{I. $\quad$ AREAS OF REVIEW}

The organization responsible for the review of transient and accident analyses evaluates the thermal, mechanical, and materials design of the fuel system. The basic fuel system as applied to modular high temperature gas-cooled reactor (mHTGR) technology focuses on the tristructural-isotropic-coated (TRISO) fuel particle and includes associated components of the reactor core and other related components that can affect operations and safety.

The TRISO-coated particle consists of a dense ceramic kernel that contains fissile or fertile fuel materials protected by four coating layers that function collectively as an effective fission product barrier to both gaseous and solid fission products. The TRISO coating consists of a lowdensity, porous, non-load-bearing buffer carbon layer surrounding the fuel kernel material, followed by three load-bearing composite layers that surround the buffer layer. These composite layers consist of a near theoretical dense silicon carbide (SiC) layer sandwiched between two high density, isotropic pyrocarbon $(\mathrm{PyC}$ ) layers called the inner-PyC (iPyC) and outer-PyC (oPyC) layers.

The nuclear design of the modular HTGR reactor and the way associated systems (including TRISO-coated particle fuel) work together are to be reviewed to assure acceptably low likelihood of accidents is maintained. This section also discusses operation of reactivity control elements that contribute to assuring that the consequences of design-basis accidents (DBAs) do not cause unacceptable risk to public health and safety.

Modular HTGRs utilize a graphite-moderated/reflected prismatic block-type or pebble bed-type reactor with periodic or continuous refueling (depending on design type). Different modular HTGR designs have been evaluated to varying degrees by the NRC and should be reviewed as they relate to the more recent and complete systems of similar designs. This may include Section 4.2 and Tables 1.3 and 1.6 of the 1989 draft preapplication safety evaluation and Sections 3.4.3.2, 4.2.1, thorough 4.2.3, and 8.3.1 of the 1995 draft final preapplication safety evaluation for the Standard Modular High-Temperature Gas-Cooled Reactor (MHTGR), NUREG-1338. Additional review insights covering the 2001-2014 timeframe may also be available as a result of prelicensing interactions for Exelon's Pebble Bed Modular Reactor (PBMR) program and DOE's Next Generation Nuclear Plant (NGNP) program. 
The modular HTGR fuel safety review provides assurance that (1) the specified quality requirements for TRISO coated particle fuel are met by manufacture under statistical quality control/quality assurance plans, and that acceptance criteria are met with acceptable statistical certainty, (2) the fuel performance is not significantly degraded as a result of normal operation and anticipated operational occurrences (AOOs), (3) fuel performance is never diminished as to prevent reactivity control as required to prevent radioactive release to the environment, (4) in-service performance requirements and fission product release requirements are met for all design basis events (DBEs) and DBAs, and (5) fuel performance and fission product releases can be accurately predicted/modeled with verified and validated fuel performance and fission product transport codes under all normal operating conditions (including AOOs) and DBEs/DBAs.

Modular HTGR Advanced Reactor Design Criterion (mHTGR-DC) 10, which is reflected in Draft Regulatory Guide DG-1330 (Proposed New Regulatory Guide 1.232) as guidance for complying with the requirements of Appendix A to 10 CFR Part 50, also addresses item 2 above. More specifically, mHTGR-DC 10 establishes meaningful and appropriate specified acceptable core radionuclide release design limits (SARRDLs) for use in modular HTGRs. SARRDLs are not be exceeded during any condition of normal operation, including the effects of AOOs. As discussed in Chapter 15 of the SAR, SARRDLs are set to allow for acceptable amounts of particle degradation or failure during normal operations and AOOs beyond the specified allowable asmanufactured defect level. SARRDLs are also set to provide for an acceptable amount of particle degradation or failure that may occur during an accident. Design limits established according to mHTGR-DC 10 (i.e., the SARRDLs) are to accomplish these objectives. The dose analysis required by 10 CFR Part 100 for DBEs/DBAs must therefore account for projected degradation and/or failure of coated particle fuel radionuclide barrier performance.

Coolability, in general, means that the fuel graphite elements (prismatic block) or the spherical matrix (pebble bed) of the modular HTGR core and vessel assembly retain their geometry with adequate cooling to permit removal of residual heat as needed to preserve safety even after a beyond design basis event (BDBE). The general requirements to maintain reactivity control and core-related coolability appear repeatedly in the mHTGR-DC found in DG-1330 as it applies to Appendix A to 10 CFR Part 50, (e.g., mHTGR-DC 27 and 34).

Modular High Temperature Gas-Cooled Review Plan (mHTGR-RP) Section 4.2 discusses key elements relating to TRISO-coated particle fuel performance criteria and related factors that may affect radionuclide barrier performance. However, because modular HTGR technology is relatively new, additional factors that could affect fuel performance may be identified in the SAR and require review and evaluation. The radioactive fission product inventory available in the helium pressure boundary and in the as-fabricated defective TRISO-coated particle fuel (i.e., the release fission product inventory expressed as a release fraction) is provided to the U.S. Nuclear Regulatory Commission (NRC) organization responsible for review of radiological consequence analyses for use in estimating the radiological consequences of plant releases.

The specific areas of review are as follows:

1. Design Bases. Design bases for the safety analysis address fabrication of the fuel and includes TRISO-coated fuel particles, fuel compacts or spheres, burnable poisons, and graphite fuel elements (prismatic block core). All mechanisms that may result in degradation of radiological barrier system performance are to be examined. This includes known fuel particle failure mechanisms and factors that affect fuel system performance under normal operating conditions and DBEs. Limiting values for important

Comment [A139]: This text anticipates the NRC RG for advanced reactor design criteria and subsequent mHTGR-DC (proposed RG 1.232). The current markup reflects the proposed language in Draft RG-1330.

Comment [A140]: "Channels” was removed.

Comment [A141]: This text anticipates the NRC RG for advanced reactor design criteria and subsequent mHTGR-DC (proposed RG 1.232). The current markup reflects the proposed language in Draft RG-1330. 
fuel performance parameters are to be provided to prevent damage from exceeding acceptable levels. The design bases should reflect the safety review objectives as described above.

The reviewer should evaluate established (past) design-basis limits and associated SARRDLs as they are available to determine whether they are applicable and meaningful to the TRISO-coated particle fuel design (including the introduction of new materials) given the operating conditions of the design (e.g., temperature, burnup, and power). If they do not apply, new limits must be established based on appropriate data.

2. Description and Design Drawings. The reviewer examines the fuel system description and design drawings. In general, the description will emphasize product specifications rather than process specifications.

3. Design Evaluation. The reviewer evaluates the performance of the fuel system during normal operation, AOOs, DBEs, and DBAs, to determine whether all design bases are met. Coated particle fuel system components and their associated radiological barriers are reviewed not only as separate components but also as integral units appropriate to the overall design function. This includes TRISO-coated fuel particles, fuel compacts/pebbles, and associated fuel elements (prismatic block design). New fuel designs, new operating limits (e.g., coated particle fuel burnup and power), and the introduction of new materials into the fuel system require a review to verify that design basis limits are applicable, that analytical fuel performance models and fission product transport evaluation methods, remain applicable for the specific fuel design under normal operation, AOOs, and DBEs/DBAs. The review also evaluates operating experience, direct experimental comparisons, detailed mathematical analyses (including fuel models and fission product transport performance codes), and other information.

4. Testing, Inspection, and Surveillance Plans. The licensee performs testing and inspection of new fuel components to ensure that the coated particle fuel and elements associated with associated radiological barrier performance are fabricated in accordance with the design and that they reach the plant site and are loaded in the core without unacceptable degradation in performance. Online TRISO-coated particle fuel failure monitoring (based on direct fission product release measurements) and post-irradiation surveillance testing should be performed as necessary to confirm that the fuel system is performing as expected or to detect any anomalies. Monitoring of burnable poisons during post-irradiation surveillance may be considered as a means to ensure effectiveness. The organization responsible for reactor systems reviews the testing, inspection, and surveillance plans, along with their reporting provisions, to ensure that the fuel design considerations important to modular HTGR operations and safety have been addressed.

5. Inspections, Tests, Analyses, and Acceptance Criteria (ITAAC). For design certification (DC) and combined license (COL) reviews, the staff reviews the applicant's proposed ITAAC associated with the structures, systems, and components (SSCs) related to this mHTGR-RP section in accordance with mHTGR-RP Section 14.3, "Inspections, Tests, Analyses, and Acceptance Criteria." The staff recognizes that the review of ITAAC cannot be completed until after the rest of this portion of the application has been reviewed against acceptance criteria contained in this mHTGR-RP section. Furthermore, the staff reviews the ITAAC to ensure that all SSCs in this area of review are identified and addressed as appropriate in accordance with mHTGR-RP Section 14.3. 
6. COL Action Items and Certification Requirements and Restrictions. For a DC application, the review will also address COL action items and requirements and restrictions (e.g., interface requirements and site parameters).

For a COL application referencing a DC, a COL applicant must address COL action items (referred to as COL license information in certain DCs) included in the referenced DC. Additionally, a COL applicant must address requirements and restrictions (e.g., interface requirements and site parameters) included in the referenced DC.

\section{$\underline{\text { Review Interfaces }}$}

Modular HTGR-RP Section 4.2 addresses the conduct of a review involving TRISO-coated particle fuel manufactured for use in a pebble-bed or prismatic block core design and the performance criteria for associated radiological barriers. Circulating and plated-out condensable radioactive fission product inventory in the reactor helium pressure boundary and as-fabricated defective coated fuel particle (i.e., the circulating inventory expressed as a release fraction) information is provided to those organizations that used the information to estimate radiological consequences of plant releases in accordance with mHTGR-RP Chapter 15.

Other mHTGR-RP sections that interface with this section are as follows:

1. Review of the nuclear design of the fuel elements or fuel spheres, control systems, and reactor core under mHTGR-RP Section 4.3.

2. Review of the applicant's quality assurance and reliability assurance programs (including plans for vendor audits and inspections) under mHTGR-RP Chapter 17 to verify statistically based fuel fabrication controls and the applicant's program for independent checks to verify continuing fuel quality and performance prior to fuel irradiation.

3. Review of the probabilistic risk analysis under mHTGR-RP Chapter 19 to assure that the statistical nature of quality verification measures used during the fuel fabrication process and resulting predicted performance is properly reflected in the evaluation of risk to public health and safety.

4. Review of thermal margins, the aspects of absorbed/desorbed fission products in the primary system, the effects of oxidation and corrosion products (e.g., graphite dust and metallic surface oxides), and the acceptability of fluid pressure-induced loads under mHTGR-RP Section 4.4.

5. Review of the design bases for the reactor cavity cooling system (RCCS), including the RCCS acceptance criteria as developed for mHTGR-DC 34, under mHTGR-RP Section 6.3.

6. Review of postulated TRISO-coated particle fuel failures mechanisms under accident conditions in Chapter 15 resulting from factors such as: (a) coating pressure vessel failure of standard (intact) or as-fabricated defective TRISO-coated particles; (b) kernel migration leading to SiC failure; (c) fission product/SiC interactions leading to SiC failure; (d) $\mathrm{CO} / \mathrm{SiC}$ interactions leading to $\mathrm{SiC}$ failure; (e) $\mathrm{SiC}$ decomposition leading to $\mathrm{SiC}$ failure; (f) heavy metal dispersion in buffer/iPyC layers leading to SiC failure; 
(g) irradiation-induced failure of iPyC resulting in SiC cracking; and (h) irradiation and temperature induced failure of oPyC layer.

7. Review of the reserve shutdown system, including borated $\left(B_{4} C\right)$ spheres, in mHTGR-RP Sections 4.5.1 and 4.6.

8. Review of the reactivity control rod drive mechanism design in mHTGR-RP Section 3.9.4 and reactor internals design under mHTGR-RP Section 3.9.5.

9. Review of the adequacy and sensitivity of instrumentation under mHTGR-RP Chapter 7 and adequacy of arrangements of instrumentation in the helium purification system under mHTGR-RP Chapter 9 to detect fission product release from defective or failed fuel particles.

10. Review of the estimates of radiological dose consequences under Chapter 15.

11. Review of the proposed technical specifications under mHTGR-RP Chapter 16 to assess the adequacy of the detection of and acceptable limits for failed fuel fractions in terms of fission products in the circulating helium coolant during normal plant operations.

The specific acceptance criteria and review procedures are contained in the referenced mHTGR-RP sections.

\section{ACCEPTANCE CRITERIA}

\section{Requirements}

Acceptance criteria are based on meeting the relevant requirements of the following Commission regulations:

1. 10 CFR 50.67 as it relates to cooling performance analysis of the RCCS using an acceptable evaluation model and acceptance criteria appropriate for the modular HTGR design under review.

2. 10 CFR Part 100 and 10 CFR 50.67 , as they relate to determining the acceptability of a reactor site based on calculating the exposure to an individual as a result of fission product releases to the environment following a major DBA.

3. $\mathrm{mHTGR}-\mathrm{DC}$ 10, as it relates to assuring specified acceptable core radionuclide release design limits associated with TRISO-coated particle fuel radiological barrier performance are not exceeded during any condition of normal operation, including the effects of AOOs.

4. mHTGR-DC 26, as it relates to the reactivity control system(s) being designed with appropriate margin and being capable of controlling reactivity to the extent necessary to protect the core and radiological barriers under post-accident conditions.

5. mHTGR-DC 34, as it relates to providing a RCCS to transfer heat away from the reactor core at a rate such that; (1) radionuclide barrier performance that could result in unacceptable radionuclide release is prevented, and (2) other system damage that may affect safety is limited to negligible amounts.
Comment [A144]: High temperature control

rod" was deleted.

Comment [A145]: The need for new regulations for mHTGRs and applicability of existing regulations must be determined

Comment [A146]: "Core damage" deleted

Comment [A147]: Core-related damage changed to system damage. 
6. 10 CFR $52.47(b)(1)$, which requires that a DC application contain the proposed inspections, tests, analyses, and acceptance criteria (ITAAC) that are necessary and sufficient to provide reasonable assurance that, if the inspections, tests, and analyses are performed and the acceptance criteria met, a plant that incorporates the design certification is built and will operate in accordance with the design certification, the provisions of the Atomic Energy Act, and the NRC's regulations.

7. 10 CFR 52.80(a), which requires that a COL application contain the proposed inspections, tests, and analyses, including those applicable to emergency planning, that the licensee shall perform, and the acceptance criteria that are necessary and sufficient to provide reasonable assurance that, if the inspections, tests, and analyses are performed and the acceptance criteria met, the facility has been constructed and will operate in conformity with the combined license, the provisions of the Atomic Energy Act, and the NRC's regulations.

8. 10 CFR 50, Appendix B, as it relates to the conduct of testing, acquisition and documentation of TRISO-coated particle fuel manufacturing data.

\section{$\underline{\text { mHTGR-RP Acceptance Criteria }}$}

Specific acceptance criteria acceptable to meet the relevant requirements of the NRC's regulations identified above follow for the review described in this MHTGR-RP section.

The fuel design bases must reflect the five objectives described in Subsection I, Areas of Review. To satisfy these objectives, acceptance criteria are needed concerning asmanufactured fuel quality [Item 1], fuel system performance under normal operation and AOOs [Items 2 \& 3], fuel system performance for DBEs/DBAs [Item 4], and statistical accuracy of fuel performance and fission product release modeling [Item 5].

\section{Design Bases}

The fuel design bases must reflect the objectives described in Subsection I, Areas of Review. Acceptance criterion are needed for (A) as-manufactured TRISO fuel quality, (B) fuel system performance under normal operation and AOOs, (C) fuel system performance for DBEs/DBAs, , and (D) statistical accuracy of fuel performance and fission product release modeling. Factors in establishing these criteria are discussed in the following paragraphs:

\section{A. $\quad$ As-Manufactured Fuel Quality}

Based upon a statistical analysis of appropriate QC information obtained from a statistically significant sample of fuel kernels, TRISO coated particles and fuel pebbles or fuel compacts, insure as-manufactured fuel quality limits are met. Fuel specification requirements with prescribed statistical certainty are required on important as-fabricated material properties for the fuel kernels, TRISO coated particles, fuel compacts or pebbles, and lumped burnable poison.

To meet the requirements of 10 CFR 50, Appendix B, a statistically-based FuelProduction Quality Assurance Plan (FPQAP) must be established that addresses all quality requirements for the fabrication of the fuel system. The FPQAP must 
demonstrate these requirements are satisfied with respect to the conduct of testing, acquisition and documentation of data through use of ASME NQA-1 standards, or equivalent, as implemented and documented by the fuel fabricator's quality assurance program plan. To achieve compliance with the quality requirements, all operations performed on the fuel product shall utilize qualified personnel, controlled processes, and measurement techniques traceable to recognized industry standards. A description of the FPQAP should be submitted with the application and show how fuel system design meets requirements of 10 CFR 50, Appendix $B$.

The as-manufactured fuel quality criteria shall assure manufacturing and quality control processes are in place for the coated particle fuel that results in; (1) a robust TRISO-coated fuel particle that will experience a low fraction of incremental particle failure during normal operation, including AOOs, and DBEs/DBAs, with a high statistical certainty, and (2) a very small beginning-of-life (BOL) defective particle fraction as evidenced by the level of heavy metal (HM) contamination and defect particle fraction levels. These fuel quality criteria relate closely to the radionuclide source term circulating in the modular HTGR reactor helium pressure boundary available for release.

The quality of TRISO coated particle fuel is based on an overall manufacturing process in which process controls and statistical quality control are maintained for each process operation. Process control is maintained by employing a standardized production method with specified process conditions (such as coating gas temperature, composition, flow rates and associated tolerances) that yield a product with established properties. To assure an acceptable product, specific properties for each fuel component, defined quantitatively in a Fuel Product Specification, are sampled using statistically accepted methods, measured using standardized procedures, and the results statistically analyzed. Acceptance can be based on the property value as well as its statistical certainty compared to the specification. In this manner the manufacturing processes can be proven to meet specifications with high statistical confidence. This method of statistical process control applies to the production of all fuel components including:

i. TRISO Coated Particles and their constituent elements - the fuel kernels and ceramic coatings;

a. $\quad$ Fuel Kernel - Properties controlled for fuel kernels (e.g., lowenriched UCO) include dimensions (diameter and aspect ratio), density, composition (e.g., carbon-uranium and oxygen-uranium ratios, total uranium content, isotopic content/enrichment, and impurity levels.

b. $\quad$ TRISO coating - Properties controlled for each of the four layers of the TRISO coatings applied to fuel kernels are: dimensions (thickness of each layer and particle aspect ratio); density of each layer; microporosity of iPyC and oPyC layers; anisotropy of the iPyC and oPyC; defective coating fractions ((a) missing or defective buffer layers; (b) missing or defective iPyC layers; and (c) missing or defective oPyC layers); and in particular for the SiC 
coating: density, crystallographic phase, grain size and orientation, and Weibull properties (characteristic strength and modulus).

ii. Overcoated TRISO particle - Properties controlled on overcoated TRISO particles are: dimensions (overcoating thickness and aspect ratio) and overcoating density.

iii. Statistical Certainty - Acceptance testing of fuel particles to determine conformance to specified fabrication requirements is necessarily performed on a statistical basis. The Fuel Product Specification establishes acceptance criteria for the properties controlled as well as the confidence levels with which the population must meet the specific criterion. The properties monitored are either a variable or an attribute type; Kernel or coating properties are typically variable, while particle coating defect levels are attributes.

Variable properties are defined by a continuous distribution (i.e., normal distribution), and their acceptance criteria are stated in terms of the population mean and/or the population dispersion. The criterion for the population mean is that it lies within a specified interval and the ends of the interval are generally the limits for the mean. The criterion for the population dispersion is that no more than a specified fraction can exceed or be less than predetermined values. These values represent the dispersion critical limits.

Attribute properties are discrete in terms of the property being measured - coatings/particles are either defective or not. The acceptance criterion for an attribute property is defined as the allowable fraction of the defective property that is permitted. A random sample of the population is drawn and tested to determine whether it is defective or not. If the property defect fraction is sufficiently small, it is accepted. Typical for confidence testing of attribute properties, sample sizes are based on hypergeometric or binominal probabilities to achieve the desired statistical certainty.

iv. Fuel (compact or pebble) properties include dimensions (diameter and length), density, uranium content, homogeneity, impurity level, heavy metal (HM) contamination (based on high-temperature $\mathrm{HCl}$ Leach method), SiC defect fraction (based on Burn-Leach method), and defective particle fractions for (a) missing or defective buffer layers, (b) missing or defective iPyC layers, and (c) missing or defective oPyC layers.

v. Lumped Burnable Poison (compact or pebble) properties include; dimensions (diameter and length), density, B4C stoichiometry, boron isotopic content and PyC coating thickness.

vi. Important properties and quality control considerations concerning fabricated fuel pebbles or prismatic fuel elements are to be identified and appropriate limits established. Although limited cracking in prismatic fuel 
elements may be allowable during normal steady-state operation, extensive structural damage that could lead to blockage should remain extremely unlikely. Sources of stress affecting fuel element integrity include varying temperature and fluence fields and mechanical loads due to gravity, fluid forces and seismic events. Allowable peak stress-tostrength ratio limits of fuel element materials should reflect differences in function, structural redundancy, and loading for each type of fuel element.

\section{B. $\quad$ Coated Particle Fuel Performance - Normal Operations and AOOs}

This subsection applies to TRISO fuel performance under normal operation and AOOs. Section 4.2 of the safety analysis report should contain information related to this review.

To meet the requirements of modular HTGR-DC 10, as it relates to SARRDLs for normal operation, including AOOs, coated particle fuel performance criteria should be included for known degradation and failure mechanisms relative to the potentially affected fuel components.

With respect to demonstrating acceptable TRISO coated fuel and fuel compact or pebble sphere performance, the requirements of 10 CFR 50, Appendix B will be satisfied with respect to the conduct of testing and acquisition and documentation of data using ASME NQA-1 or equivalent quality assurance methods.

Coated particle fuel performance criteria should be established to assure that fuel specifications remain within operational tolerances and that functional capabilities are not reduced below those assumed in the safety analysis. When applicable, the coated particle fuel performance criteria should consider high burnup temperature, and fast neutron fluence effects based on irradiated material properties data. Complete TRISO-coated particle fuel performance criteria should address the following:

i. The design bases for the coated particle fuel should be clearly presented and include an analysis of associated radiological barrier design and function. Design considerations and functional descriptions should ensure the components of coated particle fuel design contribute to overall radionuclide barrier performance. The discussion must include design limits of the coated particle fuel and radiological barrier functions associated with the core. The technological and safety-related bases for these limits must be clearly identified. Maintaining the integrity of radionuclide barrier(s) associated with the coated particle fuel, the core, and the reactor helium pressure boundary should be the most important design objective.

ii. The chemical, physical, and material performance characteristics of coated particle fuel and fuel elements related to radionuclide barrier performance should be chosen for compatibility with each other and the anticipated operational environment. They must be compatible with performance characteristics needed to assure reliable radionuclide barrier function during normal and AOO design conditions. The design should take into account factors and characteristics that could affect or limit 
barrier integrity. Important characteristics include oxidation, corrosion and erosion associated with coolant flow, physical stresses from thermal, mechanical and internal pressures, fuel burnup, radiation damage, and effects cause by retention of fission products.

iii. The design basis for coated particle fuel should maintain acceptable levels of radionuclide barrier integrity under the relevant operating conditions assumed in the safety analysis. Loss of integrity is defined as the escape of unacceptable levels of fission products from primary barrier(s) associated with the coated particle fuel design. The reviewer should be able to conclude that the applicant has included all information necessary to establish limiting characteristics.

iv. Stress, strain, or loading limits for fuel compacts or pebbles, lumped burnable poisons, and graphite fuel blocks (prismatic block core design) should be provided. Approved American Society of Mechanical Engineers (ASME) test procedures are acceptable when available. Other proposed limits must be justified.

v. The cumulative number of strain fatigue cycles on graphite components (compacts or pebbles) should be significantly less than the design fatigue lifetime which is based on appropriate data covering the number of cycles. Proposed limits should be justified.

vi. Wear and removal of material at contact points between graphite fuel components should be limited. Wear tests and analyses that demonstrate compliance with the design basis should be provided.

vii. Oxidation of graphite surfaces as well as internal oxidation, corrosion, and the buildup of other materials such as oxide films on metallic primary circuit surfaces and graphite dust accumulations, should be limited as they ultimately contribute to fission product transport during accident conditions. Limits on graphite oxidation and oxide film buildup should be specified for all graphite and metallic components exposed to the primary circuit coolant. These limits should be established based on testing appropriate to demonstrate each potentially affected component will maintain acceptable performance. Tested mechanical properties should include strength and ductility. The safety analysis report should discuss allowable oxidation, corrosion, and dust level generation within the helium pressure boundary. The effect of oxidation, corrosion, and material buildup on thermal and helium flow considerations and neutronic considerations are reviewed as described in mHTGR-RP Sections 4.3 and 4.4 .

viii. Control rods are designed to change reactivity by changing the amount of neutron absorber in or near the reactor core. Depending on their function in the specific design, control rods can be designated as regulating, safety, shim, or transient rods. To scram the reactor, negative reactivity is introduced by dropping control rods into the core. Control rods can serve a dual function (control and safety) but control and safety systems for power reactors are expected to be completely separate. Depending on 
the design, reserve shutdown material (e.g., boronated graphite balls) may also be present in modular HTGRs for use as a supplemental safety system. A scram should not challenge reactor safety or cause undue strain on any systems or components associated with the reactor.

The control rod system should be designed conservatively to withstand all anticipated stresses and challenges from mechanical and thermal forces and effects of the chemical and radiation environment. Control rods should be sufficient in number and reactivity worth to comply with the requirements of modular HTGR-DC 27; that is, it should be possible to shut down the reactor and comply with the requirements of minimum shutdown margin with the highest worth control rod stuck out of the core. The control rods should be sufficient to control the reactor in all operating modes and shut down the reactor safely from any operational condition. Additional control rod criteria considerations are provided in MHTGR-RP Section 4.3. Technical specifications should be proposed according to guidance in Chapter 14 of the format and content guide, which describes important design aspects and proposes limiting conditions for operations and surveillance requirements, and should be justified in this section of the SAR.

ix. Dimensional changes, such as irradiation induced growth of fuel components (compacts or pebbles), lumped burnable poison (if present), and graphite fuel elements (prismatic block design) should remain within operational tolerances to prevent unacceptable fuel degradation and radiological barrier failure or a situation in which the thermal limits established in Section 4.4 are exceeded. Functional capabilities should not be reduced below those assumed in the safety analysis. Design analysis should be conducted to evaluate irradiation induced dimensional changes that could result in significant interference fit between fuel components. For prismatic block designs, the fuel compact and the fuel hole surface of machined graphite fuel elements are to be examined as excessive dimensional changes could result in a configuration control change in the fuel or burnable poison compacts.

x. Lumped burnable poison irradiation-induced $\mathrm{B}_{4} \mathrm{C}$ particle damage and resulting dimensional changes should remain below specified design limits during normal operations

C. Coated Particle Fuel System Performance - Design Basis Events (DBEs) and Design Basis Accidents (DBAs)

This subsection applies to coated particle fuel system performance testing and characterization under DBEs/DBAs. Section 4.2 of the safety analysis report should contain the necessary information for review.

With respect to demonstrating acceptable TRISO coated fuel and fuel compact or pebble sphere performance, the requirements of 10 CFR 50, Appendix $B$ will be satisfied with respect to the conduct of testing, acquisition and documentation of data through the use of ASME NQA-1 or equivalent. 
Performance criteria for DBEs/DBAs should address the following:

i. Demonstrated performance limits for TRISO coated fuel particles should be provided that meet requirements with the required statistical certainty. Performance limits are to be established in a controlled environment of a special test facility, an irradiation test capsule, or a demonstration facility capable of simulating the DBEs/DBAs and quantifying any detectable particle failures or fission product releases

ii. Behavior of lumped burnable poison involving air or moisture ingress

Comment [A154]: "compacts" deleted

iii. Oxidation of fuel compacts and fuel elements (prismatic block) or pebble carbon matrix involving air or moisture ingress

D. Fuel Performance and Fission Product Release Modeling and their Statistical Accuracy

The capability to predict (with statistical certainty) fuel performance and fission product release under normal operating (including AOOs) conditions and DBEs/DBAs, is a requirement for prismatic block-type and pebble bed modular HTGRs. This requirement dictates that a verified and validated (V\&V) coated particle fuel performance code be available based on first principles understanding of the physical, chemical and thermal processes that can lead to coated particle failure under all normal and off-normal operations. This requirement includes the capability to accurately predict fission product release from the coated particle fuel (from failed particles and diffusive release through intact particle coatings) and their transport through fuel compacts and graphite fuel elements (prismatic block designs) or fuel pebble spheres to the reactor primary coolant.

Fuel performance model development requires a fundamental understanding and knowledge base of the potential particle failure mechanisms and the dependency these mechanisms have on normal irradiation conditions (e.g., temperature, burnup and fluence) and conditions of DBEs/DBAs (e.g., high temperatures for long periods and environmental effects). Accurate fuel performance modeling also requires knowledge of fuel constituent material properties together with their behavior and interaction under normal irradiation and the extremes of accident conditions.

Irradiation testing of fuel constituent materials should provide separate affects data to support the performance models. A fuel performance code which contains the first principles based fuel performance models should be benchtested against various irradiation and safety tests for verification purposes. Separate, independent reference fuel irradiation and hot cell safety tests may be necessary to provide validation of the fuel performance code for normal operating conditions and DBE/DBA conditions. 


\section{Description and Design Drawings}

The reviewer determines that the TRISO-coated particle fuel system and associated radiological barrier description and design drawings provide an accurate representation and supply information needed in audit evaluations. Completeness is a matter of judgment but the following information (with associated tolerances) will generally be necessary for an acceptable fuel description:

\section{A. Fissile [UCO] fuel kernels:}
i. Diameters and critical limits
ii. Density and critical limits
iii. Total uranium content
iv. Uranium isotopic content (w/o)
v. Impurity content (ppmv)
vi. Oxygen/Uranium (atomic ratio) and critical limits
vii. Carbon/Uranium (atomic ratio) and critical limits

\section{B. Fertile [UCO] fuel kernels:}

i. Diameters and critical limits

ii. Density and critical limits

iii. Total uranium content

iv. Uranium isotopic (w/o)

v. Impurity content (ppmv)

vi. Oxygen/Uranium (atomic ratio) and critical limits

vii. Carbon/Uranium (atomic ratio) and critical limits

C. TRISO coatings on fissile [UCO] fuel (PyC Buffer layer, iPyC layer, SiC layer \& $\underline{\text { oPyC layer) }}$
i. Thickness and critical limits and allowable fraction outside limits
ii. Density, critical limits and allowable fraction outside limits
iii. Microporosity for PyC layers (iPyC and oPyC)
iv. Anisotropy (BAFO units), critical limits and allowable fraction outside limits (iPyC and oPyC)
v. Aspect Ratio, critical limits and allowable fraction outside limits (total coated particle)
vi. Defective Particle Fractions, Maximum Expected Level (50\% confidence level) and Design Level (95\% confidence level)

D. TRISO coatings on fertile [UCO] fuel (PyC Buffer layer, iPyC layer, SiC layer \& oPyC layer)
i. Thickness and critical limits and allowable fraction outside limits
ii. Density, critical limits and allowable fraction outside limits
iii. Microporosity for PyC layers (iPyC and oPyC)
iv. Anisotropy (BAFO units), critical limits and allowable fraction outside limits (iPyC and oPyC)
v. Aspect Ratio, critical limits and allowable fraction outside limits (total coated particle

Comment [A157]: Presumed enrichment level of 19.8 text removed.

Comment [A158]: Presumed enrichment level text of 0.7 removed to maintain consistency with item $\mathrm{C}$ above. 
vi. Defective Particle Fractions, Maximum Expected Level (50\% confidence level) and Design Level (95\% confidence level)

\section{E. Fuel Compacts and Pebbles (heat-treated):}

i. Dimensions - diameter and length

ii. Coke content $(g$-coke $/\{g$-coke + filler $\})$

iii. Macroporosity (\% matrix composite void)

iv. Heavy Metal Contamination (hot gaseous $\mathrm{HCl}$ Leach):
a. Uranium $\left(\mathrm{U}_{\text {leached }} / \mathrm{U}_{\text {total }}\right)$
b. Thorium $\left(\mathrm{Th}_{\text {leached }} / \mathrm{Th}_{\text {total }}\right)$

v. Mean Defective SiC Layer Fraction (Burn Leach):
a. Uranium (Uleached/Utotal)

vi. Mean Defective iPyC Layer Fraction (HM Dispersion)

vii. Mean Impurities (ppm Boron equivalent) and critical limits:
a. Burnable (B, Cd, Eu, Gd, Li, Sm)
b. Nonburnable (Na, S, Ca, Yb, Ti, V, Cr, Lu, Mn, Fe, Co, Al, Dy, Ni, $\mathrm{Cu}, \mathrm{Zn}, \mathrm{Hf}, \mathrm{Mo}, \mathrm{Ag}, \mathrm{In}, \mathrm{Ta}, \mathrm{La}, \mathrm{Ce}, \mathrm{W}, \mathrm{Pr}, \mathrm{Nd}, \mathrm{Tb}, \mathrm{Ho}, \mathrm{Er}, \mathrm{Tm})$
c. Iron Content Fraction (outside $\mathrm{SiC}$ layer)
d. Transition Metals (ppm of $\mathrm{Cr}, \mathrm{Mn}, \mathrm{Co}$ and $\mathrm{Ni}$ )
e. Hydrogen (ppm of compact wt.)
f. Chlorine (ppm of compact matrix wt.)
g. Sulfur content fraction (ppm of matrix + shim particles)

F. Graphite Shim Particles;
i. Grade
ii. Particle Size Distribution and critical limits
iii. Particle Shape

\section{G. Composite Matrix Material:}
i. Resin and filler grades
ii. Matrix additives
iii. Filler crystallite size
iv. Filler particle size and critical limits

H. Lumped Burnable Poison:
i. Dimensions - diameter and length
ii. Coke content (g-coke/ $\{\mathrm{g}$-coke + filler $\})$
iii. Macroporosity (\% matrix composite void)
iv. Total Boron (B) content
v. ${ }^{10} B$ enrichment (w/o) 
I. Machined graphite hexagonal "Standard" fuel element (prismatic block):

i. Length and distance across flats

ii. Graphite surface finish

iii. Number of coolant holes, their diameter, pitch and surface finish

iv. Number of fuel holes, their diameter, pitch, depth and surface finish

v. Graphite plugs (diameter and thickness)

vi. Dowel location and depth

J. Machined graphite "Reserve Shutdown" sphere openings/passages:

i. Length and distance across flats

ii. Graphite surface finish

iii. Number of coolant holes, their diameter, pitch and surface finish

iv. Number of fuel holes, their diameter, pitch, depth and surface finish

v. Location of through hole for reserve shutdown pellets, diameter and surface finish

vi. Graphite plugs (diameter and thickness)

vii. Dowel location and depth

K. Machined graphite "Control Rod" openings/passages:

i. Length and distance across flats

ii. Graphite surface finish

iii. Number of coolant holes, their diameter, pitch and surface finish

iv. Number of fuel holes, their diameter, pitch, depth and surface finish

v. Location of through-hole for control rod, diameter and surface finish

vi. Graphite plugs (diameter and thickness)

vii. Dowel location and depth

\section{Design Evaluation}

The reviewer will evaluate methods for demonstrating that the design bases are met. Methods include fuel quality manufacturing experience, operating experience under normal and off-normal testing experience, prototype testing, and analytical predictions. Many of these methods will be presented generically in topical reports and incorporated in the safety analysis report by reference.

The SAR should contain sufficient information to support the following types of conclusions:

- $\quad$ The applicant has described the coated particle fuel system and associated radiological barrier components used in the design. The discussion includes design limits of coated particle fuel components and clearly provides the technological and safety-related bases for associated limits.

- The applicant has discussed constituents, materials, components, and fabrication specifications for the various coated particle fuel components. Compliance with the specifications for all fuel acquisitions assures uniform characteristics and compliance with the design bases and safety-related requirements. 
- $\quad$ The applicant has referred to the coated particle fuel development program under which all fuel and radiological barrier characteristics and parameters that are important to safe operation of the reactor were investigated. Design limits are clearly identified for use in the design bases to support technical specifications.

- Information on the design and development program for the fuel offers reasonable assurance that the fabricated coated particle fuel can function safely in the reactor without adversely affecting the health and safety of the public.

Detailed discussions are required concerning the following topics as they relate to the TRISO-coated particle fuel design:

\section{A. Manufacturing Experience}

Manufacturing experience of the as-fabricated quality of the fuel (e.g., fuel kernels, TRISO-coated particles, fuel compacts/pebbles and burnable poisons) should be described and include the standardized manufacturing processes employed, the actual processing conditions, and specific physical and material properties of the fuel system components identified in the Fuel Product Specification. Demonstration of acceptable as-fabricated fuel quality should be obtained by employing a statistically based sampling plan, standardized property measurement procedures and a complete statistical analysis of results.

Acceptance demonstration for specific controlled physical and material properties on fuel kernels, TRISO particles, fuel and burnable poisons should be based upon the actual range in measured property values, their critical limits or confidence levels, and a direct comparison to quality requirements in the Fuel Product Specification.

Acceptance demonstration of as-fabricated fuel quality relative to heavy metal (HM) contamination and defective particle fractions (i.e., defective or missing particle layers) should be based on analysis of a statistically significant sample of suitably manufactured fuel compacts to meet required statistical certainty. Acceptance is established by a direct comparison to HM contamination limits, defective coating layer fractions and the two-tiered (50\% and 95\%) confidence limits defined in the Fuel Product Specification.

B. Operating Experience (normal operating conditions and AOOs)

The statistically low in-reactor fuel failure fractions required of TRISO-coated particle fuel necessitate a rigorous evaluation of all fuel performance data derived from prior operating experience. Operating experience with TRISO-coated particle fuel systems of the same or similar design conducted in material test reactors (MTRs) or from available experimental HTGRs should be described, including: range in normal operating conditions and AOOs experienced [operating temperatures, range in fissile burnup achieved expressed in percent of fissions in initial heavy metal atoms (\% FIMA), and range in accumulated fast neutron fluence $\left(\times 10^{25}\right.$ neutrons $\left.\left./ \mathrm{m}^{2}, \mathrm{E}>0.18 \mathrm{MeV}\right)\right]$; and a statistical assessment of the irradiation performance based on monitored in-reactor fission gas release data, and non-destructive and destructive post-irradiation examinations and analysis of the irradiated fuel. Any significant differences in the 
irradiation environment where the operating experience was obtained and that expected in the design under review should be identified and explained relative to fuel integrity, fission product retentiveness, and influence on the radionuclide source term.

Demonstrated acceptable performance should be based on a direct comparison of the observed in-reactor performance with normal operating condition and AOO performance requirements. These include both in-service TRISO particle failure fractions and fission product release (e.g., ${ }^{137} \mathrm{Cs}$ and ${ }^{110 \mathrm{~m}} \mathrm{Ag}$ ) requirements along with their respective statistical certainty.

When adherence to specific design criteria can be conclusively demonstrated with operating experience, prototype testing and design analyses that were performed prior to gaining that experience need not be reviewed. Design criteria for graphite wear, oxidation, and oxide layer buildup on graphite surfaces exposed to the helium pressure boundary may be addressed in this manner.

\section{Accident Condition (DBE/DBA) Testing Experience}

The fuel system should be designed to assure acceptable radionuclide retention performance of the TRISO-coated fuel for DBE/DBA conditions. Accident condition testing experience of systems that are the same or similar in design should be described, including: the prior irradiation exposure of the test elements [operating temperatures, fuel burnup (\% FIMA), and accumulated fast fluence $\left(x 10^{25}\right.$ neutrons $\left.\left./ \mathrm{m}^{2}, \mathrm{E}>0.18 \mathrm{MeV}\right)\right]$; description/explanation of the accident condition event and full disclosure of accident condition test conditions and test facilities used in simulating the event; and a statistical assessment of the fuel behavior during the accident condition testing based on monitored in-test fission gas release data, and non-destructive and destructive post-test examinations and analysis of the accident irradiated fuel. Significant deviations from the realtime conditions should be identified and explained relative to fuel system integrity, fission product retentiveness, or influence to the radionuclide source term.

Demonstrations of experience acceptability should be based on direct comparisons of the observed accident condition fuel behavior accident condition performance requirements. These include both accident condition TRISO particle failure fraction requirements and fission product release $\left({ }^{137} \mathrm{Cs}\right.$ and $\left.{ }^{110 \mathrm{~m}} \mathrm{Ag}\right)$ requirements along with their respective statistical certainty.

\section{D. $\quad$ Prototype Testing}

When conclusive operating experience is unavailable as may occur with the introductions of a fuel design change, prototype testing information should be reviewed. Out-of-reactor tests should be performed when indicated to determine characteristics of the new fuel design. No definitive requirements have been developed regarding new design features other than existing requirements concerning as-manufactured fuel quality, fuel performance under normal operating conditions and, fuel performance under DBE and DBA conditions, which are still applicable. In addition, new fuel designs should not introduce additional fuel failure mechanisms and must demonstrate conformance to 
accepted fuel performance models and fission product transport codes.

In-reactor testing of key fuel system design features and partial- or full-graphite fuel component irradiations for a new fuel system design should be reviewed. The maximum burnup (\%FIMA) or fluence $\left(\times 10^{25}\right.$ neutrons $/ \mathrm{m}^{2}, \mathrm{E}>0.18 \mathrm{MeV}$ ) experience associated with such tests should also be reviewed and considered in relation to the specified maximum burnup or fluence limit for the new design. In some cases, in-reactor testing of a new coated particle fuel design or a new design feature cannot be accomplished before operation of the design's full core. An inability to perform in-reactor testing may result from an incompatibility of the new design with previous designs or available testing platforms. In such cases, special attention should be given to surveillance plans (see Subsection II.4, Item C below).

\section{E. Analytical Predictions}

Some coated-particle fuel design bases and related parameters can only be evaluated with calculational procedures. The analytical methods used to make performance predictions must be reviewed. Many such reviews have been performed in the past and can provide general examples for the reviewer but with respect to coated particle fuel systems, analytical models and methods suitable for making analytical fuel system performance predictions may be quite new or in a stage of final development.

All prior and current gas-cooled reactor fuel development programs (international and domestic) have included efforts to model the performance of coated particle fuel. They addressed the thermal, structural/mechanical and chemical processes that lead to particle failure, investigated fission product release from failed and non-failed fuel particles and their transport through fuel constituent materials (e.g., fuel kernel materials, PyC and SiC coating materials, fuel matrix and fuel element graphite).

Analytical methods used to make fuel performance predictions under normal operating, AOO, and DBE/DBA conditions must be thoroughly reviewed. This review should include; the knowledge base of the fundamental phenomena responsible for fuel particle failure and the synergies between them; benchmarking of the resultant models/codes to irradiation testing and safety tests conducted on current- and past-generations of coated particle fuels; demonstrated achievement of design fuel system performance requirements at the one-sided upper 50\% and 95\% confidence levels for all normal operating conditions and accident (DBE/DBA) conditions; and a thorough identification and knowledge base of the key thermo-chemical, thermo-mechanical, and thermophysical properties and their constitutive relations for fuel constituent materials (fuel kernels, TRISO coatings, and fuel compacts/pebbles) as function of fabrication, irradiation and DBE/DBA conditions.

Verification and validation ( $\& \& \mathrm{~V})$ is required of fuel performance models/codes and the fission product transport model/codes used for licensing under normal operating and DBE/DBA conditions. The technical basis of the analytical methods, verification of these methods, along with the testing activities to generate an independent database for validating the fuel performance 
model/codes under normal operating and accident conditions should be reviewed. This review should cover the full validation process including:

i. An evaluation of the quantitative pre-test predictions of fuel performance, including the required statistical certainty, based on the measured attributes and properties of the qualified test fuel, anticipated normal operating and accident conditions, incorporated into the verified analytical models/codes for fuel performance and fission product transport

ii. After-test adjustments to pre-test predictions in consideration of differences between actual and anticipated irradiation and accident testing conditions

iii. A quantitative statistical assessment, at the required confidence levels, of the irradiation performance and accident condition performance of the qualified test fuel based on monitored fission product release data, and non-destructive/destructive post-test examinations and analysis

iv. A quantitative statistical comparison of the pre-test predictions and the post-testing assessment of irradiation performance and accident condition performance of the pre-qualified test fuel over a representative range of normal operating conditions and DBEs/DBAs

Validated demonstration of fuel performance and transport models/codes should be based on a direct comparison of predicted and observed fuel performance and behavior to normal and DBE/DBA condition performance limits at the required statistical certainty.

\section{Testing, Inspection, and Surveillance Plans}

Plans are to be reviewed for each plant for testing and inspection of new TRISO-coated particle fuel and for monitoring and surveillance of irradiated fuel.

\section{A. $\quad$ Testing and Inspection of New Coated Particle Fuel}

Testing and inspection plans for new fuel system components should verify asfabricated fuel integrity, fuel component dimensions, fuel enrichment, heavy metal loadings, burnable poison concentration, and absorber composition. Quality control reports should document details of the manufacturer's testing and inspection programs and should be referenced and summarized in the safety analysis report. The program for onsite inspection of new coated particle fuel elements after they have been delivered to the plant should also be described. When overall testing and inspection programs are essentially the same as those for previously approved plants, a statement to that effect should be made. In that case, the safety analysis report need not include program details but an appropriate reference should be cited and a summary (tabular) presented. 


\section{B. Online Fuel System Monitoring}

The applicant's online fuel particle failure detection methods should be reviewed. Both the sensitivity of fission product detection instruments and the applicant's commitment to use those instruments should be evaluated.

Surveillance is also needed to assure that the $\mathrm{B}_{4} \mathrm{C}$ materials used as a burnable poison are not losing reactivity. The reviewer should assure that the boron compounds are not susceptible to degradation (by mechanisms such as leaching in the presence of moisture ingress) in the anticipated operational environment.

\section{Postirradiation Surveillance}

A post-irradiation fuel surveillance program should be described for each plant to detect anomalies or confirm expected fuel performance. The extent of an acceptable program will depend on the history of the fuel design and whether the fuel design being reviewed is the same as currently operating fuel or incorporates new design features.

For a fuel design similar to that in other operating plants, a minimum acceptable program should include a quantitative statistical performance assessment of statistically significant quantities of representative discharged coated particle fuel compacts or fuel spheres from each refueling. Such a program should be sufficient to identify gross problems of graphite structural integrity, graphite wear, graphite oxidation or oxide layer buildup on surfaces exposed to the primary coolant, fuel compact or pebble performance, fuel compact bowing, fuel compact or fuel sphere dimension changes, and TRISO particle failure fractions. The program should also commit to perform additional surveillance if unusual behavior is noticed in visual and detailed testing examinations or if plant instrumentation indicates unacceptable levels of degradation in coated particle fuel performance. The surveillance program should also address the disposition of fuel elements or spheres that undergo detailed destructive examination.

In addition to the plant-specific surveillance program, a continuing TRISO-coated particle fuel surveillance effort should exist for each given type, make, or class of particle-coated fuel that can be suitably referenced by all plants using the similar fuel. In the absence of such a cross-cutting (generic) program, the reviewer should expect a more detail in the plant-specific program.

For a fuel design that introduces new features, a more detailed surveillance program should be described commensurate with the nature of change in fuel design. This program should include appropriate qualitative and quantitative inspections to be carried out at interim and end-of-life refueling points. This surveillance program should be coordinated with prototype testing discussed in Subsection II.3.D. When prototype testing cannot be performed, a special detailed surveillance program should be planned for the first irradiation of a new fuel design. 


\section{$\underline{\text { Technical Rationale }}$}

The technical rationale for application of these acceptance criteria to the areas of review addressed by this $\mathrm{mHTGR}$-RP section is discussed in the following paragraphs:

1. 10 CFR Part 100 requires the calculation of exposure to an individual caused by the release of fission products from a modular HTGR to the environment during DBE/DBA conditions and consideration of the result when determining acceptability of a reactor site. Requirements contained in 10 CFR 50.34 apply to new reactors with DC applications after January 10, 1997. Mechanistic source terms for new reactors are based on total effective dose equivalent rather than whole body dose as is used in 10 CFR Part 100 and RG 1.195 and RG 1.196. Insights are provided by RG 1.25, RG 1.183, and RG 1.196 concerning establishing acceptable assumptions that may be used to evaluate radiological consequences associated with a fuel-handling accident at a fuel handling and storage facility at reactor sites. Evaluation of radiological dose consequences associated with DBEs/DBAs as prescribed in 10 CFR Part 100 and applied to modular HTGRs, provides assurance that nuclear reactors can be operated safely under worst-case conditions.

2. mHTGR-DC 10 requires that the reactor core and associated heat removal, control, and protection systems be designed with appropriate margin to ensure that specified acceptable core radiological release design limits are not exceeded during any condition of normal operation, including the effects of AOOs. One objective of the fuel system safety review cited in this section is to ensure that fuel system performance is not damaged during normal operations or AOOs. This section reviews specified design limits that accomplish this objective and alternative design limits proposed by vendors. Compliance with mHTGR-DC 10 significantly reduces the likelihood of significant reduction in coated particle fuel performance during normal operations or AOOs, thereby minimizing the possible release of fission products. In addition, preventing fuel performance degradation during normal operation and AOOs may also reduce the severity of reduced radiological barrier performance during an accident.

3. mHTGR-DC 26 requires that the reactivity control system be designed with margin to have a combined capability of reliably controlling reactivity changes. Reviews under Section 4.2 ensures that fuel system performance is never so degraded as to preclude control of reactivity when it is required. Maintaining the ability to insert reactivity control devices during DBEs/DBAs minimizes the challenge to fuel radiological barrier performance and thus reduces the potential amount of fission products that can released to the helium pressure boundary during design conditions.

4. mHTGR-DC 34 requires that a system be provided to transfer heat from the reactor vessel following loss of other core cooling capacities at a rate such that (1) fuel system components and associated radionuclide barriers continue to perform as required to maintain safety, and (2) reactor vessel and core geometries related to the cooling capability are maintained with performance degradation limited to negligible amounts. This section guides the review of coated particle fuel performance under all design conditions as well as related analysis and methods used to demonstrate compliance with mHTGR-DC 34. Application of mHTGR-DC 34 to coated particle fuel design ensures potential offsite radiological releases are minimized under all design conditions. 


\section{REVIEW PROCEDURES}

The reviewer will select material from the procedures described below as may be appropriate for a particular case.

These review procedures are based on the identified mHTGR-RP acceptance criteria. For deviations from these specific acceptance criteria, the staff should review the applicant's evaluation of how proposed alternatives provide an acceptable method of complying with the relevant NRC requirements identified in Subsection II.

1. For review of a DC application, the reviewer should follow the procedures to verify that the design, including requirements and restrictions (e.g., interface requirements and site parameters), set forth in the final safety analysis report (FSAR) meets the acceptance criteria. DCs have referred to the FSAR as the design control document (DCD). The reviewer should also consider the appropriateness of identified COL action items. The reviewer may identify additional COL action items; however, to ensure these COL action items are addressed during a COL application, they should be added to the DC FSAR. For review of a COL application, the scope of the review is dependent on whether the COL applicant references a DC, an early site permit (ESP) or other NRC approvals (e.g., manufacturing license, site suitability report or topical report).

2. For review of both DC and COL applications, mHTGR-RP Section 14.3 should be followed for the review of ITAAC. The review of ITAAC cannot be completed until after the completion of this section.

3. For construction permit (CP) applications, the review should ensure that the design bases set forth in the preliminary safety analysis report (PSAR) meet the acceptance criteria given in Subsection II.A. In addition, the CP review should determine, from a study of the preliminary fuel system design, that there is reasonable assurance that the final fuel system design will meet the design bases. This judgment may be based on experience with similar designs.

4. For operating license $(\mathrm{OL})$ applications, the review should confirm that the design bases set forth in the final safety analysis report (FSAR) meet the acceptance criteria given in Subsection II.A and that the final fuel system design meets the design bases.

Much of the fuel review is generic and not repeated for each similar plant utilizing TRISO-coated particle fuel of the same design and fuel fabrication specification. That is, the reviewer will not have to re-evaluate the TRISO-coated fuel design or certain aspects of fuel system design if done in previous PSARs, FSARs, and licensing topical reports. All previous reviews on which the current review depends should be referenced so that the plant safety evaluation report comprises a completely documented safety evaluation. In particular, the NRC safety evaluation reports for all relevant licensing topical reports should be cited. Staff in the organization responsible for reactor systems has also performed certain generic reviews, the findings of which have been issued as NUREG or WASH series reports. NUREG-1338 should be reviewed for modular HTGRs. Additional insights may also be contained in RG 1.25, RG 1.60 and $R G$ 1.183. Deviation from guidelines or established prior positions should be explained. After briefly discussing the related reviews, the plant safety evaluation should concentrate on those areas in which the application is not identical to those previously reviewed and approved as well as on areas related to newly discovered problems. 
Analytical predictions discussed in Subsection II.3.C will be reviewed in PSARs, FSARs, or licensing topical reports. The validity of analytical models used to predict the performance of fuel system design, and their applicability up to the fuel design limits should be reviewed. Coated particle fuel burnup and power limits should be specified for each fuel type used in the reactor and justified based as-fabricated fuel quality and material properties data, irradiation performance and accident condition performance and prototypic test results. An exception may be made for prototype fuel test assemblies, in which case only an estimate of the maximum temperature limit, burnup, fast fluence limit and power needs to be provided. When the methods are being reviewed, the staff may perform calculations to verify the adequacy of the analytical methods. Thereafter, audit calculations will not typically be performed to verify the results of an approved method that has been submitted in a safety analysis report. Calculations, benchmarking exercises, and additional reviews of generic methods, may be undertaken however, at any time a clear need arises to reconfirm the adequacy of the method.

\section{EVALUATION FINDINGS}

The reviewer verifies that the applicant has provided sufficient information and that the review and calculations (if applicable) support conclusions of the following type to be included in the staff's safety evaluation report. The reviewer also states the bases for those conclusions.

The staff concludes that the coated particle fuel system of the

has been designed so that (1) coated particle fuel performance will not be significantly diminished as a result of normal operation and anticipated operational occurrences, (2) fuel performance during DBEs/DBAs will not be adversely affected enough to preclude reactivity control when required, and (3) the fuel system will maintain acceptable levels of integrity and performance even after DBEs/DBAs, thereby meeting the requirements of mHTGR-DC 10, 27, and 34 as provided by RG XXX [TBD] for satisfying Appendix A to 10 CFR Part 50 requirements; and 10 CFR Part 100 (for existing reactors) or 10 CFR 50.34 (for new reactors) or 10 CFR 50.67 (as an alternative to 10 CFR Part 100 for existing reactors). This conclusion is based on the following:

1. The applicant has provided sufficient evidence that these design objectives will be met based on coated particle fuel manufacturing experience, operating experience, accident condition testing, prototype testing, and analytical predictions.

2. The applicant has provided for testing and inspection of new coated particle fuel to ensure that it is within design tolerances at the time of core loading. The applicant has made a commitment to perform online coated particle fuel performance monitoring and post-irradiation inspection and surveillance to detect anomalies or confirm that the fuel has performed as expected.

The staff concludes that the applicant has described methods of adequately predicting fuel system performance so that radioactivity releases are not underestimated and thereby meets the related requirements of 10 CFR Part 100 or 10 CFR 50.67 or 10 CFR 50.34 (for new reactors). In meeting these requirements, the applicant has (1) developed a plausible and conservative mechanistic source term concerning fission-product release and (2) performed 
the analysis for coated particle fuel and fuel system performance for bounding DBE/DBA conditions.

For DC and COL reviews, the findings will also summarize the staff's evaluation of requirements and restrictions (e.g., interface requirements and site parameters) and COL action items relevant to this $\mathrm{mHTGR}$-RP section.

In addition, to the extent that the review is not discussed in other SER sections, the findings will summarize the staff's evaluation of the ITAAC, including design acceptance criteria, as applicable.

\section{IMPLEMENTATION}

The staff will use this mHTGR-RP section in performing safety evaluations of DC applications and license applications submitted by applicants pursuant to 10 CFR Part 50 or 10 CFR Part 52. Except when the applicant proposes an acceptable alternative method for complying with specified portions of the Commission's regulations, the staff will use the method described herein to evaluate conformance with Commission regulations.

The provisions of this mHTGR-RP section apply to reviews of applications submitted six months or more after the date of issuance of this mHTGR-RP section, unless superseded by a later revision.

Implementation schedules for conformance to parts of the method discussed herein are contained in the referenced RGs and NUREGs.

\section{RESOURCES}

NOTE: THE FOLLOWING LIST IDENTIFIES THE PRINCIPAL RESOURCES USED IN DRAFTING THE INITIAL VERSION OF MHTGR-RP CHAPTER 4.2. ADDITIONAL REFERENCES SHOULD BE ADDED AS MHTGR-RP CHAPTER 4.2 IS FINALIZED.

1. NUREG 1338, "Draft Preapplication Safety Evaluation Report for the Modular HighTemperature Gas Cooled Reactor," (Draft) March 1989. (ML052780497)

2. NUREG 1338, "Preapplication Safety Evaluation Report for the Modular HighTemperature Gas-Cooled Reactor (MHTGR)," June 1995. (ML052780519)

3. INL/EXT-07-12967, Revision 1, "Next Generation Nuclear Plant Pre-Conceptual Design Report," November 2007

4. D. Petti, T. Abram, R. Hobbins, and J. Kendall, Updated NGNP Fuel Acquisition Strategy, INL/EXT-07-12441, Rev. 2, December 2101.

5. $\quad 10$ CFR Part 50, Appendix A, General Design Criterion 10, "Reactor Design."

6. $\quad 10$ CFR Part 100, "Reactor Site Criteria."

7. 10 CFR Part 50, Appendix A, General Design Criterion 27, "Combined Reactivity Control Systems Capability." 
8. DOE-HTGR-90257, Revision 0, "MHTGR Fuel Process and Quality Control Description," September 1991.

9. NUREG/CR-6844, "TRISO-Coated Particle Fuel Phenomena Identification and Ranking Tables (PIRTs) for Fission Product Transport Due to Manufacturing, Operations, and Accidents," July 2004.

10. 10 CFR Part 52, "Early Site Permits; Standard Design Certifications; and Combined Licenses for Nuclear Power Plants.

11. 10 CFR 50.34, "Contents of Applications; Technical Information."

12. R. L. Bratton, "Status of ASME Section III Task Group on Graphite Core Support Structures," INL/EXT-05-00552, August 2005.

13. 10 CFR 50, Appendix B, "Quality Assurance Criteria for Nuclear Power Plants and Fuel Reprocessing Plants."

14. 10 CFR 52.47, "Contents of Applications."

15. 10 CFR 52.80 (a), "Contents of Applications; additional technical information."

16. INL/EXT-10-17686, Revision 0, "NGNP Fuel Qualification White Paper," July 2010.

17. General Atomics Report GA-A25402, "H2-MHR Pre-Conceptual Design Report: THEBased Plant," April 2006.

18. IAEA-TECDOC-CD-1645, "High Temperature Gas Cooled Reactor Fuels and Materials," March 2010.

19. G. Miller et al., "Current Capabilities of the Fuel Performance Modeling Code PARFUME," INEEL/CON-04-02240, HTR-2004, September 2004.

20. INL/EXT-05-02615, "Development of Improved Models and Designs for Coated-Particle Gas Reactor Fuels," Final Report Under International Nuclear Energy Research Initiative (INERI), December 2004.

21. Regulatory Guide 1.60, "Design Response Spectra for Seismic Design of Nuclear Power Plants."

22. Regulatory Guide 1.182, "Assessing and Managing Risk Before Maintenance Activities at Nuclear Power Plants."

23. Regulatory Guide 1.206, "Combined License Applications for Nuclear Power Plants."

24. Regulatory Guide 1.68, "Initial Startup Test Program To Demonstrate Remote Shutdown Capability For Water-Cooled Nuclear Power Plants."

25. Regulatory Guide 1.215, "Guidance For ITAAC Closure Under 10 CFR Part 52." 
26. Regulatory Guide 1.196, "Control Room Habitability at Light-Water Nuclear Power Reactors."

27. Regulatory Guide 1.25, "Assumptions Used for Evaluating the Potential Radiological Consequences of a Fuel Handling Accident in the Fuel Handling and Storage Facility for Boiling and Pressurized Water Reactors."

28. NUREG-75/077, "The Role of Fission Gas Release in Reactor Licensing," November 1975.

29. INL/EXT-10-18610, "NGNP Fuel Qualification White Paper," Next Generation Nuclear Plant Project, Idaho National Laboratory, July 2010.

30. INL/EXT-10-17997, "Mechanistic Source Terms White Paper," Next Generation Nuclear Plant Project, Idaho National Laboratory, July 2010.

31. NRC, "Assessment of White Paper Submittals on Fuel Qualification and Mechanistic Source Terms, Revision 1," Next Generation Nuclear Plant Project 0748, ML14174A845, July 17, 2014.

32. INL/EXT-13-30872, "Modular High Temperature Gas-Cooled Reactor Safety Basis and Approach," Next Generation Nuclear Plant Project, Idaho National Laboratory, January 2014. 


\section{MODULAR HIGH TEMPERATURE GAS- COOLED REACTOR REVIEW PLAN}

\subsection{NUCLEAR DESIGN \\ REVIEW RESPONSIBILITIES}

Primary - Organization responsible for the review of the assessment of reactor physics, neutronics, and nuclear design

Secondary - None

\section{AREAS OF REVIEW}

The review of the nuclear design of the coated particle fuel blocks (or pebbles), control systems, and reactor core is carried out to aid in confirming that specified acceptable core radionuclide release design limits will not be exceeded during normal operation or anticipated operational transients and that the effects of evaluated reactivity accidents will not cause significant damage to the reactor helium pressure boundary or impair the capability to cool the core and to assure conformance with the requirements of modular High-Temperature Gas-Cooled Reactor (HTGR) Design Criteria (mHTGR-DC) 10, 11, 12, 13, 20, 25, 26, 27, and 28, which are reflected in Draft Regulatory Guide DG-1330 (Proposed New Regulatory Guide 1.232) as guidance for complying with the requirements of 10 CFR Part 50, Appendix A General Design Criteria (GDC) 10, 11, 12, $13,20,25,26,27$, and 28.

The specific areas of review are as follows:

1. Confirmation that design bases are established as required by the appropriate mHTGRDC.

2. The areas concerning core power distribution, including the following:

A. The presentation of expected power distributions including normal and extreme cases for steady-state and allowed load-follow transients and covering a full range of reactor conditions of time in cycle, allowed control rod positions, and possible fuel burnup distributions (including the effects of continuous pebble bed fuel reloading). Predictions and calculations, by the applicant, are needed and required by the staff.

B. The presentation of the core power distributions as axial, radial, and local distributions and peaking factors to be used in the transient and accident analyses. Power distributions within graphite fuel elements is also required. The effects of any phenomena that can affect coated particle fuel fission product retention performance should be included in these distributions and factors.

Comment [A163]: This text anticipates the NRC RG for advanced reactor design criteria and subsequent mHTGR-DC (proposed RG 1.232). The current markup reflects the proposed language in Draft RG-1330.

$(4.3-1$ 
C. The translation of the design power distributions into operating power distributions, including instrument-calculation correlations; operating procedures and measurements; and necessary limits on these operations.

D. The requirements for instruments, the calibration and calculations involved in their use, and the uncertainties involved in translation of instrument readings into power distributions.

E. Limits and setpoints for actions, alarms, or scram for the instrument systems and demonstration that these systems can maintain the reactor within design power distribution limits.

F. Measurements in previous reactors and critical experiments and their use in the uncertainty analyses and the measurements to be made on the reactor under review, including startup confirmatory tests and periodically required measurements.

G. The translation of design limits, uncertainties, operating limits, instrument requirements, and setpoints into technical specifications.

3. The areas concerning reactivity coefficients. These are:

A. The applicant's presentation of calculated nominal values for the reactivity coefficients, such as the moderator coefficient, which takes the form of a temperature coefficient; the Doppler coefficient; and power coefficients. The range of reactor states to be covered includes the entire operating range from cold shutdown through full power and the extremes reached in transient and accident analyses. It includes the extremes of time in cycle and an appropriate range of control rod insertions for the reactor states. The applicant needs to demonstrate that the coefficients used are conservative. The applicant should provide information on reactivity coefficients in the form of curves covering the full applicable range of the variables.

B. The applicant's presentation of uncertainty analyses for nominal values, including the magnitude of the uncertainty and the justification of the magnitude by examination of the accuracy of the methods used in calculations, and comparison where possible with reactor experiments. For comparisons to experiments, it is important for the applicant to show that the experiments are applicable and relevant.

C. The applicant's combination of nominal values and uncertainties to provide suitably conservative values for use in reactor steady-state analysis, stability analyses, and the transient and accident analyses presented in SAR Chapter 15.

4. The areas concerning reactivity control requirements and control provisions. These are:

A. The control requirements and provisions for control necessary to compensate for long-term reactivity changes of the core. These reactivity changes occur because of depletion of the fissile material in the fuel, depletion of burnable poisons, and buildup of fission products and transuranic isotopes. 
B. The control requirements and provisions for control needed to compensate for the reactivity change caused by changing the temperature of the reactor from the hot zero power condition to the safe shutdown condition.

C. The control requirements and provisions for control needed to compensate for the reactivity effects caused by changing the reactor power level from full power to zero power.

D. The applicant needs to provide tables and discussions on control requirements and provisions at beginning of life (BOL), end of life (EOL), and intermediate times during the fuel cycle.

E. The control requirements and provisions for control needed to compensate for the effects on the power distribution and stability of the high cross-section neutron capture of the fission product nuclide xenon-135.

F. The adequacy of the control systems to assure that the reactor can be returned to and maintained in the cold shutdown condition at any time during operation. The applicant shall discuss shutdown margins (SDM). Shutdown margins need to be demonstrated by the applicant throughout the fuel cycle.

G. The applicant's analysis and experimental basis for determining the reactivity worth of a stuck control rod of highest worth and margins for stuck rods.

H. Uncertainties associated with the control rods needs to be considered, including:

i. Manufacturing tolerances

ii. Methods errors

iii. Operation other than planned

iv. Control element absorber depletion

v. Measurement uncertainty in shutdown margin demonstration

I. The provision of two independent control systems.

5. The areas of control rod patterns and reactivity worths. These are:

A. Descriptions and figures indicating the control rod patterns expected to be used throughout a fuel cycle. This includes operation of single rods or of groups, or banks of rods, rod withdrawal order, and insertion limits as a function of power and core life.

B. Descriptions of allowable deviations from the patterns indicated above, such as for misaligned rods, stuck rods, or rod positions used for spatial power shaping.

C. Descriptions, tables, and figures of the maximum worths of individual rods or banks as a function of position for power and cycle life conditions appropriate to rod withdrawal transients and rod ejection accidents. Descriptions and curves of maximum rates of reactivity increase associated with rod withdrawals, experimental confirmation of rod worths or other factors justifying the reactivity increase rates used in control rod accident analyses, and equipment,
Comment [A164]: Changed from cold to safe based on stakeholder feedback. However, this is not a universal change because cold shutdown has additional implications. 
administrative procedures, and alarms which may be employed to restrict potential rod worths should be included.

D. Descriptions and graphs of scram reactivity as a function of time after scram initiation and other pertinent parameters, including methods for calculating the scram reactivity.

6. The area of criticality of the reactor during refueling. Discussions and tables giving values of $k_{\text {eff }}$ for single fuel blocks and groups of adjacent fuel blocks up to the number required for criticality. The applicant needs to describe the basis for assuming that the maximum stated $\mathrm{k}_{\mathrm{eff}}$ will not be exceeded.

7. The areas concerning stability. These are:

A. As per [TBD], phenomena and reactor aspects that influence the stability of the nuclear reactor will be discussed by the applicant.

B. Calculations and considerations given to xenon-induced spatial oscillations.

C. Potential stability issues due to other phenomena or conditions, as presented by the applicant.

D. Verification of the analytical methods for comparison with measured data.

8. The areas concerning analytical methods. These are:

A. Descriptions of the analytical methods used in the nuclear design, including those for predicting criticality, reactivity coefficients, burnup, and stability.

B. The database and/or nuclear data libraries used for neutron cross-section data and other nuclear parameters, including delayed neutron and photoneutron data and other relevant data.

C. Verification of the analytical methods for comparison with measured data.

9. The areas concerning reactor vessel irradiation. These are:

A. Neutron flux spectrum above 1 million electron volts (MeV) in the core, at the core boundaries, and at the inside reactor vessel wall.

B. Assumptions used in the calculations, these include the power level, the use factor, the type of fuel cycle considered, and the design life of the vessel.

C. Computer codes used in the analysis.

D. The database for fast neutron cross-sections.

E. The geometric modeling of the reactor, reactor internals, and reactor vessel.

F. Uncertainties in the calculation.

Comment [A165]: It does not appear that this item applies to pebble bed cores; that design does not have a discrete refueling operation. A mix of fresh pebbles are constantly added over time. Core powe variations caused by a mix of fresh and partiallyexpended fuel pebbles would be addressed by review item 2.A (see page 4.3-2).

Comment [A166]: Applicability of specific sections, parts, and revisions of Codes and Standards must be determined. 
10. Inspections, Tests, Analyses, and Acceptance Criteria (ITAAC). For design certification (DC) and combined license (COL) reviews, the staff reviews the applicant's proposed ITAAC associated with the structures, systems, and components (SSCs) related to this mHTGR-RP section in accordance with mHTGR-RP Section 14.3, "Inspections, Tests, Analyses, and Acceptance Criteria." The staff recognizes that the review of ITAAC cannot be completed until after the rest of this portion of the application has been reviewed against acceptance criteria contained in this mHTGR-RP section.

Furthermore, the staff reviews the ITAAC to ensure that all SSCs in this area of review are identified and addressed as appropriate in accordance with mHTGR-RP Section 14.3.

11. COL Action Items and Certification Requirements and Restrictions. For a DC application, the review will also address COL action items and requirements and restrictions (e.g., interface requirements and site parameters).

For a COL application referencing a DC, a COL applicant must address COL action items (referred to as COL license information in certain DCs) included in the referenced DC. Additionally, a COL applicant must address requirements and restrictions (e.g., interface requirements and site parameters) included in the referenced DC.

\section{$\underline{\text { Review Interfaces }}$}

Other mHTGR-RP sections interface with this section as follows:

1. The organization responsible for the review/assessment of nuclear design reviews the thermal, mechanical, and materials design of the fuel system as part of its review responsibility for $\mathrm{mHTGR}-\mathrm{RP}$ Section 4.2 .

2. The organization responsible for the review/assessment of nuclear design reviews thermal margins, adequacies of power distribution limits, the effects of dust, and the acceptability of fluid and structural loads as part of its review responsibility for mHTGRRP Section 4.4 .

3. The organization responsible for the review/assessment of nuclear design verifies that the Reserve Shutdown System meets reactivity control requirements for anticipated transients without scram (ATWS) as part of its primary review responsibility for $\mathrm{mHTGR}$ RP Sections 9.3.5 and 15.8.

4. The organization responsible for the review/assessment of nuclear design reviews coated particle fuel performance as part of its responsibilities in mHTGR-RP Chapter 15.

5. The organization responsible for the review/assessment of nuclear design verifies compliance with requirements applicable to reactivity accidents (mHTGR-DC 28) as part of its review responsibility for mHTGR-RP Sections 15.4.8 and 15.4.9.

In addition, the organization responsible for the review/assessment of nuclear design will coordinate with other organization's evaluations that interface with the overall review of the system as follows:

1. The organization responsible for materials and chemical engineering reviews the neutron-induced embrittlement of the reactor vessel materials as part of its review responsibility for mHTGR-RP Sections 5.3.1 and 5.3.2. 
2. The organization responsible for instrumentation and control (I\&C) reviews the adequacy of proposed instrumentation to meet the requirements for maintaining the reactor operating within defined limits as part of its review responsibility for mHTGR-RP Sections 7.1 through 7.6.

3. The organization responsible for nuclear plant systems verifies that the new fuel will be maintained in a subcritical status during all credible conditions as part of its review responsibility for $\mathrm{mHTGR}$-RP Section 9.1.1.

The specific acceptance criteria and review procedures are contained in the referenced mHTGR-RP sections.

\section{II. $\quad$ ACCEPTANCE CRITERIA}

\section{$\underline{\text { Requirements }}$}

Acceptance criteria are based on meeting the relevant requirements of the following Commission regulations:

1. mHTGR-DC 10 requires that acceptable core radionuclide release design limits be specified that are not to be exceeded during normal operation, including the effects of anticipated operational occurrences.

2. mHTGR-DC 11 requires that, in the power operating range, the prompt inherent nuclear feedback characteristics tends to compensate for a rapid increase in reactivity.

3. mHTGR-DC 12 requires that power oscillations that could result in conditions exceeding specified acceptable core radionuclide release design limits are not possible or can be reliably and readily detected and suppressed.

4. mHTGR-DC 13 requires provision of instrumentation and controls (I\&C) to monitor variables and systems over their anticipated ranges for normal operation, for anticipated operational occurrences, and for design basis event/design basis accident (DBE/DBA) conditions, as appropriate to ensure adequate safety, including those variables and systems that can affect the fission process, the integrity of the reactor core, the primary coolant boundary, and the containment and its associated systems. Appropriate controls are required to maintain these variables and systems within prescribed operating ranges.

5. mHTGR-DC 20 requires automatic initiation of the reactivity control systems (RCSs) to assure that specified acceptable core radionuclide release design limits are not exceeded as a result of anticipated operational occurrences and to assure automatic operation of systems and components important to safety occurs under accident conditions.

6. mHTGR-DC 25 requires that specified acceptable core radionuclide release design limits are not exceeded during any anticipated operational occurrence accounting for a single malfunction of the reactivity control systems.

Comment [A169]: Revised to reflect the mHTGR-DC 25 requirements contained in DG1330.

7. $\mathrm{mHTGR}-\mathrm{DC} 26$ requires that the RCS have redundancy and the capability to provide (1) a means of shutting down the reactor to ensure that, under conditions of normal operation, including abnormal operational occurrences, and with appropriate margin for malfunctions, design limits for fission product barriers are not exceeded, (2) a means of shutting down the reactor and maintaining a safe shutdown under design-basis event 
conditions, with appropriate margin for malfunctions, and a second means of reactivity control that is independent, diverse, and capable of achieving and maintaining safe shutdown under design-basis event conditions, and (3) a system for holding the reactor subcritical under cold conditions.

8. mHTGR-DC 28 requires that the effects of evaluated reactivity accidents neither result in damage to the reactor helium pressure boundary greater than limited local yielding, nor sufficiently disturb the core, its support structures or other reactor vessel internals to impair significantly the capability to cool the core.

9. $\quad 10$ CFR 52.47(b)(1), which requires that a DC application contain the proposed inspections, tests, analyses, and acceptance criteria (ITAAC) that are necessary and sufficient to provide reasonable assurance that, if the inspections, tests, and analyses are performed and the acceptance criteria met, a plant that incorporates the design certification is built and will operate in accordance with the design certification, the provisions of the Atomic Energy Act, and the NRC's regulations;

10. 10 CFR 52.80(a), which requires that a COL application contain the proposed inspections, tests, and analyses, including those applicable to emergency planning, that the licensee shall perform, and the acceptance criteria that are necessary and sufficient to provide reasonable assurance that, if the inspections, tests, and analyses are performed and the acceptance criteria met, the facility has been constructed and will operate in conformity with the combined license, the provisions of the Atomic Energy Act, and the NRC's regulations.

\section{mHTGR-RP Acceptance Criteria}

Specific mHTGR-RP acceptance criteria acceptable to meet the relevant requirements of the NRC's regulations identified above are as follows for review described in this $\mathrm{mHTGR}-\mathrm{RP}$ section. The mHTGR-RP is not a substitute for the NRC's regulations, and compliance with it is not required. However, an applicant is required to identify differences between the design features, analytical techniques, and procedural measures proposed for its facility and the mHTGR-RP acceptance criteria and evaluate how the proposed alternatives to the mHTGR-RP acceptance criteria provide acceptable methods of compliance with the NRC regulations.

The following discussion presents less formal criteria and guidelines used in the review of the nuclear design for meeting the relevant requirements of the mHTGR-DCs identified above.

1. There are no direct or explicit criteria for the power densities and power distributions allowed during (and at the limits of) normal operation, either steady-state or loadfollowing. These limits are determined from an integrated consideration of fuel limits (SAR Section 4.2), thermal limits (SAR Section 4.4), scram limits (SAR Chapter 7), and transient and accident analyses (SAR Chapter 15). The design limits for power densities (and thus for peaking factors) during normal operation should be such that specified acceptable core radionuclide release design limits are not exceeded during anticipated transients and that other limits are not exceeded during DBEs/DBAs. The limiting power distributions are then determined such that the limits on power densities and peaking factors can be maintained in operation. These limiting power distributions may be maintained (i.e., not exceeded) administratively (i.e., not by automatic scrams), provided a suitable demonstration is made that sufficient, properly translated information and alarms are available from the reactor instrumentation to keep the operator informed.

The acceptance criteria in the area of power distribution are that the information presented should satisfactorily demonstrate that:
Comment [A170]: Revised to reflect the mHTGR-DC 26 requirements contained in DG1330. Reference to mHTGR DC 27 is deleted.

Comment [A171]: Revised to reflect the mHTGR-DC 28 requirements contained in DG1330. 
A. A reasonable probability exists that the proposed design limits can be met within the expected operational range of the reactor, taking into account the analytical methods and data for the design calculations; uncertainty analyses and experimental comparisons presented for the design calculations; the sufficiency of design cases calculated covering times in cycle, rod positions, load-follow transients, etc.; and special problems such as power spikes due to possible asymmetries, misaligned rods, or other modular HTGR-related phenomena.

B. A reasonable probability exists that in normal operation the design limits will not be exceeded, based on consideration of information received from the power distribution monitoring instrumentation; the processing of that information, including calculations involved in the processing; the requirements for periodic check measurements; the accuracy of design calculations used in developing correlations when primary variables are not directly measured; the uncertainty analyses for the information and processing system; and the instrumentation alarms for the limits of normal operation (e.g., offset limits, control bank limits) and for abnormal situations (e.g., tilt alarms for control rod misalignment).

Criteria for acceptable values and uses of uncertainties in operation, instrumentation numerical requirements, limit settings for alarms or scram frequency and extent of power distribution measurements, and use of ex-core and in-core instruments and related correlations and limits for offsets and tilts, all vary with reactor type. They can be found in staff safety evaluation reports and in appropriate sections of the technical specifications and accompanying bases for reactors similar to the reactor under review.

Generally, special or newly emphasized problems related to core power distributions will not be a direct part of normal reviews but will be handled in special generic reviews. The use of uncertainties in design limits is an example of this area.

2. The only directly applicable mHTGR-DC in the area of reactivity coefficients is mHTGRDC 11, which states "...the net effect of the prompt inherent nuclear feedback characteristics tend to compensate for a rapid increase in reactivity," and is considered to be satisfied by the existence of the Doppler and negative power coefficients.

The acceptability of the coefficients in a particular case is determined in the reviews of the analyses in which they are used, e.g., control requirement analyses, stability analyses, and transient and accident analyses. The use of spatial effects such as weighting approximations as appropriate for individual transients are included in the analysis reviews. The judgement to be made under this mHTGR-RP section is whether the reactivity coefficients have been assigned suitably conservative values by the applicant. The basis for that judgment includes the use to be made of a coefficient, i.e., the analyses in which it is important; the state of the art for calculation of the coefficient; the uncertainty associated with such calculations, experimental checks of the coefficient in operating reactors; and any required checks of the coefficient in the startup program of the reactor under review.

3. Acceptance criteria relative to control rod patterns and reactivity worths include:

A. The predicted control rod worths and reactivity insertion rates must be reasonable bounds to values that may occur in the reactor. These values are used in the transient and accident analyses and judgment as to the adequacy of the uncertainty allowances are made in the review of the transient and accident analyses. 
B. Equipment, operating limits, and procedures necessary to restrict potential rod worths or reactivity insertion rates should be shown to be capable of performing these functions. It is a position of the organization responsible for the review/assessment of nuclear design to require, where feasible, an alarm when any limit or restriction is violated or is about to be violated.

4. There are no specific criteria that must be met by the analytical methods or data that are used by an applicant or reactor vendor. In general, the analytical methods and database should be representative of the state of the art, and the experiments used to validate the analytical methods should be adequate representations of fuel designs in the reactor and encompass a sufficient range of variables and operating conditions.

\section{Technical Rationale}

The technical rationale for application of these acceptance criteria to the areas of review addressed by this mHTGR-RP section is discussed in the following paragraphs:

1. mHTGR-DC 10 requires that acceptable core radionuclide release design limits be specified that are not to be exceeded during normal operation, including the effects of anticipated operational occurrences. The reactor core's nuclear design is one of several key design aspects that ensure fuel design limits will not be exceeded during normal operations. Compliance with mHTGR-DC 10 significantly reduces the likelihood of fuel failures occurring during normal operations, including anticipated operational occurrences, thereby minimizing the possible release of fission products to the environment.

2. mHTGR-DC 11 requires that the net effect of prompt inherent nuclear feedback characteristics in the core tends to compensate for rapid increases in reactivity when operating in the power range. The nuclear design of the reactor core establishes the various reactivity coefficient values that produce the desired feedback characteristics. Compliance with mHTGR-DC 11 causes the reactor core to be inherently safe during power range operations, thus eliminating the possibility of an uncontrolled nuclear excursion.

3. mHTGR-DC 12 requires that the reactor core, control, and protection systems be designed to ensure that power oscillations that result in conditions exceeding specified acceptable core radionuclide release design limits are not possible, or can be reliably and readily detected and suppressed. Power oscillations within the reactor core may result from conditions such as improper fuel design or loading or improper reactivity control including control rod positioning.

The occurrence of power oscillations can lead to excessive localized power peaking or cyclic thermal fatigue, and may cause core radionuclide release design limits to be exceeded. Compliance with mHTGR-DC 12 provided assurance that the nuclear design of the reactor core will prevent power oscillations that could challenge the integrity of the fuel and cause the possible release of fission products to the environment.

4. $\mathrm{mHTGR}-\mathrm{DC} 13$ requires that I\&C be provided to monitor variables and systems that can affect the fission process over normal operating ranges, anticipated operational occurrences, and DBE/DBA conditions, and to maintain the variables and systems within the prescribed operating ranges. The nuclear design review includes verification that instrumentation and systems, along with the data processing systems and alarms, will reasonably assure maintenance of core power distributions within specified design limits. 
Compliance with mHTGR-DC 13 provides assurance that I\&C systems can adequately monitor changes in core reactivity and maintain variables that affect core reactivity within designed operating ranges, thus minimizing the possibility of an adverse transient affecting the integrity of the coated particle fuel.

5. mHTGR-DC 20 requires automatic initiation of the RCSs to assure that specified acceptable core radionuclide core design limits are not exceeded as a result of anticipated operational occurrences and to assure automatic operation of systems and components important to safety under DBE/DBA conditions. Review of the nuclear design verifies the adequacy of control systems and setpoints necessary to shut down the reactor at any time during operation. The automatic initiation of control systems during a reactor transient supports adherence with acceptable core radionuclide design limits and, in the early stages of a reactor accident, will minimize the impacts on the coated particle fuel fission product retention performance, thus reducing the release of fission products to the helium coolant system and possibly the environment.

6. mHTGR-DC 25 requires specified acceptable core radionuclide release design limits are not exceeded during any anticipated operational occurrence accounting for a single malfunction of the RCS. The nuclear design review includes verification that no single malfunction of the RCS can causes the core radionuclide release design limits to be exceeded. Meeting the requirements of $\mathrm{mHTGR}-\mathrm{DC} 25$ significantly reduces the possibility that a malfunction in the RCS would affect particle fuel fission product retention performance.

7. $\mathrm{mHTGR}-\mathrm{DC} 26$ requires that the RCS can reliably control core reactivity and shut down the reactor to ensure that design limits for fission product barriers are not exceeded under conditions of normal operation, including anticipated operational occurrences, with appropriate margin for malfunctions. Review of the nuclear design verifies that the RCS can hold the core subcritical under cold conditions. Compliance with mHTGR-DC 26 provides assurance that core reactivity can be safely controlled and that sufficient negative reactivity exists to maintain the core subcritical under cold conditions, thus minimizing the impacts on coated particle fuel fission product retention performance and the likelihood of subsequent release of fission products.

8. $\mathrm{mHTGR}-\mathrm{DC} 26$ also requires that, under DBE/DBA conditions, the safe shutdown condition can be maintained with appropriate margin for stuck rods. A second independent and diverse means of reactivity control is also required to maintain safe shutdown under design-basis event conditions, again with appropriate margin for malfunctions.. The nuclear design review verifies that the RCSs provide a movable control rod system and a liquid poison addition system and that the core has sufficient shutdown margin assuming a stuck rod. Meeting the requirements of mHTGR-DC 26 provides assurance that the RCS will be designed such that impacts on particle fuel fission product retention performance in the event of an accident will be minimized.

9. $\quad \mathrm{mHTGR}-\mathrm{DC} 28$ requires that the effects of evaluated reactivity insertion accidents not result in damage to the helium pressure boundary or cause sufficient damage to impair the capability to cool the core. This MHTGR-RP section reviews the reactivity coefficients and rod worths assumed in the analysis of reactivity insertion events in Chapter 15 of the mHTGR-RP. Compliance with mHTGR-DC 28 provides assurance that the helium pressure boundary that minimizes the release of fission products to the environment will not be damaged in the event of a reactivity insertion accident were to occur and that core cooling will not be prevented by the structural collapse of fuel in the core.
Comment [A172]: Revised per DG-1330.

Comment [A173]: Revised per DG-1330. AOO provisions.

Comment [A174]: Revised per DG-1330. DBE/DBA provisions. 


\section{REVIEW PROCEDURES}

The reviewer will select material from the procedures described below, as appropriate.

These review procedures are based on the identified mHTGR-RP acceptance criteria. For deviations from these specific acceptance criteria, the staff should review the applicant's evaluation of how the proposed alternatives provide an acceptable method of complying with the relevant NRC requirements identified in Subsection II.

The review procedures below apply in general to the COL which supersedes the earlier sequential construction permit $(\mathrm{CP})$ and operating license $(\mathrm{OL})$ stage reviews. At the CP stage, parameter values and certain design aspects may be preliminary and subject to change. At the OL stage, final values of parameters should be used in the analysis presented in the SAR. The review of the nuclear design of a plant is based on the information provided by the applicant in the SAR, as amended, and in meetings and discussions with the applicant and the applicant's contractors and consultants. This review in some cases will be supplemented by independent calculations performed by the staff or staff consultants. Files of audit calculations are maintained by the organization responsible for the review/assessment of nuclear design for reference by the reviewer.

For DC and COL applications submitted under Part 52, the level of information reviewed should be consistent with that of a FSAR submitted in an OL application. However, verification that the as-built facility conforms to the approved design is performed through the ITAAC process.

1. The reviewer confirms, as part of the review of specific areas of the nuclear design outlined below, that the design bases, design features, and design limits are established in conformance with the mHTGR-DCs listed in Subsection II of this mHTGR-RP section.

2. The reviewer examines the information presented in the SAR to determine that the core power distributions for the reactor can reasonably be expected to fall within the design limits throughout all normal (steady-state and load-follow) operations, and that the instrument systems employed, along with the information processing systems and alarms, will reasonably assure the maintenance of the distributions within these limits for normal operation.

The review examines the calculation of effective delayed neutron fraction $\left(\beta_{\text {eff }}\right)$ and prompt neutron lifetime $\left(1^{*}\right)$ and verifies that appropriate values are used in the reactivity accidents reviewed under mHTGR-RP Sections 15.4.8 and 15.4.9. Regulatory Guide 1.77 provides guidance for calculating effective delayed neutron fraction and prompt neutron lifetime values. The applicant should use spatially dependent methods. It is necessary to ensure that the methods are appropriate and that the cross-section date and other parameters used as input are appropriately parameterized. [TBD] provides further guidance and additional relevant information to the applicant.

For a normal review, many areas related to core power distribution may have been examined in generic reviews or earlier reviews of reactors with generally similar core characteristics and instrument systems. A large part of the review on a particular case may then involve comparisons with information from previous application reviews. The comparisons may involve the shapes and peaking factors of normal and limiting distributions over the range of operating states of the reactor, the effects of power spikes and related factors that may affect coated particle fuel fission product retention, assigned uncertainties and their use, calculation methods and data used, correlations used in control processes, instrumentation requirements, information processing methods,

Comment [A175]: Universal need to adjust to reflect appropriate interfaces.

Comment [A176]: This regulatory guide is specifically for LWRs, but this reference points to guidance in Appendix A that may still be useful to modular HTGR. Other references should be identified if possible.

Comment [A177]: Applicability of specific sections, parts, and revisions of Codes and Standards must be determined. 
including computer use setpoints for operational limits and alarm limits, and alarm limits for abnormalities such as flux asymmetries.

An important part of this review, focusing on considerations of operations, covers the relevant sections of the proposed technical specifications where power distributions and related controls such as control rod limits are discussed. Here the instrument requirements, limit settings, and measurement frequencies and requirements are set forth in full detail. The comparison of technical specifications should reveal any differences between essentially identical reactors or any lack of difference between reactors with changed core characteristics. Where these occur the reviewer must assess the significance and validity of the differences or lack of differences. This review and comparison may be supplemented with examinations of related topical reports from reactor vendors, generic studies by staff consultants, and startup reports from operating reactors which contain information on measured power distributions.

3. Some vendor codes do not use reactivity coefficients. When they are used, the reviewer determines from the applicant's presentations that suitably conservative reactivity coefficients have been developed for use in reactor analyses such as those for control requirements, stability, and transients and accidents. The reviewer examines:

A. The applicability and accuracy of methods used for calculations including the use of more accurate check calculations.

B. The models involved in the calculations, such as the model used for effective fuel temperature in Doppler coefficient analyses.

C. The reactor state conditions assumed in determining values of the coefficients.

D. The applicability and accuracy of experimental data from critical experiments and operating reactors used to determine or justify uncertainty allowances. As part of the review, comparisons are made between the values and uncertainty allowances for reactivity coefficients for the reactor under review and those for similar reactors previously reviewed and approved. Generally, many essential areas will have been covered during earlier reviews of similar reactors. The reviewer notes any differences in results for essentially identical reactors and any lack of differences for reactors with changed core characteristics, and judges the significance and validity of any differences or lack of differences.

E. The appropriateness of reactivity coefficients used in evaluating reactivity accidents reviewed under mHTGR-RP Sections 15.4.8 and 15.4.9.

4. The review procedures in the area of reactivity control requirements and control provisions are as follows:

A. The reviewer determines that independent RCSs of different design are provided.

B. The reviewer examines the tabulation of control requirements, the associated uncertainties, and the capability of the control systems, and determines by inspection and study of the analyses and experimental data that the values are realistic and conservative.

C. The reviewer determines that one of the control systems is capable of returning the reactor to the cold shutdown condition and maintaining it in this condition at any time in the cycle. It is necessary that proper allowance must be made for all 
of the mechanisms that change the reactivity of the core as the reactor is taken from the cold shutdown state to the hot full-power operating state. The reviewer should determine that proper allowance is made for the decrease in fuel temperature and moderator temperature as the reactor goes from the power operating range to cold shutdown.

D. The reviewer determines that one of the control systems is capable of rapidly returning the reactor to the hot standby (shutdown) condition from any power level at any time in the cycle. Typically, this requirement is met by rapid insertion of control rods. Proper allowance for the highest worth control rod being stuck in the full-out position must be made. The reviewer must pay particular attention to the proposed rod insertion limits in the power operating range, to assure that the control rods are capable of rapidly reducing the power and maintaining the reactor in the hot standby condition.

E. The reviewer determines that each of the independent RCSs is capable of controlling the reactivity changes resulting from planned, normal power operation. This determination is made by comparing the rate of reactivity change resulting from planned, normal operation to the capabilities of each of the control systems. Sufficient margin must exist to allow for the uncertainties in the rate.

5. The review procedures in the area of control rod patterns and reactivity worths are:

A. The reviewer determines by inspection and study of the information described in Subsection I.5 of this mHTGR-RP section that the control rod and bank worths are reasonable. This determination involves evaluation of the appropriateness of the analytical models used, the applicability of experimental data used to validate the models, and the applicability of generic positions or those established in previous reviews of similar reactors.

B. The reviewer determines the equipment, operating restrictions, and administrative procedures that are required to restrict possible control rod and bank reactivity worths, and the extent to which the alarm criterion in Subsection II.3.B of this mHTGR-RP section is satisfied. If the equipment involved is subject to frequent downtime, the reviewer must determine if alternative measures should be provided or the extent of proposed outage time is acceptable.

C. The reviewer will employ the same procedures as in item 5.A, above, to evaluate the scram reactivity information described in Subsection 1.5 of this $\mathrm{mHTGR}-\mathrm{RP}$ section. The scram reactivity is a property of the reactor design and is not easily changed, but if restrictions are necessary the procedures in item 5.B, above, can be followed as applicable.

D. The reviewer confirms the appropriateness of control rod reactivity worths used in the reactivity accident analyses reviewed under mHTGR-RP Sections 15.4.8 and 15.4 .9

6. The information presented on criticality of fuel assemblies is reviewed in the context of the applicant's physics calculations and the ability to calculate criticality of a small number of fuel assemblies.

7. The reviewer exercises professional judgment and experience to ascertain the following about the applicant's analytical methods: 
A. The computer codes used in the nuclear design are described in sufficient detail to enable the reviewer to establish that the theoretical bases, assumptions, and numerical approximations for a given code reflect the current state of the art.

B. The source of the neutron cross-sections used in fast and thermal spectrum calculations is described in sufficient detail so that the reviewer can confirm that the cross-sections are comparable to those in acceptable sources for modular HTGRs. If modifications and normalization of the cross-section data have been made, the bases used must be determined to be acceptable.

C. The procedures used to generate problem-dependent cross-section sets are given in sufficient detail so that the reviewer can establish that they reflect the state of the art. The reviewer confirms that the methods used for the following calculations are of acceptable accuracy: the fast neutron spectrum calculation; the computation of the uranium-238 resonance integral and correlation with experimental data; the computation of resonance integrals for other isotopes as appropriate (for example, plutonium-240); calculation of the Dancoff correction factor for a given fuel lattice; the thermal neutron spectrum calculation; the lattice cell calculations, including fuel rods, control assemblies, lumped burnable poison rods, fuel assemblies, and groups of fuel assemblies, and calculations of fuel and burnable poison depletion and buildup of fission products and transuranium isotopes.

D. The gross spatial flux calculations that are used in the nuclear design are discussed in sufficient detail so that the reviewer can confirm that the following items are adequate to produce results of acceptable accuracy: the method of calculation (e.g., diffusion theory, $\mathrm{S}_{\mathrm{n}}$ transport theory, Monte Carlo, synthesis); the number of energy groups used; the number of spatial dimensions $(1,2$, or 3$)$ used; the number of spatial mesh intervals, when applicable; and the type of boundary conditions used, when applicable.

E. The calculation of power oscillations and stability indices for diametral xenon reactivity transients, axial xenon reactivity transients, other possible xenon reactivity transients, and non-xenon-induced reactivity transients are discussed in sufficient detail so that the reviewer can confirm for each item that the method of calculation (e.g., nodal analysis, diffusion theory, transport theory, synthesis) and the number of spatial dimensions used $(1,2$, or 3$)$ are acceptable.

F. Verification of the database, computer codes, and analysis procedures has been made by comparing calculated results with measurements obtained from critical experiments and operating reactors. The reviewer ascertains that the comparisons cover an adequate range for each item and that the conclusions of the applicant are acceptable.

8. The analysis of neutron irradiation of the reactor vessel may be used in two ways. It may provide the design basis for establishing the vessel material nil-ductility transition temperature as a function of the neutron fluence. Neutron fluence is the time integrated neutron fluence rate (i.e. neutron flux) as expressed in neutrons per square centimeter. Neutron fluence is often represented by the somewhat archaic term "nvt," where " $n$ " is the neutron density, " $v$ " is the velocity, and "t" is the time interval. Or, it may provide the relative flux spectra at various positions between the reactor vessel and the reactor core so that the flux spectra for various test specimens may be estimated. This information is used in determining the reactor vessel material surveillance program requirements and 
pressure-temperature limits for operation under mHTGR-RP Sections 5.3.2 and 5.3.3. The organization responsible for the review/assessment of nuclear design reviews the calculational method, the geometric modeling, and the uncertainties in the calculations under mHTGR-RP Section. The review procedures for pressure vessel irradiation include determinations that:

A. The calculations were performed by suitable radiation transport methods that are fundamentally more correct and accurate than diffusion methods.

B. The geometric modeling and source distribution is detailed enough to properly estimate the relative flux spectra at various positions from the reactor core boundary to the pressure vessel wall.

C. The peak vessel wall fluence for the design life of the plant is less than 10 neutrons per square centimeter $\left(\mathrm{n} / \mathrm{cm}^{2}\right)$ for neutrons of energy greater than 1 $\mathrm{MeV}$. If the peak fluence is found to be greater than this value, the reviewers of mHTGR-RP Sections 5.3.2 and 5.3.3 are notified.

9. For review of a DC application, the reviewer should follow the above procedures to verify that the design, including requirements and restrictions (e.g., interface requirements and site parameters), set forth in the final safety analysis report (FSAR) meets the acceptance criteria. DCs have referred to the FSAR as the design control document (DCD). The reviewer should also consider the appropriateness of identified COL action items. The reviewer may identify additional COL action items; however, to ensure these COL action items are addressed during a COL application, they should be added to the DC FSAR.

For review of a COL application, the scope of the review is dependent on whether the COL applicant references a DC, an early site permit (ESP) or other NRC approvals (e.g., manufacturing license, site suitability report or topical report).

10. For review of both DC and COL applications, mHTGR-DC Section 14.3 should be followed for the review of ITAAC. The review of ITAAC cannot be completed until after the completion of this section.

\section{EVALUATION FINDINGS}

The reviewer verifies that the applicant has provided sufficient information and that the review and calculations (if applicable) support conclusions of the following type to be included in the staff's safety evaluation report. The reviewer also states the bases for those conclusions.

These areas include codes and calculational methodology used by the applicant in assessing the nuclear design and operational behavior. In particular, reactivity effects and coefficients will be closely assessed.

The applicant has described the computer programs and calculational techniques used to predict the nuclear characteristics of the reactor design and has provided examples to demonstrate the ability of these methods to predict experimental results. The staff concludes that the information presented adequately demonstrates the ability of these analyses to predict reactivity and physics characteristics of the plant.

To allow for changes of reactivity due to reactor heatup, changes in operating conditions, fuel burnup, and fission product buildup, a significant amount of excess reactivity is designed into the core. The applicant has provided substantial information relating to core reactivity 
requirements for the first cycle and has shown means have been incorporated into the design to control excess reactivity at all times. The applicant has shown that sufficient control rod worth is available to shut down the reactor with at least the currently accepted ( $\% \Delta \mathrm{k} / \mathrm{k}$ ) subcritical margin in the hot condition at any time during the cycle with the highest worth control rod stuck in the fully withdrawn position.

On the basis of our review, the staff concludes that the applicant's assessment of reactivity control requirements over the first core cycle is suitably conservative, and that adequate negative worth has been provided by the control system to assure shutdown capability. Reactivity control requirements will be reviewed for additional cycles as this information becomes available.

The staff concludes that the nuclear design is acceptable and meets the requirements of mHTGR-DC 10, 11, 12, 13, 20, 25, 26, and 28. This conclusion is based on the following:

1. The applicant has met the requirements of $\mathrm{mHTGR}-\mathrm{DC} 11$ with respect to prompt inherent nuclear feedback characteristics in the power operating range by:
A. Calculating a negative power coefficient of reactivity.
B. Using calculational methods that have been found acceptable.

The applicant needs to present reactivity coefficients actually used in transient analyses and safety assessments and show that suitably conservative values are used. The staff has reviewed the Doppler reactivity coefficients in this case and found them to be suitably conservative.

2. The applicant has met the requirements of $\mathrm{mHTGR}-\mathrm{DC} 12$ with respect to power oscillations that could result in conditions exceeding specified acceptable core radionuclide release design limits by:
A. Showing that such power oscillations are not possible and/or can be easily detected and thereby remedied.

B. Using calculational methods that have been found acceptable.

The staff has reviewed the analysis of these power oscillations in this case and found them to be suitably conservative.

3. The applicant has met the requirements of $\mathrm{mHTGR}-\mathrm{DC} 13$ with respect to provision of I\&C to monitor variables and systems that can affect the fission process by:
A. Providing instrumentation and systems to monitor the core power distribution, control rod positions and patterns, and other process variables such as temperature and pressure.
B. Providing suitable alarms and/or control room indications for these monitored variables.

4. The applicant has met the requirements for mHTGR-DC 26 with respect to provision of independent RCSs of different designs by:

A. Having a system that can reliably control anticipated operational occurrences. 
B. Having a system that can hold the core subcritical under cold conditions.

C. Having a system that can control planned, normal power changes.

5. The applicant has also met the requirements of mHTGR-DC 26 with respect to RCSs that have a combined capability in conjunction with poison addition (Reserve Shutdown System) of reliably controlling reactivity changes under DBE/DBA conditions by:

A. Providing a movable control rod system and a poison addition system.

B. Performing calculations to demonstrate that the core has sufficient shutdown margin with the highest worth stuck rod.

6. The applicant has met the requirements of $\mathrm{mHTGR}-\mathrm{DC} 28$ with respect to evaluated reactivity accidents by (reviewed by the organization responsible for the review/assessment of nuclear design under mHTGR-RP Sections 15.4.8 or 15.4.9):
A. Meeting the fuel enthalpy limit criteria in [TBD].
B. Meeting the criteria on the capability to cool the core.
C. Using calculational methods that have been found acceptable for reactivity insertion accidents.

7. The applicant has met the requirements of mHTGR-DC 10, 20, and 25 with respect to specified acceptable core radionuclide release design limits by providing analyses demonstrating: A. That normal operation, including the effects of anticipated operational
occurrences, have met core release design criteria.

B. That the automatic initiation of the RCS assures that core release design criteria are not exceeded as a result of anticipated operational occurrences and assures the automatic operation of systems and components important to safety under DBE/DBA conditions.

C. That no single malfunction of the RCS causes violation of the fuel design limits.

8. For DC and COL reviews, the findings will also summarize the staff's evaluation of requirements and restrictions (e.g., interface requirements and site parameters) and COL action items relevant to this $\mathrm{mHTGR}-\mathrm{RP}$ section.

9. In addition, to the extent that the review is not discussed in other SER sections, the findings will summarize the staff's evaluation of the ITAAC, including design acceptance criteria, as applicable.

\section{IMPLEMENTATION}

The staff will use this $\mathrm{mHTGR}$-RP section in performing safety evaluations of DC applications and license applications submitted by applicants pursuant to 10 CFR Part 50 or 10 CFR Part 52. Except when the applicant proposes an acceptable alternative method for complying with specified portions of the Commission's regulations, the staff will use the method described herein to evaluate conformance with Commission regulations. 
The provisions of this mHTGR-RP section apply to reviews of applications submitted six months or more after the date of issuance of this mHTGR-RP section, unless superseded by a later revision.

Review procedure III.3.E applies to reviews for all new applications.

\section{VI. $\quad$ REFERENCES}

The following list of references was not reviewed in detail for applicability to mHTGR designs. References to materials produced by the NRC that have since been withdrawn-such as regulatory guides-are proposed for deletion. In addition, NRC letters and industry letters on very specific $L W R$ topics are proposed for deletion from the reference list. The remainder of the original SRP reference list, including industry codes and standards, is left to provide insight on the topical areas necessary to provide adequate review. Additional effort will be required to either enhance the information in the existing references to be relevant to advanced non- $L W R$ designs, replace existing references with equivalent documentation, or delete references as appropriate.

1. 10 CFR Part 50, "Domestic Licensing of Production and Utilization Facilities."

2. mHTGR-DC 10, "Reactor Design."

3. mHTGR-DC 11, "Reactor Inherent Protection."

4. MHTGR-DC 12, "Suppression of Reactor Power Oscillations."

5. mHTGR-DC 13, "Instrumentation and Control."

6. $\quad$ mHTGR-DC 20, "Protection System Functions."

7. mHTGR-DC 25, "Protection System Requirements for Reactivity Control Malfunctions."

8. mHTGR-DC 26, "Reactivity Control System Redundancy and Capability."

9. mHTGR-DC 27, "Combined Reactivity Control Systems Capability."

10. mHTGR-DC 28, "Reactivity Limits."

11. 10 CFR Part 52, "Early Site Permits; Standard Design Certifications; and Combined Licenses for Nuclear Power Plants."

12. Regulatory Guide 1.206, "Combined License Applications for Nuclear Power Plants (LWR Edition)," September 2006.

13. Branch Technical Position 4-1, "Westinghouse Constant Axial Offset Control," July 1975

14. NUREG-0085, "The Analysis of Fuel Densification," July 1976.

15. Regulatory Guide 1.126, "An Acceptable Model and Related Statistical Methods for Fuel Densification," Rev. 1, March 1976. 
16. Regulatory Guide 1.77, "Assumptions Used for Evaluating a Control Rod Ejection Accident for Pressurized Water Reactors." M. B. Chadwick, I. P. Oblowzinsk y, M. Herman, N. M. Greene, R. D. McKnight, D. L. Smith, P. G. Young, R. E. MacFarlane, G. M. Hale, S. C. Frank.e, A. C. Kahler, T. Kawano, R. C. Little, D. G. Madland, P. Moller, R. D. Mosteller, P. Page, P. Talou, H. Trellue, M. C. White, W. B. Wilson, R. Arcilla, C. L. Dunford, S. F. Mughabghab, B. Pritychenko, D. Rochman, A. A. Sonzogni, C. R. Lubitz, T. H. Trumbull, J. P. Weinmann, D. A. Brown, D. E. Cullen, D. P. Heinrichs, D. P.

McNabb, H. Derrien, M. E. Dunn, N. M. Larson, L. C. Leal, A. D. Carlson, R. C. Block, J. B. Briggs, E. T. Cheng, H. C. Huria, K. S. Kozier, A. Courcella, V. Pronyaev, S. C. van der Marck, AENDF/B-VII.o: Next Generation Evaluated Nuclear Data Library for Nuclear Science and Technology,@ Nuclear Data Sheets, Vol. 107, Issue 12, pp. 2931B3118, December 2006.

Comment [A179]: Applicability of specific sections, parts, and revisions of Codes and Standards must be determined. 



\section{MODULAR HIGH TEMPERATURE GAS- COOLED REACTOR REVIEW PLAN}

\subsection{THERMAL AND HELIUM FLOW DESIGN \\ REVIEW RESPONSIBILITIES}

Primary - Organization responsible for the review of thermal and helium flow design for modular high temperature gas-cooled reactors (HTGRs)

Secondary - Organization responsible for the review of heat transfer correlations

\section{AREAS OF REVIEW}

The objectives of the review are to confirm that the thermal and helium flow design of the reactor system and the helium pressure boundary (HPB) (1) uses acceptable analytical methods, (2) is equivalent to or is a justified extrapolation from proven designs or applicable experience, (3) provides acceptable margins of safety from conditions that would lead to exceeding specified acceptable core radionuclide release design limits (SARRDLs) during normal reactor operation and anticipated operational occurrences (AOOs), and (4) is not susceptible to thermal and helium-flow instability. The review covers thermal and helium flow design elements to assure conformance with the requirements of modular High-Temperature Gas-Cooled Reactor (HTGR) Design Criteria (mHTGR-DC) 10, and 12 which are reflected in Draft Regulatory Guide DG-1330 (Proposed New Regulatory Guide 1.232) as guidance for complying with the requirements of 10 CFR Part 50, Appendix A General Design Criteria (GDC) 10 , and 12.

The specific areas of review are as follows:

1. This mHTGR-RP section describes the normal review of thermal and helium-flow design (i.e., a design for a plant similar in reactor system and HPB design to previously reviewed plants). The review of new plants, new heat transfer correlations, and new analysis methods require additional independent audit analyses. The required analyses may be in the following form:
A. Independent computer calculations to verify/substantiate reactor vendor analyses.
B. Reduction and correlations derived from experimental data to validate models and phenomena applicable to reactor design.

C. Independent comparisons and correlations of data from experimental programs.

These reviews also include analyses of experimental techniques, test repeatability, and data reduction methods. The review should incorporate insights gained from the related
Comment [A180]: Helium flow is better description than hydraulic for a gas reactor.

Comment [A181]: Description of SARRDLs is included in Guidance for Developing Principal Design Criteria for Advanced (Non-Light Water) Reactors, INL/EXT-31179, Revision 1, December 2014. This is the advanced reactor design criteria report from DOE to NRC.

Comment [A182]: This text anticipates the NRC RG for advanced reactor design criteria and subsequent mHTGR-DC (proposed RG 1.232). The current markup reflects the proposed language in Draft RG-1330. 
uncertainties and how these uncertainties impact the thermal and helium flow design margins.

2. The review evaluates the proposed technical specifications regarding safety limits and limiting safety system settings to ascertain that they are consistent with applicable design precedents. Note that some HTGR safety limits/settings from previous HTGRs may not be applicable given that previous HTGR designs did not completely rely on passive safety systems and that more recent particle fuel research data are now available.

3. For new plant applicants, the review determines the acceptability of analyses and procedures related to thermal and helium-flow conditions under all modes of reactor operations.

4. The review determines the largest flow-induced loads on reactor system and HPB components during normal operation and design-basis event/design-basis accident (DBE/DBA) conditions. This information is used in the review of stacked fuel block stability and the effects of interstitial bypass flows on reactor system stability.

5. The review evaluates the uncertainty analysis methodology and the uncertainties of variables and correlations related to compliance with the SARRDLs. The review also evaluates the uncertainties associated with the combination of variables.

6. To accomplish the objectives, the reviewer examines reactor system and HPB component features, key process variables for the helium coolant system, calculated parameters characterizing thermal performance, data serving to support new correlations or changes in accepted correlations, and assumptions in the equations and solution techniques used in the analyses. The reviewer determines that the applicant has used approved analysis methods described in topical reports and applied in staff reports. The analysis methods to be addressed include reactor system thermal and helium flow calculations to establish local helium flow conditions, modeling assumptions impacting calculated fuel temperatures, and thermal and helium flow stability evaluation. If an applicant has used previously unapproved correlations or analysis methods, the reviewer initiates an evaluation, either generic or plant specific. Once analysis methods have been accepted, any changes to codes, correlations, and analytical procedures, or the addition of new ones, must be reviewed to determine that they are justified on theoretical or empirical grounds.

7. Inspections, Tests, Analyses, and Acceptance Criteria (ITAAC). For design certification (DC) and combined license (COL) reviews, the staff reviews the applicant's proposed ITAAC associated with the structures, systems, and components (SSCs) related to this mHTGR-RP section in accordance with mHTGR-RP Section 14.3, "Inspections, Tests, Analyses, and Acceptance Criteria." The staff recognizes that the review of ITAAC cannot be completed until after the rest of this portion of the application has been reviewed against acceptance criteria contained in this mHTGR-RP section.

Furthermore, the staff reviews the ITAAC to ensure that all SSCs in this area of review are identified and addressed as appropriate in accordance with $\mathrm{mHTGR}-\mathrm{RP}$ Section 14.3.

Comment [A183]: Inadequate core cooling hardware is not relevant to HTGRs.

Comment [A184]: Universal need to adjust to reflect appropriate interfaces. 
8. COL Action Items and Certification Requirements and Restrictions. For a DC application, the review will also address COL action items and requirements and restrictions (e.g., interface requirements and site parameters).

For a COL application referencing a DC, a COL applicant must address COL action items (referred to as COL license information in certain DCs) included in the referenced DC. Additionally, a COL applicant must address requirements and restrictions (e.g., interface requirements and site parameters) included in the referenced DC.

\section{$\underline{\text { Review Interfaces }}$}

Other mHTGR-RP sections interface with this section as follows:

1. The review of power distribution assumptions made for the reactor system thermal and helium flow analysis is coordinated with the review for core physics calculations under $\mathrm{mHTGR}-\mathrm{RP}$ Section 4.3. The reviewer verifies that the reactor system monitoring techniques that rely on in-core or ex-core neutron sensor inputs are evaluated.

2. The review of material properties and their variation under neutron irradiation that are important to heat transfer and helium flow such as thermal conductivity, convection, radiation heat transfer and helium properties under mHTGR-RP Section 4.5.2.

3. The review of anticipated transients without scram (ATWS) and various loss of forced cooling accidents is performed under mHTGR-RP Section 15.

4. The review of the adequacy of components and structures under accident loads and the preoperational vibration test program is performed under mHTGR-RP Sections 3.9.3 and 3.9.6.

5. The review of the core protection and reactor protection hardware to determine compliance with the requirements applicable to reactor trip systems is performed under mHTGR-RP Section 7.2.

6. The review of the applicant's training program is performed under mHTGR-RP Sections 13.2.1 and 13.2.2.

7. The review of emergency procedure guidelines (EPGs) and associated programs for development of plant-specific emergency operating procedures is performed under mHTGR-RP Section 13.3. This includes setting the thermal conditions that impact SARRDLs and the related sorption/desorption on HPB surfaces as the SARRDLs serve as a starting assumption in accident scenarios and can impact EP and plant specific operating procedures.

Comment [A185]: Revised to use SARRDLs.

8. The review of the human factors aspects of information displays is performed under mHTGR-RP Chapter 18.

9. For new plant applicants, the review of shutdown risk assessment is performed under mHTGR-RP Chapter 19.

10. The thermal and helium flow review for normal operation and AOOs is coordinated with a thermal stress review under mHTGR-RP Section 4.5.2. 
11. Under mHTGR-RP Sections 15.3.1-15.3.2, the thermal stress review is also conducted for upper head components (thermal shield, reactor vessel head and control rod drive penetrations) for the effects of hot gas plumes during pressurized loss of forced cooling accidents. The thermal stress review under these mHTGR-RP Sections also includes the core radial restraint devices (located outside the graphite reflector and inside the core barrel), the core barrel and reactor vessel during depressurized core conduction cooldown transients.

The primary review organizations will use the results of these reviews to complete the overall evaluation of the thermal and helium flow review; the results will also be incorporated into the safety evaluation report (SER).

The specific acceptance criteria and review procedures are contained in the referenced mHTGR-RP sections.

\section{II. $\quad$ ACCEPTANCE CRITERIA}

\section{$\underline{\text { Requirements }}$}

Acceptance criteria are based on meeting the relevant requirements of the following Commission regulations:

1. Modular HTGR Design Criterion (mHTGR-DC) 10, as it relates to whether the design of the reactor system includes appropriate margin to assure that SARRDLs are not exceeded during normal operation or AOOs.

2. mHTGR-DC 12, as it relates to whether the design of the reactor core and associated control, and protection systems assures that power oscillations, which can result in conditions exceeding SARRDLs, are not possible or can be reliably and readily detected and suppressed. This includes xenon oscillations as well as apparent core thermal fluctuations from shifting blocks (affecting bypass flow).

3. 10 CFR 52.47(b)(1), which requires that a DC application contain the proposed inspections, tests, analyses, and acceptance criteria (ITAAC) that are necessary and sufficient to provide reasonable assurance that, if the inspections, tests, and analyses are performed and the acceptance criteria met, a plant that incorporates the design certification is built and will operate in accordance with the design certification, the provisions of the Atomic Energy Act, and the NRC's regulations.

4. 10 CFR 52.80(a), which requires that a COL application contain the proposed inspections, tests, and analyses, including those applicable to emergency planning, that the licensee shall perform, and the acceptance criteria that are necessary and sufficient to provide reasonable assurance that, if the inspections, tests, and analyses are performed and the acceptance criteria met, the facility has been constructed and will operate in conformity with the combined license, the provisions of the Atomic Energy Act, and the NRC's regulations.

\section{$\underline{\text { mHTGR-RP Acceptance Criteria }}$}

Specific mHTGR-RP acceptance criteria acceptable to meet the relevant requirements of the NRC's regulations identified above are as follows for review described in this MHTGR-RP 
section. The mHTGR-RP is not a substitute for the NRC's regulations, and compliance with it is not required. However, an applicant is required to identify differences between the design features, analytical techniques, and procedural measures proposed for its facility and the mHTGR-RP acceptance criteria and evaluate how the proposed alternatives to the mHTGR-RP acceptance criteria provide acceptable methods of compliance with the NRC regulations.

Specific criteria necessary to meet the requirements of mHTGR-DC 10 and mHTGR-DC 12 are as follows:

1. MHTGR-RP Section 4.2 specifies the acceptance criteria for the evaluation of fuel design limits. One criterion provides assurance that there be at least a 95-percent probability at the 95-percent confidence level that the SARRDLs with not be exceeded during normal operation or AOOs.

Uncertainties in the values of process parameters (e.g., reactor power, coolant flow rate, core bypass flow, inlet temperature and pressure, core peaking factors), core design parameters, and calculational methods used in the assessment of thermal margin should be treated with at least a 95-percent probability at the 95-percent confidence level. The assessment of thermal margin should also consider the uncertainties in instrumentation. The origin of each uncertainty parameter, such as fabrication uncertainty, computational uncertainty, or measurement uncertainty (e.g., reactor power, coolant temperature, flow), should be identified. Each uncertainty parameter should be identified as statistical or deterministic and should clearly describe the methodologies used to combine uncertainties.

2. Problems impacting helium flows, such as fuel or reflector block bowing or gross core movement, are to be accounted for if significant. The review should include the effects of bypass and cross flows and their impacts on overall core flow distribution.

3. The design should address the possibility of core oscillations. Thermal and helium flow phenomena that have been observed in HTGRs (such as flow redistributions) are to be addressed. The possibility of hot streaks and the mixing phenomena in the lower plenum under changing flow conditions should be considered. There should be no helium flow instability in any fuel channel that could lead to exceeding the SARRDLs.

4. Methods for calculating single-phase flow in the reactor vessel and other components should include classical fluid mechanics relationships and appropriate empirical correlations.

5. The proposed technical specifications should ensure that the plant can be safely operated at steady-state conditions under all expected combinations of system parameters. The safety limits and limiting safety settings must be established for each parameter, or combinations of parameters, to satisfy specific acceptance criterion 1, above.

6. Preoperational and initial startup test programs should follow the recommendations of Regulatory Guide 1.68, as it relates to measurements and the confirmation of thermal and helium flow design aspects.

7. The design description and proposed procedures for use of the loose parts monitoring system should be consistent with the requirements of Regulatory Guide 1.133.

Comment [A190]: Concern about loose insulation in the upper vessel head potentially coming loose and blocking some of the helium flow channels; this could lead to fuel damage.
Comment [A189]: Laminar flow concern at low power and low flow conditions that originates from NUREG-1338.

Comment [A188]: Most of this wording is from

NUREG-1537.

Comment [A187]: Power uprates would not be needed for licensing new advanced designs. 
8. Instrumentation provided for helium flow, reactor vessel measurement systems, and core inlet/exit thermocouples, must meet the design requirements for high temperature operation.

9. Thermal and helium flow stability performance of the core during an ATWS event should not exceed acceptable fuel design limits.

\section{Technical Rationale}

The technical rationale for application of these acceptance criteria to the areas of review addressed by this $\mathrm{mHTGR}$-RP section is discussed in the following paragraphs:

1. mHTGR-DC 10 requires that the reactor system and associated control, and protection systems be designed with appropriate margin to assure that SARRDLs are not exceeded during any condition of normal operation, including the effects of AOOs. Proper thermal and helium flow design of the reactor system and associated systems is necessary to assure that sufficient margin exists with regard to maintaining adequate heat transfer from the fuel to the helium transport system or shutdown cooling system (as appropriate). Compliance with mHTGR-DC 10 provides assurance that compliance with the SARRDLs will be maintained.

2. mHTGR-DC 12 requires that the reactor system and associated control, and protection systems be designed to assure that power oscillations that result in conditions exceeding SARRDLs are not possible or can be reliably and readily detected and suppressed. Power oscillations within the reactor system may result from conditions such as improper fuel design or loading; improper reactivity control related to burnable poison design and control rod positioning; and xenon oscillations. The occurrence of power oscillations can lead to excessive localized power peaking, cyclic thermal fatigue, and subsequent exceedance of SARRDLs. Compliance with mHTGR-DC 12 provides assurance that the thermal and helium flow design of the reactor core and associated systems protect the reactor from the consequences of power oscillations that could potentially challenge the integrity of the particle fuel coatings and result in the release of fission products.

\section{REVIEW PROCEDURES}

The OL and COL reviews also encompass the proposed technical specifications to assure that they are adequate with regard to safety limits, limiting safety system settings, and conditions of operation.

These review procedures are based on the identified mHTGR-RP acceptance criteria. For deviations from these specific acceptance criteria, the staff should review the applicant's evaluation of how the proposed alternatives provide an acceptable method of complying with the relevant NRC requirements identified in Subsection II.

For DC and COL applications submitted under Part 52, the level of information reviewed should be consistent with that of a FSAR submitted in an OL application. However, verification that the as-built facility conforms to the approved design is performed through the ITACC process.

1. The reviewer must understand currently acceptable thermal and helium flow design practice for the modular HTGR reactor type under review. This understanding can be
Comment [A191]: Possible requirements that the instrumentation be able to identify helium flow distributions, hot streaking, and flow blockages; The HTGR designers might say that it would be hard to have those types of instruments in the core region. 
most readily gained from (1) topical reports describing particle fuel correlations, system helium flow models and tests, and core analysis methods, (2) standard texts and other technical literature which establish the methodology and the nomenclature of this technology, (3) documents that summarize current staff positions concerning acceptable modular HTGR design methods, (4) overall modular HTGR historical experience base, and (5) studies of postulated modular HTGR accidents.

2. The reviewer compares the information in the applicant's SAR or DCD for new plants to the documents referenced by the applicant or included in this mHTGR-RP section to determine conformance to the bounds established by such documents. The reviewer confirms that (1) pressure drop and heat transfer correlations used to estimate helium conditions are within the ranges of applicability specified by their authors or in previous staff reviews (if applicable), (2) the fuel and graphite thermal properties and correlations are within ranges of applicability specified by referenced research sources or in previous staff reviews (if applicable), (3) the analysis methods are used in the manner specified by their developers or in previous staff reviews (if applicable), (4) the reactor design falls within the ranges of applicability specified for accepted analysis methods, and (5) the design is within the criteria specified in Subsection II, above, and is not an unexplained or unwarranted extrapolation of other thermal and helium flow designs.

3. The reviewer evaluates the analytical methods used in the thermal and helium flow analysis, including the applicability of the codes and correlations used and the uncertainty analysis methodologies implemented. For transient analysis, the setpoint limits and instrumentation uncertainty values used for establishing steady-state conditions preceding transient initiation should be evaluated to ensure appropriate conservatism. The review examines the method of employing power peaking factors and peak fuel temperatures in the thermal and helium flow analysis as well as time-attemperature calculations for the fuel regions. The basis for the input parameters used in the uncertainty evaluation and the resulting uncertainty in reactor thermal and helium flow parameters should also be evaluated.

4. The reviewer should evaluate the calculational results provided. The reviewer should also ensure that the design analyses are based on statistical design methodologies include the coefficients required by the statistical model and define the parameter ranges for which the coefficients are applicable. Uncertainties in computer codes, correlations, design methods, and setpoint methodologies should be quantified and the method(s) of accounting for these uncertainties in the design procedures should be discussed. On occasion (e.g., if a new design or new design method is proposed), the staff or consultants, under the direction of the primary review organization, perform independent analyses. These analyses verify the design or establish the range of applicability and associated accuracy of the new method; the reviewer ensures it is applied accordingly.

5. The reviewer evaluates the functional requirements for instrumentation used in monitoring those thermal and helium flow parameters important to safety, such as incore power distribution and helium temperature measurements. Chapter 7 of the SAR or DCD for new plants and the review requirements in mHTGR-RP Section 7 should detail the instrumentation design and logic.

6. The reviewer establishes that the thermal and helium flow design accomplishes the goal of not exceeding the SARRDLs in a manner that accounts for all possible reactor operating states as determined from operating maps. This includes load-following 
evolutions as well as steady-state conditions. In this regard, the reviewer confirms that the power distribution assumptions in the applicant's technical information submittal are a conservative (i.e., worst-case) accounting of the power distributions derived in in the applicant's technical information submittal from core physics analyses. The reviewer also confirms that the mass flow used in these calculations accounts for the core flow distribution and the worst case estimates of core bypass flow. The reviewer confirms that startup measurements will verify the helium flow range shown in the operating map.

7. The reviewer considers the design review areas of applicability associated with ATWS and thermal and helium flow instability using the guidance found in the requirements of mHTGR-RP Sections 15.8 and 15.9.

8. The reviewer examines the calculation of helium flow-induced loads for normal operations, including AOOs, to ensure that they are properly estimated for the worst cases. Worst-case helium flow-induced loads for normal operations are to be provided for use in the analysis of lifting force of the fuel (mHTGR-RP Section 4.2). The reviewer will also provide calculations for DBE/DBA conditions. The review of the adequacy of components and structures under design-basis accident loads is performed under mHTGR-RP Sections 3.9.3 and 3.96. The review to determine that a coolable core geometry is maintained is performed under mHTGR-RP Section 4.2.

9. The reviewer should ensure that adequate loose parts considerations (such as machinery or insulation) have been addressed.

10. The reviewer should evaluate the vibration monitoring equipment and procedures to ensure that they are adequate for the plant under review based on the experience of comparable plants (if available).

11. The reviewer verifies that analyses of the thermal and helium flow conditions during shutdown and low-power operations have been completed, including operation of the shutdown cooling system (SCS). The analysis should be of sufficient depth to provide a basis for shutdown procedures, instrumentation, equipment interaction, equipment response, and operator response.

12. The reviewer determines whether the applicant's proposed preoperational and initial startup test programs are consistent with the intent of [TBD]. The reviewer assures that the applicant has provided sufficient information to clearly identify the test objectives, methods of testing, and acceptance criteria.

The test scope should include verification of any safety analysis codes or methods that could affect the thermal and helium flow evaluations and that have not been previously verified.

The reviewer evaluates the proposed test programs to determine whether they provide reasonable assurance that the reactor system and HPB will satisfy functional requirements. As a supplement to this evaluation, the reviewer may compare the reactor system and HPB design to that of previously reviewed plants (if available) or to information obtained from international sources. If the design is essentially identical and the proposed test programs are essentially the same as performed previously on other plants, the reviewer may conclude that the proposed test programs are adequate for the reactor system and HPB.

Comment [A193]: Applicability of specific sections, parts, and revisions of Codes and Standards must be determined.
Comment [A192]: This needs to be checked to determine applicability for modular HTGRs. 
If the reactor system or the HPB differs significantly from that of previously reviewed designs, the impact of the proposed changes on the preoperational and initial startup testing programs are reviewed at the COL stage. This effort should particularly evaluate the need for any special design features required to perform acceptable test programs for first-of-a-kind reactor designs.

13. The reviewer evaluates the proposed technical specifications that relate to the reactor system and the HPB. This evaluation covers all safety limits and bases that could affect the thermal and helium flow performance of the core. The limiting safety system settings are reviewed to ascertain that acceptable margins exist between the values at which reactor trip occurs automatically for each parameter (or combinations of parameters) and the safety limits. The reviewer confirms that the limiting safety system settings and limiting conditions for operation, as they relate to the HPB, do not permit operation with any expected combination of parameters that would exceed the SARRDLs.

14. For review of a DC application, the reviewer should follow the above procedures to verify that the design, including requirements and restrictions (e.g., interface requirements and site parameters), set forth in the final safety analysis report (FSAR) meets the acceptance criteria. DCs have referred to the FSAR as the design control document (DCD). The reviewer should also consider the appropriateness of identified COL action items. The reviewer may identify additional COL action items; however, to ensure these COL action items are addressed during a COL application, they should be added to the DC FSAR.

For review of a COL application, the scope of the review is dependent on whether the COL applicant references a DC, an early site permit (ESP) or other NRC approvals (e.g., manufacturing license, site suitability report or topical report).

15. For review of both DC and COL applications, mHTGR-RP Section 14.3 should be followed for the review of ITAAC. The review of ITAAC cannot be completed until after the completion of this section.

\section{EVALUATION FINDINGS}

The reviewer verifies that the applicant has provided sufficient information and that the review and calculations (if applicable) support conclusions of the following type to be included in the staff's safety evaluation report. The reviewer also states the bases for those conclusions.

1. The following paragraph is applicable to DC:

The thermal and helium flow design of the reactor system for the plant was reviewed. The scope of review included the design criteria, preliminary reactor system design, and steady-state analysis of the core thermal and helium flow performance. The review concentrated on the differences between the proposed reactor system design (and criteria) and those designs and criteria that have been previously reviewed (including any test and validation data from applicable experience) and found acceptable by the staff. It was found that the applicant satisfactorily justified all such differences. The applicant performed its thermal and helium flow analyses using analytical methods and correlations that have been either previously reviewed by the staff or currently reviewed for this reactor and found to be acceptable. 
2. For OL and COL applications, the following types of conclusions should be supported:

The staff concludes that the thermal and helium flow design of the core meets the requirements of mHTGR-DC 10 and 12 and is acceptable for final design approval. The staff also concludes that the reactor system and associated control, and protection systems have been designed with appropriate margin to assure that SARRDLs are not exceeded during steady-state operation or anticipated operational occurrences. In meeting this objective, the design provides assurance that the reactor will perform its safety functions throughout its design lifetime under all modes of operation. This conclusion is based on the applicant's analyses of the core thermal and helium flow performance which was reviewed by the staff and found to be acceptable. The applicant has committed to a preoperational and initial startup test program in accordance with [TBD] to measure and confirm the thermal and helium flow design aspects. The staff has reviewed the applicant's preoperational and initial startup test program and has concluded that it is acceptable.

3. For DC and COL reviews, the findings will also summarize the staff's evaluation of requirements and restrictions (e.g., interface requirements and site parameters) and COL action items relevant to this $\mathrm{mHTGR}-\mathrm{RP}$ section.

4. In addition, to the extent that the review is not discussed in other SER sections, the findings will summarize the staff's evaluation of the ITAAC, including design acceptance criteria, as applicable.

\section{IMPLEMENTATION}

The staff will use this mHTGR-RP section in performing safety evaluations of DC applications and license applications submitted by applicants pursuant to 10 CFR Part 50 or 10 CFR Part 52. Except when the applicant proposes an acceptable alternative method for complying with specified portions of the Commission's regulations, the staff will use the method described herein to evaluate conformance with Commission regulations.

The provisions of this mHTGR-RP section apply to reviews of applications submitted six months or more after the date of issuance of this mHTGR-RP section, unless superseded by a later revision.

Implementation schedules for conformance to parts of the method discussed herein are contained in the referenced regulatory guides, NUREGs, and generic letters. 


\section{REFERENCES}

The following list of references was not reviewed in detail for applicability to mHTGR designs. References to materials produced by the NRC that have since been withdrawn-such as regulatory guides - are proposed for deletion. In addition, NRC letters and industry letters on very specific $L W R$ topics are proposed for deletion from the reference list. The remainder of the original SRP reference list, including industry codes and standards, is left to provide insight on the topical areas necessary to provide adequate review. Additional effort will be required to either enhance the information in the existing references to be relevant to advanced non-LWR designs, replace existing references with equivalent documentation, or delete references as appropriate.

1. $\quad 10$ CFR 50.34(f), "Additional TMI-Related Requirements," paragraph 10 CFR 50.34(f)(2)(xviii).

2. $\quad 10$ CFR Part 52, "Early Site Permits; Standard Design Certifications; and Combined Licenses for Nuclear Power Plants."

3. mHTGR-DC 10, "Reactor Design."

4. MHTGR-DC 12, "Suppression of Reactor Power Oscillations."

5. Regulatory Guide 1.68, "Initial Test Programs for Water-Cooled Nuclear Power Plants," March 2007.

6. Regulatory Guide 1.133, Rev. 1, "Loose Parts Detection Program for the Primary System of Light-Water-Cooled Reactors," May 1981, ADAMS Accession No. ML003740137.

7. NUREG-0737, "Clarification of TMI Action Plan Requirements," November 1980.

8. NUREG-1449, "Shutdown and Low-Power Operation at Commercial Nuclear Power Plants in the United States," Final Report, Office of Nuclear Reactor Regulation, U.S. Nuclear Regulatory Commission, September 1993.

9. NRC Letter to All Licensees of Operating Westinghouse and CE PWRs (Except Arkansas Nuclear One-Unit 2 and San Onofre Units 2 and 3), "Inadequate Core Cooling Instrumentation System (Generic Letter No. 82-28)," December 10, 1982.

10. B.S. Mullanax, R.J. Walker, and B.A. Karrasch, "Reactor Vessel Model Flow Tests," BAW-10037 (nonproprietary version of BAW-10012), Rev. 2, Babcock and Wilcox Company, September 1968.

11. "Design and Performance of General Electric Boiling Water Reactor Jet Pumps," APED-5460, General Electric Company, September 1968.

12. H.T. Kim, "Core Flow Distribution in a Modern Boiling Water Reactor as Measured in Monticello," NEDO-10299, General Electric Company, January 1971. DRAFT Rev. 2, April 1996, 4.4-16. 
13. H. Chelemer, L.H. Boman, and D.R. Sharp, "Revised Thermal Design Procedure," WCAP-11397-P-A, Westinghouse Electric Corporation, July 1975.

14. Review Standard RS-001, "Review Standard for Extended Power Uprates," RS-001, Revision 0, December 2003.

15. NRC Inspection Manual Chapter IMC-2504, "Construction Inspection Program Non-ITAAC Inspections," April 25, 2006.

16. "TEMP - Thermal Enthalpy Mixing Program," BAW-10021, Babcock and Wilcox Company, April 1970.

17. H. Chelemer, P.T. Chu, and L.E. Hochreiter, "THINC-IV - An Improved Program for Thermal-Hydraulic Analysis of Rod Bundle Cores," WCAP-7956, Westinghouse Electric Corporation, June 1973. (See also WCAP-7359-L and WCAP-7838.)

18. B.C. Slifer and J.E. Hench, "Loss of Coolant Accident and Emergency Core Cooling Models for General Electric Boiling Water Reactors," NEDO-10329, Appendix C, General Electric Company, April 1971.

19. J. Duncan and P.W. Marriott, "General Electric Company Analytical Model for Loss of Coolant Accident Analysis in Accordance with 10 CFR Part 50, Appendix K," NEDO-20566, General Electric Company, November 1975. 


\section{MODULAR HIGH TEMPERATURE GAS- COOLED REACTOR REVIEW PLAN}

\subsubsection{CONTROL ROD DRIVE STRUCTURAL MATERIALS}

\section{REVIEW RESPONSIBILITIES}

Primary - Organization responsible for the review of control drive structural materials

Secondary - Organization responsible for the review of materials engineering issues related to flaw evaluation and welding

\section{AREAS OF REVIEW}

Modular HTGR Advanced Reactor Design Criterion (mHTGR-DC) 26 requires that one of the reactivity control systems use control rods, preferably with a positive means for inserting the rods, and be capable of reliably controlling reactivity changes for assurance that specified acceptable core radionuclide release design limits are not exceeded under conditions of normal operation, including anticipated operational occurrences. The review areas are similar to those of Modular High Temperature Gas-Cooled Reactor Review Plan mHTGR-RP Section 5.2.3, "Reactor Helium Pressure Boundary Materials." For purposes of this mHTGR-RP section, the control rod system is comprised of the Control Rod Drive Mechanism (CRDM) and extends only to the coupling interface with the reactivity control (poison) elements in the reactor vessel; it does not include the electrical and cable systems necessary to actuate the CRDMs. The review covers control rod drive structural materials to ensure conformance with modular HTGR Advanced Reactor Design Criteria (mHTGR-DC) 1, 14, and 26 which are reflected in Draft Regulatory Guide DG-1330 (Proposed New Regulatory Guide 1.232) as guidance for complying with the requirements of 10 CFR Part 50, Appendix A General Design Criteria (GDC) 1, 14, and 26.

The specific areas of review are as follows:

1. Materials Specifications. The properties of the control rod drive materials are reviewed for adequate performance throughout the design life of the plant (or component). Materials that may be used include austenitic stainless steels (which may be cold-worked), chromium-plated stainless steels, martensitic stainless steels, precipitation-hardening stainless steels like 17-4 $\mathrm{PH}$, and such other special-purpose materials as cobalt-base alloys (Stellites), Inconel-750, Incoloy $800 \mathrm{H}$, Colmonoy-6, and Graphitar-14.

2. Austenitic Stainless Steel Components. Areas of review for austenitic stainless steel components are similar to the applicable subsections of mHTGR-RP Section 5.2.3 for fabrication and processing of austenitic stainless steels.

The use of sensitized stainless steels is reviewed and should be controlled to prevent stress-corrosion cracking of the material during plant operation. Welding procedures are reviewed and should be controlled to reduce the probability of sensitization and

Comment [A197]: This text anticipates the NRC RG for advanced reactor design criteria and subsequent mHTGR-DC (proposed RG 1.232). The current markup reflects the proposed language in Draft RG-1330.

Comment [A198]: Compare this list to proposed HTGR designs to reduce the list of materials. 
micro-fissure formation. The use of cold-worked stainless steel is reviewed, and to reduce the probability of stress-corrosion cracking during plant operation, cold-worked stainless steels should not have high-yield stress higher than [TBD].

3. Other Materials. Special requirements for materials other than austenitic stainless steels include tempering and aging temperatures for martensitic and precipitation-hardening stainless steels to prevent their deterioration by stress corrosion during plant operation. The compatibility of these materials with the reactor helium environment is reviewed for whether they will continue to perform satisfactorily throughout the life of the component.

The staff reviews to ensure that metallic and non-metallic materials used in the CRDM that are not included in [TBD], are identified.

4. Cleaning and Cleanliness Control. Cleaning and cleanliness control procedures are reviewed to confirm that proper care should be taken in handling the materials and parts of the CRDM during fabrication, shipping, and onsite storage for assurance that all cleaning solutions, processing compounds, degreasing agents, and other foreign materials are removed completely and that all parts are dried and properly protected following any flushing treatment with water.

5. Inspections, Tests, Analyses, and Acceptance Criteria (ITAAC). For design certification (DC) and combined license (COL) reviews, the staff reviews the applicant's proposed ITAAC associated with the structures, systems, and components (SSCs) related to this mHTGR-RP section in accordance with mHTGR-RP Section 14.3, "Inspections, Tests, Analyses, and Acceptance Criteria." The staff recognizes that the review of ITAAC cannot be completed until after the rest of this portion of the application has been reviewed against acceptance criteria contained in this mHTGR-RP section. Furthermore, the staff reviews the ITAAC to ensure that all SSCs in this area of review are identified and addressed as appropriate in accordance with $\mathrm{mHTGR}-\mathrm{RP}$ Section 14.3.

6. COL Action Items and Certification Requirements and Restrictions. For a DC application, the review will also address COL action items and requirements and restrictions (e.g., interface requirements and site parameters).

For a COL application referencing a DC, a COL applicant must address COL action items (referred to as COL license information in certain DCs) included in the referenced DC. Additionally, a COL applicant must address requirements and restrictions (e.g., interface requirements and site parameters) included in the referenced DC.

\section{$\underline{\text { Review Interfaces }}$}

Other mHTGR-RP sections interface with this section as follows:

1. Section 3.13: review of the adequacy of programs for assuring the integrity of bolting and threaded fasteners.

2. Section 3.9.4: review of the mechanical aspects of the control rod drive system other than the reactivity control elements.
Comment [A199]: The need for new codes and standards for mHTGRs and applicability of specific parts and revisions of existing codes and standards must be determined

Comment [A200]: The need for new codes an standards for mHTGRs and applicability of specific parts and revisions of existing codes and standards must be determined 
3. Section 4.2: review of the mechanical design, thermal performance, and chemical compatibility of the reactivity control elements.

4. Section 5.2.3: review of control rod drive system portions that are part of the reactor helium pressure boundary (HPB); verification of whether materials of construction and fabrication controls satisfy criteria for HPB materials.

5. Section 5.3.1: review of control rod drive portions that are reactor vessel attachments or appurtenances; verification of whether materials of construction and related fabrication controls satisfy the criteria for reactor vessel materials.

Section 12.1: review of the plant design, including selection of materials to minimize activation products, for whether occupational radiation exposures will be as low as is reasonably achievable.

The specific acceptance criteria and review procedures are contained in the referenced mHTGR-RP sections.

\section{ACCEPTANCE CRITERIA}

\section{$\underline{\text { Requirements }}$}

Acceptance criteria are based on meeting the relevant requirements of the following Commission regulations:

1. MHTGR-DC 1, as it relates to SSCs important to safety being designed, fabricated, erected, and tested to quality standards commensurate with the importance of the safety functions to be performed.

2. mHTGR-DC 14, as it relates to the HPB being designed, fabricated, erected, and tested to have an extremely low probability of abnormal leakage, rapidly propagating failure, or gross rupture.

3. mHTGR-DC 26, as it relates to control rods being capable of reliable control of reactivity changes to assure that under conditions of normal operation, including anticipated operational occurrences, and with appropriate margin of malfunctions, specified acceptable core radionuclide release design limits are not exceeded.

4. 10 CFR 50.55a, as it relates to SSCs being designed, fabricated, erected, constructed, tested, and inspected to quality standards commensurate with the importance of the safety function to be performed.

5. 10 CFR 52.47(b)(1), which requires that a DC application contain the proposed inspections, tests, analyses, and acceptance criteria (ITAAC) that are necessary and sufficient to provide reasonable assurance that, if the inspections, tests, and analyses are performed and the acceptance criteria met, a plant that incorporates the design certification is built and will operate in accordance with the design certification, the provisions of the Atomic Energy Act, and the NRC's regulations; 
6. 10 CFR 52.80(a), which requires that a COL application contain the proposed inspections, tests, and analyses, including those applicable to emergency planning, that the licensee shall perform, and the acceptance criteria that are necessary and sufficient to provide reasonable assurance that, if the inspections, tests, and analyses are performed and the acceptance criteria met, the facility has been constructed and will operate in conformity with the combined license, the provisions of the Atomic Energy Act, and the NRC's regulations.

\section{mHTGR-RP Acceptance Criteria}

Specific mHTGR-RP acceptance criteria acceptable to meet the relevant requirements of the NRC's regulations identified above are as follows for the review described in this $\mathrm{mHTGR}-\mathrm{RP}$ section. The mHTGR-RP is not a substitute for the NRC's regulations, and compliance with it is not required. However, an applicant is required to identify differences between the design features, analytical techniques, and procedural measures proposed for its facility and the mHTGR-RP acceptance criteria and evaluate how the proposed alternatives to the mHTGR-RP acceptance criteria provide acceptable methods of compliance with the NRC regulations.

With respect to compliance with mHTGR-DCs 1, 14, and 26 and 10 CFR 50.55a:

1. Materials Specifications. The properties of the materials selected for the CRDM should be equivalent to those of [TBD]. Cold-worked austenitic stainless steels should have a [TBD], to reduce the probability of stress corrosion cracking in these systems.

2. Austenitic Stainless Steel Components. Acceptance criteria include criteria described in mHTGR-RP Section 5.2.3, Subsections II.4.D and E, and the criteria described below.

RG 1.44 describes accepted methods for preventing intergranular corrosion of stainless steel components. Furnace-sensitized material should not be allowed, and methods described in this guide should be followed for cleaning and protecting austenitic stainless steels from contamination during handling, storage, testing, and fabrication and for determining the degree of sensitization during welding.

The controls for abrasive work on austenitic stainless steel surfaces should be adequate for preventing contamination that promotes stress corrosion cracking. The final surfaces should meet the acceptance standards specified in ASME NQA-1[TBD] Edition, "Quality Assurance Requirements for Nuclear Facilities." Tools that contain materials that could contribute to stress-corrosion cracking or that, from previous usage, may be contaminated with such materials should not be used on austenitic stainless steel surfaces.

3. Other Materials. All materials for use in this system should be selected for their compatibility with the reactor helium environment as described in Articles [TBD] of the ASME Code. The tempering temperature of martensitic stainless steels and the aging temperature of precipitation-hardening stainless steels should be specified for assurance that these materials will not deteriorate from stress corrosion cracking in service.

4. Cleaning and Cleanliness Control. Onsite cleaning and cleanliness control should be in accordance with ASME NQA-1[TBD] edition.

\section{$\underline{\text { Technical Rationale }}$}

Comment [A204]: The need for new codes and standards for mHTGRs and applicability of specific parts and revisions of existing codes and standards must be determined

Comment [A205]: The need for new codes an standards for mHTGRs and applicability of specific parts and revisions of existing codes and standards must be determined

Comment [A206]: The need for new codes an standards for mHTGRs and applicability of specific parts and revisions of existing codes and standards must be determined
Comment [A201]: The need for new codes and must be determined

Comment [A203]: The applicability of LWRbased RGs must be considered. 
The technical rationale for application of these acceptance criteria to the areas of review addressed by this $\mathrm{mHTGR}$-RP section is discussed in the following paragraphs:

1. mHTGR-DC 1 and 10 CFR 50.55a require that SSCs be designed, fabricated, erected, constructed, tested, and inspected to quality standards commensurate with the importance of the safety functions performed. 10 CFR $50.55 \mathrm{a}$ also incorporates by reference applicable editions and addenda of the ASME Boiler and Pressure Vessel Code. The control rod drive system positions control rods for reactivity control and comprises a part of the HPB. Application of 10 CFR 50.55a and mHTGR-DC 1 to the control rod drive structural materials provides assurance that the control rod drive structure materials will perform as designed.

2. mHTGR-DC 14 requires that the HPB be designed, fabricated, erected, and tested so as to have an extremely low probability of abnormal leakage, of rapidly propagating failure, and of gross rupture. The HPB provides a fission product barrier and a confined volume for the inventory of reactor helium. The HPB includes portions of the control rod drive system. Application of mHTGR-DC 14 assures that control rod drive materials are selected, fabricated, installed, and tested for an extremely low probability of significant degradation and, in the extreme, gross HPB failure that could substantially reduce capability to contain reactor helium inventory or capability to confine fission products.

3. mHTGR-DC 26 establishes requirements for reactivity control system redundancy and capability. mHTGR-DC 26 requires a control rod system, preferably including a positive means for inserting the rods, capable of reliably controlling reactivity changes to assure that under conditions of normal operation, including anticipated operational occurrences, the specified acceptable core radionuclide release design limits are not exceeded. The control rod drive system provides for rod positioning including insertion for reactivity control. Application of mHTGR-DC 26 to the control rod drive system materials ensures that material selection and fabrication support reliable rod movement for reactivity control; it also preserves fuel integrity, the primary barrier to the release of fission products.

\section{REVIEW PROCEDURES}

The reviewer will select material from the procedures described below, as may be appropriate for a particular case.

These review procedures are based on the identified mHTGR-RP acceptance criteria. For deviations from these acceptance criteria, the staff should review the applicant's evaluation of how the proposed alternatives provide an acceptable method of complying with the relevant NRC requirements identified in Subsection II.

1. Material Specifications. The reviewer compares the properties of the material proposed for the control rod system to the criteria of [TBD], or acceptable material code cases. The reviewer verifies whether cold-worked austenitic stainless steels used in fabrication of the reactivity control mechanisms comply with Subsection II.1 of the ASME Code.

2. Austenitic Stainless Steel Components. Review procedures include those described in mHTGR-RP Section 5.2.3, Subsections III.4.D and E. The reviewer examines the applicant's 1) methods of controlling sensitized stainless steel and compares them to the positions of RG 1.44, especially as to cleaning and protection from contamination during

Comment [A207]: The need for new codes and standards for mHTGRs and applicability of specific parts and revisions of existing codes and standards must be determined

Comment [A208]: RG 1.85 has been withdrawn. Reference to RG 1.85 is deleted. 
handling and storage, 2) verification of non-sensitization of the material, and 3) qualification of the welding process for production. The qualification of the welding process uses the [TBD]. If the applicant proposes alternative methods of testing the qualification welds for degree of sensitization, the reviewer determines whether these are satisfactory, taking into account branch positions taken on previous applications and their degrees of equivalence. The reviewer may ask the applicant to justify the technical basis for any departures from the cited positions. Alternative tests that have been accepted include the use of [TBD].

The reviewer examines the methods of controlling and measuring the amount of delta ferrite in stainless steel weld deposits and compares them to the criteria of the [TBD], especially as to the filler metal acceptance procedures for the determination of delta ferrite content. If the applicant proposes alternative positions, the reviewer determines whether these are satisfactory, taking into account branch positions on previous applications. The reviewer may ask the applicant to justify the technical basis for any departures from the acceptance criteria stated in subsection II.2 of this mHTGR-RP section.

The reviewer verifies the applicant's description of abrasive work controls for austenitic stainless steel surfaces is adequate to minimize the cold-working of surfaces and the introduction of contaminants that may promote stress corrosion cracking.

3. Other Materials. The reviewer examines the information in the applicant's safety analysis report on the compatibility of the materials (other than austenitic stainless steels) in contact with the reactor helium to determine whether the materials are compatible with the modular HTGR service environment so that unacceptable degradation due to corrosion or stress corrosion of the component will not occur during its lifetime. Metallic and nonmetallic materials identified in subsection I.3 of this mHTGR-RP section are reviewed for compatibility so loss of integrity will not occur during the life of the component.

Operating experience indicates that certain nickel-chromium-iron alloys (e.g., Inconel) are susceptible to cracking due to corrosion. Inconel 690 alloy has improved corrosion resistance compared to Inconel alloy 600 previously used in reactor applications. Where nickel-chromium-iron alloys are proposed, the reviewer verifies whether an acceptable technical basis is either identified (by demonstrated satisfactory use in similar applications) or presented by the applicant for use of the material. The reviewer particularly emphasizes the corrosion-resistant and stress corrosion cracking-resistant properties of the proposed nickel-chromium-iron alloy(s).

The reviewer determines whether the tempering temperatures of all martensitic stainless steels and the aging temperatures of precipitation-hardening stainless steels have been specified and are in accordance with the acceptance criteria of subsection II.3 of this mHTGR-RP section.

4. Cleaning and Cleanliness Control. The reviewer verifies whether onsite cleaning and cleanliness control procedures are satisfactory and in accordance with the acceptance criteria stated in subsection II.4 of this MHTGR-RP section.

5. For review of a DC application, the reviewer should follow the above procedures to verify that the design, including requirements and restrictions (e.g., interface requirements and
Comment [A209]: The need for new codes and standards for mHTGRs and applicability of specific parts and revisions of existing codes and standards must be determined

Comment [A210]: A-708-1974 is withdrawn

Comment [A211]: The need for new codes and standards for mHTGRs and applicability of specific parts and revisions of existing codes and standards must be determined 
site parameters), set forth in the final safety analysis report (FSAR) meets the acceptance criteria. DCs have referred to the FSAR as the design control document (DCD). The reviewer should also consider the appropriateness of identified COL action items. The reviewer may identify additional COL action items; however, to ensure these COL action items are addressed during a COL application, they should be added to the DC FSAR.

For review of a COL application, the scope of the review is dependent on whether the COL applicant references a DC, an early site permit (ESP) or other NRC approvals (e.g., manufacturing license, site suitability report or topical report).

6. For review of both DC and COL applications, mHTGR-RP Section 14.3 should be followed for the review of ITAAC. The review of ITAAC cannot be completed until after the completion of this section.

\section{EVALUATION FINDINGS}

The reviewer verifies that the applicant has provided sufficient information and that the review and calculations (if applicable) support conclusions of the following type to be included in the staff's safety evaluation report. The reviewer also states the bases for those conclusions.

1. The staff concludes that the CRDM structural materials are acceptable and meet the requirements of $\mathrm{mHTGR}-\mathrm{DCs} 1,14$, and 26 and of 10 CFR $50.55 \mathrm{a}$. This conclusion is based on the applicant's demonstration that the properties of materials selected for the CRDM components exposed to the reactor coolant satisfy [TBD], and the applicant's compliance with the staff position that the yield strength of cold-worked austenitic stainless steel should not exceed [TBD]. As to materials not selected in accordance with ASME Code provisions, the applicant has used materials of construction that are in accordance with the acceptable ASME code cases described in RG X.XX [TBD] or that are otherwise acceptable for the application.

2. In addition, the controls imposed upon the austenitic stainless steel of the mechanisms comply with the criteria of [TBD], ASME NQA-1-[TBD] Edition, RG 1.44, "Control of the Use of Sensitized Stainless Steel," and the related criteria described in mHTGR-RP Section 5.2.3, "Reactor Helium Pressure Boundary Materials." Fabrication and heat treatment practices in accordance with these recommendations add assurance that stress corrosion cracking will not occur during the design life of the component. Both martensitic and precipitation-hardening stainless steels have been given tempering or aging treatments in accordance with staff positions. Cleanliness control is in accordance with ASME NQA-1-[TBD] Edition.

3. For DC and COL reviews, the findings will also summarize the staff's evaluation of requirements and restrictions (e.g., interface requirements and site parameters) and $\mathrm{COL}$ action items relevant to this $\mathrm{mHTGR}-\mathrm{RP}$ section.

4. In addition, to the extent that the review is not discussed in other SER sections, the findings will summarize the staff's evaluation of the ITAAC, including design acceptance criteria, as applicable. 


\section{IMPLEMENTATION}

The staff will use this mHTGR-DC section in performing safety evaluations of DC applications and license applications submitted by applicants pursuant to 10 CFR Part 50 or 10 CFR Part 52. Except when the applicant proposes an acceptable alternative method for complying with specified portions of the Commission's regulations, the staff will use the method described herein to evaluate conformance with Commission regulations.

The provisions of this mHTGR-RP section apply to reviews of applications submitted six months or more after the date of issuance of this mHTGR-RP section, unless superseded by a later revision.

\section{REFERENCES}

The following list of references was not reviewed in detail for applicability to mHTGR designs. References to materials produced by the NRC that have since been withdrawn-such as regulatory guides-are proposed for deletion. In addition, NRC letters and industry letters on very specific $L W R$ topics are proposed for deletion from the reference list. The remainder of the original SRP reference list, including industry codes and standards, is left to provide insight on the topical areas necessary to provide adequate review. Additional effort will be required to either enhance the information in the existing references to be relevant to advanced non-LWR designs, replace existing references with equivalent documentation, or delete references as appropriate.

1. $\quad 10$ CFR 50.55a, "Codes and Standards."

2. MHTGR-DC 1, "Quality Standards and Records."

3. mHTGR-DC 14, "Reactor Helium Pressure Boundary."

4. mHTGR-DC 26, "Reactivity Control System Redundancy and Capability."

5. Regulatory Guide 1.44, "Control of the Use of Sensitized Stainless Steel."

6. ASME Boiler and Pressure Vessel Code, Section II, "Materials," Parts A, B, C, and D; and Section III, "Rules for Construction of Nuclear Plant Components," Division 1, including Appendix I; American Society of Mechanical Engineers.

7. ASTM, A-262-1970, "Detecting Susceptibility to Intergranular Attack in Stainless Steels;" Practice A "Oxalic Acid Etch Test for Classification of Etch Structures of Stainless Steels"; Practice E, "Copper-Copper Sulfate-Sulfuric Acid Test for Detecting Susceptibility to Intergranular Attack in Stainless Steels"; Annual Book of ASTM Standards, American Society for Testing and Materials.

8. ASTM A-708-1974, "Detection of Susceptibility to Intergranular Corrosion in Severely Sensitized Austenitic Stainless Steel," Annual Book of ASTM Standards, American Society for Testing and Materials. 
9. ASME NQA-1-1994 Edition, "Quality Assurance Requirements for Nuclear Facility Applications," Revision and Consolidation of ASME NQA-1-1989 and ASME NQA-2-1989 Editions, American Society of Mechanical Engineers.

Comment [A219]: The need for new codes and standards for mHTGRs and applicability of specific parts and revisions of existing codes and standards must be determined 



\title{
MODULAR HIGH TEMPERATURE GAS- COOLED REACTOR REVIEW PLAN
}

\author{
4.5.2 REACTOR INTERNAL AND CORE SUPPORT STRUCTURE MATERIALS \\ REVIEW RESPONSIBILITIES \\ Primary - Organization responsible for review of component integrity issues related to \\ reactor vessel internals
}

Secondary - Organization responsible for the review of materials engineering issues related to flaw evaluation and welding

\section{AREAS OF REVIEW}

Section 50.55a, "Codes and Standards," of 10 CFR Part 50, and modular High Temperature Gas-cooled Reactor Design Criterion (mHTGR-DC) 1 are reflected in Draft Regulatory Guide DG-1330 (Proposed New Regulatory Guide 1.232) as guidance for complying with the requirements of 10 CFR Part 50, Appendix A General Design Criteria 1 require that structures, systems, and components (SSCs) important to safety be designed, fabricated, and tested to quality standards commensurate with the importance of the safety function to be performed. The purpose of this mHTGR review plan (mHTGR-RP) section is to review and evaluate the adequacy of the metallic materials and graphite selected for the construction of the reactor internal and core support structures and to assure that the reactor internal and core support structures (including nuclear grade graphite) meet applicable regulations, including [TBD] of Section III of the ASME Boiler and Pressure Vessel Code (hereafter "the Code"). The reactor internal and core support structures reviewed under this mHTGR-RP section include all structures and components within the pressure vessel other than the fuel and control assemblies, and instrumentation.

This mHTGR-RP section covers the material, component design, fabrication and inspection to assure structural integrity in compliance with mHTGR-DC 1 and Section 50.55a.

The following areas in the applicant's safety analysis report (SAR) relating to reactor internal and core support structure materials are reviewed; specific areas of review are as follows:

1. Materials. The review includes the acceptability of the materials, including weld materials, to be used for the reactor internals and core support structures.

The adequacy and suitability of the materials specified for the reactor internals and core support structures are reviewed in terms of their fracture toughness, stress corrosion resistance, fabricability, use in high temperature and high radiation environments, and other mechanical and physical properties.

Note: While ASME design rules for high temperature metallic components have been developed (i.e., ASME Code, Section III, Division 5, Subpart A, "Metallic Materials."), this code section has not yet been endorsed by the NRC. Therefore, the designation "TBD"

Comment [A220]: This text anticipates the NRC RG for advanced reactor design criteria and subsequent mHTGR-DC (proposed RG 1.232). The current markup reflects the proposed language in Draft RG-1330.

Comment [A221]: The need for new codes and standards for mHTGRs and applicability of specific parts and revisions of existing codes and standards must be determined 
is used to identify areas where later endorsed code references can be inserted at a later date.

2. Controls on Welding. The review includes the controls on welding for reactor internals and core support structures.

3. Nondestructive Examination. The review includes information submitted by the applicant on the nondestructive examination procedures used for inspection of each product form.

4. Austenitic Stainless Steel. Austenitic stainless steels may be used for the construction of the reactor internals and core support structures. These steels may be used in a variety of product forms, including several stabilized product forms. Unstabilized austenitic stainless steels, such as Types 304 and 316, may be specified.

Since unstabilized compositions are susceptible to stress corrosion cracking when exposed to certain environmental conditions, process controls must be exercised during all stages of component manufacturing and reactor construction to avoid sensitization of the material, and to minimize exposure of the stainless steel to contaminants that lead to stress corrosion cracking. The review includes information submitted by the applicant in these areas, as described in MHTGR-RP Section 5.2.3, "Reactor Helium Pressure Boundary Materials."

5. Graphite. Nuclear grade graphite components are relied upon to establish core geometry, serve as the moderator in support of the nuclear heat generation process, and direct the flow of helium coolant. They also serve as a path for passive removal of heat in the case of certain licensing basis events. Graphite components are evaluated in terms of dimensional changes under irradiation, density, structural/seismic loads, neutron absorption cross-section, and thermal conductivity. These properties are a function of the raw materials used during fabrication and their associated impurities.

Note: While ASME design rules for nuclear grade graphite have been developed (i.e., ASME Code, Section III, Division 5, Subpart B, "Graphite Materials."), this code section has not yet been endorsed by the NRC. Therefore, the designation "TBD" is used to identify areas where later endorsed code references can be inserted at a later date.

6. Other Materials. Materials other than austenitic stainless steels are reviewed and evaluated in terms of their fracture toughness, corrosion resistance, fabricability, suitability for high temperature and high radiation conditions, and other mechanical and physical properties.

7. Inspections, Tests, Analyses, and Acceptance Criteria (ITAAC). For design certification (DC) and combined license (COL) reviews, the staff reviews the applicant's proposed ITAAC associated with the structures, systems, and components (SSCs) related to this mHTGR-RP section in accordance with mHTGR-RP Section 14.3, "Inspections, Tests, Analyses, and Acceptance Criteria." The staff recognizes that the review of ITAAC cannot be completed until after the rest of this portion of the application has been reviewed against acceptance criteria contained in this mHTGR-RP section. Furthermore, the staff reviews the ITAAC to ensure that all SSCs in this area of review are identified and addressed as appropriate in accordance with mHTGR-RP Section 14.3 
8. COL Action Items and Certification Requirements and Restrictions. For a DC application, the review will also address COL action items and requirements and restrictions (e.g., interface requirements and site parameters).

For a COL application referencing a DC, a COL applicant must address COL action items (referred to as COL license information in certain DCs) included in the referenced DC. Additionally, a COL applicant must address requirements and restrictions (e.g., interface requirements and site parameters) included in the referenced DC.

\section{$\underline{\text { Review Interfaces }}$}

Other mHTGR-RP sections interface with this section as follows:

1. The review of the adequacy of programs for assuring the integrity of bolting and threaded fasteners is performed under mHTGR-RP Section 3.13, "Threaded Fasteners - ASME Code 1, 2, and 3."

2. The evaluation of corrosion and compatibility of reactor internals and core support structures materials with the expected environment during service is performed using procedures under mHTGR-RP Section 5.2.3, "Reactor Helium Pressure Boundary Materials."

3. The review of acceptability of the reactor helium contaminant chemistry and associated Helium Purification System as it relates to removal of chemical and radioactive impurities is performed under mHTGR-RP Section [TBD].

4. The review of the adequacy of design fatigue curves for reactor internals and core support structures materials with respect to cumulative reactor service-related environmental and usage factor effects and consideration of each combination of loadings is performed under mHTGR-RP Sections 3.9.1, "Special Topics for Mechanical Components," and 3.9.3, "ASME Code Class 1, 2, and 3 Components, Component Supports, and Core Support Structures."

5. The review of the reactor internals and core support structures with respect to their mechanical design adequacy to withstand design and service loading combinations is performed under mHTGR-RP Section 3.9.5, "Reactor Vessel Internals."

6. The review of the plant design, including the selection of materials to minimize activation products, to verify that occupational radiation exposures will be as low as is reasonably achievable (ALARA) is performed under mHTGR-RP Section 12.1, "Assuring That Occupational Radiation Exposures Are As Low As Is Reasonably Achievable."

The specific acceptance criteria and review procedures are contained in the reference mHTGR-RP sections.

\section{ACCEPTANCE CRITERIA}

\section{$\underline{\text { Requirements }}$}

Acceptance criteria are based on meeting the relevant requirements of the following Commission regulations:

Comment [A222]: The need for new codes and standards for mHTGRs and applicability of specific parts and revisions of existing codes and standards must be determined

Comment [A223]: Clarified the relationship between 4.5.2 and 5.2.3. Section 5.2.3 does not specifically address reactor internals or core suppor structures but it provides procedures that could be used for internals and core support materials. 
The design, fabrication, and testing of the materials used in the reactor internals and core support structures are reviewed and evaluated to meet codes and standards commensurate with the safety functions to be performed such that the relevant requirements of $10 \mathrm{CFR} 50.55 \mathrm{a}$ and $\mathrm{mHTGR}$-DC 1 are met.

1. 10 CFR 50.55a, "Codes and Standards," which requires that SSCs shall be designed, fabricated, erected, constructed, tested, and inspected to quality standards commensurate with the importance of the safety function to be performed.

2. mHTGR-DC 1, "Quality Standards and Records," which requires that SSCs important to safety shall be designed, fabricated, erected, and tested to quality standards commensurate with the importance of the safety functions to be performed. Where generally recognized codes and standards are used, they shall be identified and evaluated to determine their applicability, adequacy, and sufficiency and shall be supplemented or modified as necessary to assure a quality product in keeping with the required safety function. $\mathrm{mHTGR}$-DC 1 also requires that appropriate records of the design, fabrication, erection, and testing of SSCs important to safety shall be maintained by or under the control of the nuclear power unit licensee throughout the life of the unit.

3. 10 CFR $52.47(b)(1)$, which requires that a DC application contain the proposed inspections, tests, analyses, and acceptance criteria (ITAAC) that are necessary and sufficient to provide reasonable assurance that, if the inspections, tests, and analyses are performed and the acceptance criteria met, a plant that incorporates the design certification is built and will operate in accordance with the design certification, the provisions of the Atomic Energy Act, and the NRC's regulations;

4. $\quad 10$ CFR 52.80(a), which requires that a COL application contain the proposed inspections, tests, and analyses, including those applicable to emergency planning, that the licensee shall perform, and the acceptance criteria that are necessary and sufficient to provide reasonable assurance that, if the inspections, tests, and analyses are performed and the acceptance criteria met, the facility has been constructed and will operate in conformity with the combined license, the provisions of the Atomic Energy Act, and the NRC's regulations.

\section{$\underline{\text { mHTGR-RP Acceptance Criteria }}$}

Specific mHTGR-RP acceptance criteria acceptable to meet the relevant requirements of the NRC's regulations identified above are as follows for the review described in this $\mathrm{MHTGR}-\mathrm{RP}$ section. The mHTGR-RP is not a substitute for the NRC's regulations, and compliance with it is not required. However, an applicant is required to identify differences between the design features, analytical techniques, and procedural measures proposed for its facility and the mHTGR-RP acceptance criteria and evaluate how the proposed alternatives to the mHTGR-RP acceptance criteria provide acceptable methods of compliance with the NRC regulations.

1. Materials. For core support structures and reactor internals, the permitted material specifications are those given in [TBD] and any subsequent code cases. The properties of these materials are specified in Tables [TBD] of Section II of the Code.

Additional permitted materials and their applications are identified in ASME Code Cases approved for use as described in [TBD].

Comment [A224]: The need for new codes and standards for mHTGRs and applicability of specific parts and revisions of existing codes and standards must be determined

Comment [A225]: The need for new codes and standards for mHTGRs and applicability of specific parts and revisions of existing codes and standards must be determined 
2. Controls on Welding. Methods and controls for core support structures and reactor internals welds shall be in accordance with [TBD]. The examination requirements and acceptance criteria for these welds are specified in Article [TBD].

3. Nondestructive Examination. Nondestructive examinations shall be in accordance with the requirements of [TBD]. The nondestructive examination acceptance criteria shall be in accordance with the requirements of [TBD].

4. Austenitic Stainless Steels. The acceptance criteria for this area of review are given in mHTGR-RP Section 5.2.3, subsections II.2 and II.4.a, b, d, and e.

Regulatory Guide 1.44 provides acceptance criteria for preventing intergranular corrosion of stainless steel components. In conformance with this guide, furnace sensitized material should not be allowed. Methods described in this guide should be followed for cleaning and protecting austenitic stainless steel from contamination during handling, storage, testing, and fabrication, and for determining the degree of sensitization that occurs during welding.

5. Graphite. The requirements for the design, construction, examination, and testing of graphite Core Components and Graphite Core Assemblies used within the reactor pressure vessels of nuclear power plants are found in [TBD].

6. Other Materials. All materials used for reactor internals and core support structures must be selected for compatibility with the potential reactor helium contaminants, as specified in [TBD]. The tempering temperature of martensitic stainless steels and the aging temperature of precipitation-hardened stainless steels should be specified to provide assurance that these materials will not deteriorate in service.

Other materials shall have similar appropriate heat treat and fabrication controls in accordance with strength and compatibility requirements.

\section{$\underline{\text { Technical Rationale }}$}

The technical rationale for application of these acceptance criteria to the areas of review addressed by this mHTGR-RP section is discussed in the following paragraphs:

mHTGR-DC 1 and 10 CFR 50.55a require that SSCs be designed, fabricated, erected, constructed, tested, and inspected to quality standards commensurate with the importance of the safety function to be performed. $10 \mathrm{CFR} 50.55 \mathrm{a}$ also incorporates by reference the applicable editions and addenda of the ASME Boiler and Pressure Vessel Code. The reactor internals and core support structures include SSCs that perform safety functions and/or whose failure could affect the performance of safety functions by other SSCs. These safety functions include reactivity monitoring and control, passive core cooling, and fission product confinement (within both the coated particle fuel and the reactor helium pressure boundary). Application of $10 \mathrm{CFR} 50.55 \mathrm{a}$ and $\mathrm{mHTGR}-\mathrm{DC} 1$ to the materials of construction provides assurance that established standard practices of proven or demonstrated effectiveness for selecting materials, fabrication, and testing/ inspection of SSCs are used to achieve a high likelihood that these safety functions will be performed.
Comment [A226]: The need for new codes and standards for mHTGRs and applicability of specific parts and revisions of existing codes and standards must be determined

Comment [A227]: The need for new codes and standards for mHTGRs and applicability of specific parts and revisions of existing codes and standards must be determined

Comment [A228]: The need for new codes and standards for mHTGRs and applicability of specific parts and revisions of existing codes and standards must be determined

Comment [A229]: The need for new codes and standards for mHTGRs and applicability of specific parts and revisions of existing codes and standards must be determined 


\section{REVIEW PROCEDURES}

The reviewer will select material from the procedures described below, as may be appropriate for a particular case.

These review procedures are based on the identified mHTGR-RP acceptance criteria. For deviations from these acceptance criteria, the staff should review the applicant's evaluation of how the proposed alternatives provide an acceptable method of complying with the relevant NRC requirements identified in Subsection II.

1. Materials. The list of the materials for reactor internals and core support structures that are exposed to potential reactor helium contaminants is reviewed.

The metallic materials identified for each component or part used in the reactor internals and core support structures are compared with the materials identified as being acceptable in [TBD]. The requirements for nuclear grade graphite are found in [TBD]. The reviewer verifies that any exceptions to the ASME Code-specified materials are clearly identified. The reviewer evaluates the basis for the exceptions, taking into account precedents set in earlier cases, and determines the acceptability of such materials.

2. Controls on Welding. The reviewer verifies that welding methods and controls for the reactor internals and core support structures are in accordance with the procedures of [TBD]. The reviewer verifies that welding controls submitted by the applicant are in conformance with the welding controls in mHTGR-RP Section 5.2.3, which are also considered applicable to welding of reactor internals. The reviewer assures that any special welding processes or welding controls conform to the qualification requirements of ASME Code, Section IX, or that justification is made for any deviation.

3. Nondestructive Examination. The information submitted by the applicant is reviewed to determine methods used for nondestructive examination. The reviewer verifies that the nondestructive examination methods proposed by the applicant are in conformance with the examination methods specified by the ASME Code. [TBD] of the ASME Code specifies that examination by either radiographic or ultrasonic examination plus surface examinations as required is acceptable. Nondestructive examination requirements for nuclear grade graphite are found in [TBD].

4. Austenitic Stainless Steel. The materials and fabrication procedures used for reactor internals are reviewed. The areas of review and review procedures include those described in mHTGR-RP Section 5.2.3. The reviewer verifies that environmental conditions are controlled and welding procedures are developed such that the probabilities of sensitization and microfissuring are minimized. mHTGR-RP Section 4.5.1, Subsection III.2, identifies an acceptable alternate to the methods described in Regulatory Guide 1.44 for verifying the degree of sensitization that occurs during welding. In addition, the reviewer verifies that materials are selected to assure compatibility with the compositions of potential reactor helium contaminants.

Comment [A230]: The need for new codes and standards for mHTGRs and applicability of specific parts and revisions of existing codes and standards must be determined

Comment [A231]: The need for new codes and standards for mHTGRs and applicability of specific parts and revisions of existing codes and standards must be determined

Comment [A232]: The need for new codes and standards for mHTGRs and applicability of specific parts and revisions of existing codes and standards must be determined 
Where cast austenitic stainless steels are proposed for use, the reviewer verifies that, under the expected environmental conditions, the selected material will provide adequate fracture toughness over its design life (e.g., considering thermal aging due to exposure to reactor helium operating temperatures).

5. Graphite. The information submitted by the applicant is reviewed to determine if the nuclear grade graphite was constructed with accepted materials and fabricated in accordance with the design rules found in [TBD]. Ensure that the applicant includes consideration of mechanical and thermal stresses due to cyclic operation and deterioration that may occur in service as a result of radiation effects and oxidation. Design properties important to the evaluation of irradiation induced and mechanical loads and stresses in accordance with the ASME graphite design rules are found in [TBD].

6. Other Materials. The reviewer verifies that the heat treatment and welding controls provided in the material specifications and fabrication procedures are appropriate for the material. The reviewer verifies that the fabrication and cleaning controls will preclude contamination of materials, e.g., by chloride ions, fluoride ions, or lead.

The reviewer verifies that acceptable augmented inspection requirements have been proposed based on operating experience and service conditions. For all HPB environments, particular review emphasis is placed upon the materials and other degradation mechanisms.

7. For review of a DC application, the reviewer should follow the above procedures to verify that the design, including requirements and restrictions (e.g., interface requirements and site parameters), set forth in the final safety analysis report (FSAR) meets the acceptance criteria. DCs have referred to the FSAR as the design control document (DCD). The reviewer should also consider the appropriateness of identified COL action items. The reviewer may identify additional COL action items; however, to ensure these COL action items are addressed during a COL application, they should be added to the DC FSAR.

For review of a $\mathrm{COL}$ application, the scope of the review is dependent on whether the $\mathrm{COL}$ applicant references a DC, an early site permit (ESP) or other NRC approvals (e.g., manufacturing license, site suitability report or topical report).

8. For review of both DC and COL applications, mHTGR-RP Section 14.3 should be followed for the review of ITAAC. The review of ITAAC cannot be completed until after the completion of this section.

\section{EVALUATION FINDINGS}

The reviewer verifies that the applicant has provided sufficient information and that the review and calculations (if applicable) support conclusions of the following type to be included in the staff's safety evaluation report. The reviewer also states the bases for those conclusions.

1. The staff concludes that the materials used for the reactor internals and core support structures are acceptable and meet the requirements of 10 CFR 50.55a and mHTGRDC 1. This conclusion is based upon the following considerations: 
The applicant has selected, and identified by specification, materials for the reactor internals and core support structures that satisfy the requirements of [TBD] and Tables [TBD] of Section II of the ASME Code. For materials not in accordance with ASME Code provisions, the applicant has selected materials of construction that are approved for use by NRC-accepted ASME Code Cases, as identified in [TBD], or that have otherwise been demonstrated acceptable for the application. As proven by extensive tests and satisfactory performance, the specified materials are compatible with the expected environment and corrosion is expected to be negligible.

The applicant has demonstrated that the design, fabrication, and testing of the materials used in the reactor internals and core support structures are of high quality standards and are adequate to assure structural integrity. The controls imposed upon austenitic stainless steel components satisfy the positions of Regulatory Guide 1.44, "Control of the Use of Sensitized Stainless Steel," and the related criteria provided in mHTGR-RP Section 5.2.3, "Reactor Helium Pressure Boundary Materials."

The controls imposed on the helium purity provide reasonable assurance that the reactor internals and core support structures will be adequately protected during operation from conditions that could lead to degradation of the materials and loss of component structural integrity.

The material selection, fabrication practices, examination and testing procedures, and control practices provide reasonable assurance that the materials used for the reactor internals and core support structures will be in a metallurgical condition that will preclude inservice deterioration.

Conformance with relevant requirements of the ASME Code, or accepted Code Cases, and the recommendations of Regulatory Guides [TBD] and 1.44 and the related criteria in mHTGR-RP Section 5.2.3, constitutes an acceptable basis for meeting the relevant requirements of 10 CFR 50.55a and mHTGR-DC 1.

2. For DC and COL reviews, the findings will also summarize the staff's evaluation of requirements and restrictions (e.g., interface requirements and site parameters) and COL action items relevant to this mHTGR-RP section.

3. In addition, to the extent that the review is not discussed in other SER sections, the findings will summarize the staff's evaluation of the ITAAC, including design acceptance criteria, as applicable.

\section{IMPLEMENTATION}

The following is intended to provide guidance to applicants and licensees regarding the staff's plan for implementing this section of the Standard Review Plan.

The staff will use this mHTGR-RP section in performing safety evaluations of DC applications and license applications submitted by applicants pursuant to 10 CFR Part 50 or 10 CFR Part 52. Except when the applicant proposes an acceptable alternative method for complying with specified portions of the Commission's regulations, the staff will use the method described herein to evaluate conformance with Commission regulations.
Comment [A233]: The need for new codes and standards for mHTGRs and applicability of specific parts and revisions of existing codes and standards must be determined

Comment [A234]: The need for new codes and standards for mHTGRs and applicability of specific parts and revisions of existing codes and standards must be determined 
The provisions of this mHTGR-RP section apply to reviews of applications submitted six months or more after the date of issuance of this mHTGR-RP section, unless superseded by a later revision.

Implementation schedules for conformance to parts of the method discussed herein are contained in the referenced regulatory guides.

\section{REFERENCES}

The following list of references was not reviewed in detail for applicability to mHTGR designs. References to materials produced by the NRC that have since been withdrawn-such as regulatory guides-are proposed for deletion. In addition, NRC letters and industry letters on very specific LWR topics are proposed for deletion from the reference list. The remainder of the original SRP reference list, including industry codes and standards, is left to provide insight on the topical areas necessary to provide adequate review. Additional effort will be required to either enhance the information in the existing references to be relevant to advanced non-LWR designs, replace existing references with equivalent documentation, or delete references as appropriate.

1. $\quad 10$ CFR 50.55a, "Codes and Standards."

2. MHTGR-DC 1, "Quality Standards and Records."

3. Regulatory Guide 1.44, "Control of the Use of Sensitized Stainless Steel."

4. Regulatory Guide 1.84, "Design, Fabrication, and Material Code Case Acceptability, ASME Section III."

5. ASME Boiler and Pressure Vessel Code, Section II, "Materials," Tables 2A, 2B and 4; Section III, "Rules for Construction of Nuclear Facility Components," Division 1; and Section IX, "Welding and Brazing Qualifications." American Society of Mechanical Engineers.

Comment [A235]: The need for new codes and standards for mHTGRs and applicability of specific parts and revisions of existing codes and standards must be determined. 



\title{
MODULAR HIGH TEMPERATURE GAS- COOLED REACTOR REVIEW PLAN
}

\author{
4.6 FUNCTIONAL DESIGN OF CONTROL ROD DRIVE SYSTEM \\ REVIEW RESPONSIBILITIES
}

Primary - $\quad$ Organization responsible for the review of transient and accident analyses

Secondary - Organization responsible for the review of plant design for protection of structures, systems, and components from internal and external hazards

\section{AREAS OF REVIEW}

The organization responsible for reactor systems reviews the functional performance of the control rod drive system (CRDS) to confirm the system can affect a safe shutdown, respond within acceptable limits during anticipated operational occurrences (AOOs), and prevent or mitigate the consequences of design basis events (DBEs) and design basis accidents (DBAs). The review covers the CRDS to ensure conformance with modular High Temperature GasCooled Reactor Design Criteria (mHTGR-DC) 4, 23, 25, 26, 28, and 29 which are reflected in Draft Regulatory Guide DG-1330 (Proposed New Regulatory Guide 1.232) as guidance for complying with the requirements of 10 CFR Part 50, Appendix A General Design Criteria (GDC) $4,23,25,26,28$, and 29.

The specific areas of review are as follows:

1. Examination of the CRDS design to identify possible single failures.

2. Evaluation of the CRDS to verify the following:
A. Essential portions can be isolated from nonessential portions.
B. The CRDS cooling system meets the design requirements.
C. The functional tests verify the proper rod insertion, withdrawal, and scram operation times, or that the inspections, tests, analyses, and acceptance criteria (ITAAC) are sufficient to ensure that rod insertion, withdrawal, and scram operation times will operate in accordance with the certification.

D. Redundant reactivity control systems are not vulnerable to common mode failures.

3. Inspections, Tests, Analyses, and Acceptance Criteria (ITAAC). For design certification (DC) and combined license (COL) reviews, the staff reviews the applicant's proposed ITAAC associated with the structures, systems, and components (SSCs) related to this mHTGR-Review Plan (mHTGR-RP) section in accordance with mHTGR-RP Section 
14.3, "Inspections, Tests, Analyses, and Acceptance Criteria." The staff recognizes that the review of ITAAC cannot be completed until after the rest of this portion of the application has been reviewed against acceptance criteria contained in this MHTGR-RP section. Furthermore, the staff reviews the ITAAC to ensure that all SSCs in this area of review are identified and addressed as appropriate in accordance with $\mathrm{mHTGR}-\mathrm{RP}$ Section 14.3.

4. COL Action Items and Certification Requirements and Restrictions. For a DC application, the review will also address COL action items and requirements and restrictions (e.g., interface requirements and site parameters).

For a COL application referencing a DC, a COL applicant must address COL action items (referred to as COL license information in certain DCs) included in the referenced DC. Additionally, a COL applicant must address requirements and restrictions (e.g., interface requirements and site parameters) included in the referenced DC.

\section{$\underline{\text { Review Interfaces }}$}

Other mHTGR-RP sections interface with this section as follows:

1. The review encompasses all transients and accidents in Chapter 15 of the safety analysis report (SAR) that requires reactivity control systems to function. The reviewer ascertains that the reactivity and response characteristics of the reactivity control system are conservative with respect to the parameters assumed in the Chapter 15 analyses.

2. Verification of the reactivity control requirements is performed under $\mathrm{mHTGR}-\mathrm{RP}$ Section 4.3.

3. Verification of the results of failure modes and effects analyses to ensure that a single failure occurring in the control rod system, or an operator error, will not result in the loss of capability for safe shutdown is performed under mHTGR-RP Section 7.2.

4. Verification of the adequacy of the control rod drive mechanisms to perform their mechanical functions (e.g., rod insertion and withdrawal, scram operation and time) and to maintain the reactor helium pressure boundary is performed under mHTGR-RP Section 3.9.4. Verification that the design and requirements, as applicable to the assigned safety class and seismic category, are met is performed under mHTGR-RP Sections 3.2.1 and 3.2.2. Under mHTGR-RP Section 3.6.2, postulated piping failures, including their associated locations and dynamic effects, are evaluated, as they relate to the protection of SSCs against such effects.

5. Determination of the acceptability of the design and analyses, procedures, and criteria used to establish the ability of seismic Category I structures housing the system and supporting systems to withstand the effects of natural phenomena such as the safeshutdown earthquake, the probable maximum flood, and the tornado missiles, is performed under mHTGR-RP Sections 3.3.1, 3.3.2, 3.5.3, 3.7.1 through 3.7.4, 3.8.4, and 3.8.5.

6. Verification of the adequacy of the design, installation, inspection, and testing of all electrical systems (sensing, control, and power) required for proper operation is 
performed under mHTGR-RP Section 7.1 and Appendix 7-A and mHTGR-RP Section 8.3.1.

7. The evaluation of potential sources of internally generated missiles and, where applicable, determination that SSCs are adequately protected against the effects of such missiles are performed under mHTGR-RP Sections 3.5.1.1 and 3.5.1.2. The verification of the adequacy of specified environments and service conditions for equipment qualification as they relate to the locations of affected equipment and the overall demonstration that systems and components are qualified to perform their function and are performed under mHTGR-RP Section 3.11.

8. Reviews of fire protection, technical specifications, and quality assurance and maintenance are performed under mHTGR-RP Sections 9.5.1 and Chapters 16 and 17, respectively.

9. Review of the seismic qualification of Category I instrumentation and electrical equipment and the environmental qualification of electrical and mechanical equipment is performed under mHTGR-RP Sections 3.10 and 3.11, respectively.

The specific acceptance criteria and review procedures are contained in the referenced mHTGR-RP sections.

\section{ACCEPTANCE CRITERIA}

\section{$\underline{\text { Requirements }}$}

Acceptance criteria are based on meeting the relevant requirements of the following Commission regulations:

1. mHTGR-DC 4, as it relates to the structures, systems, and components important to safety that shall be designed to accommodate the effects of and to compatible with the environmental conditions during normal plant operation as well as during DBEs/DBAs.

2. mHTGR-DC 23, as it relates to the protection system failure modes such that the system shall fail into a safe state or into a state demonstrated to be acceptable on some other defined basis if conditions such as disconnection of system, loss of energy, or postulated adverse environment are experienced.

3. mHTGR-DC 25, as it relates to the coated particle fuel design such that the specified acceptable core radionuclide release design limits (SARRDLs) are not exceeded for any single malfunction of the reactivity control system.

4. mHTGR-DC 26, as it relates to the reactivity control system redundancy and capability of providing (1) a means of shutting down the reactor to ensure that, under conditions of normal operation, including abnormal operational occurrences, and with appropriate margin for malfunctions, design limits for fission product barriers are not exceeded, (2) a means of shutting down the reactor and maintaining a safe shutdown under design-basis event conditions, with appropriate margin for malfunctions, and a second means of reactivity control that is independent, diverse, and capable of achieving and maintaining safe shutdown under design-basis event conditions, and (3) a system for holding the reactor subcritical under cold conditions.

Comment [A238]: Revised to reflect the mHTGR-DC 26 requirements contained in DG1330. 
5. mHTGR-DC 28, as it relates to reactivity limits such that reactivity control systems shall be designed with appropriate limits on the potential amount and rate of reactivity increase to assure that the effects of DBEs/DBAs can neither result in damage to the reactor helium pressure boundary nor disturb the core and its supports structures to significantly impair the capability to cool the core.

6. mHTGR-DC 29, as it relates to protecting system against AOOs such that the design of the protection and reactor control systems should assure an extremely high probability of accomplishing their safety functions in the event of anticipated operational occurrences.

7. 10 CFR $52.47(b)(1)$, which requires that a DC application contain the proposed inspections, tests, analyses, and acceptance criteria (ITAAC) that are necessary and sufficient to provide reasonable assurance that, if the inspections, tests, and analyses are performed and the acceptance criteria met, a plant that incorporates the design certification is built and will operate in accordance with the design certification, the provisions of the Atomic Energy Act, and the NRC's regulations.

8. 10 CFR 52.80(a), which requires that a COL application contain the proposed inspections, tests, and analyses, including those applicable to emergency planning, that the licensee shall perform, and the acceptance criteria that are necessary and sufficient to provide reasonable assurance that, if the inspections, tests, and analyses are performed and the acceptance criteria met, the facility has been constructed and will operate in conformity with the combined license, the provisions of the Atomic Energy Act, and the NRC's regulations.

\section{$\underline{\text { mHTGR-RP Acceptance Criteria }}$}

Specific mHTGR-RP acceptance criteria acceptable to meet the relevant requirements of the NRC's regulations identified above are as follows for the review described in this $\mathrm{mHTGR}$-RP section. The mHTGR-RP is not a substitute for the NRC's regulations, and compliance with it is not required. However, an applicant is required to identify differences between the design features, analytical techniques, and procedural measures proposed for its facility and the mHTGR-RP acceptance criteria and evaluate how the proposed alternatives to the mHTGR-RP acceptance criteria provide acceptable methods of compliance with the NRC regulations.

1. To meet the requirements of mHTGR-DC 4, the CRDS should remain functional and provide reactor shutdown capabilities under adverse environmental conditions and after DBEs/DBAs.

2. To meet the requirements of mHTGR-DC 23, the CRDS should fail in an acceptable condition, even under adverse conditions, that prevents significant degradation in coated particle fuel performance and excessive reactivity changes during failure.

3. To meet the requirements of mHTGR-DC 25, the design of the reactivity control systems should assure that a single malfunction of the CRDS will not result in exceeding SARRDLS.

4. To meet the requirements of mHTGR-DC 26, the CRDS should be capable of providing sufficient operational control and reliability during reactivity changes during normal operation and AOOs.
Comment [A239]: DG-1330 incorporated the requirement of GDC 27 into mHTGR-DC 26.

Comment [A240]: 10 CFR 50.62(c)(3) pertains only to BWRs

Comment [A241]: Coated particle fuel performance based on statistical measures 
5. To meet the requirements of MHTGR-DC 27, the capability of CRDS should reliably control the reactivity changes to assure the capability to cool the core under DBE/DBA conditions.

6. To meet the requirements of MHTGR-DC 28, the CRDS should be designed to assure that postulated reactivity accidents do not result in damage to the reactor helium pressure boundary, or result in sufficient damage to the core or support structures so as to significantly impair the capability to cool the core.

7. The CRDS should be designed to ensure an extremely high probability of functioning during AOOs in conformance with mHTGR-DC, 29.

\section{$\underline{\text { Technical Rationale }}$}

The technical rationale for application of these acceptance criteria to the areas of review addressed by this $\mathrm{mHTGR}$-RP section is discussed in the following paragraphs:

1. mHTGR-DC 4 requires that SSCs be designed to accommodate the effects of, and to be compatible with, the environmental conditions associated with normal operation, maintenance, testing, and postulated accidents, and be appropriately protected against dynamic effects, including the effects of missiles, pipe whipping, and discharging fluids, that may result from equipment failures and from external events. The CRDS provides the capability to safely shut down the reactor during normal operations and AOOs and either prevents or mitigates the consequences associated with DBE/DBA scenarios. The design of the CRDS must ensure that the ability to perform these safety-related functions is not compromised by adverse environmental conditions. Compliance with mHTGR-DC 4 ensures that the CRDS will remain functional under adverse postulated environmental conditions and provide essential reactor shutdown capabilities.

2. mHTGR-DC 23 requires that the protection system be designed to fail into a safe state in the event of adverse conditions or environments. The CRDS provides positive core reactivity control through the use of movable control rods. The movable control rods provide reactivity control for all modes of operation, including all plant conditions from the cold shutdown condition to the full-load condition. The CRDS, in conjunction with the protection system, must actuate the control rods to effect safety-related functions when necessary to provide core protection during normal operation, AOOs, and DBEs/DBAs. Meeting the requirements of $\mathrm{MHTGR}-\mathrm{DC} 23$ provides assurance that the protection system in conjunction with the CRDS will fail in a manner that prevents significant degradation in coated particle fuel performance by providing positive control and preventing excessive reactivity changes during a failure.

3. mHTGR-DC 25 requires that the protection system be designed to ensure that SARRDLs are not exceeded for any single malfunction of the reactivity control systems. The CRDS provides the motive force for the moveable control rods providing one functional method for reactivity control. Meeting the requirements of mHTGR-DC 25 by designing these systems to withstand single failures ensures that a single malfunction of the rod control drive system, such as accidental withdrawal, will not prevent proper control of core reactivity and therefore will not result in exceeding SARRDLs. Maintaining SARRDLs enhances plant safety by preventing the occurrence of mechanisms that could lead to increased degradation in coated particle fuel performance by means such 
as severe overheating, excessive strain, or exceeding the thermal margin limits. Preventing excessive challenge to coated particle fuel performance ensures fission product barrier integrity and effectiveness.

4. mHTGR-DC 26 requires reactivity control system redundancy and capability. mHTGRDC 26 requires a control element/rod system, preferably including a positive means for inserting the elements/rods or actuating other means of reactor shutdown, capable of (1) shutting down the reactor to ensure that, under conditions of normal operation, including abnormal operational occurrences, and with appropriate margin for malfunctions, design limits for fission product barriers are not exceeded, (2) shutting down the reactor and maintaining a safe shutdown under design-basis event conditions, with appropriate margin for malfunctions, with a second means of reactivity control that is independent, diverse, and capable means of achieving and maintaining safe shutdown under designbasis event conditions, and (3) holding the reactor subcritical under cold conditions. The CRDS is designed to control reactivity during both normal operation and AOOs. The CRDS should be capable of rendering a reactor subcritical under conservative conditions with the control rod with the highest rod worth fully withdrawn from the core. The conservative conditions include the highest positive reactivity contributions resulting from effects such as temperature and power and the lowest negative reactivity contributions from poisons. Meeting the requirements of mHTGR-DC 26 ensures that the CRDS will be capable of providing sufficient operational control, reliability, and safety during reactivity changes, including those during normal operation and AOOs.

5. mHTGR-DC 28 requires that the reactivity control systems be designed with appropriate limits on the potential amount and rate of reactivity increase to prevent the adverse effects of postulated reactivity accidents. A postulated failure of the control rod system, such as rod ejection, has the potential to result in a relatively high rate of positive reactivity insertion which, if large enough, could contribute to a prompt power excursion. Such an excursion could promote degradation in coated particle fuel performance. This type of event is accompanied by the conversion of nuclear energy to mechanical energy, which if sufficient, could challenge the reactor helium pressure boundary, core support structures, core internals, or impair coolability of the core. Meeting the requirements of mHTGR-DC 28 for the CRDS enhances plant safety by limiting the effects of postulated reactivity accidents, thereby mitigating the adverse effects which could result in challenge to the reactor helium pressure boundary or impair the capability to cool the core.

6. $\mathrm{mHTGR}-\mathrm{DC} 29$ requires that the protection and reactivity control systems be designed to ensure an extremely high probability of accomplishing their safety functions in the event of AOOs. The design relies on the CRDS to function in conjunction with the protection systems under AOOs, including tripping of the turbine generator, isolation of the primary heat exchanger, and loss of external power. The CRDS provides an adequate means of inserting sufficient negative reactivity to shut down the reactor and prevent exceeding SARRDLs during AOOs. Meeting the requirements of mHTGR-DC 29 for the CRDS prevents occurrence of mechanisms that could unacceptably diminish coated particle fuel performance. Preventing excessive challenge to coated particle fuel radionuclide barrier performance in the event of anticipated transients ensures maintenance of associated fission product barrier integrity.

7. 10 CFR 52.47(b)(1) and 10 CFR 52.80(a) require that ITAAC be identified for DCs and COLs. Because the DC or license approval is being granted before facility construction, 
there is a potential that the as-built configuration of a facility may not meet the requirements of the DC or COL as granted. The purpose of the ITAAC is to ensure that the as-built facility meets the requirements set forth in the DC or COL.

\section{III. $\quad$ REVIEW PROCEDURES}

The reviewer will select material from the procedures described below, as may be appropriate for a particular case.

These review procedures are based on the identified mHTGR-RP acceptance criteria. For deviations from these acceptance criteria, the staff should review the applicant's evaluation of how the proposed alternatives provide an acceptable method of complying with the relevant NRC requirements identified in Subsection II.

1. The reviewer evaluates the CRDS design with respect to associated fluid systems and possible single failures. The review of the system description includes piping and instrumentation diagrams (P\&IDs), layout drawings, process flow diagrams, and descriptive information on essential supporting systems. The review evaluates the SAR to ascertain that failure modes and effects analyses have been completed to determine that the CRDS (not the individual drives) is capable of performing its safety-related function following the loss of any active component.

2. The reviewer evaluates the CRDS, P\&IDs, layout drawings, and component descriptions and characteristics to verify that essential portions of the system are correctly identified and are isolable from nonessential portions. The essential portions should be protected from the effects of dynamic conditions (such as high- or moderate-energy line breaks). The reviewer examines layout drawings of the system to ensure that no high- or moderate-energy piping systems are close to the CRDS, or that protection is provided from the effects of high- or moderate-energy pipe breaks. If the dynamic effects of pipe ruptures are proposed to be excluded from the design basis, then the review includes analyses justifying the exclusion. When an essential system or component is designed to perform multiple functions, the review encompasses the additional operating modes to ensure that there can be no adverse impacts on the essential system function. The reviewer should ensure that systems not relied on for safe shutdown cannot impair essential or passive component functions. Where two or more reactivity systems are used, the reviewer evaluates the combined functional performance under DBE/DBA conditions.

3. For plants containing control rod drive cooling systems (e.g., using a coolant), the reviewer examines descriptions and drawings to determine that the systems meet the design requirements. The SAR should delineate essential equipment. The reviewer of transient and accident analyses confirms by failure modes and effects analysis that the cooling system is capable of maintaining the CRDS temperature below the applicant's maximum temperature criterion. The review performed under mHTGR-RP Section 7.2 confirms that there are sufficient instrumentation and controls available so that the reactor operator in the control room can monitor the CRDS conditions, including significant parameters that may include but is not limited to coolant flow, temperature, pressure, and stator temperature.

4. Reviewers examine the functional tests of the CRDS related to rod insertion and withdrawal and scram operation and time. The reviewers check the elements of the test 
program to ensure that all required thermal-fluid conditions have been included for all postulated operating conditions. The test program should include experimental verification of system operation where a single failure has been assumed. The reviewers ensure that the system requirements (such as required scram times) are clearly identified and are consistent with the system requirements in the technical specifications and mHTGR-RP Sections 14 and 15.

5. The reactivity control systems are evaluated to verify that redundant reactivity control systems are not vulnerable to common mode failures. The review identifies the common mode failures and evaluates transient and accident analyses under mHTGR-RP Sections 7.4, and 3.9.4.

6. For review of a DC application, the reviewer should follow the above procedures to verify that the design, including requirements and restrictions (e.g., interface requirements and site parameters), set forth in the final safety analysis report (FSAR) meets the acceptance criteria. DCs have referred to the FSAR as the design control document (DCD). The reviewer should also consider the appropriateness of identified COL action items. The reviewer may identify additional COL action items; however, to ensure these COL action items are addressed during a COL application, they should be added to the DC FSAR.

For review of a COL application, the scope of the review is dependent on whether the COL applicant references a DC, an early site permit (ESP) or other NRC approvals (e.g., manufacturing license, site suitability report or topical report).

7. For review of both DC and COL applications, mHTGR-RP Section 14.3 should be followed for the review of ITAAC. The review of ITAAC cannot be completed until after the completion of this section.

Upon request from the primary reviewer, the organization with secondary responsibilities will provide input for the areas of review stated in Subsection I. The primary reviewer obtains and uses such input as required to ensure that this review procedure is complete.

\section{EVALUATION FINDINGS}

The reviewer verifies that the applicant has provided sufficient information and that the review and calculations (if applicable) support conclusions of the following type to be included in the staff's safety evaluation report. The reviewer also states the bases for those conclusions.

The staff has reviewed the functional design of the control rod drive system (CRDS) to confirm the system has the capability to shut down the reactor with appropriate margin during normal operation, AOOs, and DBE/DBA conditions, including single failures. The scope of review included process flow diagrams, layout drawings, piping and instrumentation diagrams, and descriptive information for the systems and for supporting systems essential for operation of the system.

The review has determined the adequacy of the applicant's proposed design criteria, design basis, and safety classification of the CRDS and the requirements for providing a safe shutdown during normal operation, AOOs, and DBE/DBA conditions, including single failures. The staff concludes that the design of the CRDS is acceptable and meets the requirements of modular HTGR Design 
Criteria (mHTGR-DC) 4, 23, 25, 26, 28, and 29 in Regulatory Guide X.XXX[TBD] to satisfy the requirements of 10 CFR Part 50, Appendix A. This conclusion is based on the following:

1. The applicant has met the requirements of mHTGR-DC 4 (GDC 4) with respect to the design of the system against the adverse effects of missile hazards, pipe whipping and jets caused by breaches, and adverse environmental conditions resulting from high- and moderate-energy breaches during normal plant operations, AOOs, and DBE/DBA conditions.

2. The applicant has met the requirements of mHTGR-DC 23 (GDC 23) by demonstrating the ability to insert the control rods upon any failure of the drive mechanism or any induced failure by an outside force (e.g., loss of electric power, instrumentation air, fire, radiation, extreme heat, pressure, cold, water ingress).

3. The applicant has met the requirements of mHTGR-DC 25 (GDC 25) by ensuring that no coated particle fuel specified acceptable core radionuclide release design limits are exceeded for any single malfunction or rod withdrawal accident.

4. The applicant has met the requirement of mHTGR-DC 26 (GDC 26) by demonstrating the ability to control reactivity changes to ensure that, under normal operation and AOOs with the appropriate margin for malfunction (such as stuck rods), no coated particle fuel specified acceptable core radionuclide release design limits are exceeded and the reactor can be maintained subcritical under cold conditions.

5. The applicant has also met the requirements of mHTGR-DC 26 (GDC 26) by demonstrating the ability to reliably control reactivity changes under DBE/DBA conditions to ensure that fuel design limits associated with those conditions are exceeded and the reactor can be maintained subcritical under cold conditions.

6. The applicant has met the requirements of mHTGR-DC 28 (GDC 28) by demonstrating the ability to reliably control the amount and rate of reactivity change to ensure that no postulated reactivity accident will damage the reactor helium pressure boundary or disturb the core or the core's appurtenances so as to unacceptably impair heat transfer from the core. The postulated reactivity accidents should include rod ejection, helium pressure boundary rupture, core temperature changes, pressure changes, and water ingress.

7. The applicant has met the requirements of mHTGR-DC 29 (GDC 29) by demonstrating a high probability of control rod insertion under AOOs.

For DC and COL reviews, the findings will also summarize the staff's evaluation of requirements and restrictions (e.g., interface requirements and site parameters) and COL action items relevant to this mHTGR-RP section.

In addition, to the extent that the review is not discussed in other SER sections, the findings will summarize the staff's evaluation of the ITAAC, including design acceptance criteria, as applicable. 


\section{IMPLEMENTATION}

The staff will use this mHTGR-RP section in performing safety evaluations of DC applications and license applications submitted by applicants pursuant to 10 CFR Part 50 or 10 CFR Part 52. Except when the applicant proposes an acceptable alternative method for complying with specified portions of the Commission's regulations, the staff will use the method described herein to evaluate conformance with Commission regulations.

The provisions of this mHTGR-RP section apply to reviews of applications submitted six months or more after the date of issuance of this mHTGR-RP section, unless superseded by a later revision.

\section{VI. $\quad$ REFERENCES}

The following list of references was not reviewed in detail for applicability to mHTGR designs. References to materials produced by the NRC that have since been withdrawn-such as regulatory guides-are proposed for deletion. In addition, NRC letters and industry letters on very specific $L W R$ topics are proposed for deletion from the reference list. The remainder of the original SRP reference list, including industry codes and standards, is left to provide insight on the topical areas necessary to provide adequate review. Additional effort will be required to either enhance the information in the existing references to be relevant to advanced non- $L W R$ designs, replace existing references with equivalent documentation, or delete references as appropriate.

1. Modular High Temperature Gas-Cooled Reactor Design Criterion 23, "Protection System Failure Modes."

2. Modular High Temperature Gas-Cooled Reactor Design Criterion 25, "Protection System Requirements for Reactivity Control Malfunctions."

3. Modular High Temperature Gas-Cooled Reactor Design Criterion 26, "Reactivity Control System Redundancy and Capability."

4. Modular High Temperature Gas-Cooled Reactor Design Criterion 27, "Combined Reactivity Control Systems Capability."

5. Modular High Temperature Gas-Cooled Reactor Design Criterion 28, "Reactivity Limits."

6. Modular High Temperature Gas-Cooled Reactor Design Criterion 29, "Protection Against Anticipated Operational Occurrences."

7. Regulatory Guide on Advanced Reactor Design Criteria, RG X.XXX, TBD.

Comment [A246]: LWR-specific references are deleted. 